\title{
Monitoring der Resistenzentwicklung des Maiszünsler (Ostrinia nubilalis, Hübner) gegenüber Bt-Mais
}

\author{
Dissertation \\ zur Erlangung des Doktorgrades \\ der Mathematisch-Naturwissenschaftlichen Fakultäten \\ der Georg-August-Universität zu Göttingen
}

vorgelegt von

Thomas Meise

aus Rheda-Wiedenbrück

Göttingen, 2003 
D 7

Referent: Prof. Dr. Matthias Schaefer Institut für Zoologie und Anthropologie Georg-August-Universität Göttingen

Korreferent: Prof. Dr. Stefan Vidal Institut für Pflanzenpathologie und Pflanzenschutz Georg-August-Universität Göttingen

Tag der mündlichen Prüfung: 06.11.2003 


\section{Danksagung}

Der Umfang dieser Arbeit wäre ohne die große Unterstützung, die ich von verschiedenen Seiten erhalten habe, nicht möglich gewesen. Dafür möchte ich mich besonders bedanken bei:

Herrn Dr. Langenbruch (BBA Darmstadt), Mitinitiator dieser Arbeit. Er unterstützte mich nicht nur durch seine intensive Betreuung und horizonterweiternde Diskussionen, sondern auch durch direkte Mithilfe bei den Freiland- und Laborarbeiten. Seine Erfahrung und sein Wissen trugen ganz entscheidend zum Gelingen dieser Arbeit bei.

Herrn Prof. Dr. Schaefer (Universität Göttingen, Institut für Zoologie und Anthropologie) für die Begutachtung der Arbeit und den gewährten Freiraum bei der Durchführung der Untersuchungen.

Herrn Prof. Dr. Vidal (Universität Göttingen, Institut für Pflanzenpathologie und Pflanzenschutz) danke ich für die kritische Durchsicht des Manuskripts, die anregenden Diskussionen und die Übernahme des Korreferates.

allen Mitarbeitern des Instituts für biologischen Pflanzenschutz der Biologischen Bundesanstalt für Land- und Forstwirtschaft (BBA) Darmstadt für das gute kollegiale Arbeitsklima und der Unterstützung, besonders wenn mal wieder "Not am Mann" war. Der Institutsleitung Prof. Dr. Huber danke ich für die Bereitstellung des Arbeitsplatzes und der benötigten Labor- und Freilandmaterialien.

Ein sehr großer Dank gebührt für ihren unermüdlichen Einsatz den technischen Assistentinnen Bettina Frank, Ursula Kleefeldt, Yvonne Schad, Bärbel Löber, Pia Panndorf und Anne Metke. Ohne ihre vielen geleisteten Arbeitstunden, ihre fachliche Kompetenz und ihr Engagement wäre diese Arbeit nicht so umfangreich geworden.

Helga Maul, Jorg Gollner, Hua Li, Helge Schmidt, Claudia Hampe, Maja Teklic, Rebecca Langer, Britta Stratmann, Jana Fautz, Leslie Schlüter, Lieselotte Damaschke, Bao Nagyren, Anita Dietz, Nadja Bednarz, Johannes Bewerungen, Katja Domes, Aline Fiedler, Karo Pawletko, Christine Hein, Katja Metzler für die Betreuung der Maiszünslerzuchten.

Herrn Grundwürmer und Sohn, Anton Meise, Arthur Kromm, Dr. Rupert Fersch, Sven Hommel und Freunde, Swantje Wigger, Andy Ackermann, Hannes Kalz, Herrn Kübler, Herrn Fassauer, Frau Götzke und Herrn Dr. Magg für die tatkräftige Unterstützung beim Sammeln der Larven und der Bereitstellung von Befallsdaten.

allen Landwirten, auf deren Feldern Maiszünsler gesammelt wurden und die das Aufstellen von Lichtfallen unterstützt haben.

meinen Kollegen Dr. Lorenz und Dr. Felke für die vielen Tipps und die gute Zusammenarbeit.

Frau Dr. R. Kleespies und Frau Ratke für die Unterstützung bei den Mikrosporidienuntersuchungen.

Herrn Prof. Dr. Piepho für die statistische Datenauswertung und die Einweisung in die statistischen Methoden; ebenso Herrn Dr. Moll und Herrn Prof. Dr. Hothorn für die statistische Beratung. 
Herrn Linneweber und Herrn Horstmann von der Firma Syngenta Seeds für die Bereitstellung von Saatgut und den Informationen zu den Bt-Maisflächen.

Herrn Mülleder von der Firma Monsanto für die Bereitstellung von Saatgut und den Informationen zu den Bt-Maisflächen.

den Kollegen und Freunden Dr. Hommel und Frau Liebe (BBA Kleinmachnow) für die Überlassung der Biotestdaten zum Standort Oderbruch und die hervorragende Zusammenarbeit.

Herrn Dr. Jehle, Manuela Berlingho und Hao Hang Nguyen Thu für die Produktion des Cry1 Ab-Toxins und die hilfreiche Diskussion über die Toxinunterschiede.

allen Kollegen des BMBF-Projektes für die kritischen Diskussionen und die Denkanstöße, die die Arbeit immer wieder nach vorne gebracht haben.

Herrn Dr. Jürgen Kreutz für die genaue und kritische Durchsicht des Manuskripts und für die vielen Tipps.

Frau Jutta Ungerland für die stets freundliche Aufnahme in Göttingen und Tobias Uliczka für die überraschende Hilfe bei den letzten Korrekturen.

meiner Freundin Claudia Uliczka für ihre Unterstützung in allen Phasen dieser Arbeit. Ohne ihre praktische Hilfe bei den Zuchten und dem Sammeln sowie ihrer kritischen Korrektur des Manuskripts und ihrer ständigen Motivation wäre diese Arbeit nicht zu Stande gekommen.

meinen Freunden, Kollegen und meiner Familie für die Tipps, Hilfsbereitschaft und moralische Unterstützung.

dem Bundesministerium für Bildung und Forschung (BMBF) für die Finanzierung dieser Arbeit im Rahmen des BMBF-Förderprogramms "BioMonitor".

allen, die mir geholfen haben, die aber auf Grund der Vielzahl der Helfer nicht persönlich erwähnt wurden. 


\section{INHALTSVERZEICHNIS}

Seite

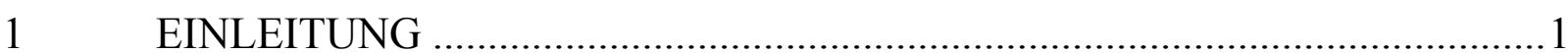

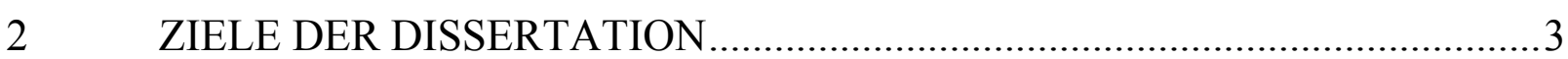

3 ALLGEMEINE GRUNDLAGEN ZU BACILLUS THURINGIENSIS, BT-MAIS, OSTRINIA NUBILALIS UND RESISTENZMANAGEMENT ...............................................................4

3.1 Bacillus thuringiensis (B.t.) ..................................................................4

3.1.1 Wirkungsweise und Nomenklatur der Bt-Toxine.........................................4

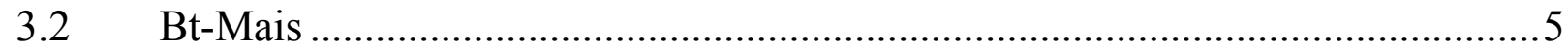

3.2.1 Stand der Zulassung von Bt-Mais in Deutschland ......................................... 7

3.2.2 Anbau von Bt-Mais ....................................................................... 8

3.3 Biologie und Verbreitung des Maiszünslers Ostrinia nubilalis (Hübner) ...........9

S.4 Schaden durch den Maiszünsler ................................................................... 12

3.5 Maßnahmen zur Bekämpfung des Maiszünslers ..........................................13

3.6 Geschichte der Resistenzentwicklung gegen Bt-Toxine ............................. 15

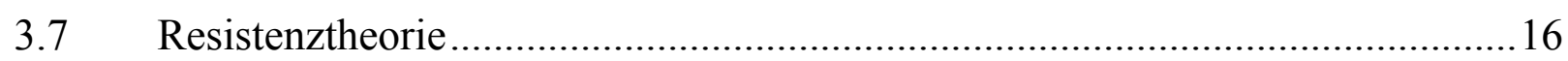

3.8 Monitoring zur Entdeckung von resistenten Insekten auf transgenen

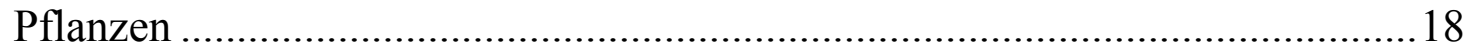

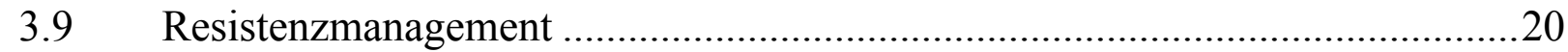

3.9.1 "Refugien/Hoch Dosis"-Strategie.........................................................21

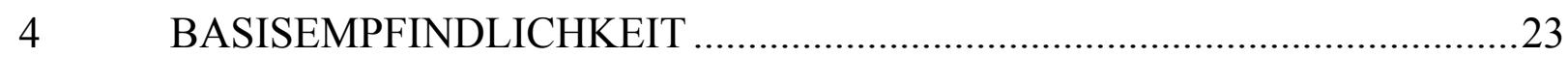

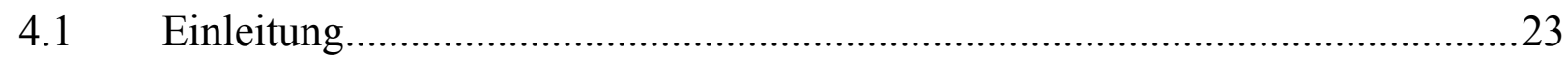

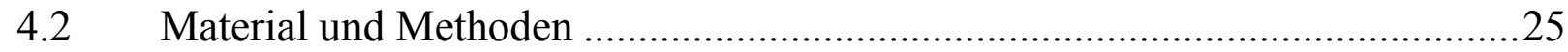

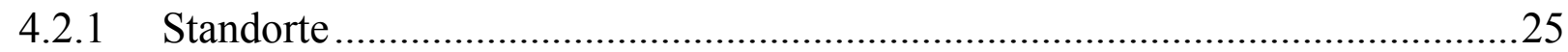

4.2.2 Sammelverfahren der Maiszünsler ............................................................. 30

4.2.3 Laborstamm Darmstadt (LA) ................................................................. 31

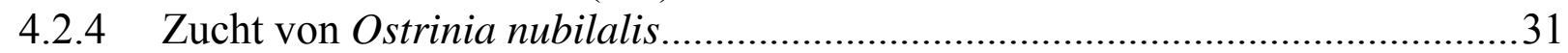

4.2.5 Bt-Toxin Cry1 Ab................................................................................... 34

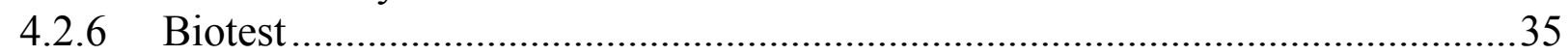

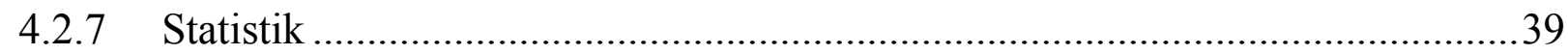

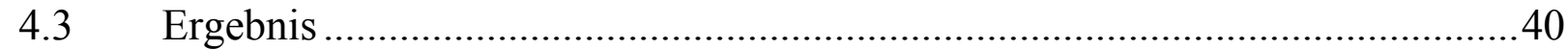

4.3.1 Basisempfindlichkeit im Jahr 2000 .........................................................40

4.3.2 Basisempfindlichkeit im Jahr 2001 ............................................................4 41

4.3.3 Basisempfindlichkeit im Jahr 2002 ..........................................................42

4.3.4 Zusammenfassung der Basisempfindlichkeit für alle Stämme, Jahre und

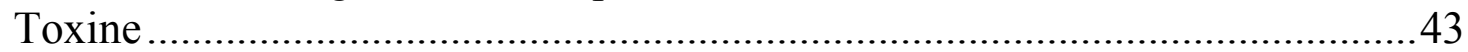

4.3.5 Vergleich der Cry1Ab-Chargen N1, J1 und J3 .........................................47

4.3.6 Vergleich der Oberflächen-Methode und der Untermisch-Methode .................51

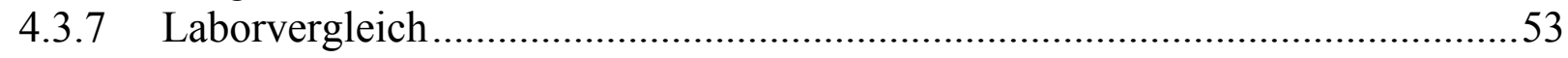


4.4 Diskussion ...................................................................................... 55

4.4.1 Unterschiede in der Basisempfindlichkeit der Populationen verschiedener Anbaugebiete in Deutschland ................................................................... 55

4.4.2 Bewertung der verwendeten Toxinchargen ..............................................61

4.4.3 Schwankungen der Basisempfindlichkeit innerhalb und zwischen den Populationen .......................................................................................63

4.4.4 Bewertung der Oberflächen-Methode im Vergleich zur Untermisch-

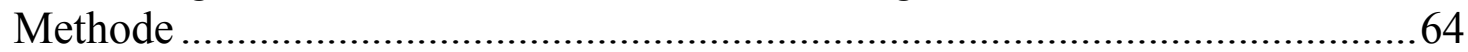

4.4.5 Bewertung der Untersuchungen in Kleinmachnow und Darmstadt.................65

4.4.6 Bewertung der Ergebnisse für ein Resistenzmonitoring ................................66

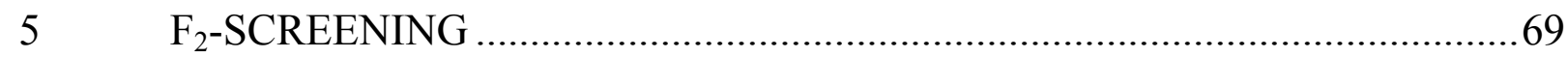

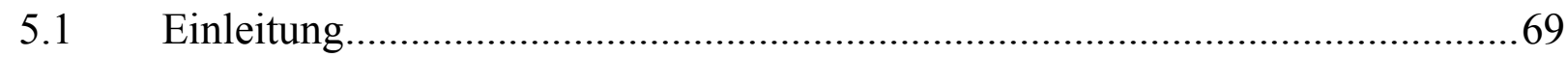

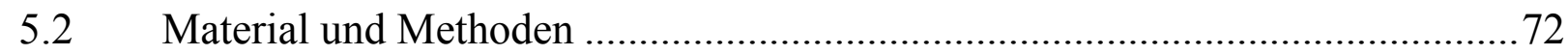

5.2.1 Bestimmung des Flugverlaufes ............................................................ 72

5.2.2 Berechnung der Temperatursummen...................................................... 72

5.2.3 Sammeln der Maiszünsler ........................................................................ 72

5.2.4 Haltung und Zucht von Maiszünslern im Labor............................................72

5.2.5 Test auf Resistenz ............................................................................ 74

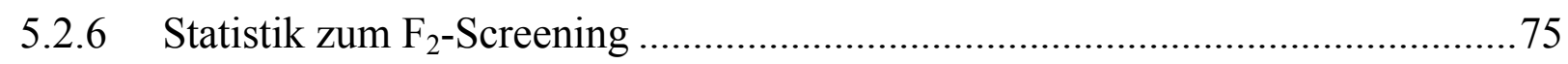

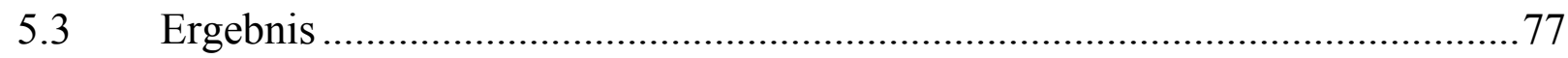

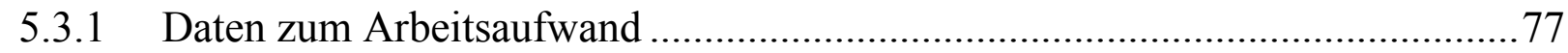

5.3.2 Zucht-Daten ...................................................................................... 77

5.3.3 Vorversuch zur Mortalität von Larven auf Bt-Maispflanzen ............................82

5.3.4 Mortalität bei den Blattversuchen und in den Nährmedium-Versuchen ............83

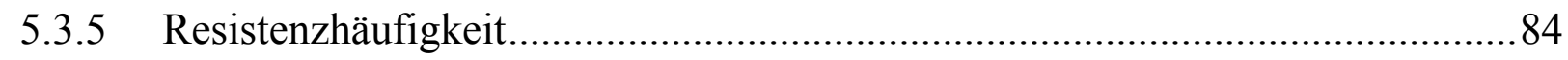

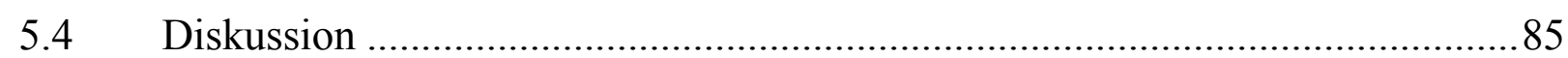

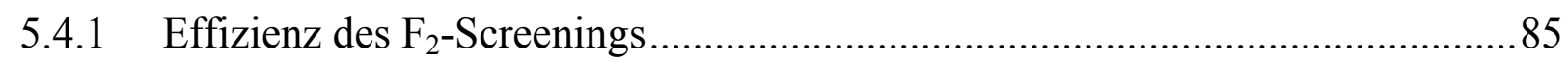

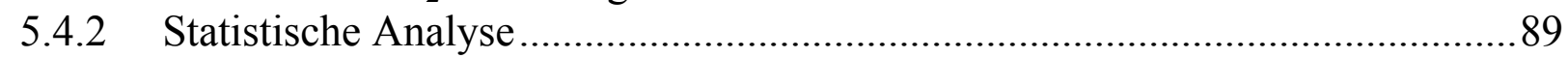

6 MONITORING RESISTENTER MAISZÜNSLER AUF BTMAISFELDERN ............................................................................ 95

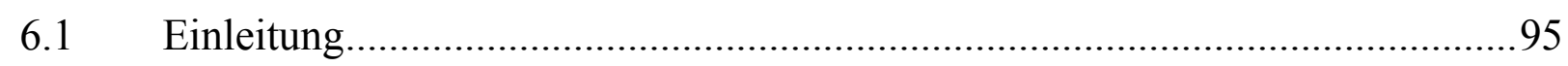

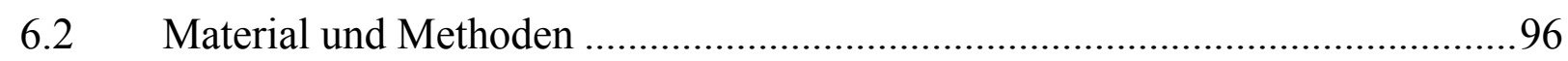

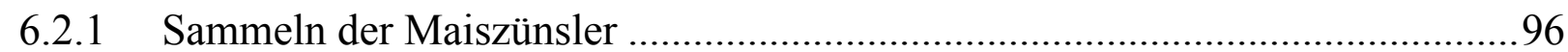

6.2.2 PCR-Untersuchungen von Bt-Maisblattstücken............................................98

6.2.3 Statistik zum Resistenz-Screening.........................................................99

6.2.4 Haltung und Zucht von Maiszünslern im Labor...........................................99

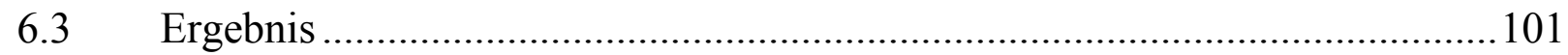

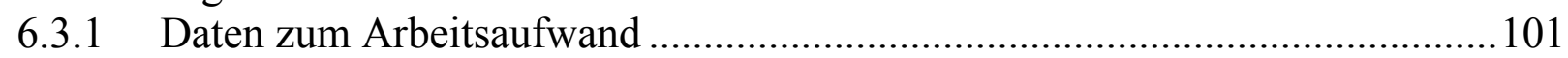

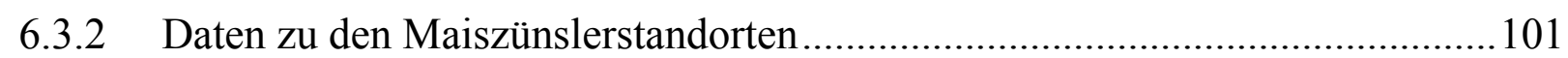

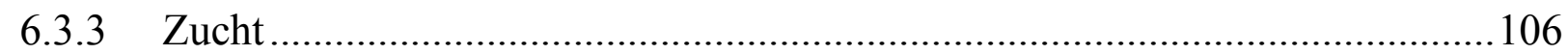

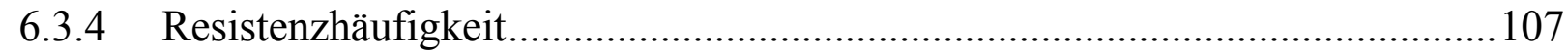

6.3.5 Vergleich der Methoden $\mathrm{F}_{2}$-Screening und Screening auf Bt-Maisfeldern ..... 108

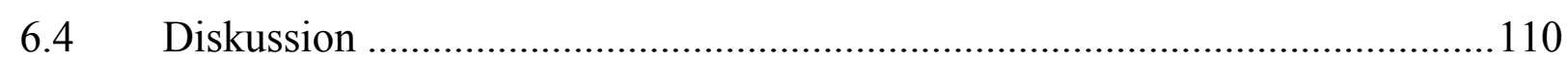


6.4.1 Vergleich der Monitoring-Methode von Venette (2000) mit der in dieser Arbeit durchgeführten Methode

6.4.2 Bewertung des Sammelzeitpunktes für die Bestimmung der Resistenzhäufigkeit......

6.4.3 Eignung des Bt-Events zur Bestimmung der Resistenzhäufigkeit....................112

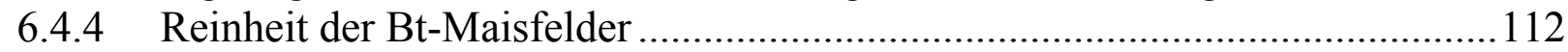

6.4.5 Bewertung der Annahmen zum Befallsdruck................................................114

6.4.6 Bestätigung der Resistenz der auf Bt-Mais gesammelten Larven....................115

6.4.7 Bewertung der Resistenzhäufigkeit ................................................................116

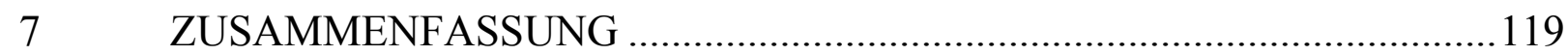

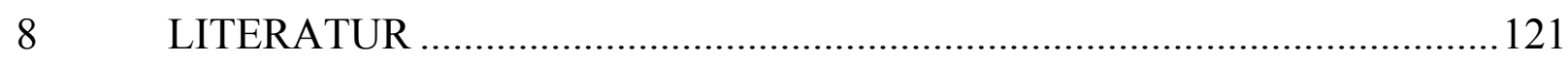

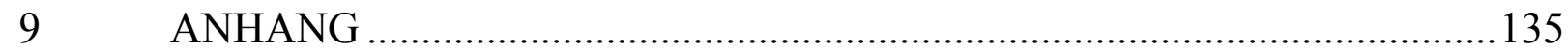

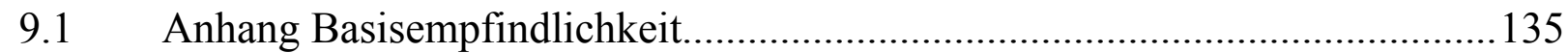

9.1.1 Toxinproduktion der Chargen J1 und J3 ……….........................................135

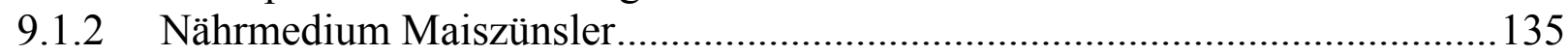

9.1.3 SAS Prozedur zur Berechnung und zum Vergleich der $\mathrm{LC}_{50}$-Werte ................137

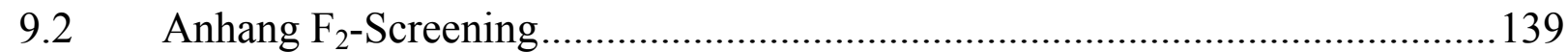

9.2.1 $\quad \mathrm{F}_{2}$-Screening nach Andow und Alstad (1998)...............................................139

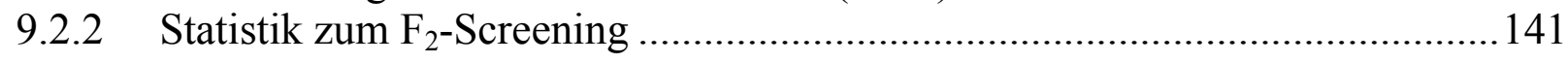

9.3 Monitoring resistenter Maiszünsler auf Bt-Maisfeldern ................................... 145

9.3.1 PCR-Untersuchungen von Bt-Maisblattstücken..............................................145

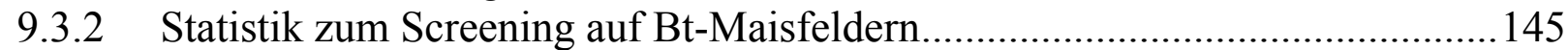

9.3.3 Schätzen des Anteils von Nicht-Bt-Pflanzen im Bt-Feld .................................148

9.3.4 Statistik zur Effizienz der Methoden $\mathrm{F}_{2}$-Screening und Screening auf BtMaisfeldern 


\section{Tabellenverzeichnis}

Tab. 1: Literaturdaten zur Bt-Toxin-Konzentration in drei Bt-Mais-Linien.

Tab. 2: Überblick zum internationalen Zulassungsstatus der in Europa zugelassenen gentechnisch veränderten Bt-Maiskonstrukte mit Part C-Genehmigung...........8

Tab. 3: Praxisanbau von Bt-Mais mit Part C-Genehmigung am Standort

Deutschland im Rahmen der Vertriebsgenehmigung nach $\S 3$ Abs. 2 des

Saatgutverkehrsgesetzes .

Tab. 4: Sammeldaten und Kenngrößen vom Stamm Niedernberg (NI) .......................25

Tab. 5: Sammeldaten und Kenngrößen vom Stamm Hessisches Ried (HR) ................26

Tab. 6: Sammeldaten und Kenngrößen vom Stamm Pocking (PO) ............................27

Tab. 7: Sammeldaten und Kenngrößen Halle/Saale .............................................28

Tab. 8: Sammeldaten und Kenngrößen Oderbruch ....................................................29

Tab. 9: Befunde der Mikrosporidienuntersuchungen 2000 und 2002 ...........................33

Tab. 10: Produktionsdaten der verwendeten Toxinchargen des CryIAb-Toxins ............35

Tab. 11: Konzentrationsbereich der eingesetzten Verdünnungsstufen bei den Dosis-

Wirkungs-Tests .

Tab. 12: Ergebnisse der $\mathrm{LC}_{50}$-Berechnungen für Ostrinia nubilalis im Jahr 2000 für die Stämme Pocking (PO), Niedernberg (NI), Hessisches Ried (HR) und Laborstamm Darmstadt (LA)

Tab. 13: Ergebnisse der $\mathrm{LC}_{50}$-Berechnungen für Ostrinia nubilalis im Jahr 2001 für die Stämme Pocking (PO), Niedernberg (NI), Hessisches Ried (HR), Oderbruch (OD) und Laborstamm Darmstadt (LA) für zwei Applikationsmethoden

Tab. 14: Ergebnisse der $\mathrm{LC}_{50}$-Berechnungen für Ostrinia nubilalis im Jahr 2002 für die Stämme Pocking (PO), Niedernberg (NI), Hessisches Ried (HR), Oderbruch (OD) und Laborstamm Darmstadt (LA) für zwei Applikationsmethoden

Tab. 15: Basisempfindlichkeit $\left(\mathrm{LC}_{50}\right)$ von Ostrinia nubilalis gegenüber dem

Cry1 Ab-Toxin für die Stämme Pocking (PO), Niedernberg (NI), Hessisches Ried (HR), Halle (HA) und Oderbruch (OD) sowie dem Laborstamm Darmstadt (LA) in den Jahren 2000 - 2002 über drei Toxinchargen gemittelt.

Tab. 16: Unterschiede in den $\mathrm{LC}_{50}$-Werten der Standorte Pocking (PO), Niedernberg (NI), Hessisches Ried (HR), Halle (HA) und Oderbruch (OD) sowie Laborstamm Darmstadt (LA) in den Jahren 2000-2002

Tab. 17: Angabe der Rangordnung der Empfindlichkeit der verschiedenen Stämme und Versuche

Tab. 18: $\mathrm{LC}_{50}$ für die drei Toxinchargen gemittelt über Orte und Jahre .......................48

Tab. 19: $\mathrm{LC}_{50}$ für die drei Toxinchargen im Paar-Vergleich........................................48

Tab. 20: Vergleich Oberflächen-Methode (O) versus Untermisch-Methode (U) für die Jahre 2001 und 2002 gemittelt über die Stämme Pocking, Niedernberg und Hessisches Ried

Tab. 21: Vergleich Oberflächen-Methode (O) versus Untermisch-Methode (U) für die Stämme Pocking, Niedernberg und Hessisches Ried.

Tab. 22: Vergleich Oberflächen-Methode (O) versus Untermisch-Methode (U) im Parallelversuch mit dem Laborstamm und der Toxincharge J3 . 
Tab. 23: Einfluss des Larvenalters auf die $\mathrm{LC}_{50}$-Bestimmung am Beispiel des Laborstamms Darmstadt ..........................................................................5 54

Tab. 24: Vergleich des Einflusses der Kühlung der Larven auf den $\mathrm{LC}_{50}$-Wert............54

Tab. 25: Literaturdaten zur Basisempfindlichkeit von Ostrinia nubilalis Stämmen

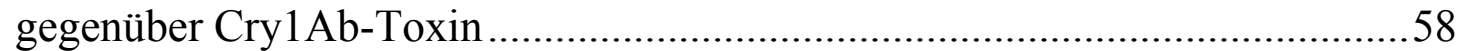

Tab. 26: Notwendige Probengröße bei einem diagnostischen Konzentrations-Test für verschiedene Häufigkeiten von resistenten Individuen bzw.

Resistenzallelen.

Tab. 27: Toxinkonzentrationen beim $\mathrm{F}_{2}$-Screening für die Jahre 2000 bis 2002

Tab. 28: Kenndaten zur Zucht der $\mathrm{P}_{1}$-Falter vom Standort Niedernberg in den Jahren 1999 bis 2001

Tab. 29: Schlupfzeitraum und Eiablagezeitraum der $F_{1}$-Generation, Standort

Niedernberg, für die Jahre 2000 und 2001

Tab. 30: Reduktion der gesammelten Larven bis zur Bildung der Isolinien im Jahr 2000 und 2001

Tab. 31: Reduktion der Isolinien von der Elterngeneration $\left(\mathrm{P}_{1}\right)$ bis $\mathrm{zur}_{\mathrm{F}_{2}}$ Generation im Jahr 2000 u. 2001.

Tab. 32: Mortalität von $\mathrm{L}_{1}$ - und $\mathrm{L}_{2-3}$-Larven nach sieben Tagen auf Bt- und Nicht-

Bt-Maispflanzen

Tab. 33: Aufenthaltsort der Larven nach sieben Tagen.

Tab. 34: Anzahl der Isolinien und die Entdeckungswahrscheinlichkeit $\left(\mathrm{P}_{\text {no }}\right)$, berechnet anhand der getesteten $\mathrm{F}_{2}$-Larven und Paare der $\mathrm{F}_{1}$-Generation ........84

Tab. 35: Clopper-Pearson der Resistenzallelfrequenz in Niedernberg 2000 und 2001 ..84

Tab. 36: Kenndaten der Bt-Maisflächen 2000 ............................................................97

Tab. 37: Kodierung der Standorte, Felder und Sorten 2000......................................... 97

Tab. 38: Kenndaten der Bt-Maisflächen 2001 ............................................................98

Tab. 39: Kodierung der Standorte und Felder sowie Sorten 2001 ..............................98

Tab. 40: Zeitaufwand für das Sammeln von Larven im Bt-Maisfeld in Abhängigkeit vom Maiszünslerbefall (MzB) im Jahr 2001 ............................................. 101

Tab. 41: Maiszünslerbefall auf den Maisfeldern im Jahr 2001 ................................... 102

Tab. 42: Ergebnisse der PCR-Untersuchungen im Jahr 2000 ..................................... 103

Tab. 43: Ergebnisse der PCR-Untersuchungen im Jahr 2001 ..................................... 103

Tab. 44: Reduktion der Larven des Sammelzeitpunktes im Jahr 2000 bis zur Testung auf Resistenz für Larven

Tab. 45: Reduktion der Larven des Sammelzeitpunktes im Jahr 2001 bis zur

Testung auf Resistenz für Larven ............................................................. 106

Tab. 46: Berechnung der Resistenzhäufigkeit [q] für die Standorte im Jahr 2001 ....... 108

Tab. 47: Bestandteile für das Maiszünsler-Nährmedium ........................................... 136

Tab. 48: Verteilung der $\mathrm{F}_{1}$-Nachkommen einer $\mathrm{P}_{1}$-Kreuzung der $\mathrm{i}$-ten Isolinie ............ 141

Tab. 49: Verteilung der $\mathrm{F}_{1}$-Paarungen der $i$-ten Isolinie ............................................. 142

Tab. 50: Verteilung der F1-Paarungen ..................................................................... 142

Tab. 51: Verteilung der $\mathrm{F}_{1}$-Paarung....................................................................... 143

Tab. 52: Wahrscheinlichkeit $u$ anfälliger Nachkomme in Abhängigkeit von der $F_{1}$ -

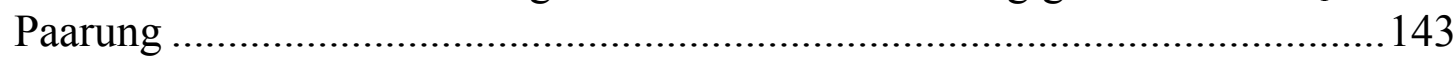

Tab. 53: Konzentrationen der Reagenzien der PCR zum Bt-Nachweis ....................... 145

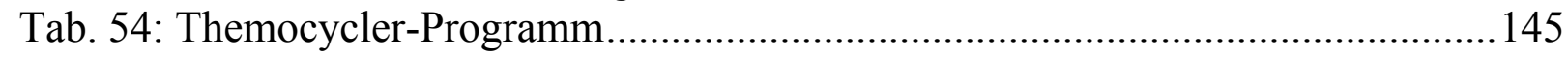




\section{Abbildungsverzeichnis}

Seite

Abb. 1: Basisempfindlichkeit $\left(\log \mathrm{LC}_{50}\right)$ von Ostrinia nubilalis gegenüber Cry1 AbToxin in Deutschland in den Jahren 2000 - 2002 über drei Toxinchargen gemittelt.

Abb. 2: Untersuchung zum möglichen Abbau des Toxins, $\mathrm{LC}_{50}$-Werte für die Toxincharge J1 und die Laborzucht über 411 Tage nach Herstellung des Toxins.

Abb. 3: Untersuchung zum möglichen Abbau des Toxins in der Verdünnungs-

Lösung; $\mathrm{LC}_{50}$-Werte für die Toxincharge $\mathrm{J} 1$ und $\mathrm{J} 3$ über einen Zeitraum von 142 Tagen.

Abb. 4: Laborvergleich BBA Darmstadt und Kleinmachnow, Laborstamm

Darmstadt, Larven $<24 \mathrm{~h}$, Oberflächen-Methode und Toxincharge J3.

Abb. 5: Flugverlauf der Maiszünsler am Standort Niedernberg und Schlupfverlauf der Maiszünsler des Standortes Niedernberg im Gewächshaus in Darmstadt in Abhängigkeit vom Temperaturverlauf im Jahr 2000 (a) und 2001 (b).

Abb. 6: Gewichte der Larven aus Bt-Maisfeldern und Nicht-Bt-Mais-Feldern zu unterschiedlichen Sammelzeitpunkten im Jahr 2000.

Abb. 7: Effizienz der Methoden $\mathrm{F}_{2}$-Screening auf Nicht-Bt-Maisfeldern und Screening auf Bt-Maisfeldern für vier Verunreinigungs-Stufen ( $\beta$ ) der BtMaisfelder. 


\section{Abkürzungsverzeichnis}

\begin{tabular}{|c|c|}
\hline${ }^{\circ} \mathrm{C}$ & Grad Celsius \\
\hline AS & Aminosäuren \\
\hline B.t. $=\mathrm{Bt}$ & $\begin{array}{l}\text { Bacillus thuringiensis. Beide Abkürzungen werden synonym } \\
\text { verwendet, wobei B.t. für das Bakterium selbst benutzt wird. }\end{array}$ \\
\hline BBA & Biologische Bundesanstalt für Land- und Forstwirtschaft \\
\hline BMBF & Bundesministerium für Bildung und Forschung \\
\hline $\mathrm{D}$ & Dunkel \\
\hline $\mathrm{E}(-\mathrm{Rasse})$ & $\begin{array}{l}\text { trans (E- steht für den Hauptbestandteil, trans -1- } \\
\text { Tetradecenylacetat, im Pheromon der Maiszünslerrasse) }\end{array}$ \\
\hline ED & $\begin{array}{l}\text { Effektive Dosis, als Endpunkt wurde nicht der Tod der Larve } \\
\text { bestimmt }\end{array}$ \\
\hline EPA & U.S. Environmental Protection Agency \\
\hline $\mathrm{F}_{\mathrm{x}}$ & x. Generation \\
\hline GVO & Gentechnisch veränderter Organismus \\
\hline $\mathrm{h}$ & Stunde \\
\hline HA & Halle \\
\hline HR & Hessisches Ried \\
\hline k.A. & keine Angaben \\
\hline $\mathrm{kDa}$ & Kilo Dalton \\
\hline $\mathrm{L}$ & Licht \\
\hline $\mathrm{L}_{1}-\mathrm{L}_{5}$ & 1. Larvenstadium bis 5. Larvenstadium \\
\hline LA & Laborstamm Darmstadt \\
\hline $\mathrm{LC}_{50}$ & Letale Konzentration \\
\hline $\mathrm{LD}_{90}$ & Letale Dosis \\
\hline $\mathrm{N}$ & Anzahl, Größe einer Stichprobe \\
\hline $\mathrm{n}$ & Anzahl \\
\hline NI & Niedernberg \\
\hline $\mathrm{O}$ & Oberflächen-Methode \\
\hline OD & Oderbruch \\
\hline $\mathrm{P}, \mathrm{p}$ & Wahrscheinlichkeit \\
\hline pers. Mitt. & persönliche Mitteilung \\
\hline $\mathrm{PO}$ & Pocking \\
\hline q & Häufigkeit von Resistenzallelen \\
\hline $\mathrm{r}$ & rezessives Gen für Resistenz gegen Bt-Toxin \\
\hline $\mathrm{S}$ & dominates Gen für die Empfindlichkeit gegen Bt-Toxin \\
\hline tda & 11-Tetradecenylacetat \\
\hline $\mathrm{U}$ & Untermisch-Methode \\
\hline Z & cis \\
\hline
\end{tabular}

Synonyme

\begin{tabular}{|l|l} 
Novartis & Firma Novartis Seeds = Syngenta Seeds \\
\hline Poplation
\end{tabular}

\begin{tabular}{l|l|}
\hline Population & Stamm; Maiszünsler aus einem geografisch abgegrenzten Gebiet.
\end{tabular}

Die Population wird im Labor durch die Nachkommen (Stamm)

\begin{tabular}{ll} 
Wirkungsquotient & Resistenzfaktor (engl.: resistance factor) \\
\hline
\end{tabular} 


\section{EINLEITUNG}

Der Mais (Zea mays) ist eine der ältesten Kulturpflanzen und zeigt als C4-Pflanze erstaunliche Biomassenzuwachse. C4-Pflanzen nutzen die Sonnenenergie effektiver als andere Kulturpflanzen, da sie ein wirkungsvolles $\mathrm{CO}_{2}$-Auffang-Assimilationssystem und ein effizientes Transpirationssystem besitzen. C3-Pflanzen, wie z. B. Getreide, können diesen Vorteil durch eine längere Vegetationszeit ausgleichen. Kaum eine Pflanze benötigt weniger Wasser zur Bildung von Pflanzentrockenmasse und zur Energiegewinnung als der Mais. Dank der C4-Eigenschaften verwertet die Maispflanze den Stickstoff besonders effizient, weswegen der Mais neben dem Weizen und dem Reis weltweit zu den wichtigsten Nahrungsenergielieferanten gehört. Der Einsatz von Mais ist vielfältig. In vielen südamerikanischen Ländern dient das Korn als Grundnahrungsmittel. Maisbestandteile werden in großem Maßstab als Zutaten für Lebensmittel eingesetzt und haben auch als Stärkelieferant für technische Anwendungen eine große Bedeutung. Als Tiernahrung ist Mais in nördlichen Anbauregionen unverzichtbar geworden, da er zum Ausgleich des eiweißreichen Grünlandaufwuchses eingesetzt wird.

Die wirtschaftliche Bedeutung des Mais führte früh $\mathrm{zu}$ wissenschaftlichen Forschungen und züchterischen Anstrengungen. Neben der Züchtung von ertragreichen, an immer mehr Standortbedingungen angepassten Hybridsorten, liegt ein Schwerpunkt in der Ertragssicherung durch Pflanzenschutzmaßnahmen. Wobei im letzten Jahrzehnt verstärkt gentechnische Methoden eingesetzt wurden. Neben der Züchtung von herbizidresistenten Maissorten liegt ein weiterer Schwerpunkt auf der Entwicklung von insektenresistenten Sorten wie dem Bt-Mais. Bt-Maispflanzen zeichnen sich dadurch aus, dass sie zum Schutz gegen Schädlinge ein insektizides Protein im Gewebe produzieren. Das kodierende Gen stammt ursprünglich aus dem Bodenbakterium Bacillus thuringiensis (B.t.), daraus wurde der Name Bt-Mais abgeleitet.

Die Anwendung der Gentechnik in der Pflanzenzüchtung kann zu unerwarteten, ökologisch negativen Begleiterscheinungen führen. Durch die Gentechnik können Züchtungsschritte beschleunigt werden und ganz neue Eigenschaften über den Gentransfer direkt in den Genpool eingeschleust werden. Die Schnelligkeit und die Überwindung von Artgrenzen kann zu unerwünschten Folgen für den Menschen und die Umwelt führen. Das Vorsorgeprinzip, nach dem sich politisches Handeln richten soll, erfordert die Abschätzung von Risiken dieser neuen Technik. Danach müssen neben den direkten Wirkungen der gentechnisch veränderten Organismen (GVOs) auf die menschliche Gesundheit auch die ökologischen Folgen von gentechnisch veränderten Pflanzen untersucht werden. Bei der ökologischen Risikobewertung von Bt-Mais spielt neben den Auswirkungen von Bt-Mais auf Nichtzielorganismen die Frage der Nachhaltigkeit und der Stabilität der Schädlingsresistenz eine große Rolle. Überwinden die Schädlinge innerhalb von wenigen Jahren den Schutz der Maispflanzen, so geht der Nutzen der Pflanzen verloren, was für die Risiko-Nutzenabwägung im Sinne einer Risikobewertung von großer Relevanz wäre.

Ein Resistenzmanagement, wie es in den USA betrieben wird, dient dazu, die Resistenzentwicklung zu verzögern und zu verhindern (U.S. Environmental Protection Agency (EPA), 2001). Resistenzmanagement-Programme sollten von einem Resistenzmonitoring begleitet werden; dessen Grundlage ist die Bestimmung der 
Basisempfindlichkeit sowie die Bestimmung der natürlich vorkommenden Resistenzhäufigkeit bevor ein Selektionsdruck aufgebaut wurde (Andow et al., 1998b). Da der Resistenz-Begriff im Verhältnis zu sensiblen Organismen gesehen wird, dient die Basisempfindlichkeit dazu, den Anstieg und die Geschwindigkeit des Resistenzfaktors zu bestimmen. Die natürliche Resistenzhäufigkeit gibt Aufschluss darüber, wie groß Refugienflächen sein müssen, um eine Resistenz zu vermeiden. Der Anstieg der Resistenzhäufigkeit, falls er frühzeitig entdeckt wird, ermöglicht die Einleitung von Gegenmaßnahmen, die eine Entstehung von vollständig resistenten Populationen verhindern. Für ein Resistenzmonitoring in Deutschland bei einem großflächigen Bt-Maisanbau fehlen bisher Daten zur Basisempfindlichkeit der Maiszünsler und zur Häufigkeit von natürlich vorkommenden Resistenzallelen.

Im Jahr 1997 wurde von der EU-Kommission eine Arbeitsgruppe "Expert Group on Monitoring for Insect Resistance to Bt-Toxins" einberufen, die 1998 ein vorläufiges Protokoll für das Monitoring von Maiszünslerresistenzen gegen Bt-Mais erstellte (Scientific Commitee on Plants at the EU-Commission, 1998). Da für Deutschland keine Erfahrungen zum Resistenzmonitoring von Bt-Mais vorlagen, wurde im Jahr 1999 vom Bundesministerium für Bildung und Forschung (BMBF) im Rahmen des BMBFFörderprogramms "BioMonitor" das Forschungsvorhaben "Monitoring der ökologischen Auswirkungen insektenresistenter Kulturpflanzen mit rekombinanten Bacillus thuringiensis-Toxin-Genen" initiiert. Im Teilprojekt 2 "Auswirkungen auf Maiszünsler" dieses Verbundprojektes arbeiteten das Institut für biologischen Pflanzenschutz in Darmstadt, das Institut für integrierten Pflanzenschutz in Kleinmachnow und das Institut für Pflanzenvirologie, Mikrobiologie und biologische Sicherheit der Biologische Bundesanstalt für Land- und Forstwirtschaft (BBA) zusammen, um Grundlagen für ein Resistenzmonitoring in Deutschland zu entwickeln.

In Kooperation mit diesem Verbundprojekt wurde diese Thematik auch vom Lehrstuhl für Biologie V (Ökologie, Ökotoxikologie, Ökochemie) der RWTH Aachen im Rahmen eines weiteren BMBF-Forschungsprojektes bearbeitet. Grundlage dieser Dissertation waren die Untersuchungen, die im Teilprojekt der BBA Darmstadt durchgeführt wurden. Zusätzlich wurden die Ergebnisse der Untersuchungen eines zweiten Forschungsvorhabens "Untersuchungen zur frühzeitigen Entdeckung einer Resistenzentwicklung des Maiszünslers und zur Aufklärung der Resistenzmechanismen", das ab dem Jahr 2001 als Ergänzung zu den ersten Untersuchungen vom BMBF gefördert wurde, mit einbezogen. 


\section{ZIELE DER DISSERTATION}

Die Schäden, die durch den Maiszünsler hervorgerufen werden, und die Schwierigkeiten bei der Bekämpfung haben zur Entwicklung von Bt-Mais geführt. Für eine nachhaltige Nutzung dieser Technik ist eine möglichst lange Verzögerung bzw. Vermeidung von resistenten Maiszünslerpopulationen notwendig. Dies wird durch Resistenzmanagement-Programme gewährleistet. Zur Durchführung und zur Erfolgskontrolle eines Resistenzmanagements sind die Bestimmung der Basisempfindlichkeit sowie die Bestimmung der natürlich vorkommenden Resistenzhäufigkeit von entscheidender Bedeutung (Andow et al., 1998b). Ziel dieser Arbeit war es im Rahmen des Verbundprojektes "Monitoring der ökologischen Auswirkungen insektenresistenter Kulturpflanzen mit rekombinanten Bacillus thuringiensis-Toxin-Genen. Teilprojekt 2: Auswirkungen auf Maiszünsler" Daten zur Basisempfindlichkeit und zur Resistenzhäufigkeit bereitzustellen bzw. Methoden zu entwickeln und zu testen, die ein Monitoring der Resistenzentwicklung in Deutschland ermöglichen.

Dabei waren folgende Fragen zu klären:

1. Wie hoch ist die Basisempfindlichkeit der Maiszünslerpopulationen in Deutschland gegenüber dem Cry1Ab-Toxin?

Europa ist das Ursprungsland des Maiszünslers, daher ist im Vergleich zu den USA mit einer größeren genetischen Variabilität zu rechnen. Zusätzlich besteht die Theorie, dass die Besiedlung durch die Z-Rasse in Deutschland auf unterschiedliche Ausgangspopulationen zurückzuführen ist. Daher muss überprüft werden, ob es Unterschiede in der Basisempfindlichkeit der Maiszünsler in den verschiedenen Maisanbauregionen gibt. Auch die Stabilität und die Reproduzierbarkeit der Bestimmung der Basisempfindlichkeit über mehrere Jahre ist für ein Monitoring von entscheidender Bedeutung und wurde in dieser Arbeit untersucht.

2. Wie hoch ist die natürliche Häufigkeit von Resistenzallelen gegen das Cy1AbToxin in Deutschland und welche Methoden eignen sich unter den in Deutschland bestehenden Anbaubedingungen zur Bestimmung der Resistenzhäufigkeit?

Die entwickelten Methoden und die Erfahrungen können als Grundlage für die Diskussion eines nationalen bzw. europäischen Resistenzmonitoring-Programms dienen. Erfahrungen und Methoden, die bei der Resistenzvermeidung beim Maiszünsler gesammelt werden, können nach Anpassung evtl. auch auf andere Schädlinge und gentechnisch veränderte Pflanzen übertragen werden. 


\section{ALLGEMEINE GRUNDLAGEN ZU BACILLUS THURINGIENSIS, BT-MAIS, OSTRINIA NUBILALIS UND RESISTENZMANAGEMENT}

\subsection{Bacillus thuringiensis (B.t.)}

Schon am Anfang des letzten Jahrhunderts wurden die besonderen Eigenschaften von Bacillus thuringiensis (B.t.) entdeckt. Der deutsche Wissenschaftler Ernst Berliner isolierte 1915 aus einer kranken Mehlmotte (Ephestia kuehniella) ein Bakterium. Er bezeichnete das gram-positive sporenbildende Bakterium als Bacillus thuringiensis und wies es als den Erreger der "Schlaffsucht“ nach. Vierzehn Jahre vorher war das Bakterium von dem japanischen Wissenschaftler Ishawata als Bacillus sotto aus der Seidenraupe (Bombyx mori) isoliert und beschrieben worden, jedoch ohne die Entdeckung seines großen Potentials. In den späten 20er Jahren wurden erste vielversprechende Feldversuche mit Bacillus thuringiensis gegen den Maiszünsler (Ostrinia nubilalis) durchgeführt (Knowles, 1994). Das erste kommerzielle Mittel „Sporeine“" wurde bereits 1938 in Frankreich produziert (Van Frankenhuyzen, 1993). In den 60er Jahren wurden Bacillus thuringiensis-Präparate erstmals in der Agrar- und Forstwirtschaft zur Schädlingsbekämpfung großflächig verwendet. 1964 wurde das erste B.t.-Präparat in Deutschland als Pflanzenschutzmittel amtlich anerkannt. Der Durchbruch begann 1970 mit der Entdeckung des besonders virulenten Stammes HD-1 von Bacillus thuringiensis kurstaki und 1976 mit der Isolierung des ersten Stammes A60 von Bacillus thuringiensis israelensis, der Nematoceren-Spezifität besitzt (Krieg, 1986). Durch die Entdeckung immer neuer Bacillus thuringiensis-Stämme mit neuen Wirtsspektren konnte der Einsatz von Bacillus thuringiensis stark erweitert werden. So fanden Krieg et al. einen Stamm BI256-82 (Bacillus thuringiensis tenebrionis) mit toxischer Wirkung auf Chrysomeliden (Krieg et al., 1983). B.t.-Produkte werden heute in Deutschland vor allem im Weinbau, Forst und öffentlichem Grün sowie im Kartoffel-, Obst- und Gemüseanbau eingesetzt und haben eine besondere Bedeutung für den ökologischen Landbau.

\subsubsection{Wirkungsweise und Nomenklatur der Bt-Toxine}

Bacillus thuringiensis produziert während der Sporulation einen parasporalen Proteinkristall, der aus mehreren Protoxinen, auch als $\delta$-Endotoxin bezeichnet, besteht. Das $\delta$-Endotoxin ist für die spezifische Wirkung des Bacillus thuringiensis verantwortlich. Die hohe Spezifität liegt im speziellen vierstufigen Wirkmechanismus, der für die meisten Toxinvarianten gilt (Krieg, 1986).

Die Toxinkristalle werden im alkalischen Milieu des Insektendarms gelöst:

1. Durch spezifische Proteasen wird das Protoxin in die aktive Form überführt.

2. Das aktive Toxin bindet an komplementäre Rezeptoren des Darmepithels.

3. Ein Teil des Toxins senkt sich in die Zellmembran und bildet eine Pore aus, wodurch es zur kolloid-osmotischen Lyse der Darmepithelzellen kommt. 
Der Tod der Insekten kündigt sich meist durch Fraßstopp, Diarrhoe und eine charakteristische Turgorabnahme ("Schlaffsucht") an. Im Laufe der Jahre wurden neue Stämme von Bacillus thuringiensis entdeckt, die ein oder mehrere $\delta$-Endotoxine bilden. Die $\delta$-Endotoxine und damit auch die verschiedenen Bacillus thuringiensis-Stämme unterscheiden sich in ihrem Wirtsspektrum, was Krieg (1986) veranlasste die Stämme nach ihrem Pathotyp zu ordnen. Er unterschied drei Pathotypen mit klar abgrenzbarem Wirtsbereich:

1. Der Lepidopteren-spezifische Pathotyp A.

2. Der Nematoceren-spezifische Pathotyp B.

3. Der Chrysomeliden-spezifische Pathotyp C.

Da die bei serologischen Untersuchungen bestimmten Verwandtschaftsverhältnisse nicht mit den Pathotypen übereinstimmten, führten Höfte und Whitley (1989) eine Klassifizierung der B.t.-Toxine anhand der Nukleotidsequenz der Gene, die das B.t.Toxin codieren, ein. Sie teilten die Toxingene, die eine ähnliche Struktur besitzen und im Wirkspektrum übereinstimmen, in vier Hauptklassen (CryI-IV) ein (Höfte und Whiteley, 1989):

1. CryI: Lepidopteren-spezifisch.

2. CryII: Lepidopteren- und Dipteren-spezifisch.

3. CryIII: Coleopteren-spezifisch.

4. CryIV: Dipteren-spezifisch.

Zusätzlich wurde die Klasse Cyt für ein $27 \mathrm{kDa}$ großes Peptid aus Bacillus thuringiensis var. isralensis, das cytolytische Effekte auf verschiedene Invertebraten und Vertebraten zeigt, eingeführt. Die Hauptklassen sind in Unterklassen unterteilt, die mit Großbuchstaben gekennzeichnet werden (z. B. Haupklasse CryI, Unterklasse A-C). Eine Zuordnung der Bacillus thuringiensis-Stämme zu den Genklassen sowie Angaben über die Homologie der Genklassen finden sich bei Höfte und Whiteley (1989) und Lereclus et al. (1993).

Auf Grund der Fülle der neu entdeckten B.t.-Toxine wurde 1993 das "Bacillus thuringiensis $\delta$-Endotoxin Nomenklatur Komitee" gegründet. Es ordnete die Toxine anhand der Ähnlichkeiten der Aminosäuresequenzen und der Gensequenzen und gab den Bezug zum Wirtsspektrum auf. 1998 wurde die Schreibweise der Toxine geändert, so wurde CryIA(b) in Cry1Ab umbenannt (Crickmore et al., 1998). Der aktuelle Stand der Nomenklatur und die Bezeichnung neuer Toxine findet sich im Internet (Crickmore et al., 2002). Für das Toxin CrylAb werden in der Datenbank 18 verschiedene Varianten angegeben, die sich in ihrer Gensequenz unterscheiden (Stand 07.01.03).

\subsection{Bt-Mais}

Die hohe Selektivität der Bt-Toxine gegenüber bestimmten Schädlingen waren Anlass, die entsprechenden kodierenden Gene aus den verschiedenen Bacillus thuringiensisStämmen $\mathrm{zu}$ isolieren, teilweise $\mathrm{zu}$ verändern und in Pflanzenzellen $\mathrm{zu}$ übertragen. Durch das Bt-Gen produzieren die Pflanzen in ihrem Gewebe das Bt-Toxin. Schädlinge, die gegen das verwendete Toxin empfindlich sind, nehmen dieses durch Fraß auf und sterben an der Toxinwirkung. Je nach Schadinsekt wurden meist nur einzelne Gene 
bzw. Toxine mit dem optimalen Wirtsspektrum in die Pflanzen eingesetzt. So wurde z. B. Cry1 Ab, das hoch wirksam gegen den Maiszünsler und andere Lepidopterenarten ist, in Mais eingebaut. In Baumwolle findet sich das Cry1Ac-Toxin, welches unter anderem hoch wirksam gegen den Tobacco budworm (Heliothes virescens) und den afro-asiatischen Baumwollkapselwurm (Helicoverpa armigera) ist. Gegen den Kartoffelkäfer (Lepinotarsa decemlineata) wurde das Cry3A-Toxin in Kartoffeln eingebaut. Drei Linien Bt-Mais werden zurzeit in Deutschland zu Versuchszwecken bzw. unter wissenschaftlicher Begleitung angebaut.

\section{Bt-Mais Event Bt-176}

Das Bt-Mais Event Bt-176 wurde 1995 von der Firma Ciba Geigy entwickelt. Ab 1996 wurde Bt-176 durch Novartis Seeds (Novartis = Fusion von Ciba Geigy und Sandoz) und ab Dezember 2000 durch Syngenta (Fusion von Novartis Seeds und dem Agrarbereich von AstraZeneca) in Deutschland vertrieben.

Bt-176-Mais produziert Cry1Ab-Toxin. Das Gen, welches für das Protein kodiert, stammt ursprünglich aus Bacillus thuringiensis kurstaki HD-1. Das synthetisch hergestellte Bt-Gen ist durch einen höheren GC-Gehalt und eine verkürzte Sequenz an die Maispflanze angepasst worden (Koziel et al., 1993a). Das Protein liegt in der Pflanze in gelöster Form vor und mit einer Größe von 72,6 kDa zwischen dem Protoxin (130,6 kDa) und dem aktivierten Toxin (60 - 68 kDa) (Höfte und Whiteley, 1989; Jehle, pers. Mitt.). Das Protein wird in allen grünen Pflanzenteilen sowie im Pollen expremiert, jedoch nicht im Kolben (siehe Tab. 1). Zur Selektion der Transformanten enthält Bt-176-Mais zwei Markergene. Das bla-Gen vermittelt eine Resistenz gegenüber dem Antibiotikum Ampicillin, das bar-Gen eine Toleranz gegenüber dem herbiziden Wirkstoff Phosphinothricin. Das betreffende Gen für die Antibiotika-Resistenz ist in der Bt-176-Transformante nicht aktiv. Ein Resistenzmechanismus wird daher nicht in Gang gesetzt. Das bar-Gen wird in der Pflanze in nur geringem Ausmaß expremiert, daher kann die durch das Bar-Gen vermittelte Herbizidtoleranz gegen Liberty in Bt-176-Mais landwirtschaftlich nicht genutzt werden (U.S. Environmental Protection Agency (EPA), 2001).

\section{Bt-Mais Event Mon810}

Mon810-Mais ist eine Entwicklung der Firma Monsanto und enthält wie Bt-176 ein Cry1Ab-Gen, das für das Bt-Protein codiert und ursprünglich aus Bacillus thuringiensis kurstaki stammt. Das Protein hat eine Größe von $92 \mathrm{kDa}$ und unterscheidet sich in der Länge des C-terminalen Teils des nicht trypsinierten Toxins (Jehle, pers. Mitt.). Markergene, die zu Anfang der gentechnischen Transformation verwendet wurden, sind in der Transformante Mon810 und ihren Nachkommen nicht mehr enthalten (Genius Biotechnology GmbH, 2000). Im Gegensatz zu Bt-176 produziert Mon810 Bt-Toxin im Kolben, aber nur wenig im Pollen (Tab. 1).

\section{Bt-Mais Event Bt-11}

Syngenta entwickelte parallel zum Bt-176-Mais die Linie Bt-11. Durch die Verwendung neuer Promotoren wird das Cry1Ab-Toxin, dessen kodierendes Gen mit dem Gen aus Bt-176 vergleichbar ist, in einer hohen Konzentration in den grünen Pflanzenteilen und in sehr geringer Konzentration im Pollen produziert (Tab. 1). Zusätzlich zum Bt-Gen ist 
in Bt-11 das pat-Gen eingebaut, welches für die Phosphinothricin Acetyltransferase (PAT) kodiert und eine Toleranz gegen Glufosinat-Herbizide bewirkt. Markergene, die zu Anfang der gentechnischen Transformation verwendet wurden, sind in der Transformante Bt-11 und ihren Nachkommen nicht enthalten (agbios, 2001a).

Tab. 1: Literaturdaten zur Bt-Toxin-Konzentration in drei Bt-Mais-Linien

\begin{tabular}{|c|c|c|c|}
\hline & Bt-176 ${ }^{1}[\mu \mathrm{g} / \mathrm{g}]^{5}$ & Bt-11 $[\mu \mathrm{g} / \mathrm{g}]^{5}$ & $\operatorname{Mon810}[\mu \mathrm{g} / \mathrm{g}]^{5}$ \\
\hline Blätter & $\begin{array}{l}0,596-1,159^{4 a} \\
0,530-3,029^{4 b} \\
0,442-0,471^{4 c} \\
0,066-0,225^{4 d}\end{array}$ & $\begin{array}{l}15-29^{4} \\
3,3^{2}\end{array}$ & $\begin{array}{l}9,35-12,15^{3} \\
7,93-10,34^{4,2}\end{array}$ \\
\hline Pollen & $1,137-2,348^{4}$ & $\begin{array}{l}<0,09^{2} \\
\text { Trockengewicht }\end{array}$ & $\begin{array}{l}<0,09^{2} \\
\text { Trockengewicht }\end{array}$ \\
\hline Wurzeln & $0,008^{4}$ & $\begin{array}{l}2,2-37,0^{2} \\
\mu \mathrm{g} / \mathrm{g} \text { Protein }\end{array}$ & k.A. \\
\hline Mark & $<0,008^{4}$ & k.A. & k.A. \\
\hline Maiskörner & $<0,005^{4}$ & $\begin{array}{l}3,7-4,76^{4} \\
1,4^{2}\end{array}$ & $\begin{array}{l}0,31-0,57^{3} \\
0,19-0,39^{2}\end{array}$ \\
\hline \multicolumn{4}{|c|}{$\begin{array}{l}1 \text { drei Genotypen; }{ }^{2} \text { (U.S. Environmental Protection Agency (EPA), 2000). } \\
\text { Daten aus } 4 \text { Jahren (Monsanto, 2002). } \\
4 \text { agbios 2001a-c }\end{array}$} \\
\hline
\end{tabular}

\subsubsection{Stand der Zulassung von Bt-Mais in Deutschland}

Die Zulassung von gentechnisch veränderten Pflanzen richtet sich in der EU seit Februar 2001 nach der Freisetzungs-Richtlinie (2001/18/EG), die die bisherige Freisetzungs-Richtlinie (90/220EWG) ersetzt hat. Diese regelte seit 1990 das Verfahren zur Genehmigung von absichtlicher Freisetzung gentechnisch veränderter Organismen in die Umwelt sowie die Festlegung von Anforderungen und Modalitäten an die im Regelfall erforderliche Umweltverträglichkeitsprüfungen. Die Richtlinie bezieht sich sowohl auf experimentelle Freisetzungsversuche (Part B), die unter bestimmten Bedingungen auf begrenzten Flächen stattfinden, als auch auf das Inverkehrbringen (Part C). Die Freisetzungsversuche werden im Teil B nach dem „case by case“- und „step by step“-Verfahren behandelt. Das Inverkehrbringen von GVOs wird im Teil C geregelt und ist in der neuen Richtlinie auf 10 Jahre beschränkt. Die Inverkehrbringung wird in einem EU-weiten Genehmigungsverfahren entschieden, wobei die Marktzulassungen für alle Mitgliedsstaaten der EU gelten. In Deutschland liegt die Zuständigkeit für die Überwachung von Produkten, die in Verkehr gebracht worden sind, bei den Bundesländern. Die für die eingehende wissenschaftliche Bewertung und letztlich auch Zulassung zuständige Deutsche Bundesbehörde ist das Robert-KochInstitut (RKI) in Berlin, welches dem Bundesministerium für Gesundheit untersteht. Als Einvernehmensbehörden sind das Umweltbundesamt (UBA), die Biologische Bundesanstalt (BBA) und das Bundesinstitut für gesundheitlichen Verbraucherschutz und Veterinärmedizin (BgVV) bei der Zulassung von GVOs beteiligt. Weiter werden Stellungnahmen der Zentralen Kommission für Biologische Sicherheit (ZKBS), ein interdisziplinär zusammengesetztes Wissenschaftlergremium, und der zuständigen 
Behörde des betroffenen Bundeslandes bei den Entscheidungen durch das RKI berücksichtigt. Zurzeit ist eine Verlagerung der Zuständigkeiten des RKI auf das Bundesamt für Verbraucherschutz und Lebensmittelsicherheit, das zum Geschäftsbereich des Verbraucherschutzministeriums gehört, in der gesetzlichen Vorbereitung. In Europa verfügen drei gentechnisch veränderte Bt-MaisTransformanten über eine Part C-Genehmigung (Tab. 2). Diese Mais-Linien und ihre Nachkommen besitzen außer in der EU in den USA, Kanada, Japan und Argentinien eine Genehmigung zum freien Anbau und zur Verwendung in Lebens- und Futtermitteln. In der Schweiz liegen für diese Linien Bewilligungen zur Verwendung in Lebens- und Futtermitteln vor (Genius Biotechnology GmbH, 2000).

Tab. 2: Überblick zum internationalen Zulassungsstatus der in Europa zugelassenen gentechnisch veränderten Bt-Maiskonstrukte mit Part C-Genehmigung

\begin{tabular}{|c|c|c|c|}
\hline & $\begin{array}{l}\text { Bt-Mais } \\
\text { 'Bt-176' } \\
\text { (Novartis) } \\
\end{array}$ & $\begin{array}{l}\text { Bt-Mais } \\
\text { 'Bt11' } \\
\text { (Novartis) } \\
\end{array}$ & $\begin{array}{l}\text { Bt-Mais } \\
\text { 'Mon810' } \\
\text { (Monsanto) }\end{array}$ \\
\hline EU & $1997^{2}$ & $1998^{3}$ & 1997 \\
\hline USA & 1995 & 1996 & 1995 \\
\hline Kanada & 1996 & 1996 & 1997 \\
\hline Japan & 1996 & 1996 & 1997 \\
\hline Argentinien & 1996 & 2001 & 1998 \\
\hline Japan & $1998^{1}$ & 1996 & 1997 \\
\hline
\end{tabular}

Seit April 2000 ist auf Anweisung des Bundesministeriums für Gesundheit (BMG) in Deutschland die gentechnikrechtliche Genehmigung für Bt-176-Mais ausgesetzt (Bundesregierung, 2000). Derzeit ist der Anbau nur zu Zwecken der Erforschung und Erprobung erlaubt. Begleitende wissenschaftliche Studien oder agronomische Beobachtungen befassen sich mit Auswirkungen auf Nichtziel- und Zielorganismen, mit der Resistenzentwicklung des Maiszünslers, mit horizontalem oder vertikalem Gentransfer, mit der Ermittlung von Ökobilanzen und der Abklärung agronomischer Fragen. Seit dem Jahr 1999 besteht in der EU ein „De facto-Moratorium“, das bis auf weiteres keine weiteren Zulassungen von gentechnisch veränderten Pflanzen erlaubt. Unabhängig von der Genehmigung zur Inverkehrbringung von gentechnischen Pflanzen müssen die Pflanzen auch die Sortenzulassung erhalten. Für Bt-176 stand 2000 die Zulassung nach dem Sortenschutzgesetz an. Das Verfahren zur Sortenzulassung ruht solange die Genehmigung zur Inverkehrbringung ausgesetzt ist.

\subsubsection{Anbau von Bt-Mais}

Weltweit wurden seit Einführung von Bt-Mais 20 Millionen Hektar angebaut (Degenhardt et al., 2003). Im Jahr 2002 wurden weltweit 7,7 Millionen Hektar Bt-Mais plus 2,2 Millionen Hektar kombinierter Bt- und Herbizid-toleranter Mais angebaut (ca. $7 \%$ der gesamten Maisanbaufläche). Anbaugebiete waren die USA, Kanada, Argentinien, Südafrika, Spanien, Honduras und Deutschland (James, 2002). In Europa wird nur in Spanien Bt-176 großflächig angebaut. Seit 1998 werden dort ca. 20.000 - 
25.000 ha Bt-Mais angebaut - das entspricht 4 - $5 \%$ der spanischen Maiserzeugung. In einigen Regionen, etwa in Katalonien, beträgt der Anteil an Bt-Mais sogar bis zu $13 \%$. Die Anbauflächen sind seit 1998 in Spanien weitgehend konstant geblieben (TransGen e.V., 2002). Die genaue Anbaumenge für die einzelnen Bt-Mais-Linien liegt nur den Saatgutfirmen vor. In der Literatur finden sich meist nur Angaben zur maximalen Anbaufläche, die sich aus den gesetzlichen Bestimmungen ableitet bzw. grobe Schätzungen des tatsächlichen Anbaus sind (siehe Tab. 3). Bt-11 wurde bisher im geringen Umfang auf kleinparzellingen Versuchsfeldern angebaut.

Tab. 3: Praxisanbau von Bt-Mais mit Part C-Genehmigung am Standort Deutschland im Rahmen der Vertriebsgenehmigung nach $\S 3$ Abs. 2 des Saatgutverkehrsgesetzes

\begin{tabular}{|c|c|c|}
\hline & $\begin{array}{l}\text { Bt-Mais } \\
\text { 'Event 176' } \\
\text { (Novartis) }\end{array}$ & $\begin{array}{l}\text { Bt-Mais 'Mon810' } \\
\text { (Monsanto) }\end{array}$ \\
\hline 1997 & $52^{1}$ & k.A. \\
\hline 1998 & $350^{1}$ & k.A. \\
\hline 1999 & $500^{1}$ & k.A. \\
\hline 2000 & $250^{1}(12 t)^{2,4}$ & $65^{1}(30 t)^{2,4}$ \\
\hline 2001 & $<<500(12 \mathrm{t})^{3,4}$ & $<<500$ (ca.20t) $)^{3,4}$ \\
\hline 2002 & $<<500(12 t)^{4}$ & $<<500$ (ca.20t) ${ }^{4}$ \\
\hline \multicolumn{3}{|c|}{$\begin{array}{l}1 \text { Genius Biotechnology GmbH, } 2000,{ }^{2} \text { Hofstetter, } 2000,{ }^{3} \text { Greenpeace, } 2001 . \\
4 \text { Die Daten geben die maximale Menge des Saatguts, die zum Anbau erlaubt ist, an. } 2002 \text { ergab sich } \\
\text { keine rechtliche Änderung der Daten von 2001. Nach Angaben von Syngenta, Pioneer und Monsanto } \\
\text { (Degenhardt et al., 2003) waren in Deutschland zwischen 1998-2002 mehrere hundert Hektar Bt-Mais } \\
\text { pro Jahr im Praxisanbau. }\end{array}$} \\
\hline
\end{tabular}

\subsection{Biologie und Verbreitung des Maiszünslers Ostrinia nubilalis (Hübner)}

Der intensive Anbau von Mais seit 1950 durch die Einführung neuer Hybridsorten und die Ausweitung des Körnermaisanbaus durch die Züchtung kälteresistener Sorten, begünstigte die Verbreitung des hellbraunen Kleinschmetterlings Ostrinia nubilalis (Hübner) (Lepidoptera: Pyralidae). Der Maiszünsler hat sich optimal an den Vegetationszyklus des Maisanbaus angepasst und ist in Deutschland der bedeutenste Maisschädling. Im südlichen Europa tritt neben dem Maiszünsler noch Sesamia nonagrioides (Lepidoptera: Noctuidae) als Schädling auf. In Europa umfasst das Verbreitungsgebiet des Maiszünslers alle nördlichen Mittelmeer-Anrainerstaaten sowie Polen, Tschechische Republik, Slowakei, Ungarn, Schweiz und Österreich, sowie Südengland und Südschweden. Die Generationszahl pro Jahr nimmt von Süden nach Norden ab. So können in Süditalien, Griechenland und Spanien drei Generationen, in Norditalien, Nordspanien und Südfrankreich zwei Generationen und in Nordeuropa und somit auch in Deutschland eine Generation pro Jahr beobachtet werden. Auch in den USA verursacht der Maiszünsler neben einigen anderen Schädlingen große Ernteschäden. Er erreicht in Nordamerika bis zum 43-sten Breitengrad zwei Generation pro Jahr und nördlich des 43-sten Breitengrades eine Generationen pro Jahr (Flacke, 1982).

Der Maiszünsler ist sowohl an verschiedene klimatische Bedingungen als auch an eine Vielzahl von Wirtspflanzen (über 200) angepasst (Andow und Hutchison, 1998). Um das Jahr 1900 ist der Maiszünsler von Europa, seinem Ursprungsgebiet, nach 
Amerika eingeschleppt worden, wo er sich seit seiner Entdeckung 1920 massiv ausgebreitet hat (Flacke, 1982). Sein Verbreitungsgebiet reicht in Amerika von Kanada im Norden bis Florida und New Mexiko im Süden (Müller, 2001). Ab dem 43 nördlicher Breite treten zwei Generationen pro Jahr auf. In Asien und Afrika gilt der Maiszünsler ebenso als Agrarschädling.

Der Maiszünsler wird sowohl in wirtspflanzenspezifische Mais- und BeifußRassen als auch in Mono- und Bivoltine-Rassen unterschieden. Außerdem wird der Maiszünsler anhand der Zusammensetzung seines Pheromons in die Z-Rasse und die ERasse unterteilt. Der Lockstoff besteht aus einem Isomerengemisch aus cis-(Z)- bzw. trans-(E)-11-Tetradecenylacetat (tda) (Klun, 1968; Klun und Brindley, 1970). Die sogenannte Z-Rasse hat ein Mischungsverhältnis der Isomere von ca. 97 Z-11-tda : 3 E11-tda und die E-Rasse von ca. 3 Z-11-tda : 97 E-11-tda. Die Rassen sind visuell nicht zu unterscheiden. Auch sympatrisches Vorkommen und Hybride (35 Z-11-tda : 65 E11-tda) wurden nachgewiesen (Peña et al., 1988). In Deutschland und in Mitteleuropa tritt vor allem die Z-Rasse als Maisschädling auf, wohingegen die E-Rasse im Beifuß zu finden ist (Lorenz, 1993).

Das Überwinterungsstadium des Schädlings ist die $\mathrm{L}_{5}$-Larve, die als PraePuppenstadium in Hohlräumen der Pflanzenstängel in Bodennähe überwintert. Die Larven verpuppen sich relativ spät im Mai des nächsten Frühjahres und die Falter schlüpfen im Juni bis Juli bei fortgeschrittener Vegetationsperiode. Von der E-Rasse ist bekannt, dass sie ca. 12 bis 18 Tage vor der Z-Rasse schlüpft (Lorenz, 1993). Die Falter sind dämmerungs- und nachtaktiv. Die Weibchen legen Eipakete, die dachziegelartig übereinander gelegt sind, an der Blattunterseite der Wirtspflanze ab. Die frischgeschlüpften Junglarven $\left(\mathrm{L}_{1}\right)$ fressen zunächst an äußeren Pflanzenteilen und bohren sich später in den Stängel ein. Die meisten Beobachtungen zur Biologie und zur Verbreitung des Maiszünslers wurden bei Populationen auf Maisfeldern gemacht. Über die Anpassung der Maiszünsler an andere Wirtspflanzen ist wenig bekannt. Untersuchungen der Anzahl der Spermatophoren bei Maiszünslerweibchen, die in Kanada in Lichtfallen gefangen wurden, zeigten, dass $50 \%$ bis $80 \%$ der Weibchen ein Mal, $15 \%$ bis $37 \%$ zwei Mal und maximal $13 \%$ sich drei Mal paarten (Elliot, 1977). Sowohl für das Eiablegeverhalten und die Verteilung der Larven innerhalb einer Pflanze gibt es unterschiedliche Angaben. Ohnesorge und Reh (1987) vermuten, dass die unterschiedlichen Angaben in der Literatur die breite Anpassung der Maiszünsler an die Umweltbedingungen widerspiegeln. Die Maiszünslerweibchen legen bei Trockenheit die Eier eher im unteren Bereich der Pflanze ab, wo eine höhere Luftfeuchtigkeit vorherrscht. Wenn die Luftfeuchtigkeit keinen limitierenden Faktor darstellt, legen die Weibchen die Eier auch im oberen bzw. mittleren Bereich der Pflanze ab. Je nach Entwicklungsstand der Maispflanze während des Larvenschlupfes bohren sich die Larven in die Fahne ein, halten sich an den Blattachseln auf oder fressen an der Seide der Kolben. Die älteren Larven breiten sich auch auf die Nachbarpflanzen aus, zu denen sie über sich berührende Maisblätter wechseln. So können Larven bis zu sechs Pflanzen entfernt von ihrem Eiablageort gesichtet werden. Finden sich die Larven im August noch geballt um den Eiablageort wieder, so gleicht die Verteilung vor der Ernte aber stärker einer Poisson-Verteilung (Ohnesorge und Reh, 1987). Im Laufe der Vegetation bohren sich die Larven in den Stängel ein und fressen sich im Stängelinneren nach unten. Oft kann der Befall durch Maiszünsler frühzeitig durch das Abknicken der Fahne erkannt werden. Vor der Ernte erreichen die Larven i.d. R. den unteren Teil der 
Maispflanze, so dass sie bei der Ernte nicht erfasst werden. Die Maiszünsler passen sich unterschiedlichen Witterungs- und Vegetationsbedingungen durch eine Änderung des Verhaltens an. So führen unterschiedliche Temperatursummen und Fotophasen zur Ausbildung von zwei bzw. einer Generation im Jahr (Flacke, 1982).

Die Z-Rasse des Maiszünslers ist in Deutschland als expandierende Art zu bezeichnen, wohingegen die E-Rasse in ganz Deutschland verbreitet ist. Dabei ist es schwierig die Ausbreitung und die tatsächliche Verbreitung der Z- und E-Rasse zu unterscheiden. Die Ausbreitung des Maiszünslers im Mais ist gut belegt, da er als Schädling hier einer ständigen Kontrolle unterliegt (Langenbruch und Lorenz, 1992; Langenbruch und Kleespies, 1998; Langenbruch, 2003). Wobei sein Vorkommen oft erst erkannt wird, wenn ein deutlicher, meist wirtschaftlicher Schaden entstanden ist. Latenzgebiete ohne große Massenwechsel werden häufig übersehen oder können nur durch intensive Untersuchungen erkannt werden, was aber i. d. R. punktuell geschieht. Genaue Verbreitungsangaben für die Z- und E-Rasse sind, da es keine visuellen Unterschiede beider Rassen gibt, nur durch Pheromonuntersuchungen möglich. Diese sind seit 1974 durchführbar und mit einem großen Aufwand verbunden. Zudem werden i. d. R. mehrere Tiere für einen Zuchtstamm benötigt. Pheromonfallen mit entsprechenden Ködern können ebenso einen Hinweis auf das Vorhandensein der Rassen in einem Gebiet geben, wobei die Fängigkeit witterungsabhängig und nicht immer eindeutig ist. Aus diesem Grund dienen die Hauptwirtspflanzen zur Unterscheidung der Rassen. Larven aus Mais werden als Z-Rasse und Larven aus Beifuß als E-Rasse bestimmt. Dies gilt besonders für ältere Literaturangaben, bei denen keine Kenntnisse zur Rassenbildung vorlagen (Zwölfer, 1926; Zwölfer, 1928; Hase, 1929).

In den eigenen Untersuchungen wurden Maiszünslerfunde im Norden Deutschlands im Raum Göttingen und Braunschweig, im Osten im Oderbruch sowie bei Halle, in der Mitte im Raum Recklinghausen, Gütersloh, Darmstadt und Aschaffenburg sowie im Süden in Pocking gemacht. Aus der Literatur sind weitere Fundorte wie z. B. Osnabrück, Freiburg und die Kölner Bucht bekannt (Lorenz und Langenbruch, 1989; Schmitz et al., 2001; Kluge et al., 1999). Die Angaben über die einzelnen Standorte schwanken je nach untersuchter Wirtspflanze und verwendeter Methode beträchtlich. Die Z-Rasse und ihr schadhaftes Auftreten im Mais wurde von der Biologischen Bundesanstalt in Darmstadt untersucht und dokumentiert (Langenbruch und Lorenz, 1992; Langenbruch und Kleespies, 1998; Langenbruch, 2002; Langenbruch, 2003). Es ist bekannt, dass das Schadauftreten des Maiszünslers in Deutschland bis etwa 1960 auf einzelne wärmere, überwiegend südliche Regionen beschränkt war. In den letzten Jahrzehnten ist der Falter in klimatisch weniger begünstigte Gebiete vorgedrungen. Langenbruch gibt für die Ausbreitungsgrenzen des Maiszünslers an, dass die Besiedlung in Nordrhein-Westfalen und Mecklenburg-Vorpommern begonnen hat. Niedersachsen und Schleswig-Holstein sind noch befallsfrei. Ein weiteres Vordringen des Maiszünslers ist daher sehr wahrscheinlich (Langenbruch, 2002; Langenbruch, 2003). In den Regionen außerhalb der Maisbefallsgebiete wird der Maiszünsler vor allem im Beifuß gefunden. In den Befallsgebieten finden sich zum Teil in nah benachbarten Beifußstandorten keine Maiszünsler. In anderen Gebieten wie der Hallertau und im Gebiet Köthen tritt der Maiszünsler in den letzten Jahren verstärkt im Hopfen auf. Obwohl Hopfen als Wirtspflanze lange bekannt ist (er wird meist als Wirtspflanze der E-Rasse angenommen), spielte der Maiszünslerbefall dort in den 
letzten Jahrzehnten kaum eine Rolle. Lorenz (1993) erwähnt, dass die zunehmende Mechanisierung der Hopfenernte zu einer mechanischen Tötung der Larven führt und daher der Befall keine wirtschaftliche Bedeutung mehr hat. Das Auftreten im Raum Köthen und in der Hallertau ist begleitet von einem massiven Anstieg des Befalls im Mais, so dass die Vermutung nahe liegt, dass in den neuen Befallsgebieten im Hopfen die Z-Rasse eine Schadwirkung zeigt.

\subsection{Schaden durch den Maiszünsler}

Deutliche Zeichen für die Fraßtätigkeit der Larven sind geknickte oder abgebrochene Maisfahnen. Die Bohrgänge und die durch das wiederholte Aus- und Einbohren entstehenden Löcher entlang des Stängels beeinträchtigen die mechanische Stabilität der Maispflanze. Solange nur die oberen Stängelteile abknicken, ist der Schaden zu vernachlässigen. Bei starkem Befall und in Jahren mit häufigen Gewitterniederschlägen brechen die Pflanzen im unteren Bereich der Pflanze ab und der Kolben kann nicht mehr geerntet werden. Außerdem behindert der Larvenfraß die Wasser- und Nährstoffversorgung sowie den Assimilattransport. Darüber hinaus fördern die Zünslerlarven durch ihre Bohrtätigkeit den Pilzbefall. Bedeutsam sind in erster Linie die Fusarium-Arten, die einerseits Stängel- und Kolbenfäule verursachen und andererseits Mykotoxine bilden können, die die Futterqualität für monogastrische Tiere mindern (Dowd, 2000; Magg et al., 2002).

In der Praxis wird von einer hohen Schadenstoleranz der angebauten Maissorten ausgegangen. Trotz hoher Befallsstärken werden die Ertragsverluste als gering eingeschätzt. Als Schadensschwelle für den Maiszünsler im Körnermais werden etwa 4 - 6 Eigelege/100 Pflanzen angenommen (Heitefuß et al., 1986). Benbrook (2001), schätze den Ertragsverlust in den USA bei $100 \%$ im Durchschnitt auf 5,5\%. Dieser Wert hängt stark von den Witterungsbedingungen und dem Verteilungsmuster des Befalls ab. Degenhardt et al. (2003) berechnen für Deutschland bei einer geschätzten Befallsfläche von 100.000 ha und einem durchschnittlichen Ertragsausfall von $5 \%$ den monetären Verlust auf 4.400.000 €. Regional kann der Ertragsverlust aber bis zu 20\% betragen, so dass der Schaden für einen einzelnen Landwirt beträchtlich sein kann. BtMaissorten können den Befall und damit den Schaden minimieren. In Hinblick auf BtMaissorten muss bei der Bewertung des Schadens zwischen dem Kornertrag und dem monetären Ertrag des Landwirtes unterschieden werden, da der Nutzen für den Landwirt nicht nur vom Befallsdruck, sondern auch von den Preisunterschieden zwischen den BtMaissorten und den konventionellen Sorten abhängt. Ein weiterer wichtiger Gesichtspunkt ist der Vergleichsstandard. Wird der Ertrag von Bt-Maissorten mit der isogenen Sorte unter Befallsdruck verglichen, ist mit einem Ertagsgewinn zu rechnen. Bt-Maissorten bzw. ihre isogenen Vergleichssorten sind oft durch die lange Entwicklungs- und Genehmigungszeit züchterisch veraltert. Neuere Hochleistungshybridsorten haben i. d. R. einen wesentlich höheren Ertrag als die zu den Bt-Sorten isogenen Hybriden, so dass der Nettoertrag unter Befallsdruck im Vergleich zu den BtSorten gleich bzw. höher ausfallen kann. Benbrook (2001) stellte in den USA im Durchschnitt einen Maisertraggewinn pro Schlag fest, wobei der Verkaufserlös nach Abzug der Kosten unter dem der konventionellen Sorten lag. Große Schwankungen wurden bei konventionellen Maishybriden im Ertrag/Gewinn-Verhältnis gefunden. Rice und Pilcher (1998) ermittelten für den Landwirt im Vergleich mit isogenen Linien und 
unter Berücksichtigung der Mehrkosten für Bt-Mais erst bei einem Befallsdruck von einer Larve pro Pflanze einen Gewinn.

\subsection{Maßnahmen zur Bekämpfung des Maiszünslers}

Vier Möglichkeiten stehen zur Bekämpfung des Maiszünslers zur Verfügung. Die mechanische Bekämpfung durch Pflügen, die biologische Bekämpfung, die chemische Bekämpfung und der Bt-Mais. Jede der Maßnahmen hat Vor- und Nachteile und soll im Folgenden diskutiert werden.

\section{Mechanische Bekämpfung durch Pflügen}

Die Bekämpfungsmaßnahme des Pflügens wird im Gegensatz zur biologischen Bekämpfung mit Trichogramma und der chemischen Bekämpfung als Vorsorgemaßnahme und nicht als akute Befallsbekämpfung angewendet. Für die Bekämpfung des Maiszünslers ist ein sauberes, tiefes Unterpflügen der zerkleinerten Maisstoppeln und des gehäckselten Maisstrohs im Herbst notwendig, da sich die Raupen nur in trockenem Pflanzenmaterial an der Bodenoberfläche verpuppen. Durch das Pflügen wird der Befallsdruck im nächsten Sommer deutlich reduziert (Langenbruch und Lorenz, 1989; Langenbruch, 2003). Zur ausreichenden Bekämpfung des Maiszünslers ist es notwendig, dass die Methode im gesamten Befallsgebiet angewendet wird. Das Unterpflügen der Maisernterückstände vermindert zugleich das Mykotoxinrisiko durch Fusarien bei der häufig nachfolgenden Frucht Weizen. Der pfluglose Anbau bzw. die konservierende Bodenbearbeitung nahm in den letzten Jahren stetig zu und wird in Gebieten mit Erosionsgefahr empfohlen (BMVEL, 2001). In einigen Bundesländern ist die pfluglose, konservierende Bodenbearbeitung in Förderprogramme einbezogen und spielt im integrierten Pflanzenbau eine wichtige Rolle. Der pfluglose Anbau kann durch die Einsparung von Dieselkraftstoff aus betriebswirtschaftlichen oder pflanzenbaulichen Überlegungen sinnvoll sein. Daher muß der Nutzen, d.h. die Maiszünslerbekämfung, mit den Nachteilen des Pflugeinsatzes abgewogen werden.

\section{Biologische Bekämpfung}

In Deutschland wurde der Maiszünsler im Jahr 2001 auf ca. 5.600 ha Mais biologisch mit der Schlupfwespe Trichogramma bekämpft. Dies entspricht $14 \%$ der Gesamtfläche, die gegen den Maiszünsler behandelt wurden und $2 \%$ der gesamten Befallsfläche in Deutschland (Bundesministerium für Verbraucherschutz, 2001). TrichogrammaSchlupfwespen legen ihre Eier in die Eier des Schädlings. Aus den parasitierten Eiern schlüpfen nach einigen Tagen flugfähige Schlupfwespen, die wieder nach geeigneten Maiszünslergelegen für ihre Nachkommen suchen. Die Nützlinge können mit Hilfe von Kartonrähmchen, Kapseln oder Plättchen in die gefährdeten Maisbestände eingebracht werden. Der Vorteil dieses Verfahrens besteht darin, dass andere Nützlinge kaum geschädigt werden. Um Bekämpfungserfolge von über $60 \%$ zu erzielen, sind entsprechende Erfahrungen bei der Anwendung dieser Methode erforderlich (Langenbruch, 2002). Die Bestimmung der optimalen Ausbringungstermine auf der Grundlage von Fängen in Lichtfallen ist sehr aufwändig. Für die Ausbringung auf kleineren Flächen sind keine technischen Hilfsmittel erforderlich. Inzwischen gibt es 
erste Ausbringungen mit speziell ausgerüsteten Stelzenschleppern. Im Gegensatz zu BtMais und chemischer Bekämpfung ist eine Bekämpfung mit Trichogramma durch die hohen Anwendungskosten nicht wirtschaftlich (Degenhardt et al., 2003), daher werden in einigen Bundesländern, wie z. B. in Baden-Württemberg, staatliche Beihilfe für den Einsatz von Trichogramma bezahlt.

Bacillus thuringiensis-Präparate können wie synthetische Insektizide als Spritzmittel gegen die Maiszünslerraupen, die sich noch nicht eingebohrt haben, eingesetzt werden. Bt-Präparate spielten auf Grund der geringen Wirkungsgrade und der hohen Kosten in den letzten Jahren keine Rolle mehr (Bundesministerium für Verbraucherschutz, 2001). Eine Kopplung von Bacillus thuringiensis- und Trichogramma-Ausbringung wird zurzeit diskutiert (Biologische Bundesanstalt für Land- und Forstwirtschaft, 2003).

\section{Chemische Bekämpfung}

2001 wurden auf 33.000 ha (ca. $11 \%$ der Befallsfläche) chemische Insektizide, vor allem synthetische Pyrethroide, gegen die Raupen des Maiszünslers eingesetzt. In Deutschland ist BAYTHROID ${ }^{\circledR}$ (Cyfluthrin) bis Ende 2003 zugelassen; ab 2004 wird die Zulassung von STEWART ${ }^{\circledR}$ (Indoxacarb) erwartet (Biologische Bundesanstalt für Land- und Forstwirtschaft, 2003). Pyrethroide sind Fraßgifte und müssen vor dem Einbohren der Larven in den Stängel ausgebracht und von den Larven aufgenommen werden. Der Zeitrahmen für den optimalen Anwendungstermin ist begrenzt und sollte mit dem Auftreten der Masse der Junglarven übereinstimmen. Bei Falterflug, mit mehreren Flugspitzen, wäre eine zweite Anwendung erforderlich, die auf Grund der Höhe der Maispflanzen zu diesem Zeitpunkt mit einem Stelzenschlepper durchgeführt werden sollte, um Verluste zu minimieren. Durch den Einsatz der breitwirkenden Insektizide kommt es zu einer starken Schädigung der Nützlingsfauna, was im Folgenden zu einem Anstieg von sekundären Schädlingen wie Blattläusen führen kann (Biologische Bundesanstalt für Land- und Forstwirtschaft, 2003).

\section{Integrierte Bekämpfung}

Die Biologische Bundesanstalt empfiehlt zur Bekämpfung des Maiszünslers einen integrierten Ansatz, in dem unter Berücksichtigung regionaler Besonderheiten verschiedene Methoden miteinander kombiniert werden. Geeignete Ernteverfahren zur Vernichtung der Maiszünslerlarven sind z. B. der Einsatz von Mähdreschern mit tief eingestelltem, gut zerkleinerndem Strohhäcksler. Bei Silomais hilft eine Verringerung der Schnitthöhe und auf ebenen Flächen ein sauberes Unterpflügen aller Ernterückstände nach deren Zerkleinerung. Ist eine wendende Bodenbearbeitung nicht möglich, kann das Schlegeln (intensives Zerkleinern der Maisstoppeln) und folgender Einsatz von Scheibenegge und Tiefengrubber den Befallsdruck des Maiszünslers senken. Zusätzlich kann die biologische Bekämpfung mit TrichogrammaSchlupfwespen eingesetzt werden. Ist keine dieser Abwehrmaßnahmen Erfolg versprechend, sollte eine gezielte chemische Bekämpfung unter Beachtung von Bekämpfungsschwellen durchgeführt werden (Biologische Bundesanstalt für Land- und Forstwirtschaft, 2003). In Zukunft ist auch der Einsatz von Bt-Mais eine zusätzliche Alternative. 


\subsection{Geschichte der Resistenzentwicklung gegen Bt-Toxine}

Im Jahr 1914 wurde von Melander das Versagen von Schwefelkalk gegen Schildläuse, Blattläuse und Milben und damit die erste Insektizidresistenz beschrieben (Melander, 1914). In den folgenden Jahrzehnten wurden immer mehr Fälle von Resistenz dokumentiert. Die Entwicklung von organischen Insektiziden wie DDT hatte, oft in nur wenigen Jahren, die Entwicklung von resistenten Insektenpopulationen zur Folge. Gegen jedes neue Insektizid wie Cyclodien-Pestizide, Carbamate, Organophosphate, Pyrethroide und gegen Bacillus thuringiensis-Präparate traten Resistenzen auf (Tabashnik et al., 1990). Die Internetdatenbank des Insecticide Resistance Action Committee listete bis zum Jahr 20002.639 Insektenstämme, die gegen 308 Pestizide resistent sind, auf (The Database of Arthropods Resistant to Pesticide, 2003). Dieses Phänomen wird als „Pesticide Treadmill“ bezeichnet. Beim Auftreten von Schädlingen setzt der Landwirt ein Insektizid ein, um seine Ernte zu schützen. Der erhöhte Selektionsdruck führt zur Ausbildung von resistenten Insekten, die sich wieder massiv vermehren können, woraufhin der Landwirt das nächste Insektizid einsetzt und der Teufelskreis von Neuem einsetzt.

Die hohe Reproduktionsrate in Verbindung mit genetischen Faktoren und der intensive, zum Teil falsche Einsatz von Insektiziden führen zu einer immer schnelleren Entwicklung von Resistenzen. Im Schnitt wird der Schutz durch ein Insektizid in zwei bis zehn Jahren durchbrochen. Bei B.t.-Spritzpräparaten wurde lange Zeit vermutet, dass sich keine Resistenz entwickeln würde, da die B.t.-Produkte verschiedene Toxine und Bakterien beinhalten und meist zeitlich begrenzt und selektiv eingesetzt werden. 1988 berichtete McGaughey von Bt-Resistenz im Vorratsschutz (McGaughey und Beeman, 1988). Ende der 80iger Jahre trat der erste Fall von Resistenz gegen Bacillus thuringiensis im Feld auf. Die Kohlmotte (Plutella xylostella) war nach einem massiven Einsatz von B.t.-Präparaten in Brunnenkresse auf Hawai resistent geworden (Tabashnik et al., 1990). Bis zum Jahr 2000 wurden 40 gegen Bt-Toxine und B.t.-Präparate resistente Laborstämme registriert (The Database of Arthropods Resistant to Pesticide, 2003). Huang et al. (1997) provozierte bei Ostrinia nubilalis eine Resistenz gegen das Bt-Präparat DIPEL ${ }^{\circledR}$ im Labor. Eine Zusammenstellung resistenter Stämme findet sich auch bei Ferré und Van Rie (002). Die Autoren haben für verschiedene Schmetterlingsarten die Resistenzrate, d. h. den Quotienten aus $\mathrm{LC}_{50}$ des resistenten Stammes durch den $\mathrm{LC}_{50}$ eines sensiblen Stammes, ermittelt. Die Resistenzrate schwankte für die einzelnen Stämme und Toxine bzw. Bt-Produkte beträchtlich. Der Stamm Cry1C-sel (Plutella xylostella) hatte eine Resitenzrate von 12.400 wohingegen der Stamm No-95 C (Plutella xylostella) gegen das gleiche Toxin nur eine Resistenzrate von 19 besaß. Die Generationszahl bis eine Resistenz auftritt schwankte von fünf Generationen beim Stamm Cry1C-sel bis zu 25 Generationen bei einem Laborstamm von Spodoptera exigua, der gegen Cry1Ca selektiert wurde und einem Resistenzwert von 850 besaß. Für Ostrinia nubilalis konnte nach Selektion von drei Generationen eine Abnahme der Empfindlichkeit gegen DIPEL ${ }^{\circledR}$ um das 36-fache und nach vier weiteren Generationen ein Anstieg der Resistenzrate auf das 73-fache ermittelt werden (Huang et al., 1997; Huang et al., 1999b). Obwohl DIPEL ${ }^{\circledR}$-resistente Larven größere Schäden auf Bt-Maispflanzen als empfindliche Larven verursachten, entwickelte sich keine Larve bis zum Falter. 


\subsection{Resistenztheorie}

Das Insecticide Resistance Action Commitee (IRAC, 2000) definiert Resistenz als die Reduzierung der Empfindlichkeit einer Population. Sie zeigt sich daran, dass ein Insektizid seine erwartete Bekämpfungsleistung nicht zeigt, wobei Lagerschäden, Witterungseinflüsse und andere Störfaktoren ausgeschlossen sein müssen. Müller (2001) definiert die Resistenz auf der Individuenstufe als Fähigkeit eines Organismus trotz starker Exposition gegen ein Toxin zu überleben und sich weiter zu vermehren. Laut beider Definitionen ist die Resistenz kein statischer Wert, sondern ergibt sich immer aus dem Vergleich nicht-resistenter und resistenter Insekten.

Die Gründe für die Entwicklung von Resistenzen sind vielfältig. Bei der metabolischen Resistenz nutzen die Insekten ihr Enzymsystem um das Insektizid zu entgiften. Bei Bt-Toxin kann es z. B. durch Proteasen zum Abbau des Toxins kommen, oder es kommt durch eine Veränderung des pH-Milieus im Darm und des Enzymsystems nicht zur Aktivierung des Toxins (Knowles, 1994). Ein weiterer Grund für die Resistenzentwicklung ist die Veränderung der Toxin-Bindungstellen. Nachdem das Bt-Toxin proteolytisch in ein 60-68 kDa großes aktivitiertes Toxin überführt wird, bindet es an Rezeptoren des appikalen Mikrovillisaums des Darmepithels. Durch Konformationsänderungen kommt es zur Einstülpung des Toxins in die Zellmembran und der Ausbildung einer Pore, die zu einem Ionenfluß und damit zur Zelllyse führt. Veränderungen an den Rezeptoren im Fall einer Resistenzentwicklung verhindern die Andockung und damit die Zelllyse (Hua et al., 2001). Bei einer Verhaltensresistenz vermeiden die Insekten durch Änderung oder Anpassung ihres Verhaltens die Toxinaufnahme (Roush und Daly, 1990). Bt-Pflanzen wie z. B. Bt-176-Mais produzieren nicht in allen Pflanzenteilen das Bt-Toxin. Am Kolben, der eine geringe Menge Toxin enthält, können Maiszünslerlarven, die nach dem Schlupf den Kolben aufsuchen und nicht zunächst Blattmaterial aufnehmen, überleben (Meise und Langenbruch, 1999). Die Nachkommen dieser Insekten sind aber weiterhin empfindlich gegenüber dem Toxin. Die metabolische Resistenz und die Veränderung der Rezeptorbindung werden als physiologische Resistenz bzw. genetische Resistenz zusammengefasst, da sie auf der Mutation eines bzw. weniger Gene beruht. Die Verhaltensresistenz wird dagegen durch eine Vielzahl von Genen bewirkt und zeigt die Reaktion auf veränderte Umwelteinflüsse.

\section{Wie entstehen Resistenzen bei Insekten gegen Bt-Toxine?}

Mutationen entstehen ständig im Genom von Lebewesen und werden i. d. R. schnell repariert. Mutationen die nicht repariert werden, führen entweder zum Tod oder gehen bei einem Fitnessnachteil innerhalb der nächsten Generationen verloren. Mutationen, die keinen oder einen geringen Fitnessnachteil besitzen, bleiben nach dem HardyWeinberg-Gesetz mit einer konstanten Frequenz in einer Population erhalten. Bei Ostrinia nubilalis wird die intitiale Frequenz resistenter Individuen auf $10^{-3}-10^{-6}$ geschätzt (Andow und Alstad, 1998; Andow et al., 1998b). 
Erhöht sich der Selektionsdruck, überleben vermehrt Larven mit Resistenzallelen, was zur Akkumulierung der anfangs seltenen Resistenzallele in der gesamten Population führt. Die Geschwindigkeit, mit der sich Resistenzgene in einer Population ausbreiten, ist von verschiedenen Faktoren abhängig (Gould und Tabashnik, 1998; Tabashnik, 1990; Ferré und Van Rie, 2002):

1. Der Anzahl der Generationen pro Jahr.

2. Der Mobilität der Larven.

3. Der Mobilität der Adulten und das Paarungsverhalten.

4. Der Populationsanteil, der dem Toxin ausgesetzt ist.

5. Der Mortalität von heterozygoten Individuen.

6. Der Fitness der resistenten Individuen in und ohne Anwesenheit des Selektionsagens.

7. Der Ausgangsfrequenz der Resistenzallele in einer Population.

8. Der Erbgang: dominant, semi-dominant, rezessiv.

9. Der Anzahl der an der Resistenz beteiligten Genloci.

Die genannten Faktoren können sich gegenseitig beeinflussen, z. B. kann ein Fitnessnachteil im Zusammenspiel mit der Mobilität und dem Paarungsverhalten dazu führen, dass sich die Entwicklungszeit verschiebt und sich häufiger resistente Larven paaren.

\section{Vererbung der Resistenz}

Voraussetzung für das "Refugien/Hoch Dosis"-Resistenzmanagement, wie es in Nordamerika betrieben wird (Witkowski et al., 1997), ist eine rezessive Vererbung der Resistenz (Alstad und Andow, 1995; Andow et al., 1998b; Gould, 1998). Einen Überblick über den derzeitigen Wissensstand liefert ein Artikel von Ferré und Van Rie (2002). Die Autoren haben die Daten für verschiedene Bt-Toxine, Insektenarten und Bestimmungsmethoden zusammengestellt und im Hinblick auf die Vererbung der Resistenz ausgewertet. Sie führen Untersuchungen zu sieben Insektenarten bzw. 23 resistenten Stämmen auf. Die Untersuchungen zur Resistenz wurden sowohl mit BtProdukten wie DIPEL ${ }^{\circledR}$ als auch mit verschiedenen Bt-Toxinen durchgeführt. Der größte Teil der Untersuchungen lässt auf eine rezessive Vererbung schließen, wobei sowohl vollständig rezessive über partiell rezessive bis eher kodominante Vererbungen auftraten. Fünf Stämme zeigten einen eher dominanten Erbgang. Der einzige resistente Ostrinia nubilalis-Stamm, der durch Selektion mit DIPEL ${ }^{\circledR}$ erzeugt wurde, zeigte eine eher dominante Vererbung der Resistenzeigenschaften (Huang et al., 1999b). Bei den meisten Stämmen bei denen eine Rückkreuzung durchgeführt wurde, zeigte sich, dass die Resistenz durch einen Genlocus vererbt wird. Für Resistenzen gegen Cry1Ca im Stamm Cry1C-SEL von Plutella xylostella (vgl. Kapitel 3.6), gegen Cry1 Ab im Stamm SEL von Heliothis virescens, gegen Cry1Ca in Spodoptera littoralis und gegen Cry3 Aa in Leptinotarsa decemlineata konnte die 1-Loci-Hyphothese nicht durch Rückkreuzung nachgewiesen werden. Wie erwähnt, können verschiedene Ursachen zu einer Resistenz führen, so dass das Auftreten von verschiedenen Vererbungsgängen und Genloci möglich ist (Heckel, 1994). 


\subsection{Monitoring zur Entdeckung von resistenten Insekten auf transgenen Pflanzen}

Das Monitoring der Resistenzentwicklung auf Bt-Mais kann verschiedene Ziele verfolgen. Die Überwachung soll evolutionäre Prozesse verfolgen und frühzeitig, d. h. bei einer niedrigen Resistenzallelhäufigkeit, vor einer Überwindung des Toxin-Schutzes warnen. Ein weiteres Ziel des Monitoring ist es, Resistenzen bei ihrem Auftreten zu bestätigen und Managementmaßnahmen auszulösen, wozu unter anderem genaue räumliche und zeitliche Kenntnisse der Basisempfindlichkeit der Maiszünsler notwendig sind (Andow und Hutchison, 1998). In der EU-Richtlinie 2001/18/EG (EURAT, 2002) wird verbindlich ein fallspezischer Überwachungsplan vorgeschrieben, der ein Resistenzmonitoring beinhaltet. Monitoring von Resistenz ist immer ein Bestandteil von Managementmaßnahmen. In der Literatur werden verschiedene Monitoringmethoden diskutiert (Andow und Hutchison, 1998; ffrench-Constant und Roush, 1990).

\section{Basisempfindlichkeitstest bzw. Dose-Response-Test}

Bei diesem Test wird vor dem Anbau von Bt-Mais die Basisempfindlichkeit von Maiszünslerpopulationen ermittelt. Mit Hilfe eines Dosis-Wirkungs-Tests, der vier bis fünf unterschiedliche Toxindosen beinhaltet, die eine Mortalität zwischen 10 und $90 \%$ erreichen, wird ein $\mathrm{LC}_{50}$ bzw. $\mathrm{LC}_{99}$ ermittelt. Regelmäßig oder im Bedarfsfall können von Populationen die $\mathrm{LC}_{50}$-Werte bestimmt und anhand des Vergleiches mit der Basisempfindlichkeit eine Resistenz bzw. Resistenzentwicklung bestätigt werden. Der Dose-Response-Test dient als Grundlage für weitere Tests, da anhand der DosisWirkungs-Kurven die diagnostische bzw. diskriminierende Konzentration ermittelt wird.

\section{Diagnostischer bzw. diskriminierender Konzentrationstest}

Der diagnostische bzw. diskriminierende Konzentrationstest geht davon aus, dass anhand einer Konzentration die sensiblen Larven von den resistenten Larven getrennt werden können. Die Larven einer Population werden mit einer Toxinkonzentration im Bereich des $\mathrm{LC}_{99}$ gefüttert. Die überlebenden Larven sind als resistent anzusehen (Marçon et al., 2000). Bei dieser Methode überleben bei einem rezessiven Erbgang nur homozygot resistente Individuen.

\section{Kreuzung mit einem Teststamm}

Die beiden bisher beschriebenen Methoden testen die phänotypischen Erscheinungsformen von Resistenzallelen. Bei einem rezessiven Erbgang ist die Häufigkeit von homozygoten Individuen $1 / \mathrm{q}^{2}$. Wenn die Häufigkeit von Resistenzallelen bei q liegt, d. h. bei einer Häufigkeit der Allele von $10^{-3}$, findet sich eine homozygote Larve unter einer Millionen Individuen (Gould et al., 1997). Gould et al. (1997) ermittelten die initiale Resistenzfrequenz in einer Feldpopulation von Heliothis virescens indem sie männliche adulte Tabakeulen mit weiblichen Individuen eines homozygot resistenten Laborstammes kreuzten. Die $\mathrm{F}_{1}$-Generation unterzogen sie einem Biotest mit einer Konzentration, die es ermöglicht, homozygot resistente von heterozygot resistenten Individuen zu selektieren. Für diese Methode wird immer ein resistenter Insektenstamm benötigt und sie ermittelt den Resistenzmechanismus, der im Laborstamm vorliegt. 


\section{$\mathrm{F}_{2}$-Screening}

Das $\mathrm{F}_{2}$-Screening ähnelt der Kreuzung mit einem Teststamm und wurde 1998 von Andow und Alstad entwickelt (Andow und Alstad, 1998). Beim $F_{2}$-Screening werden Maiszünsler aus dem Freiland im Labor als Isofamilie gehalten, d. h. die Nachkommen eines Paares werden untereinander gekreuzt. Die Nachkommen der $F_{1}$ werden innerhalb ihrer Mutterlinie (Geschwisterpaarung) gekreuzt und die Nachkommen ( $\mathrm{F}_{2}$-Generation) einem diskriminierenden Konzentrationstest unterzogen. Isolinien, die ein heterozygotes resistentes Elternteil enthalten, haben in der $\mathrm{F}_{2}$-Generation mit einer Wahrscheinlichkeit von 1/16 einen homozygoten Enkel. Wenn Resistenzallele gefunden werden, ist die Bestimmung ihrer Frequenz möglich. Wird kein Resistenzallel gefunden, kann die obere Grenze eines Intervalls berechnet werden, in dem die tatsächliche Resistenzallelfrequenz liegen muß.

\section{Monitoring der Resistenz auf Bt-Maisflächen}

Eine weitere Möglichkeit eine initiale Resistenzfrequenz zu ermitteln, ist das Suchen von überlebenden Maiszünslerlarven in einem Bt-Maisfeld (Venette et al., 2000). Die gefundenen Larven werden in einem Biotest auf ihre tatsächliche Resistenz getestet, um Individuen (Falsch-Positiv-Entscheidung), die z. B. auf nicht expressierenden Pflanzen überlebt haben, zu eliminieren. Mit den Befallswerten eines benachbarten nichttransgenen Maisfeldes lässt sich die Resistenzhäufigkeit berechnen.

\section{Bestimmung der Resistenz anhand von genetischen Markern}

Liegen resistente Tiere vor, so können mit Hilfe von molekulargenetischen Methoden Markersequenzen gesucht werden, die typisch für resistente Larven sind. Genetische Untersuchungen sind schnell durchzuführen und besitzen eine hohe Genauigkeit (McKenzie, 1996). Bisher liegen wenige resistente Markerstrukturen vor, da nur wenige resistente Stämme untersucht wurden. Heckel et al. (1999) entdeckten bei einem resistenten Stamm von Plutella xylostella auf dem Resistenzgen Regionen, die als Marker für Resistenzuntersuchungen dienen können. Laut Literatur sind beim Maiszünsler bislang nur Resistenzen im Labor mit Bt-Präparaten provoziert worden (Huang et al., 1999c). Es ist nicht bekannt, ob die im Labor provozierten Resistenzmechanismen die gleiche Grundlage besitzen wie bei einer Resistenzentstehung auf dem Feld. Sind mehrere Resistenzmechanismen beim Maiszünsler aktiv, müssen für die Suche nach resistenten Larven mehrere Markersequenzen eingesetzt werden. 


\subsection{Resistenzmanagement}

Resistenzen gegen Bt-Toxine sind seit Jahrzehnten bekannt (siehe Kapitel 3.6). Mit der Entwicklung von Bt-Maispflanzen wurden Maßnahmen diskutiert, die eine Resistenzentwicklung gegen Bt-Pflanzen verhindern bzw. verzögern sollen, um eine nachhaltige Nutzung dieser Pflanzen zu gewährleisten. Ziel ist es, den Selektionsdruck zu verringern, so dass die evolutionären Prozesse der Resistenzbildung langsamer verlaufen. McGaughey und Whalon (1992) geben drei Strategien an, die den Selektionsdruck verringern können:

1. Eine Vervielfältigung der Mortalitätsgründe für den Schädling.

2. Verringerung des Selektionsdrucks durch den Hauptmortalitätsfaktor, z. B. durch geringe Toxinkonzentrationen.

3. Bereitstellung von empfindlichen Paarungspartnern durch Refugien oder Einwanderung.

Die meisten Strategien gehen davon aus, dass die Resistenz rezessiv vererbt wird. Unter dieser Annahme unterscheidet sich die Überlebenschance auf einer Bt-Maispflanze von heterozygot resistenten Larven (rS) und von homozygot empfindlichen Larven (SS) nicht oder kaum. Durch entsprechende Maßnahmen soll im Feld gewährleistet werden, dass es zur Paarung von rS-Larven mit SS-Larven kommt, wodurch die Nachkommen heterozygot und damit empfindlich sind. Die Paarung von rS-Maiszünslern oder resistenten rr-Maiszünslern untereinander sollen möglichst vermieden werden. Die Strategien können in Kombination angewendet werden. Zusätzlich gibt es verschiedene Ansätze, wie die einzelnen Strategien umgesetzt werden. Empfindliche Paarungspartner können durch großflächige Refugien, durch Saatgutmischungen oder durch eine zeitliche und räumliche Steuerung der Toxinproduktion erreicht werden. "Genestacking", d. h. der Einbau von verschiedenen Toxinen in einer Pflanze, verteilt den Selektionsdruck auf zwei oder mehr Mortalitätsfaktoren, wodurch eine Resistenz unter bestimmten Bedingungen unwahrscheinlicher wird. Nachdem Bt-Maispflanzen mit hohen Bt-Toxinkonzentrationen entwickelt wurden, hat sich in den USA die "Refugien/Hoch Dosis"-Strategie bei der Industrie und bei den Zulassungsbehörden durchgesetzt (Gould, 1998; Frutos et al., 1999). 


\subsection{1 "Refugien/Hoch Dosis"-Strategie}

Durch eine hohe Bt-Toxinkonzentration soll gewährleistet werden, dass die heterozygot resistenten Larven (rS) abgetötet werden. Durch die Refugienflächen werden empfindlich homozygote Falter (SS) bereitgestellt, um Paarungen wie rr x rr oder rS x rS Paarungen zu vermeiden und die Entstehung von rS-Nachkommen, die durch die Bt-Toxinkonzentration sicher abgetötet werden, zu förden. Für den Erfolg der "Refugien/Hoch Dosis"-Strategie werden von Andow und Hutchison (1998) drei Bedingungen angegeben:

1. Die Vererbung der Resistenz muss rezessiv sein und die Frequenz der Resistenzallele sollte unter $1 \times 10^{-3}$ liegen.

2. Die Toxinkonzentration in den Pflanzen muss so hoch sein, dass die Resistenz funktionell rezessiv ist, d. h. dass die rS-Larven abgetötet werden. "Hoch Dosis" wird als diejenige Dosis definiert, die $95 \%$ der heterozygoten Larven $(\mathrm{rS})$ abtötet

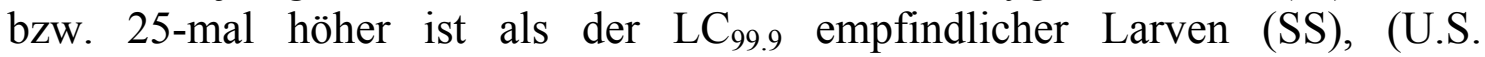
Environmental Protection Agency (EPA), 2001).

3. Die Paarung zwischen den resistenten Faltern (rr) aus den Bt-Flächen und den empfindlichen Faltern (SS) aus den Refugien muss zufällig erfolgen, und das Angebot an empfindlichen Larven muss ausreichend sein, d.h. das Verhältnis von SS-Faltern zu rS- und rr-Falter sollte 500: 1 sein.

Die EPA schreibt bei Bt-Mais eine Refugienfläche von $20 \%$ vor (U.S. Environmental Protection Agency (EPA), 2001). Die Fläche kann als Block angelegt werden und muss im Umkreis von $400 \mathrm{~m}$ (einer Viertel Meile) liegen, wobei der Streifenanbau von zwei bis sechs Reihen empfohlen wird. Saatgutmischungen, die eine Kontrolle der Einhaltungen der Refugienstrategie erleichtern würden, werden nicht empfohlen, da sie in Computermodellen zu einer Resistenzbeschleunigung führen.

Das Gelingen des Resistenzmonitoring-Programms ist von Faktoren auf der Pflanzenebene, der Ebene des Individuums und der Ebene der Schaderregerpopulation sowie von agronomischen Bedingungen abhängig. Daten zur Überprüfung der "Refugien/Hoch Dosis"-Strategie fehlen zum größten Teil (Losey et al., 2001). Die biologischen Zusammenhänge sind oft sehr komplex und wenig erforscht. Mit Computermodellen wird versucht, eine Resistenzenwicklung zu simulieren, wobei auf Grund der fehlenden Informationen häufig nicht wissenschaftlich abgesicherte Annahmen getroffen werden (Andow und Hutchison, 1998). Aus diesem Grund sind die Vorgaben der EPA für das Resistenzmanagement umstritten und für die Anlage der Refugienstruktur werden je nach Modellannahmen verschiedene Szenarien vorgeschlagen (Alstad und Andow, 1995; Andow und Hutchison, 1998; Gould und Tabashnik, 1998; Gould, 1998; Onstad und Guse, 1999; Davis und Onstad, 2000; Andow und Ives, 2002). Die zufällige Paarung der Maiszünsler aus den Refugienflächen mit den Maiszünslern aus den Bt-Maisflächen hängt von der Mobilität der Maiszünsler und dem Paarungsort ab. Wird als Paarungsort das Maisfeld angenommen, dann ist ein Streifenanbau zu bevorzugen. Erfolgt die Paarung außerhalb des Feldes auf Grasflächen, ist eine Blockanlage günstiger. Die Mobilität bedingt direkt den maximalen Abstand von Blockrefugienflächen von den Bt-Maisfeldern. Haben die überlebenden Maiszünsler auf Bt-Maisflächen einen Fitnessnachteil, kann es zu einer 
zeitlichen Verschiebung des Auftretens der Falter in Bt-Mais- und Refugienflächen kommen, wodurch eine zufällige Paarung aufgehoben würde (Liu et al., 1999). Über die Nutzung alternativer Wirtspflanzen ist wenig bekannt. Untersuchungen von Bourguet et al. (2000b) zeigen genetische Unterschiede zwischen Maiszünslern auf Beifuß (Artemisia vulgaris) und Mais. Sie vermuten daher, dass Artemisia als Refugium nicht zur Verfügung steht. Losey et al. (2001) kommen in ihren Untersuchungen zu dem Schluss, dass alternative Wirtspflanzen nicht ausreichend zur Maiszünslerpopulationsdynamik beitragen und somit Maisrefugienflächen nicht ersetzen können. Wird aber berücksichtigt, dass von der E-Rasse auf Artemisia ein früheres Schlüpfen von Faltern bekannt ist (Lorenz, 1993) und dass die überlebenden Larven auf Bt-Maisfeldern ein verändertes Schlupfverhalten zeigen, ist eine Nutzung von alternativen Wirtspflanzen als zusätzliches Refugium sinnvoll, wenn die Schlupfzeitpunkte der resistenten Falter mit dem Schlupfzeitpunkt von Faltern aus alternativen Wirtspflanzen synchron sind. Bisher sind keine Untersuchungen unter dieser Annahme durchgeführt worden.

Über die Häufigkeit von Resistenzallelen bei Ostrinia nubilalis ist wenig bekannt. In keiner Untersuchung konnte bisher eine Resistenzhäufigkeit von unter $10^{-3}$ sicher nachgewiesen werden (Andow et al., 1998a; Venette et al., 2000; Andow et al., 2000). Für Europa liegen keine Daten zur Resistenzhäufigkeit der Maiszünsler vor. Die Bereitstellung ausreichend empfindlicher Maiszünsler (SS) hängt vom Befall in den Anbaugebieten ab. Der HALO-Effekt, d. h. die Reduktion des Befalls in den BtMaisflächen, führt zur Reduktion des Befallsdrucks in den Refugienflächen und ist umso größer, je näher die Refugienflächen an bzw. in Bt-Mais-Flächen liegen, so dass der Streifenanbau, der günstiger für eine zufällige Paarung ist, durch den starken Einfluss des HALO-Effekts an Wirkung verliert. Um den tatsächlichen Nutzen von Resistenzmanagementmaßnahmen $\mathrm{zu}$ überprüfen und anzupassen, ist ein Resistenzmonitoring von entscheidener Bedeutung, wozu die Ermittlung der Grunddaten, wie die Feststellung der Basisempfindlichkeit vor einem Bt-Maisanbau und die Bestimmung der Resistenzfrequenz, gehört. 


\section{BASISEMPFINDLICHKEIT}

\subsection{Einleitung}

Resistenz ist die Fähigkeit eines Organismus trotz starker Exposition gegenüber einem Toxin zu überleben und sich weiter zu vermehren (Müller, 2001). Das Insecticide Resistance Action Commitee (IRAC) (2000) definiert Resistenz als die Reduzierung der Empfindlichkeit einer Population. Dies wird daran deutlich, dass ein Insektizid seine erwartete Bekämpfungsleistung nicht zeigt, wobei Lagerschäden, Witterungseinflüsse und andere Störfaktoren ausgeschlossen sein müssen. Laut beider Definitionen ist die Resistenz kein statischer Wert, sondern ergibt sich aus dem Vergleich nicht-resistenter und resistenter Insekten. Die Empfindlichkeit einer Population vor dem Kontakt mit einem Insektizid wird als Basisempfindlichkeit definiert und kann anhand von DosisWirkungs-Tests ermittelt werden. Beim Bt-Mais ist die Bestimmung von $\mathrm{LC}_{50}$-Werten mittels Verdünnungsreihen von Pflanzenextrakten schwierig. Aus diesem Grund werden die Versuche i. d. R. mit gereinigtem Cry1Ab-Toxin, das in Bakterien produziert wurde und dem Toxin aus der Pflanze entspricht, durchgeführt (U.S. Environmental Protection Agency (EPA), 2001). Höhere $\mathrm{LC}_{50^{-}}$bzw. LC $\mathrm{L}_{90}$-Werte einer Population zeigen im Vergleich zu einem empfindlichen Standardstamm bzw. einer Population eine Resistenz an. Nach Koziel et al. (1993b) sind durch diese Schwankungen innerhalb einer Vergleichspopulation oder zwischen geografisch verschiedenen Populationen schwach ausgeprägte Resistenzen i. d. R. schwierg zu entdecken. Über die Variabilität in der Empfindlichkeit gegenüber Bt-Toxinen zwischen geografisch verschiedenen Insektenpopulationen ist häufig berichtet worden (Tabashnik, 1994), und auch Schwankungen der Empfindlichkeit innerhalb eines Stammes über mehrere Jahre sind für verschiedene Insektizide bekannt (Savin et al., 1977; Robertson et al., 1995). Daher ist eine genaue Kenntnis der geografischen Unterschiede und der zeitlichen Stabilität von $\mathrm{LC}_{50}$-Werten für ein nationales Resistenzmonitoring-Programm von entscheidender Bedeutung und dient der Überprüfung des Erfolgs von ResistenzmanagementProgrammen (Andow et al., 1998b; U.S. Environmental Protection Agency (EPA), 2001). Für die USA liegen eine Reihe von Literaturdaten zur Basisempfindlichkeit des Maiszünslers vor (MacIntosh et al., 1990; Marçon et al., 1999b). Da die Maiszünsler Anfang des 19. Jahrhunderts aus Europa in die USA eingeschleppt wurden und somit durch einen genetischen Flaschenhals charakterisiert sind, ist eine Übertragung von $\mathrm{LC}_{50}$-Werten der amerikanischen Populationen auf europäische Maiszünsler fraglich.

Für Europa liegen nur wenige Daten zur Basisempfindlichkeit von Maiszünslern verschiedener geografischer Herkünfte vor. Gonzáles-Núñez et al. (2000) fanden in Spanien Unterschiede in der Empfindlichkeit verschiedener geografischer Populationen von Sesamia nonagrioides, jedoch nicht von Ostrinia nubilalis. Für Deutschland ist nicht bekannt, ob verschiedene geografische Populationen die gleiche Basisempfindlichkeit besitzen und den gleichen genetischen Ursprung haben. Nach der bisherigen Theorie hat sich die Maiszünslerausbreitung in Deutschland entlang des Rheingrabens von Süden nach Norden vollzogen (Langenbruch et al., 1999; Schmitz et al., 2001). Separat von diesem Befallsgebiet liegen Gebiete im Südosten von Bayern, in Sachsen-Anhalt und Brandenburg, so dass in diesen Gebieten von einer unterschiedlichen genetischen Basis auszugehen ist (Langenbruch et al., 1999). 
Im Rahmen dieser Arbeit wurde untersucht, ob sich die Empfindlichkeit verschiedener geografischer Populationen in Deutschland unterscheidet und mit welcher natürlichen Schwankungsbreite bei einem Resistenzmonitoring zu rechnen ist. Zur Bestimmung der Basisempfindlichkeit vor einem großflächigen Anbau von Bt-Mais wurden Maiszünsler in verschiedenen Regionen Deutschlands gesammelt und der $\mathrm{LC}_{50}$-Wert für die Populationen bestimmt. Die Standorte Niedernberg und Hessisches Ried liegen entlang der Ausbreitungslinie des Rheingrabens. Getrennt von diesen Befallsgebieten liegt im Südosten von Bayern im Inntal das Sammelgebiet Pocking, ein Hauptanbaugebiet von Körnermais in Deutschland. Ein weiterer, separat liegender Sammelstandort lag im Oderbruch im äußersten Osten Deutschlands. Die Untersuchungen zu diesem Standort wurden im Rahmen des BMBF-Projektes von Frau Liebe, BBA Kleinmachnow, durchgeführt. Durch den verstärkten Anbau von Körnermais in Sachsen-Anhalt innerhalb der letzten 15 Jahre hat die Maiszünslerproblematik in diesem Gebiet stark zugenommen. Von 1995 bis 2001 hat sich die Körnermaisfläche von 1.400 ha auf 2.760 ha verdoppelt (Fassauer, pers. Mitt.). Auf Grund von PCR-Untersuchungen im Jahr 2000 und 2001, die eine Verwandtschaft der Populationen im Oderbruch und in Halle vermuten ließen (Liebe, pers. Mitt.), wurde im Jahr 2002 die Population Halle in die Untersuchungen einbezogen.

Bei einem großflächigen Anbau von Bt-Mais besteht das Problem, Populationen zu finden, die keinen Kontakt mit Bt-Toxin hatten und somit als sensitive Basis dienen können. Als Referenz kann die Basisempfindlichkeit, die vor einem Einsatz von BtMais ermittelt wurde, dienen. Die natürlichen Schwankungen innerhalb der Population über die Zeit können diesen Vergleich erschweren. Auf Grund dessen lag ein weiterer Schwerpunkt dieser Arbeit in der Untersuchung der Stabilität der $\mathrm{LC}_{50}$-Werte über mehrere Jahre. Alternativ kann als Vergleich eine Maiszünslerpopulation oder ein Laborstamm, die künstlich ohne Bt-Toxinkontakt gehalten wurden, dienen. Bei diesen Stämmen können Inzucht und zuchtbedingte Selektion die Vergleichbarkeit erschweren. Um Unterschiede zwischen Laborstämmen und den Populationen aus dem Freiland zu ermitteln, wurde ein Stamm in die Untersuchungen einbezogen, der über mehrere Jahre unter Laborbedingungen gehalten wurde.

Eine Schwierigkeit im Vergleich der Untersuchungen verschiedener Autoren liegt in der Verwendung von unterschiedlichen Methoden zur Bestimmung der Basisempfindlichkeit. Es werden entweder Cry1 Ab Protoxine oder trypsinisiertes Toxin eingesetzt, oder die Applikation des Toxins erfolgt oberflächlich auf das Medium oder durch Beimischung unter das Nährmedium. Um eine Vergleichbarkeit mit zukünftigen europäischen Untersuchungen zu gewährleisten, richtete sich die Bestimmung der Basisempfindlichkeit weitestgehend nach Vorschlägen der EU-Expertengruppe zum Monitoring der Insektenresistenz gegen Bt-Toxin (Scientific Commitee on Plants at the EU-Commission, 1998). Neben der empfohlenen Oberflächen-Methode wurden Daten zur Untermisch-Methode gewonnen und verglichen. 


\subsection{Material und Methoden}

\subsubsection{Standorte}

\subsubsection{Niedernberg (NI)}

Die Stadt Niedernberg gehört zum Landkreis Aschaffenburg, der mit Miltenberg und der Stadt Aschaffenburg die Region Bayerischer Untermain bildet. Die Region liegt auf einer Höhe von 50 - 108 m ü. N. N., die mittlere Jahrestemperatur liegt bei ca. $9 \mathrm{C}$ und der Jahresniederschlag beträgt im langjährigen Durchschnitt 600 bis $650 \mathrm{~mm} .61 \%$ der landwirtschaftlich genutzten Fläche ist Ackerland und $36 \%$ wird als Grünland genutzt. $16 \%$ der Ackerfläche, die mit Getreide angebaut wird, ist Körnermais (Bayerisches Staatsministerium für Landwirtschaft und Forsten, 2002a). Das Untersuchungsgebiet umfasste ca. $15 \mathrm{~km}^{2}$ mit der geografischen Lage: West-Ost Ausdehnung O0905'30', bis O909'00''; Nord-Süd-Ausdehnung: N4956'00''- N4952'00'’). Die Maisfelder auf denen gesammelt wurde, hatten eine Größe von 0,5 -5 ha. Zum Teil fand in den Jahren 2000 und 2001 eine Maiszünslerbekämpfung mit BAYTHROID ${ }^{\circledR}$ statt.

Tab. 4: Sammeldaten und Kenngrößen vom Stamm Niedernberg (NI)

\begin{tabular}{|c|c|c|c|}
\hline & 1999 & 2000 & 2001 \\
\hline Sammelzeitpunkt & $01.11 .-08.11 .9$ & $23.10-26.10$ & $08.10 .-19.10$. \\
\hline Sammelbedingungen & Stoppeln & $\begin{array}{l}\text { Bestand, } \\
\text { Stoppeln }\end{array}$ & $\begin{array}{l}\text { Bestand, } \\
\text { Stoppeln }\end{array}$ \\
\hline Anzahl beprobter Felder [n] & 10 & 12 & 10 \\
\hline $\begin{array}{l}\text { Durchschnittliche Larven- } \\
\text { anzahl pro Feld [n] }\end{array}$ & 112 & 90 & 31 \\
\hline Feldgröße [ha] & $0,5-10$ & $0,5-10$ & $0,5-10$ \\
\hline Anzahl Larven & 1232 & 1083 & 459 \\
\hline Befallsschätzung $^{1}[\%]$ & $\begin{array}{l}\text { mittel: } \\
20-50\end{array}$ & $\begin{array}{l}\text { gering - mittel: } \\
7-40\end{array}$ & $\begin{array}{l}\text { mittel: } \\
20-30\end{array}$ \\
\hline Wintermortalität [\%] & 27,1 & 39,5 & 24,4 \\
\hline $\begin{array}{l}\text { Überlebende }{ }^{2} \text { Larven am } \\
(29.05 .00 / 5.06 .01 / 21.05 .02)\end{array}$ & 938 & 654 & 347 \\
\hline Maisart & $\begin{array}{l}\text { Körnermais, } \\
\text { CCM }\end{array}$ & $\begin{array}{l}\text { Körnermais, } \\
\text { CCM }\end{array}$ & $\begin{array}{l}\text { Körnermais, } \\
\text { CCM }\end{array}$ \\
\hline Jahresmitteltemperatur ${ }^{3}\left[{ }^{\circ} \mathrm{C}\right]$ & 10,7 & 10,9 & 10,2 \\
\hline Max. Temp $\left[{ }^{\circ} \mathrm{C}\right]$ & 32,6 & 33,1 & 34,4 \\
\hline Min. Temp $\left[{ }^{\circ} \mathrm{C}\right]$ & $-9,3$ & $-11,2$ & $-16,3$ \\
\hline $\begin{array}{l}\text { Jahresniederschlagsumme } \\
{[\mathrm{mm}]}\end{array}$ & 537,1 & 806,16 & 729 \\
\hline \multicolumn{4}{|c|}{$\begin{array}{l}{ }^{1} \text { Befallzahlen beziehen sich auf grobe Schätzungen während der Sammeltermine und sinc } \\
\text { nicht abgesichert. } \\
{ }^{2} \text { Abzüglich Larven für PCR- und Mikrosporidienuntersuchung. } \\
{ }^{3} \text { Quelle: Messnetz Bayern, Wetterstation Nr. 81, Großostheim (Bayerische Landesanstalt für } \\
\text { Landwirtschaft, 2002). }\end{array}$} \\
\hline
\end{tabular}




\subsubsection{Hessisches Ried (HR)}

Der hessische Anteil des Oberrheingrabens wird als Hessisches Ried bezeichnet und von Rhein, Main, Neckar und Odenwald begrenzt. Das Sammelgebiet umfasste die Gemeinde Riedstadt, die aus einem Zusammenschluss der Gemeinden Goddelau, Crumstadt, Erfelden, Leeheim und Wolfskehlen entstanden ist. Riedstadt ist mit 73,76 $\mathrm{km}^{2}$ Gemarkungsgröße die flächenmäßig größte Gemeinde im Kreis Groß-Gerau. Die Grenzen des Sammelgebietes waren in West-Ost-Richtung: O08 22'10' bis O08 30'10' 'und Nord-Süd-Richtung: N4953'10' bis N4947'50', Das Gebiet liegt auf einer Höhe von 80 bis $90 \mathrm{~m}$ ü. N. N. Im Sammelgebiet werden $89 \%$ der landwirtschaftlichen Fläche ackerbaulich genutzt, $11 \%$ stehen als Grünland zur Verfügung. Neben dem Getreideanbau mit $57 \%$ und dem Zuckerrübenanbau mit $18 \%$ ist der Gemüseanbau mit $10 \%$ der Ackerfläche ein wichtiger Erwerbszweig in der Landwirtschaft. Die Ackerflächen sind in dem Gebiet klein und zersplittert. Körnermais wird zu $4 \%$ und Silomais zu $2 \%$ angebaut (Hessisches Dienstleistungszentrum für Landwirtschaft, 2002). Über die Bekämpfung des Maiszünslers im Sammelgebiet liegen keine Daten vor. Aus den eigenen Beobachtungen kann gesagt werden, dass eine mechanische Bekämpfung, durch Häckseln und sauberes Unterpflügen der Pflanzenreste nicht erfolgt.

Tab. 5: Sammeldaten und Kenngrößen vom Stamm Hessisches Ried (HR)

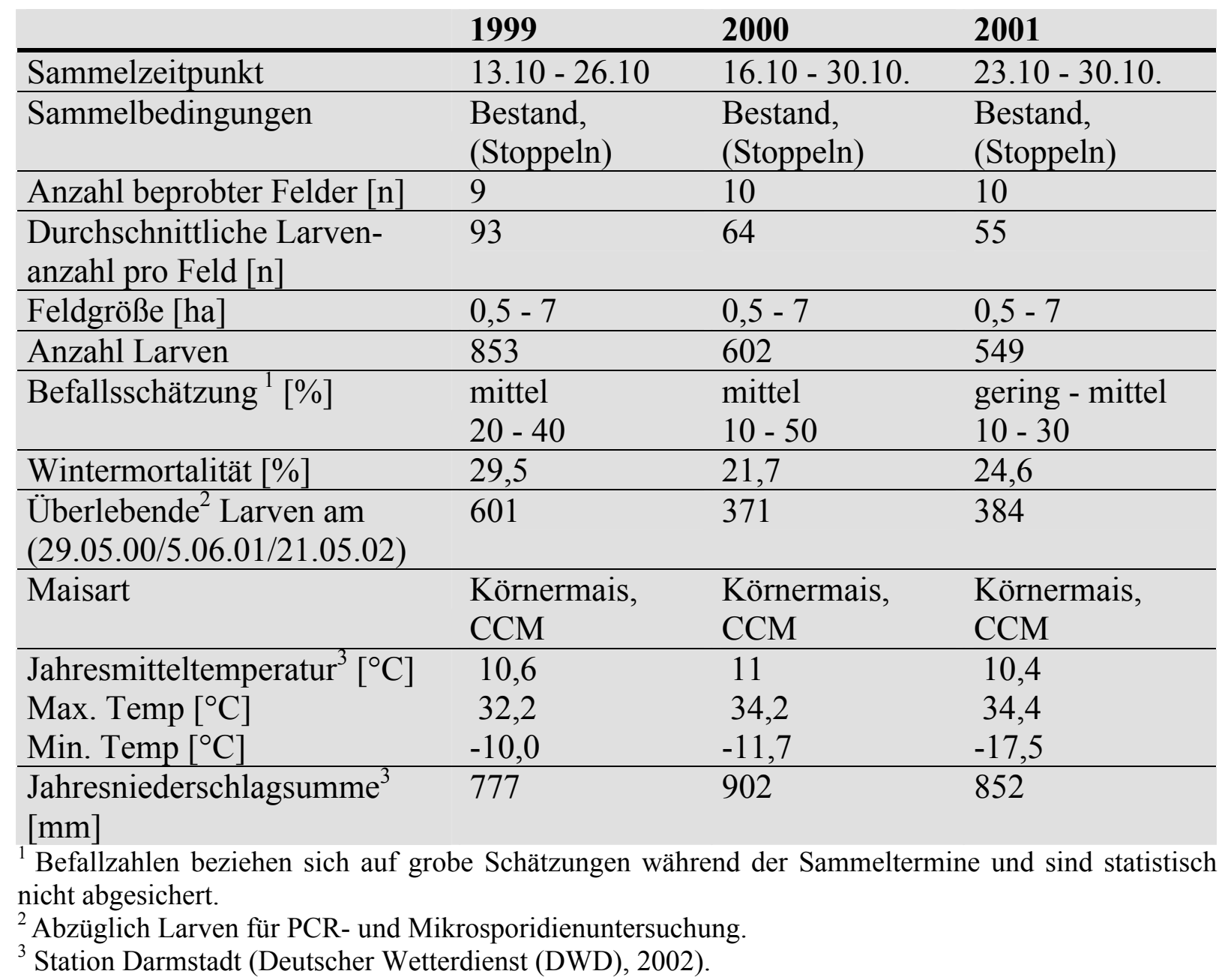




\subsubsection{Pocking (PO)}

Das Sammelgebiet Pocking gehört zum Landkreis Passau. Der Landkreis ist mit einer Fläche von 1530,28 $\mathrm{km}^{2}$ der drittgrößte Landkreis in Bayern und wird in einen nördlichen und südlichen Produktionsraum, $\mathrm{zu}$ dem das Inntal als Sammelstandort gehört, untergliedert. Das Inntal entstand aus dem Kiesgeschiebe des Inn-SalzachGletschers. In dem Gebiet herrschen mäßig steinreiche Braunerden vor, welche auf Grund der leichten Erwärmung einen idealen Maisstandort darstellen. Das Sammelgebiet hatte eine Fläche von $160 \mathrm{~km}^{2}$ und erstreckte sich in West-Ost-Richtung:

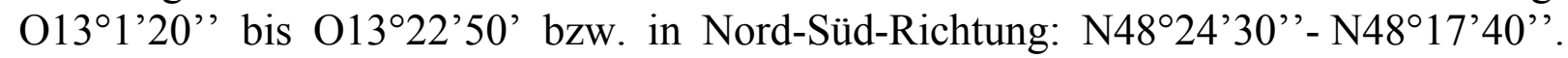
Das Höhenniveau liegt im Durchschnitt bei 320 - 450 m ü. N. N. Landwirtschaftliche Produktionsschwerpunkte sind im Inntal der Anbau von Getreide, Mais (Körnermais $33 \%$, Silomais $6 \%$ ) sowie die Produktion von Zucht- und Mastschweinen (Bayerisches Staatsministerium für Landwirtschaft und Forsten, 2002b). Im Bezirk des Landwirtschaftsamtes Rotthalmünster, zu dem das Sammelgebiet gehört, wird der Maiszünsler ausschließlich mechanisch durch Schlegeln der Stoppeln und sauberes Unterpflügen des Pflanzenmaterials bekämpft (Grundwürmer, pers. Mitt.). Das Sammeln der Maiszünsler erfolgte mit der Unterstützung von Herrn Grundwürmer, Landwirtschaftsamt Rotthalmünster.

Tab. 6: Sammeldaten und Kenngrößen vom Stamm Pocking (PO)

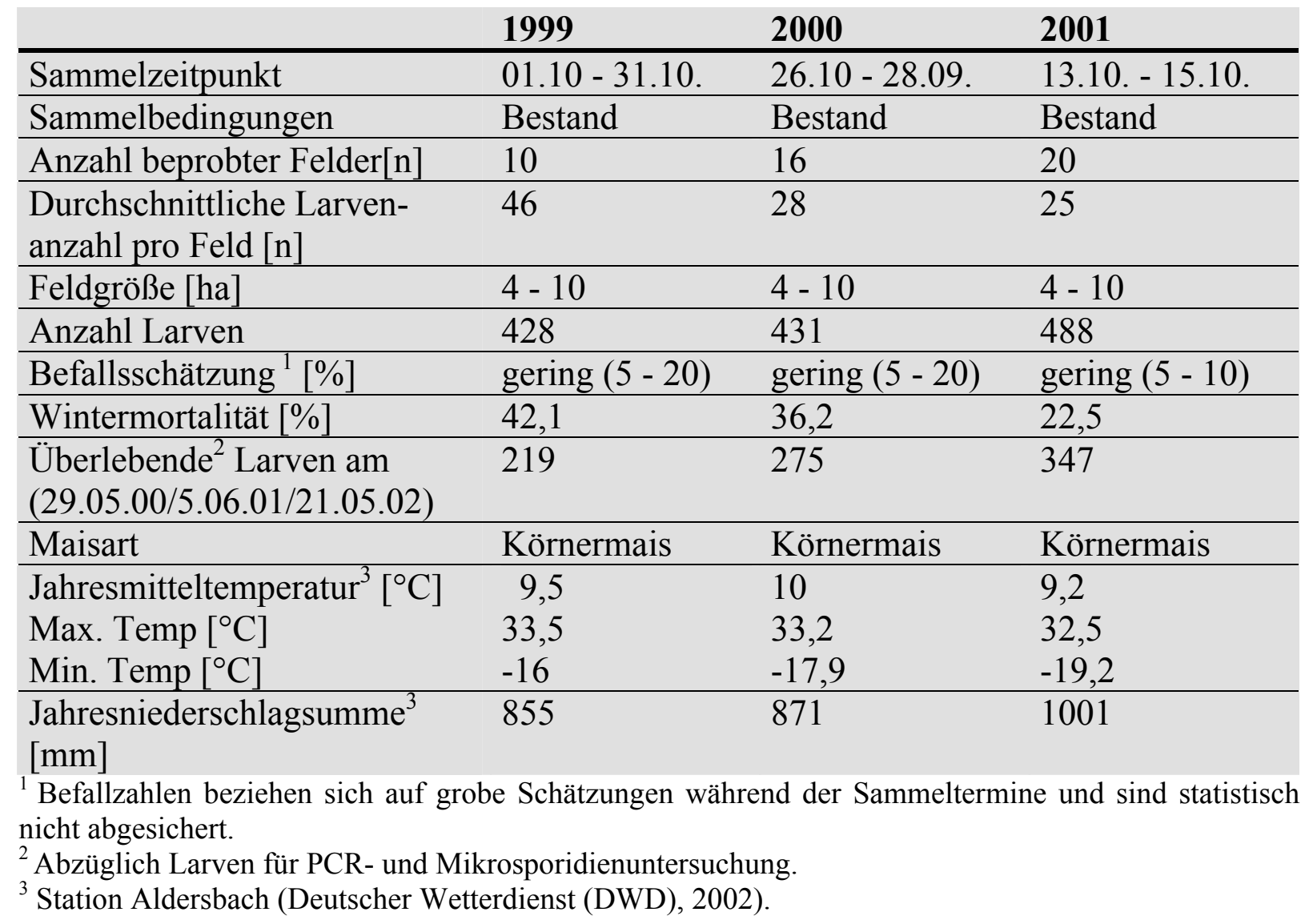




\subsubsection{Halle/Saale (HA)}

Am Standort Halle (76 m ü. N. N.) wurden erst im Jahr 2002 Maiszünsler gesammelt. Der Grund für die späte Aufnahme des Standortes Halle liegt darin, dass sich ab 1999 eine starke Maiszünslerpopulation mit Befallswerten von bis zu $100 \%$ aufgebaut hatte. 1997 lag der Befall mit Maiszünslern unter 5\% (Fassauer, pers. Mitt.). Vorläufige genetische Untersuchungen deuteten an, dass die Maiszünsler vom Standort Halle zu den Maiszünslern aus dem Oderbruch eine größere Ähnlichkeit aufweisen als zu den anderen Standorten (Liebe, pers. Mitt.). Da die Maiszünsler im Oderbruch im Jahr 2001 eine höhere Basisempfindlichkeit zeigten, wurde die Population in Halle daraufhin überprüft. Aus terminlichen Gründen war eine Sammlung von Maiszünslern im Herbst 2001 nicht möglich, so dass vom 13.06.02 bis zum 16.07.02 zwei Lichtfallen in einem Abstand von ca. $1 \mathrm{~km}$ in Zusammenarbeit mit Herrn Fassauer, Amt für Landwirtschaft und Flurneuordnung Anhalt, aufgestellt wurden. Durch Vandalismus wurde eine Lichtfalle am 12.07.01 zerstört und die Sammelaktion vorzeitig abgebrochen. Aus den bis dahin gesammelten Faltern und Eiern wurde eine Zucht aufgebaut, von der die $\mathrm{F}_{2}$ Generation auf ihre Empfindlichkeit gegenüber Cry1 Ab getestet wurde.

Der Standort Halle, der zur Magdeburger Börde zählt, ist durch ein stark kontinental beeinflusstes Binnenlandklima, mit einer häufig auftretenden Vorsommertrockenheit gekennzeichnet. Der Anbau von Mais liegt bei $10 \%$, wobei Körnermais zu $7 \%$ angebaut wird (Fassauer, pers. Mitt.). Zur Erosionsminderung und aus Kostengründen (Dieseleinsparungen) wird auf den bis zu 100 ha großen Schlägen pflugloser Maisanbau betrieben.

Tab. 7: Sammeldaten und Kenngrößen Halle/Saale

\begin{tabular}{|c|c|c|}
\hline \multirow{2}{*}{$\frac{\text { Jahr }}{\text { Falle }}$} & \multicolumn{2}{|c|}{2002} \\
\hline & $\begin{array}{l}\text { Lichtfalle } \\
\text { Pflanzenschutz }\end{array}$ & Lichtfalle BBA \\
\hline Sammelzeitpunkt & 13.06. - 16.07. & $26.06 .-11.07$ \\
\hline Sammelbedingungen & Lichtfalle & Lichtfalle \\
\hline Feldgröße [ha] & 100 & 100 \\
\hline $\begin{array}{l}\text { Anzahl Falter }[\mathrm{n}] \\
0 \\
0 \\
0\end{array}$ & $\begin{array}{l}216 \\
135 \\
81\end{array}$ & $\begin{array}{l}330 \\
209 \\
121\end{array}$ \\
\hline $\begin{array}{l}\text { Befallsschätzung }{ }^{2} \\
{[\%]}\end{array}$ & & \\
\hline Maisart & & \\
\hline Jahresmitteltemperatur & & \\
\hline Jahresniederschlagssumme $^{2}$ & & \\
\hline
\end{tabular}




\subsubsection{Oderbruch (OD)}

Das Oderbruch ist das östlichste Untersuchungsgebiet (12 m ü. N. N.) und mit $920 \mathrm{~km}^{2}$ das größte Flußpoldergebiet in Deutschland (Kofod et al., 1997). Die Oder wurde seit dem 16. Jahrhundert eingedeicht, um der Überschwemmungsgefahr entgegenzuwirken. Um die Auen bzw. Moorböden landwirtschaftlich zu nutzen, wurden bis in die 70er Jahre Entwässerungsmaßnahmen durchgeführt. Im Oderbruch wird pflugloser Maisanbau betrieben. Der Maiszünsler wurde 1985 zum ersten Mal im Mais als Schädling beobachtet (Popko, 2003). Seitdem hat sich der Befall durch den Maiszünsler von $10,6 \%$ auf heute bis zu $100 \%$ erhöht.

Die Sammlung und die Untersuchungen zur Basisempfindlichkeit des Maiszünslers im Oderbruch wurden von Frau Liebe, Institut für integrierten Pflanzenschutz (BBA, Kleinmachnow), durchgeführt und die Daten für die Auswertung zur Verfügung gestellt.

Tab. 8: Sammeldaten und Kenngrößen Oderbruch

\begin{tabular}{lll} 
Jahr & $\mathbf{2 0 0 0}$ & $\mathbf{2 0 0 1}$ \\
\hline Sammelzeitpunkt & September 2000 & 26.09 .2001 \\
\hline Sammelbedingungen & Stoppeln, Bestand & Stoppeln, Bestand \\
\hline Anzahl beprobter Felder [n] & 1 & 1 \\
\hline Abgesuchter Bereich [ha] & ca. 30 & ca. 2,2 \\
\hline Anzahl Larven [n] & 845 & 1355 \\
\hline Befall [\%] & stark & stark \\
& $75-100$ & $75-100$ \\
\hline Wintermortalität [\%] & 3 & 5 \\
\hline Überlebende Larven im Frühjahr & 820 & 1.287 \\
\hline Maisart & $\mathrm{CCM}$ & $\mathrm{CCM}$ \\
\hline Jahresmitteltemperatur ${ }^{1}\left[{ }^{\circ} \mathrm{C}\right]$ & 10,2 & 9,1 \\
Max. Temp [ $\left.{ }^{\circ} \mathrm{C}\right]$ & 36,5 & 34,3 \\
Min. Temp [ $\left.{ }^{\circ} \mathrm{C}\right]$ & $-13,6$ & $-11,2$ \\
\hline Jahresniederschlagsumme & \\
[mm] & 398 & 443 \\
${ }^{1}$ Station Manchnow (Deutscher Wetterdienst (DWD), 2002). \\
(Liebe, pers. Mitt).
\end{tabular}




\subsubsection{Sammelverfahren der Maiszünsler}

Das Sammelverfahren richtete sich nach den Empfehlungen der EUExpertenkommision zum Monitoring der Insektenresistenz gegen Bt-Toxin (Scientific Commitee on Plants at the EU-Commission, 1998). Die Maiszünsler der Standorte Pocking, Niedernberg und Hessisches Ried wurden in allen drei Jahren im Herbst kurz vor oder nach der Ernte auf mindestens 9 - 20 Feldern (0,5 - 10 ha) gesucht. Pro Feld wurden je nach Befall zwischen 25 - 150 Larven gesammelt (4.2). Angestrebt wurde eine Anzahl von 10 Feldern à 100 Larven und somit insgesamt eine Zahl von 300 bis 1.000 Larven. Die Probestellen wurden möglichst gleichmäßig über das Anbaugebiet verteilt und auch innerhalb eines Feldes wurde an mehreren Stellen gesammelt. Da kein Einfluss auf die Anbaustruktur, den Erntezeitpunkt und die Schädlingsbekämpfungsmaßnahmen in den Anbaugebieten genommen werden konnte, kam es teilweise zu einer ungleichen Verteilung der Probestellen. Dies spiegelt die tatsächliche Verteilung der Population im Gebiet wieder, da durch insektizide Behandlung oder die Massierung von Feldern in einem Gebiet die Population entsprechend beeinflusst wird. Die Larven aus dem Oderbruch wurden auf Teilen einer bis zu 70 ha großen Maisfläche gesammelt; dies entspricht etwa der abgesuchten Maisfläche an den anderen Standorten. Im Anbaugebiet Halle, das erst im Jahr 2002 in die Untersuchungen aufgenommen wurde, war ein Sammeln der Larven nicht möglich. Daher wurden Falter mit Hilfe von zwei Lichtfallen im Zeitraum vom 13.06.02 bis zum 16.07.02 gefangen. Die Fallen waren mit einer UV- und einer Weißlicht-Röhre ausgestattet und hatten einen Abstand von ca. $1 \mathrm{~km}$ zueinander. Die anfliegenden Insekten sammelten sich in einem Käfig $(\mathrm{H} \times \mathrm{B} \times \mathrm{L}=30 \mathrm{~cm} \times 30 \mathrm{~cm} \times 30 \mathrm{~cm})$, der täglich geleert wurde. Die gefangenen Falter wurden in einen Gazekäfig $(\mathrm{H} \times \mathrm{B} \times \mathrm{L}=$ $2 \mathrm{~m} \times 2 \mathrm{~m} \times 2 \mathrm{~m}$ ), der über dem Maisbestand gestellt wurde, überführt. Im Käfig wurden die Maisblätter täglich auf Eigelege abgesucht und zur Weiterzucht ins Labor versendet. Ein Teil der Falter wurde zur Eiablage ins Labor gebracht. 


\subsubsection{Laborstamm Darmstadt (LA)}

Der "Laborstamm Darmstadt" wurde im November 1999 von Dr. Hassan, BBA Darmstadt, zur Verfügung gestellt. Dieser Stamm stammt ursprünglich aus der Schweiz von der Eidgenössischen Forschungsanstalt für Agrarökologie und Landbau (FAL) und war seit drei Jahren in Dauerzucht in der BBA. Der Laborstamm wurde in einem kontinuierlichen Zuchtverfahren ohne Diapause gehalten, so dass jederzeit alle Entwicklungsstadien des Maiszünslers zur Verfügung standen (4.2.4.1). Die Generationszeit betrug zwei bis drei Monate, so dass im Jahr ca. vier bis sechs Generationen erzeugt wurden. Pro Generation wurden ca. 200 bis 300 Falter angesetzt. Anfang des Jahres 2002 zeigte sich, dass der Laborstamm mit Mikrosporidien (Nosema pyrausta) infiziert war. Die Mikrosporidien hatten sich stark ausgebreitet, so dass der Laborstamm aufgegeben wurde, um die anderen Stämme nicht durch eine Infektion zu gefährden.

\subsubsection{Zucht von Ostrinia nubilalis}

Die Zucht der Maiszünsler richtete sich weitgehend nach den Erfahrungen der Abteilung Dr. Hassan, BBA Darmstadt (pers. Mitt.). Im Verlaufe der Arbeit wurden die Zuchtbedingungen optimiert und den Untersuchungszwecken angepasst.

\subsubsection{Dauerzucht}

Die Maiszünslerfalter wurden, nachdem sie geschlüpft waren, in einem Plexiglaszylinder $(\varnothing \times \mathrm{H}=11 \mathrm{~cm} \times 20 \mathrm{~cm})$ gegeben, der auf der Innenseite mit Filterpapier ausgeschlagen und mit einer perforierten Plastikfolie oben abgeschlossen war. Um eine möglichst hohe Luftfeuchtigkeit für die Eiablage zu erhalten, wurden die Zylinder mit den Faltern auf einen Gitterrost ( $\mathrm{L}$ x B x H $=54 \mathrm{~cm}$ x $33 \mathrm{~cm} \times 2,5 \mathrm{~cm}$ ) in Euroschalen ( $\mathrm{L} \times \mathrm{B} \times \mathrm{H}=60 \mathrm{~cm} \times 40 \mathrm{~cm} \times 6,5 \mathrm{~cm}$ ), die Wasser enthielten, gestellt. Die Luftfeuchtigkeit in den Zylindern konnte auf einen Wert zwischen 70 und $93 \%$ rel. Luftfeuchte eingestellt werden. Alle zwei bis drei Tage wurden die Zylinder auf Eiablage kontrolliert, Filterpapier und Plastikfolie mit Eigelegen ausgetauscht und die toten Falter entfernt. Die Zucht erfolgte in einem klimatisierten Raum bei $22-25^{\circ} \mathrm{C}$ und Langtagbedingungen von $18 \mathrm{~h}$ Licht und $6 \mathrm{~h}$ Dunkelheit [18:6 h (H:D)]. Pro Zylinder wurden ca. 50 Falter angesetzt, wobei möglichst ein Geschlechterverhältnis von 1:1 angestrebt wurde. Um die Eiproduktion $\mathrm{zu}$ erhöhen wurde den Faltern eine 10\%ige Zuckerlösung oder Wasser auf einem Wattebausch angeboten (Kira et al., 1969; Andow, 2001). Die Eigelege wurden auf dem Filterpapier ausgeschnitten und in Petrischalen aufbewahrt. Die Petrischalen waren mit Handtuchpapier verschlossen, das regelmäßig angefeuchtet wurde. Die Weiterzucht der Eier und Larven erfolgte im Lichtthermostaten bei $25{ }^{\circ} \mathrm{C}$ und 18:6 h (H:D). Frisch geschlüpfte Larven erhielten einen dünnen Streifen Nährmedium (Anhang 9.1.2). Nach ca. einem Monat wurden die Larven in Plastikboxen ( $\mathrm{L} \times \mathrm{B} \times \mathrm{H}=20 \mathrm{~cm} \times 10 \mathrm{~cm} \times 6 \mathrm{~cm}$, Deckel mit zwei Gaze bespannten Öffnungen $(\varnothing 4,5 \mathrm{~cm})$ zur Belüftung) umgesetzt und weiter bei $25^{\circ} \mathrm{C}, 18: 6$ h (H:D) gehalten. Unter den Deckel der Plastikbox wurde ein Handtuchpapier gespannt, das bei Bedarf angefeuchtet wurde und als Verpuppungsversteck diente. Die Larven erhielten nach Bedarf frisches Nährmedium. Die Puppen wurden in Bellaplastboxen ( $\mathrm{L}$ x B x H $=18 \mathrm{~cm}$ x $14 \mathrm{~cm}$ x $6 \mathrm{~cm}$ ), die mit Handtuchpapier als Schlupfhilfe ausgelegt 
waren, überführt. Die geschlüpften Falter wurden in der oben beschriebenen Art weitergezüchtet. Für das Umsetzten und zur Kontrolle wurden die Falter mit $\mathrm{CO}_{2}$ betäubt.

\subsubsection{Zucht der gesammelten Falter}

Die im Herbst im Freiland gesammelten $\mathrm{L}_{5}$-Larven (Pocking, Niedernberg, Hessisches Ried) wurden in Plastikboxen (B x L x H $=20 \mathrm{~cm}$ x $20 \mathrm{~cm}$ x $8 \mathrm{~cm}$ ) gehalten. Zur Belüftung waren in die Deckel ca. $10 \mathrm{~cm}$ x $10 \mathrm{~cm}$ und in den Seiten im Durchmesser 4,5 $\mathrm{cm}$ große Gazestücke eingesetzt. Als Versteckmöglichkeit und Verpuppungsraum wurden den Larven im Jahr 2000 Maisstängel angeboten. Da diese stark verpilzten wurde in den folgenden Jahren zerknülltes Handtuchpapier verwendet. In jede Box wurden maximal 50 Larven gesetzt. Die Lagerung der Boxen erfolgte in belüfteten, nicht beheizten und nicht beleuchteten Gewächshäusern, so dass die Licht- und Temperaturverhältnisse weitgehend den natürlichen Bedingungen in Darmstadt in den Jahren 1999 bis 2002 entsprachen. Ab April wurden die Larven ein Mal pro Woche mit Wasser besprüht, damit sie tropfbares Wasser aufnehmen konnten (Beck, 1967). Die Puppen wurden in Plastikbechern mit perforiertem Deckel $(\varnothing \times \mathrm{H}=4,5 \mathrm{~cm} \times 7 \mathrm{~cm})$ und einem Stück Filter- oder Handtuchpapier gelegt. Im Folgenden richtete sich die Zucht nach den in Kapitel 4.2.4.1 beschriebenen Bedingungen. Die Stämme wurden bis zur $\mathrm{F}_{2}$-Generation gezüchtet und abgetötet, bevor die Larven des nächsten Jahres zum Schlupf kamen. Die Haltung der Larven aus dem Oderbruch durch Frau Liebe in der BBA Kleinmachnow richtete sich ebenfalls nach den im Kapitel 4.2.4.1 beschriebenen Bedingungen. Die Überwinterung erfolgte in auf dem Feld gesammelten Stoppeln in einem luftdurchlässigen Gazekäfig, der vor Niederschlag geschützt war, auf dem Gelände der BBA Kleinmachnow (Liebe, pers. Mitt.).

\subsubsection{Krankheiten}

Ein hoch infektiöser Parasit des Maiszünslers ist die Mikrosporidie Nosema pyrausta. Die Infektion mit $N$. pyrausta kann zu einer verringerten Fertilität und im Extremfall zum Zusammenbruch einer Maiszünslerzucht führen (Weis, 1961; King und Leppla, 1984). Die Mikrosporidieninfektion reduziert die Empfindlichkeit von Maiszünslerlarven gegenüber Bt-Toxinen (Pierce et al., 2001), weswegen die Zuchtstämme regelmäßig auf einen Mikrosporidienbefall unter Anleitung von Frau Dr. Kleespies (BBA, Darmstadt) untersucht wurden (Tab. 9). 
Tab. 9: Befunde der Mikrosporidienuntersuchungen 2000 und 2002

\begin{tabular}{|c|c|c|c|c|c|c|}
\hline \multirow[t]{2}{*}{ Stamm $^{1}$} & \multirow[t]{2}{*}{$\mathrm{Jahr}^{2}$} & \multirow{2}{*}{$\begin{array}{l}\text { Larven } \\
\text { aus dem } \\
\text { Freiland }^{3}\end{array}$} & \multirow{2}{*}{$\begin{array}{l}\text { Überwinterte } \\
\text { Larven/Falter }\end{array}$} & \multicolumn{2}{|c|}{ Generation } & \multirow{2}{*}{$\begin{array}{l}\text { Gesamt- } \\
\text { Befunde }\end{array}$} \\
\hline & & & & $\mathbf{F}_{1}$ & $\geq \mathbf{F}_{2}$ & \\
\hline $\mathrm{PO}$ & 2000 & $20 / 1$ & $16 / 0$ & $16 / 0$ & & $52 / 1$ \\
\hline $\mathrm{NI}$ & 2000 & $20 / 0$ & $268 / 4$ & $114 / 0$ & & $402 / 4$ \\
\hline HR & 2000 & $61 / 13$ & $11 / 4$ & $19 / 5$ & & $91 / 22$ \\
\hline LA & 2000 & & & & $20 / 0$ & $20 / 0$ \\
\hline $\mathrm{PO}$ & 2001 & $20 / 1$ & & $20 / 0$ & & $40 / 1$ \\
\hline $\mathrm{NI}$ & 2001 & $77 / 0$ & & $20 / 0$ & & $97 / 0$ \\
\hline HR & 2001 & $33 / 7$ & & $10 / 2$ & & $43 / 9$ \\
\hline LA & 2001 & & & & $20 / 0$ & $20 / 0$ \\
\hline $\mathrm{PO}$ & 2002 & & $64 / 0$ & $20 / 0$ & $10 / 7$ & $74 / 7$ \\
\hline $\mathrm{NI}$ & 2002 & & $44 / 0$ & $20 / 0$ & $26 / 0$ & $70 / 0$ \\
\hline $\mathrm{HR}$ & 2002 & & $19 / 3$ & $20 / 2$ & & $39 / 5$ \\
\hline LA & 2002 & & & & $25 / 23$ & $25 / 23$ \\
\hline OD & 2002 & & $45 / 1$ & $37 / 0$ & & $82 / 1$ \\
\hline HA & 2002 & & $12 / 0$ & $19 / 3$ & & $31 / 3$ \\
\hline
\end{tabular}

Larven bzw. überwinterte Falter aus Pocking und Niedernberg zeigten teilweise eine schwache Infektion mit Mikrosporidien. In den Jahren 2000 und 2002 wurden keine Mikrosporidien in der $\mathrm{F}_{1}$ - und der $\mathrm{F}_{2}$-Generation gefunden. Durch die massive Ausbreitung der Mikrosporidien in der Laborzucht im Jahr 2002, wurde die $\mathrm{F}_{2^{-}}$ Generation von Pocking infiziert. Die Infektion erfolgte nach Abschluss der Untersuchungen zur Basisempfindlichkeit. Bei der Zucht aus Halle wurde in der $\mathrm{F}_{1}$ Generation eine schwache Mikrosporidieninfektion gefunden, wobei eine Infektion innerhalb des Labors wahrscheinlich ist. Das Oderbruch zeigte eine schwache Infektion bei den überwinterten Larven und keine Infektion in der $\mathrm{F}_{2}$-Generation. Da bei den Stämmen Pocking, Niedernberg, Halle und Oderbruch die Mikrosporidien in geringer Konzentration zumeist in höheren Generationen gefunden wurden, konnte bei den frisch geschlüpften $\mathrm{F}_{1}$-Larven ein Einfluss von $N$. pyrausta auf die Biotests ausgeschlossen werden. Im Hessischen Ried waren schon die gesammelten Larven stark mit Mikrosporidien infiziert, so dass bei den frisch geschlüpften Larven ein Einfluss durch $N$. pyrausta auf die Empfindlichkeit möglich war. Die Laborzucht zeigte in den Jahren 2000 und 2001 keine Anzeichen einer Infektion mit N. pyrausta. Am 05.06.2002 wurden die ersten Mikrosporidien in Larven des Laborstamms entdeckt und bei der weiteren Untersuchung eine massive Infektion festgestellt, so dass die Laborzucht aufgegeben werden musste. Im Frühjahr 2000 zeigte die Zucht aus Pocking einen starken Milbenbefall (die Milben wurden nicht weiter bestimmt). Die Larven hatten in Maisstängelstücken überwintert. Durch eine verbesserte Hygiene und durch Abwaschen der Milben mit Alkohol konnte die nachfolgende Generation von Milben freigehalten werden. Die Waschprozedur und die Milben führten zu einer erhöhten Mortalität unter den gesammelten Larven des Jahres 1999 aus Pocking. 


\subsubsection{Bt-Toxin Cry1Ab}

Hinter dem Begriff Bt-Toxin verbergen sich eine Vielzahl von Toxinen mit ähnlicher Proteinstruktur, aber zum Teil unterschiedlichem Wirtsspektrum (3.1). In dieser Arbeit wurde mit dem lepidopterenspezifischen Cry1Ab-Toxin gearbeitet. In den Bakterien wird das Cry1Ab-Toxin als Protoxin (130,6 kDa) produziert. Die Bt-Mais-Events Bt176 und Mon810 produzieren ein verkürztes Protoxin, das einen trypsinresistenten Kern von 60 - $70 \mathrm{kDa}$, der das aktive Toxin darstellt, enthält (Höfte und Whiteley, 1989). Die Toxine der verschiedenen Bt-Maispflanzen unterscheiden sich in der Länge des Cterminalen Endes des aktiven Toxinkerns. Im Insektendarm empfindlicher Arten wird das Protoxin in die aktive Form überführt, was unabhängig von der Toxinvorstufe geschehen sollte. Da die Extraktion von Bt-Toxin aus Pflanzen aufwändig und teuer ist, werden Dosis-Wirkungs-Untersuchungen mit Cry1Ab durchgeführt, das in Bakterien produziert wurde. Dabei wurden sowohl das Protoxin als auch der trypsinresistente Kern des Cry1Ab-Toxins, der nach Trypsinbehandlung aus dem Protoxin gewonnen wurde, eingesetzt. Die U.S. Environmental Protection Agency (EPA) (2001) stellte die Äquivalenz der Cry1Ab-Toxine anhand verschiedener Studien aus den Bt-Mais-Events Bt-176 und Mon810 mit den von Bakterien produzierten Toxinen fest. Die angeführten Studien, die nicht publiziert wurden, wiesen laut EPA (2001) die Gleichheit der Pflanzen- und Bakterien-Cry1Ab-Toxine durch DNA-Sequenz-Bestimmungen sowie gelelektrophoretischen Untersuchungen mit Hilfe von immunologischen Tests und Biotests nach.

Im Jahr 2001 wurde das Cry1Ab-Toxin von der Firma Novartis (North Carolina, USA) zur Verfügung gestellt. Seit dem Jahr 2001 produzieren Dr. Jehle und seine Mitarbeiter (Staatliche Lehr- und Forschungsanstalt, SG Biotechnischer Pflanzenschutz, Neustadt a. d. Weinstrasse) das Toxin. Die Toxinchargen unterschieden sich in der Herstellungsweise und wurden in unterschiedlicher Reinheit angeboten (Tab. 10). Die Verdünnungsstufen wurden laut den Proteinkonzentrationsangaben der Hersteller angesetzt. Das Toxin wurde aliquotiert und bei $-20^{\circ} \mathrm{C}$ aufbewahrt. Ein Mal aufgetaute Aliquots und die Verdünnungsreihen wurden bei $4^{\circ} \mathrm{C}$ gelagert. Bei den Untersuchungen verursachten die Proteinchargen bei gleicher Toxinkonzentration unterschiedliche Mortalitäten (4.2.6.2). Eine Überprüfung der Toxine mittels Gelelektrophorese im Jahr 2002 ergab, dass der trypsinresistente Kern (67 kDa) bei der Charge J1 weiter abgebaut worden war. Neben der $67 \mathrm{kDa}$ Bande wurden zwei weitere Banden festgestellt. Die finale Toxingröße war ca. $60 \mathrm{kDa}$, was einer Toxincharge die von der Firma Monsanto (Lot-Nr. B8R176001, Datum 20.02.98) produziert wurde und den Projektpartnern der Universität Aachen zur Verfügung stand, entsprach (Jehle, pers. Mitt.). Das Toxin J3, das im Gegensatz zu J1 frisch produziert war, hatte die typische Größe von $67 \mathrm{kDa}$. In wieweit ein späterer Abbau der Charge J3 stattfand und ob die unterschiedliche Toxingröße durch die Herstellungsart verursacht wurde, konnte bisher nicht geklärt werden. 
Tab. 10: Produktionsdaten der verwendeten Toxinchargen des CryIAb-Toxins

\begin{tabular}{|c|c|c|c|}
\hline Interne-Nummer & N1 & $\mathbf{J 1}(\mathbf{a}+\mathbf{b})$ & $\mathbf{J 3}(\mathbf{a}+\mathbf{b})$ \\
\hline Lieferung & 15.11 .99 & a. 04.05 .01 & a. 8.11 .01 \\
\hline & & b. 23.07 .02 & b. 5.12 .01 \\
\hline Hersteller & Novartis & Jehle & Jehle \\
\hline Herstellungsdatum & 1999 & 04.03 .01 & 08.10 .01 \\
\hline Isolationsstamm & B.t. kurstaki HD1-9 & E. coli HB101 & E. coli HB101 \\
\hline Zellaufschluss & k.A. & French Press & Lysozym \\
\hline Toxinform & Protoxin & $\begin{array}{l}\text { trypsinresistenter } \\
\text { Kern }\end{array}$ & $\begin{array}{l}\text { trypsinresistenter } \\
\text { Kern }\end{array}$ \\
\hline Toxingröße [kDa] & 130 & $67^{1}$ & 67 \\
\hline Konzentration & $100 \mathrm{mg}$ & $\begin{array}{l}25 \mathrm{mg} / \mathrm{ml} \\
(18 \mathrm{mg} / \mathrm{ml})^{2}\end{array}$ & $12 \mathrm{mg} / \mathrm{ml}$ \\
\hline Reinheit $[\%]$ & 75,4 & ca. 90 & ca. 90 \\
\hline $\begin{array}{l}\text { aktives Cryl Ab-Toxin } \\
(60-67 \mathrm{kDa})[\%]\end{array}$ & 38,9 & 90 & 90 \\
\hline Lagerung $\left[{ }^{\circ} \mathrm{C}\right]$ & -20 & -20 bzw. +4 & -20 bzw. +4 \\
\hline Verwendung im Jahr & 2000 & 2001 & ab Ende 2001 \\
\hline
\end{tabular}

\subsubsection{Biotest}

\subsubsection{Dosis-Wirkungs-Test zur Bestimmung der Basisempfindlichkeit}

Für die Bestimmung der Dosis-Wirkungs-Kurven wurden die letalen Konzentrationen (LC) bestimmt. Letale Dosen (LD) wurden nicht bestimmt, da hierfür die aufgenommene Menge an Nahrung ermittelt werden muss, was bei den verwendeten L1-Larven nicht möglich war. Die Biotests wurden in Rastern (Bio-ba-128, Color-Dec Italy) durchgeführt. Die Raster bestehen aus 128 einzelnen Wannen, in die jeweils $1 \mathrm{ml}$ des Versuchsmediums gegossen wurde. Nach dem Erkalten ergab sich eine planare

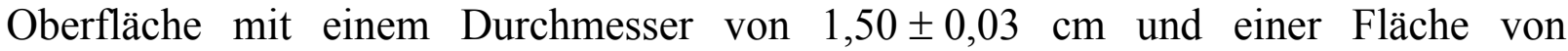
$1,77 \mathrm{~b} \pm 0,08 \mathrm{~cm}^{2}$. Von dem Toxin wurden jeweils sieben Verdünnungsstufen angesetzt. Die Verdünnungsschritte betrugen i.d.R. eine Halbierung der vorherigen Toxinkonzentration. Die Toxinkonzentrationen wurden so gewählt, dass die Mortalität von mindestens drei Toxinkonzentrationsstufen zwischen 20 und $90 \%$ lag. Die höchste Toxinkonzentration erreichte i.d. R. $100 \%$. Die Konzentrationenstufen wurden für einzelne Stämme und Methoden unter Berücksichtigung des Mortalitätsbereiches angepasst (Tab. 11), so dass für die einzelnen Versuche unterschiedliche Verdünnungen eingesetzt wurden. 
Tab. 11: Konzentrationsbereich der eingesetzten Verdünnungsstufen bei den DosisWirkungs-Tests

\begin{tabular}{lll} 
Toxin & Methode & $\begin{array}{l}\text { Bereich der Verdünnungsstufen } \\
\text { Toxinmenge }\end{array}$ \\
\hline N1 & pro Rasterwanne
\end{tabular}

Das Toxin wurde mittels PUFFERAN ${ }^{\circledR}$ (Cyclohexylaminopropansulfonsäure, Firma Roth, auf pH 10,5 eingestellt) verdünnt. Die Kontroll-Lösung bestand aus PUFFERAN ${ }^{\circledR}$ ( $\mathrm{pH}$ 10,5). Die Verdünnungsstufen und die Stammlösung wurden maximal vier Monate bei $4{ }^{\circ} \mathrm{C}$ gelagert. Die Toxinlösungen wurden den Larven durch zwei Methoden angeboten:

1. Oberflächen-Methode $(\mathrm{O})$ :

Die Toxinlösungen wurden auf die Oberfläche des Nährmediums Anhang (9.1.2) appliziert. Dazu wurden von den Toxinlösungen (4.2.5) und der Kontroll-Lösung jeweils $100 \mu \mathrm{l}$ mit Hilfe einer Eppendorf-Multipipette auf die planare Oberfläche des Mediums aufgetragen und das Raster geschwenkt, damit sich der Flüssigkeitsfilm über die gesamte Oberfläche gleichmäßig verteilt. Auf eine Zugabe von Benetzungsmitteln wurde verzichtet. Danach wurden die Raster an der Luft getrocknet, bis die Oberfläche getrocknet war (ca. 2 - 4 h). Bis Versuchbeginn wurden die Raster in Plastiktüten zum Schutz gegen die Austrocknung bei $4{ }^{\circ} \mathrm{C}$ gelagert. Der $\mathrm{LC}_{50}$-Wert wurde in $\mathrm{ng}$ Toxin $/ \mathrm{cm}^{2}$ Mediumoberfläche $\left(1,77 \mathrm{~cm}^{2}\right)$ angegeben.

2. Untermisch-Methode (U)

Bei dieser Methode wurden $100 \mu 1$ Toxinlösung/g Nährmedium (4.2.5) unter das warme flüssige Medium gemischt (Anhang 9.1.2) und jeweils $1 \mathrm{ml}$ des toxinhaltigen Nährmediums in die Rasterwannen gegeben. Bis Versuchsbeginn wurden die Raster in Plastiktüten zum Schutz gegen die Austrocknung bei $4{ }^{\circ} \mathrm{C}$ gelagert. Der $\mathrm{LC}_{50}$-Wert wurde in $\mu \mathrm{g}$ Toxin/g Nährmedium angegeben, was in etwa $\mu \mathrm{g}$ Toxin/ml Nährmedium entspricht ( $1 \mathrm{ml}$ Nährmedium $\bullet 1,05 \mathrm{~g} \pm 0,01 \mathrm{~g}$ $[\mathrm{n}=32])$.

Die ungefütterten Larven eines Ablagetermines im Alter zwischen 3 und $24 \mathrm{~h}$ wurden zufällig auf die Rasterwannen mit den unterschiedlichen Verdünnungsstufen verteilt. Um Kannibalismus zu vermeiden, wurde je Rasterwanne eine Larve angesetzt. Die Versuche wurden in Klimaschränken bei $25^{\circ} \mathrm{C}$ in Dunkelheit durchgeführt, wobei die Mortalität nach 7 Tagen bestimmt wurde. Die Versuche im Dunkeln durchzuführen hatte sich als günstig erwiesen, da die Larven die Tendenz zeigten, zum Licht zu streben und sich so vom Toxin entfernten. Als tote Larven wurden diejenigen gezählt, die nach Berührung mit einem Pinsel keine Reaktionen mehr zeigten. Pro Wiederholung und Anbauregion bzw. Laborstamm wurden zwischen minimal 128 Larven $(8 \times 16$ Larven $=$ 1 Raster) und i. d. R. 256 Larven ( 8 x 32 Larven) im Biotest angesetzt. Ab dem Jahr 2001 wurde auf Anraten des Statistikers Dr. Moll (BBA, Kleinmachnow) zur genaueren 
Bestimmung der Kontrollmortalität zusätzlich die doppelte Anzahl Larven pro Raster angesetzt. Die Dosis-Wirkung-Tests wurden mindestens drei Mal bis maximal $12 \mathrm{Mal}$ wiederholt. Die Anzahl der Wiederholungen hing von der Verfügbarkeit frisch geschlüpfter Larven ab. Die Larven einer Wiederholung stammten von ca. 50 - 100 Paaren und einem einzigen Ablagetermin der Eier. Wenn möglich erfolgte die Durchführung der Dosis-Wirkungs-Tests für mindestens zwei Stämme parallel. Für die Bestimmung der Basisempfindlichkeit der Stämme Pocking, Niedernberg, Hessisches Ried, Halle und des Laborstamms wurden die Eigelege bei $25{ }^{\circ} \mathrm{C} \mathrm{bzw} .22{ }^{\circ} \mathrm{C}$ (Laborstamm) ausgebrütet. Für die Dosis-Wirkungs-Tests des Stammes Oderbruch wurden der Schlupf der Larven aus Eigelegen verschiedener Ablagetermine durch Kühlung über 1 - 10 Tage bei $15{ }^{\circ} \mathrm{C}$ synchronisiert (Liebe, pers. Mitt.). Im Jahr 2001 hatten die Larven ein Alter von 24 - 48 h. Ab dem Jahr 2002 wurden wie in Darmstadt Larven mit einem Alter zwischen 3 und 24 h verwendet. Die Kühlung und das Alter der Larven führten zu keiner erhöhten Kontrollmortalität.

\subsubsection{Dosis-Wirkungs-Test zur Bestimmung des Einflusses von Versuchsparametern auf die Empfindlichkeit von Maiszünslerlarven}

Als Gründe für die Schwankungen der $\mathrm{LC}_{50}$-Werte innerhalb einer Versuchsreihe kamen sowohl die unterschiedliche Empfindlichkeit der Larven verschiedener Ablagetermine als auch versuchsbedingte Einflüssen in Frage. Bei der Bestimmung des Einflusses der Versuchsparameter wurden bei den Wiederholungen die Larven eines Ablagetermins zufällig auf die Versuchsvarianten aufgeteilt, um den Einfluss des Ablagetermins auszuschalten.

\subsection{Toxinvergleich}

\section{Toxinchargen}

Durch die unterschiedliche Aktivität der Toxinchargen war es notwendig die Toxine parallel zu vergleichen. Die Versuche richteten sich nach den Bedingungen wie sie im Kapitel 4.2.6.1 beschrieben wurden. Im Jahr 2001 wurden die Chargen N1 und J1 mit der $\mathrm{F}_{2}$-Generation des Stammes Hessisches Ried und dem Laborstamm Darmstadt getestet. Im Jahr 2002 wurden die Chargen J1 und J3 gegeneinander mit der $\mathrm{F}_{1}$ - bzw. $\mathrm{F}_{2}$-Generation der Stämme Niedernberg und Halle getestet. Jedes Jahr wurden pro Stamm vier Wiederholungen durchgeführt. Das Toxin wurde auf die Oberfläche des Nährmediums appliziert.

\section{Alterung des Toxins}

Um einen Abbau der CrylAb-Toxine während der Lagerung der Toxinlösungen auszuschließen, wurden für zwei Toxinchargen (J1b und J3) Lösungen angesetzt und nach $0,8,13,14,16,49,55,132$ und 142 Tagen der $\mathrm{LC}_{50}$-Wert für den Laborstamm ermittelt. 288 Larven wurden im Dosis-Wirkungs-Test pro LC $_{50}$-Bestimmung und Toxincharge eingesetzt. Die Toxincharge J1b war bis zum Versuchsbeginn bei $4{ }^{\circ} \mathrm{C}$ gelagert worden und hatte ein Alter von 269 Tagen seit Herstellung. Das verwendete Aliquot hatte zu Beginn der Versuche einen Toxingehalt von $18 \mathrm{mg} / \mathrm{ml}$. Bei der Herstellung lag der Wert bei $25 \mathrm{mg} / \mathrm{ml}$ (Berlinghof und Jehle, pers. Mitt.). Für die Berechnung der Verdünnungen wurde der Wert von $18 \mathrm{mg} / \mathrm{ml}$ verwendet. Die 
Konzentrationsstufen wurden für die $\mathrm{LC}_{50}$-Berechnung nachträglich auf $25 \mathrm{mg} / \mathrm{ml}$ bezogen. Die Toxincharge J3 war zu Versuchsbeginn 51 Tage alt.

\section{2.6.2.2 Laborvergleich, Kühlung und Alter der Larven}

Die Dosis-Wirkungs-Tests für den Laborstamm Darmstadt wurden im Jahr 2002 parallel in Kleinmachnow und in Darmstadt durchgeführt. Dazu wurden Eigelege eines Ablagetermins aufgeteilt und per Post an die beiden Labors geschickt. Die Eigelege wurden im Klimaschrank bei $25^{\circ} \mathrm{C}$ ausgebrütet. Für die $3-24 \mathrm{~h}$ alten Larven wurden die $\mathrm{LC}_{50}$-Werte unter den gleichen Bedingungen bestimmt. Der Dosis-Wirkungs-Test wurde vier Mal mit der Oberflächen-Methode und der Toxincharge J3 wiederholt. In weiteren Versuchen wurde der Einfluss der Kühlung der Larven auf die $\mathrm{LC}_{50}$-Werte bestimmt. Dazu wurden Eigelege eines Ablagetermins des Laborstammes bis zum Schlupf der Larven bei $10^{\circ} \mathrm{C}$ bzw. $15^{\circ} \mathrm{C}$ und $22^{\circ} \mathrm{C}$ gelagert. Die Dosis-WirkungsTests wurden mit der Toxincharge J3, die auf die Oberfläche des Mediums appliziert wurde, durchgeführt. Je nach Menge der Eigelege eines Ablagetermins konnten nicht alle Temperaturvarianten angesetzt werden. Die Temperaturvarianten $10^{\circ} \mathrm{C} \mathrm{bzw} .15^{\circ} \mathrm{C}$ wurden parallel $\mathrm{zu}$ einer $22^{\circ} \mathrm{C}$ Variante durchgeführt, so dass in die Ermittlung der $\mathrm{LC}_{50}$-Werte unterschiedliche Wiederholungszahlen eingingen. Von der $22^{\circ} \mathrm{C}-$ Temperaturvariante wurden 13 , von der $15^{\circ} \mathrm{C}$-Variante neun und von der $10^{\circ} \mathrm{C}$ Variante sieben Wiederholungen durchgeführt. Zur Untersuchung der Empfindlichkeit der Larven in Abhängigkeit vom Alter, wurden die Larven eines Ablagetermins im Schwarzkopfstadium der Eier aufgeteilt. Ein Teil der geschlüpften Larven wurde zwischen 3 und $24 \mathrm{~h}$ nach dem Schlüpfen im Biotest eingesetzt. Der andere Teil der Larven wurde am nächsten Tag im Alter von 24 bis $48 \mathrm{~h}$ eingesetzt.

\subsection{Vergleich Oberflächen- und Untermisch-Methode}

Der Vergleich der $\mathrm{LC}_{50^{-}}$Werte der beiden Methoden erfolgte in den Jahren 2001 und 2002 im Rahmen der Bestimmung der Basisempfindlichkeit der verschiedenen Stämme. Diese Dosis-Wirkungs-Tests unterschieden sich aber in der Wiederholungszahl. Auch wurden die Methoden in den beiden Jahren nacheinander durchgeführt, so dass die Larven aus einem anderen Ablagezeitraum stammten. Um die Schwankungen durch die verschiedenen Wiederholungszahlen und durch die variierende Empfindlichkeit der Stämme zu minimieren, wurden Anfang 2002 exemplarisch mit dem Laborstamm die Oberflächen- und Untermisch-Methode in Parallelversuchen verglichen. Aus Rationalisierungsgründen wurden bei der Untermischmethode mehrere Rasterschalen gegossen, die bis zum Versuch bei $4{ }^{\circ} \mathrm{C}$ gelagert wurden. Um einen Einfluss der Lagerung auszuschließen, wurden bei der Oberflächen-Methode zwei Ansätze verfolgt. Zum einen wurde das Toxin jeweils frisch auf das Medium appliziert, d. h. die Applikation erfolgte weniger als 3 Tage vor Versuchsbeginn (dies entsprach dem Versuchsdesign zur Bestimmung der Basisempfindlichkeit siehe Kapitel 4.2.6.1). Beim zweiten Ansatz wurde das Toxin auf das Medium gegeben und der Versuch drei Tagen später gestartet. Der Verbleib des Toxins auf dem Medium entsprach der UntermischMethode. Der Versuch wurden fünf Mal und mit dem Toxin J3 wiederholt. 


\subsubsection{Statistik}

Für die Berechnung wurde das Statistikprogramm SAS in der Windows Version 8 verwendet. Die Prozeduren sind durch Professor Piepho, Universität Hohenheim Fachgebiet Bioinformatik, erstellt worden (siehe Anhang 9.1.3). Für jede Wiederholung wurde zunächst separat der $\mathrm{LC}_{50}$-Wert geschätzt. Anstelle der üblichen SAS ProbitProzedur wurde eine NLMIXED Prozedur verwendet, die die Berechnung des Standardfehlers erlaubt. Der Standardfehler wurde in den weiteren Berechnungen zur Gewichtung der LC50-Werte der Wiederholungen in der Schätzung des Gesamt-LC50Wertes benutzt (Johnson, 1993). Die gewichteten Auswertungen des Gesamt-LC50Wertes erfolgten nach einem linearen Modell (MIXED-Prozedur). Für die Berechnung der LC50-Werte der Stämme und Jahre, die um den Toxineinfluss bereinigt waren, wurden die parallel durchgeführten Toxinvergleiche in die Berechnungen einbezogen. Die Berechnungen erfolgten durch eine Kovarianzanalyse, in der in einem linearen Modell Toxin-Effekte und Ort- mal Jahr-Effekte einbezogen und die Korrelation von Parallelversuchen berücksichtigt wurde.

Die Äquivalenz der $\mathrm{LC}_{50}$-Werte für verschiedene Stämme oder Versuchsansätze kann für eine gewählte tolerierbare Differenz $\delta$ untersucht werden. Auf der logarithmischen Skala kann die Differenz der LC $_{50}$-Werte zweier Stämme oder Versuchsansätze mit einem Vertrauensbereich geschätzt werden. Die Äquivalenz der $\mathrm{LC}_{50}$-Werte ist nachgewiesen, wenn das Vertrauensintervall zum Niveau $(1-2 \alpha)$ von den beiden Schranken $(-\log 10(\delta) ;+\log 10(\delta))$ umfasst wird. Eine Ungleichheit kann bei einem Signifikanzniveau von $2 \alpha=10 \%$ nachgewiesen werden, wenn die Vertrauensgrenzen der Differenz eines $\mathrm{LC}_{50}$-Vergleichs gleiche Vorzeichen aufweisen. Dieselben Berechnungen werden für den Vergleich zweier Steigungen der Probitgeraden durchgeführt. Zwei Dosis-Wirkungs-Kurven werden als parallel angenommen, so lange kein Unterschied auf dem Signifikanzniveau von $2 \alpha=10 \%$ nachgewiesen wurde (t-Test). Bei parallelen Dosis-Wirkungs-Kurven kann der Unterschied der beiden Kurven durch den Wirkungsquotient, der sich als Quotient der beiden $\mathrm{LC}_{50}$-Werte ergibt, angegeben werden (Unkelbach und Wolf, 1985). Die im Äquivalenztest geschätzte Differenz der $\mathrm{LC}_{50}$-Werte zweier Stämme bzw. Toxine gibt umgerechnet auf einer linearen Skala den Wirkungsquotienten (engl.: relative potency) an. Beim Vergleich einer resistenten mit einer empfindlichen Population wird der Wirkungsquotient als Resistenzfaktor (engl.: resistance factor) bezeichnet. Die Varianzunterschiede zwischen den Methoden wurden nach der Satterwaite-Methode bestimmt. Der Einfluss des Alters der Verdünnung oder weiterer Laborparameter wird durch einen t-Test statistisch überprüft. 


\subsection{Ergebnis}

\subsubsection{Basisempfindlichkeit im Jahr 2000}

Die Basisempfindlichkeit im Jahr 2000 wurde für die Stämme der Standorte Pocking, Niedernberg und Hessisches Ried bestimmt. Zusätzlich wurde die $\mathrm{LC}_{50}$ des Laborstamms Darmstadt ermittelt. Die Dosis-Wirkungs-Tests wurden mit dem von Novartis (N1) zur Verfügung gestellten Protoxin (4.2.5) durchgeführt. Es wurden frisch geschlüpfte $\mathrm{F}_{1}$-Nachkommen der im Herbst 1999 gesammelten Larven getestet, welche somit den im Jahr 2000 auf den Maispflanzen fressenden Maiszünslerlarven entsprachen. Als Zuchtbasis für die $\mathrm{F}_{1}$-Generation standen im Frühjahr, nach Abzug der Wintermortalität, für den Stamm Pocking 219 Larven, Niedernberg 938 Larven und für das Hessische Ried 601 Larven zur Verfügung. Da sich Schlupfverlauf, Eiablageverhalten der Falter und Anzahl an frisch geschlüpften Larven für die einzelnen Stämme unterschieden, konnten nicht alle Wiederholungen parallel durchgeführt werden. Die Wiederholungszahl pro Stamm war nicht konstant. Für den Standort Pocking wurden drei, für Niedernberg vier und für das Hessisches Ried und die Laborzucht sechs Wiederholungen durchgeführt. Pro Wiederholung und Standort wurden im Durchschnitt 32 Larven à sieben Konzentrationsstufen plus einer NullKontrolle verwendet. Insgesamt wurden 768 Larven des Stammes Pocking, 856 für Niedernberg, 1.792 Larven für das Hessische Ried und 1.534 Larven der Laborzucht in den Dosis-Wirkungs-Tests eingesetzt und ausgewertet (Tab. 12).

Tab. 12: Ergebnisse der $\mathrm{LC}_{50}$-Berechnungen für Ostrinia nubilalis im Jahr 2000 für die Stämme Pocking (PO), Niedernberg (NI), Hessisches Ried (HR) und Laborstamm Darmstadt (LA)

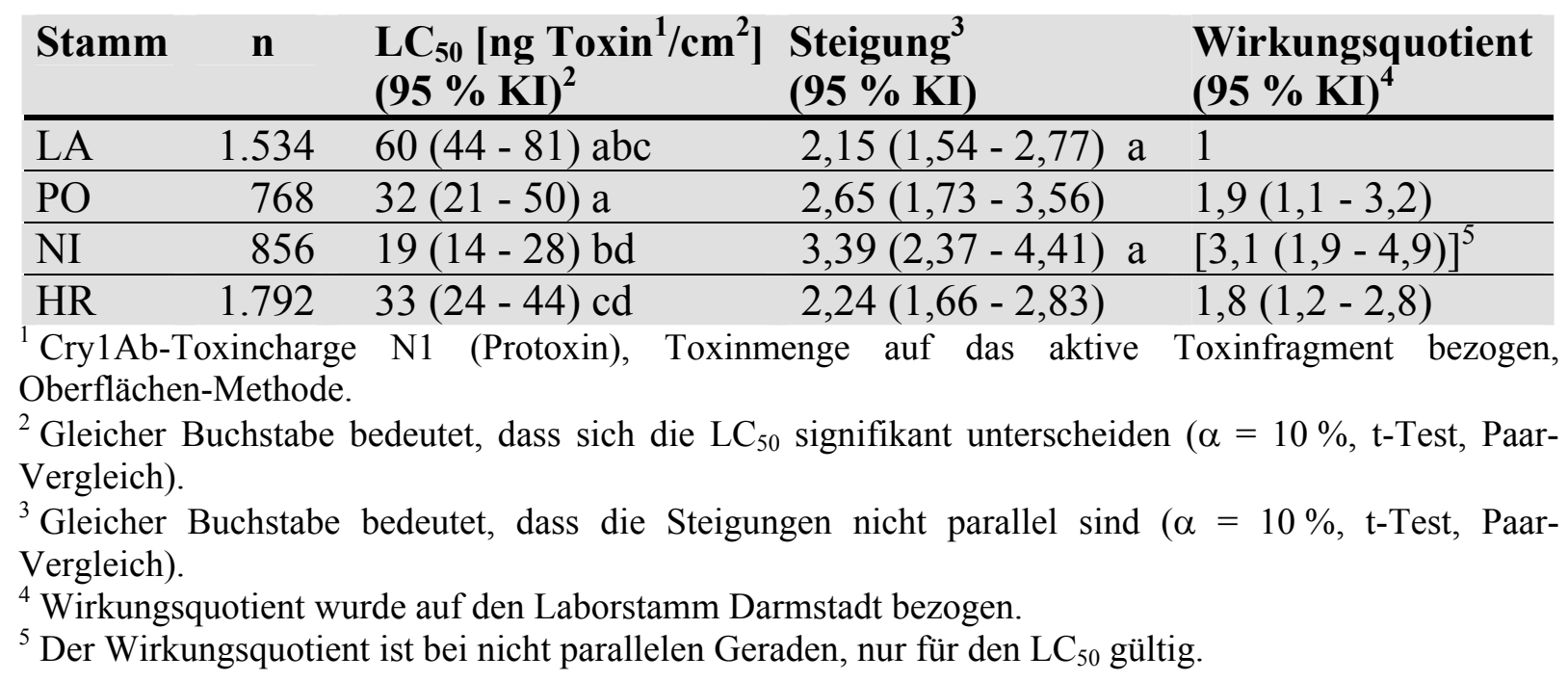

Der Laborstamm besaß mit $60 \mathrm{ng}$ Toxin $/ \mathrm{cm}^{2}$ die geringste Empfindlichkeit. Pocking, Niedernberg und das Hessische Ried zeigten eine ähnliche Basisempfindlichkeit, wobei Niedernberg sich vom Hessischen Ried bei einem $\alpha$ von $10 \%$ statistisch unterschied. Die Steigungen der Probitgeraden waren annährend parallel, wobei die Probitgeraden für Niedernberg und den Laborstamm einen signifikanten Unterschied $(\alpha=10 \%)$ zeigten. 


\subsubsection{Basisempfindlichkeit im Jahr 2001}

Die Bestimmung der Basisempfindlichkeit 2001 wurde mit der Produktionscharge J1 (4.2.5) durchgeführt. Die getesteten Larven waren die $F_{1}$-Nachkommen der im Herbst 2000 gesammelten Larven. Nach Abzug der Wintermortalität standen 2001 mehrere 100 Falter als Zuchtbasis der Stämme zur Verfügung. Vom Standort Pocking überlebten 275, vom Niedernberg 654, vom Hessischen Ried 371 und vom Oderbruch 820 Larven den Winter 2000/2001. Die Larven aus dem Oderbruch wurden von Frau Liebe betreut, die ihre Biotestdaten für die Berechnungen der Basisempfindlichkeit zur Verfügung stellte. Die Biotests wurden nach der identischen Versuchsanordnung und mit dem gleichen Toxin durchgeführt. Die Wiederholungszahl für die Versuche war für den Standort Pocking vier, für Niedernberg drei, für das Hessische Ried elf, für das Oderbruch acht und für den Laborstamm elf. Die niedrige Wiederholungszahl von Niedernberg ergab sich daraus, dass der größte Teil der Nachkommen für das $\mathrm{F}_{2^{-}}$ Screening verwendet wurde (Kapitel 5). Der Stamm Pocking hatte mit 275 die geringste Zuchtbasis und einen relativ engen Schlupfverlauf, wodurch nur vier Wiederholungen möglich waren.

Tab. 13: Ergebnisse der $\mathrm{LC}_{50}$-Berechnungen für Ostrinia nubilalis im Jahr 2001 für die Stämme Pocking (PO), Niedernberg (NI), Hessisches Ried (HR), Oderbruch (OD) und Laborstamm Darmstadt (LA) für zwei Applikationsmethoden

\begin{tabular}{|c|c|c|c|c|}
\hline \multicolumn{5}{|c|}{ Oberflächen-Methode } \\
\hline Stamm & $\mathbf{n}$ & $\begin{array}{l}\mathrm{LC}_{50}\left[\mathrm{ng} \text { Toxin } 1 / \mathrm{cm}^{2}\right] \\
(95 \% \mathrm{KI})^{2}\end{array}$ & $\begin{array}{l}\text { Steigung } \\
(95 \% \mathrm{KI})\end{array}$ & $\begin{array}{l}\text { Wirkungsquotient } \\
(95 \% \text { KI })^{4}\end{array}$ \\
\hline LA & 2.664 & $46(26-82) \quad a$ & $1,68(1,16-2,21)$ & 1 \\
\hline $\mathrm{PO}$ & 1.011 & $55(21-142) b$ & $1,97(1,06-2,87)$ & $0,84(0,27-2,57)$ \\
\hline NI & 716 & $28(9-85)$ & $1,91(0,86-2,96)$ & $1,66(0,47-5,85)$ \\
\hline $\mathrm{HR}$ & 2.429 & $28(15-50)$ & $1,76(1,21-2,31)$ & $1,66(0,72-3,80)$ \\
\hline OD & 2.880 & $10(6-19)$ & $1,88(1,36-2,41)$ & $4,43(1,90-10,31)$ \\
\hline \multicolumn{5}{|c|}{ Untermisch-Methode } \\
\hline Stamm & $\mathbf{n}$ & $\begin{array}{l}\mathrm{LC}_{50}\left[\mu \mathrm{g} \operatorname{Toxin}^{1} / \mathrm{g}\right] \\
(95 \% \mathrm{KI})^{2}\end{array}$ & $\begin{array}{l}\text { Steigung }^{3} \\
(95 \% \mathrm{KI})\end{array}$ & $\begin{array}{l}\text { Wirkungsquotient } \\
(95 \% \text { KI })^{4}\end{array}$ \\
\hline LA & 1.526 & $1,203(0,376-3,850)$ & $2,16(1,35-2,96)$ & 1 \\
\hline $\mathrm{PO}$ & 1.510 & $1,596(0,467-4,796)$ & $1,62(0,82-2,43)$ & $0,80(0,27-2,42)$ \\
\hline $\mathrm{NI}$ & 916 & $0,550(0,131-2,312)$ & $1,99(1,04-2,95)$ & $2,19(0,63-7,56)$ \\
\hline HR & 1.915 & $1,599(0,542-4,716)$ & $1,73(0,98-2,47)$ & $0,75(0,26-2,18)$ \\
\hline \multicolumn{5}{|c|}{$\begin{array}{l}\text { Cry1Ab-Toxincharge } \mathrm{J} 1 \text {. } \\
\text { Gleicher Buchstabe bedeutet, dass sich die } \mathrm{LC}_{50} \text { signifikant unterscheiden }(\alpha=10 \% \text {, t-Test, Paar- } \\
\text { Vergleich). } \\
\text { Steigungen werden als parallel angenommen, da t-Tests bei einem } \alpha=10 \% \text { keine signifikanten } \\
\text { Jnterschiede ergaben. } \\
\text { Wirkungsauotient wurde auf den Laborstamm Darmstadt bezogen. }\end{array}$} \\
\hline
\end{tabular}

Bei den Versuchen mit Oberflächenapplikation im Jahr 2001 hatte die Population aus dem Oderbruch mit $10 \mathrm{ng}$ Toxin $/ \mathrm{cm}^{2}$ die niedrigste Basisempfindlichkeit, gefolgt vom Hessischen Ried und Niedernberg mit annährend gleicher Empfindlichkeit. Im 
Gegensatz zum Jahr 2000 war die Population Pocking am unempfindlichsten. Die Steigungen der Probitgeraden zeigen keine Unterschiede und liegen in einem ähnlichen Bereich, wie die Probitgeraden bei der Untermisch-Methode, so dass davon ausgegangen werden kann, dass der Wirkungsmechanismus durch die unterschiedlichen Methoden nicht beeinflusst wurde. Auffällig ist, dass die Population Hessisches Ried bei der Untermisch-Methode die geringste Empfindlichkeit aufwies. Die Unterschiede zwischen Pocking, Hessischem Ried, Niedernberg und dem Laborstamm sind nicht signifikant (Tab. 13). Für das Oderbruch wurden keine Versuche mit der UntermischMethode durchgeführt.

\subsubsection{Basisempfindlichkeit im Jahr 2002}

Während des Versuches zur Basisempfindlichkeit im Jahr 2002 wurde festgestellt, dass sich in der Laborzucht eine Infektion mit Mikrosporidien ausgebreitet hatte. Die Versuche mit dem Laborstamm wurden eingestellt und der Laborstamm musste auf Grund der massiven Infektion zum Schutz der anderen Stämme aufgegeben werden. Für die Untermisch-Methode standen daher keine Larven aus dem Laborstamm zur Verfügung. Die Larven für Niedernberg wurden im Jahr 2002 nicht als Einzelpaare für das $\mathrm{F}_{2}$-Screening (Kapitel 5) gehalten, sondern alle Nachkommen standen für die Bestimmung der Basisempfindlichkeit zur Verfügung.

Tab. 14: Ergebnisse der $\mathrm{LC}_{50}$-Berechnungen für Ostrinia nubilalis im Jahr 2002 für die Stämme Pocking (PO), Niedernberg (NI), Hessisches Ried (HR), Oderbruch (OD) und Laborstamm Darmstadt (LA) für zwei Applikationsmethoden

\begin{tabular}{|c|c|c|c|c|}
\hline \multicolumn{5}{|c|}{ Oberflächen-Methode } \\
\hline Stamm & $\mathbf{n}$ & $\begin{array}{l}\mathrm{LC}_{50}\left[\mathrm{ng} \operatorname{Toxin}^{1} / \mathrm{cm}^{2}\right] \\
(95 \% \mathrm{KI})^{1}\end{array}$ & $\begin{array}{l}\text { Steigung }^{3} \\
(95 \% \mathrm{KI})\end{array}$ & $\begin{array}{l}\text { Wirkungsquotient } \\
(95 \% \text { KI })^{4}\end{array}$ \\
\hline LA & 1.146 & $3(1-12) \quad$ abcd & $1,54(0,91-2,17)$ & $7,68(32,91-1,79)$ \\
\hline $\mathrm{PO}$ & 2.027 & $28(11-72) \quad a$ & $1,73(1,19-2,28)$ & $0,90(2,91-0,27)$ \\
\hline $\mathrm{NI}$ & 2.688 & $17(8-37)$ & $2,09(1,64-2,54)$ & $1,46(4,20-0,51)$ \\
\hline HR & 2.273 & $16(6-38)$ & $1,95(1,41-2,50)$ & $1,61(5,01-0,52)$ \\
\hline OD & 3.066 & $9(4-19) \quad$ e & $1,98(1,54-2,42)$ & $2,92(8,41-1,02)$ \\
\hline HA & 2.880 & $25(12-51) \mathrm{de}$ & $2,08(1,65-2,51)$ & 1 \\
\hline \multicolumn{5}{|c|}{ Untermisch-Methode } \\
\hline Stamm & $\mathbf{n}$ & $\begin{array}{l}\mathrm{LC}_{50}\left[\mathrm{ng} \operatorname{Toxin}^{1} / \mathrm{cm}^{2}\right] \\
(95 \% \mathrm{KI})^{1}\end{array}$ & $\begin{array}{l}\text { Steigung }^{3} \\
(95 \% \mathrm{KI})\end{array}$ & $\begin{array}{l}\text { Wirkungsquotient } \\
(95 \% \mathrm{KI})^{4}\end{array}$ \\
\hline $\mathrm{PO}$ & 1.953 & $0,285(0,192-0,425)$ & $1,53(0,84-2,22)$ & $1,10(0,60-2,02)$ \\
\hline $\mathrm{NI}$ & 1.951 & $0,204(0,138-0,302)$ & $1,67(1,06-2,28)$ & $1,54(0,84-2,81)$ \\
\hline HR & 2.271 & $0,231(0,157-0,340)$ & $1,44(0,91-1,98)$ & $1,36(0,75-2,47)$ \\
\hline HA & 1.623 & $0,315(0,200-0,496)$ & $1,27(0,64-1,90)$ & 1 \\
\hline \multicolumn{5}{|c|}{$\begin{array}{l}\text { Cry1 Ab-Toxincharge J3. } \\
\text { Gleicher Buchstabe bedeutet, dass sich die } \mathrm{LC}_{50} \text { signifikant unterscheiden }(\alpha=10 \% \text {, t-Test, Paar- } \\
\text { Vergleich). } \\
\text { Steigungen werden als parallel angenommen, da t-Tests bei einem } \alpha=10 \% \text { keine signifikanten } \\
\text { Unterschiede ergaben. }\end{array}$} \\
\hline
\end{tabular}


Die Zuchtbasis war im Jahr 2002 für die Stämme relativ ausgeglichen; Pocking und Niedernberg starteten mit 347 und das Hessische Ried mit 384 Larven. Das Oderbruch hatte mit 1.287 Larven eine sehr breite Zuchtbasis. Der Standort Halle (HA) wurde im Jahr 2002 zum ersten Mal in die Untersuchungen einbezogen. Da keine Möglichkeit bestand im Herbst 2001 auf den Feldern am Standort Halle zu sammeln, wurden Falter $(\mathrm{n}=536)$ mit zwei Lichtfallen im Juni 2002 gefangen und zur Eiablage gebracht. Die Nachkommen $\left(F_{1}\right)$ der Falter konnten auf Grund der geringen Anzahl an frisch geschlüpften Larven nicht für die Biotests verwendet werden. Erst die $\mathrm{F}_{2}$-Generation wurde für die Dosis-Wirkungs-Tests verwendet. Da die Versuche zeitlich nahe an der Bestimmung der $\mathrm{LC}_{50}$-Werte der anderen Stämme durchgeführt wurden, wurden sie zur besseren Vergleichbarkeit der Basisempfindlichkeit 2002 zugeordnet (Tab. 14). Die massive Infektion des Laborstamms zeigte sich an dem niedrigen $\mathrm{LC}_{50}$-Wert, der sich, außer vom Oderbruch, von den anderen Stämmen unterschied. Für alle Standorte und für beide Methoden unterschied sich die Steigung der Probitgeraden nicht. Die $\mathrm{LC}_{50^{-}}$ Werte von Pocking, Niedernberg, Hessisches Ried und Halle unterschieden sich bei einem $\alpha$ von $10 \%$ nicht. Nur die Stämme Halle und Oderbruch zeigten einen signifikanten Unterschied. Die durch die beiden Methoden ermittelten Empfindlichkeitsrelationen der Populationen entsprachen sich. Bei beiden Methoden zeigten Pocking und Halle die höchste, fast identisch Basisempfindlichkeit, wohingegen Niedernberg und Hessisches Ried mit ähnlicher Empfindlichkeit darunter lagen.

\subsubsection{Zusammenfassung der Basisempfindlichkeit für alle Stämme, Jahre und Toxine}

In den Jahren 2000, 2001 und 2002 mussten unterschiedliche Produktionschargen des Cry1Ab-Toxins verwendet werden, was einen direkten Vergleich des $\mathrm{LC}_{50}$ über die Jahre erschwerte. Paar-Vergleiche der Toxinchargen N1 und J1 im Jahr 2001 sowie J1 und J3 im Jahr 2002 wurden verwendet um den Einfluss der unterschiedlichen Toxinchargen herauszurechnen und um einen Vergleich der Stämme über mehrere Jahre zu ermöglichen (Tab. 18). Die Berechnungen wurden nur für die Oberflächen-Methode durchgeführt und die Toxine auf reines trypsinresistentes CrylAb-Toxin bezogen (Tab. 15). Abb. 1 zeigt grafisch auf der logarithmischen Skala die Ergebnisse dieser Berechnung und Tab. 16 die aus den Paar-Vergleichen resultierenden signifikanten Unterschiede. Die Rangfolgen innerhalb der Jahre bleiben wie oben beschrieben bestehen. Beim Vergleich der $\mathrm{LC}_{50}$-Werte über die Standorte und Jahre (Tab. 16) ergab sich, dass sich innerhalb der Jahre 2001 und 2002 besonders das Oderbruch von den anderen Standorten unterschied. Die Stämme Pocking, Niedernberg, Hessisches Ried und der Laborstamm, die in Darmstadt untersucht wurden, zeigten untereinander keine statistischen Unterschiede. Eine Ausnahme bildete der Stamm Halle, der die niedrigste Empfindlichkeit und durch die hohe Versuchsanzahl auch eine geringere Varianz aufwies. Die $\mathrm{LC}_{50}$-Werte schwankten zwischen dem empfindlichsten Stamm (Niedernberg 2001) mit $11 \mathrm{ng}$ gereinigtes aktives Cryl Ab/ $\mathrm{cm}^{2}$ und Pocking im Jahr 2002 mit einem $\mathrm{LC}_{50}$ von $143 \mathrm{ng} / \mathrm{cm}^{2}$ um eine Zehnerpotenz. Beim Vergleich der Grenzen der Konfidenzintervalle wird ein Faktor von zwei Zehnerpotenzen überschritten. Den größten Schwankungsbereich zwischen den Jahren erreichte Pocking, wo sich der LC $_{50}$-Wert im Jahr 2000 von dem im Jahr 2002 um fast eine Zehnerpotenz unterschied. 
Tab. 15: Basisempfindlichkeit $\left(\mathrm{LC}_{50}\right)$ von Ostrinia nubilalis gegenüber dem Cry1 AbToxin für die Stämme Pocking (PO), Niedernberg (NI), Hessisches Ried (HR), Halle (HA) und Oderbruch (OD) sowie dem Laborstamm Darmstadt (LA) in den Jahren 2000 - 2002 über drei Toxinchargen gemittelt

\begin{tabular}{|c|c|c|c|c|}
\hline Stamm & Jahr & $\mathbf{n}$ & $\begin{array}{l}\mathrm{LC}_{50}\left[\mathrm{ng} \operatorname{Toxin}^{1} / \mathrm{cm}^{2}\right] \\
(95 \% \mathrm{KI})\end{array}$ & $\begin{array}{l}\text { Steigung }^{2} \\
(95 \% \mathrm{KI})\end{array}$ \\
\hline$\overline{\mathrm{LA}}$ & 2000 & 1.534 & $34(11-94)$ & $1,71(0,79-2,63)$ \\
\hline LA & 2001 & 3.686 & $47(26-87)$ & $2,00(1,53-2,47)$ \\
\hline LA & 2002 & 1.146 & $17(5-58)$ & $1,63(0,79-2,48)$ \\
\hline$\overline{\mathrm{PO}}$ & 2000 & 768 & $18(5-68)$ & $2,22(0,97-3,47)$ \\
\hline $\mathrm{PO}$ & 2001 & 1.011 & $62(20-188)$ & $2,30(1,44-3,16)$ \\
\hline $\mathrm{PO}$ & 2002 & 2.027 & $143(52-391)$ & $1,85(1,08-2,62)$ \\
\hline$\overline{\mathrm{NI}}$ & 2000 & 856 & $11(3-36)$ & $2,95(1,57-4,32)$ \\
\hline NI & 2001 & 716 & $31(9-113)$ & $2,25(1,26-3,23)$ \\
\hline NI & 2002 & 3.688 & $82(41-166)$ & $2,22(1,63-2,81)$ \\
\hline$\overline{\mathrm{HR}}$ & 2000 & 1.792 & $18(6-51)$ & $1,80(0,95-2,65)$ \\
\hline HR & 2001 & 3.388 & $35(19-64)$ & $2,11(1,60-2,61)$ \\
\hline HR & 2002 & 2.273 & $80(30-210)$ & $2,08(1,31-2,84)$ \\
\hline $\mathrm{HA}$ & 2002 & 4.476 & $134(71-255)$ & $2,14(1,61-2,67)$ \\
\hline$\overline{\mathrm{OD}}$ & 2001 & 2.880 & $12(5-25)$ & $2,23(1,67-2,79)$ \\
\hline OD & 2002 & 2.880 & $44(18-107)$ & $2,08(1,41-2,76)$ \\
\hline
\end{tabular}

Die Breite des Konfidenzintervalls hängt bei der Angabe der $\mathrm{LC}_{50}$-Werte in ng Toxin $/ \mathrm{cm}^{2}$ von der gewählten Toxinkonzentrationsabstufung ab. Da die Toxinkonzentrationsabstufungen für die einzelnen Toxine auf Grund ihrer unterschiedlichen Wirkstärke variierten, wurde ein Vergleich der Konfidenzintervalle der $\mathrm{LC}_{50}$-Werte anhand einer logarithmischen Skala gewählt (Abb. 1). Die Populationen zeigten unabhängig vom gewählten Toxin und Jahr eine große Schwankungsbreite. Auffällig war, dass die Empfindlichkeit der Standorte von 2000 bis 2002 kontinuierlich abnahm. Die Ausnahme bildete die Laborzucht die 2002 am empfindlichsten reagierte, was aber durch eine massive Mikrosporidieninfektion erklärbar war. Die Population Hessisches Ried zeigte keine besondere Empfindlichkeit, obwohl am Standort Hessisches Ried natürlicherweise eine Infektion mit Mikrosporidien vorlag. Die Abnahme der Basisempfindlichkeit ist genau entgegengesetzt der Wirkung der Toxinchargen. Das Toxin N1 zeigte die geringste Wirkung, J1 eine mittlere und J3 die stärkste Wirkung. Die Unterschiede zwischen den Toxinchargen sind statistisch abgesichert. Eine Kovarianzanalyse des Jahr- mal Toxin-Effektes bzw. des Ort- mal Toxin-Effektes konnte auf Grund der unterschiedlichen Wiederholungszahlen nicht durchgeführt werden, so dass der Unterschied auch auf die Schwankungen der Populationen über die Jahre rückführbar ist. Die Steigungen der Probitgeraden für die Toxinchargen zeigen keinen Unterschied (Tab. 18), was auf einen gleichen Wirkmechanismus schließen lässt. 
Tab. 16: Unterschiede in den $\mathrm{LC}_{50}$-Werten der Standorte Pocking (PO), Niedernberg (NI), Hessisches Ried (HR), Halle (HA) und Oderbruch (OD) sowie Laborstamm Darmstadt (LA) in den Jahren 2000-2002

\begin{tabular}{|c|c|c|c|c|c|c|c|c|c|c|c|c|c|c|c|}
\hline 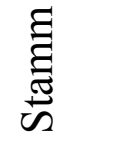 & 疍 & $\begin{array}{l}8 \\
0 \\
0 \\
0\end{array}$ & $\frac{8}{\text { Z }}$ & $\begin{array}{l}8 \\
\stackrel{0}{I} \\
\end{array}$ & 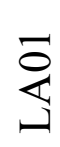 & $\begin{array}{l}\overline{8} \\
0\end{array}$ & $\overline{\mathbf{z}}$ & $\begin{array}{l}\bar{\sigma} \\
\underline{\underline{I}} \\
\end{array}$ & $\overline{8}$ & 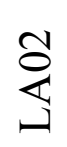 & $\begin{array}{l}\stackrel{\text { }}{\bigcirc} \\
\text { ○ }\end{array}$ & $\frac{\mathrm{O}}{\stackrel{Z}{Z}}$ & 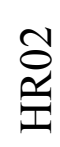 & 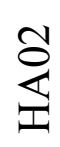 & Оิ \\
\hline LA00 & - & & & & & & & & & & & & & & \\
\hline $\mathrm{PO} 00$ & & & & & & & & & & & 米 & & & * & \\
\hline NI00 & & & & & * & 米 & & & & & 米 & 米 & * & 米 & \\
\hline HR00 & & & & & & & & & & & * & * & & * & \\
\hline LA01 & & & 米 & & - & & & & 米 & & & & & 米 & \\
\hline PO01 & & & 米 & & & & & & 米 & & & & & & \\
\hline NI01 & & & & & & & & & & & & & & 米 & \\
\hline HR01 & & & & & & & & & * & & 米 & & & 米 & \\
\hline OD01 & & & & & * & * & & * & & & 米 & *⿻丷木 & * & 米 & 米 \\
\hline LA02 & & & & & & & & & & - & 米 & 米 & *⿻丷木 & *⿻丷木 & \\
\hline PO02 & & 米 & 米 & * & & & & * & 米 & * & - & & & & * \\
\hline $\mathrm{NI02}$ & & & * & *⿻丷木 & & & & & * & * & & - & & & \\
\hline HR02 & & & * & & & & & & 米 & * & & & - & & \\
\hline HA02 & & * & 米 & 米 & * & & 米 & * & 米 & 米 & & & & - & 米 \\
\hline OD02 & & & & & & & & & * & & 米 & & & * & - \\
\hline
\end{tabular}

* Signifikanter Unterschied der $\mathrm{LC}_{50}$-Werte, zweiseitiger t-Test ( $\alpha=10 \%$, Paar-Vergleich). 


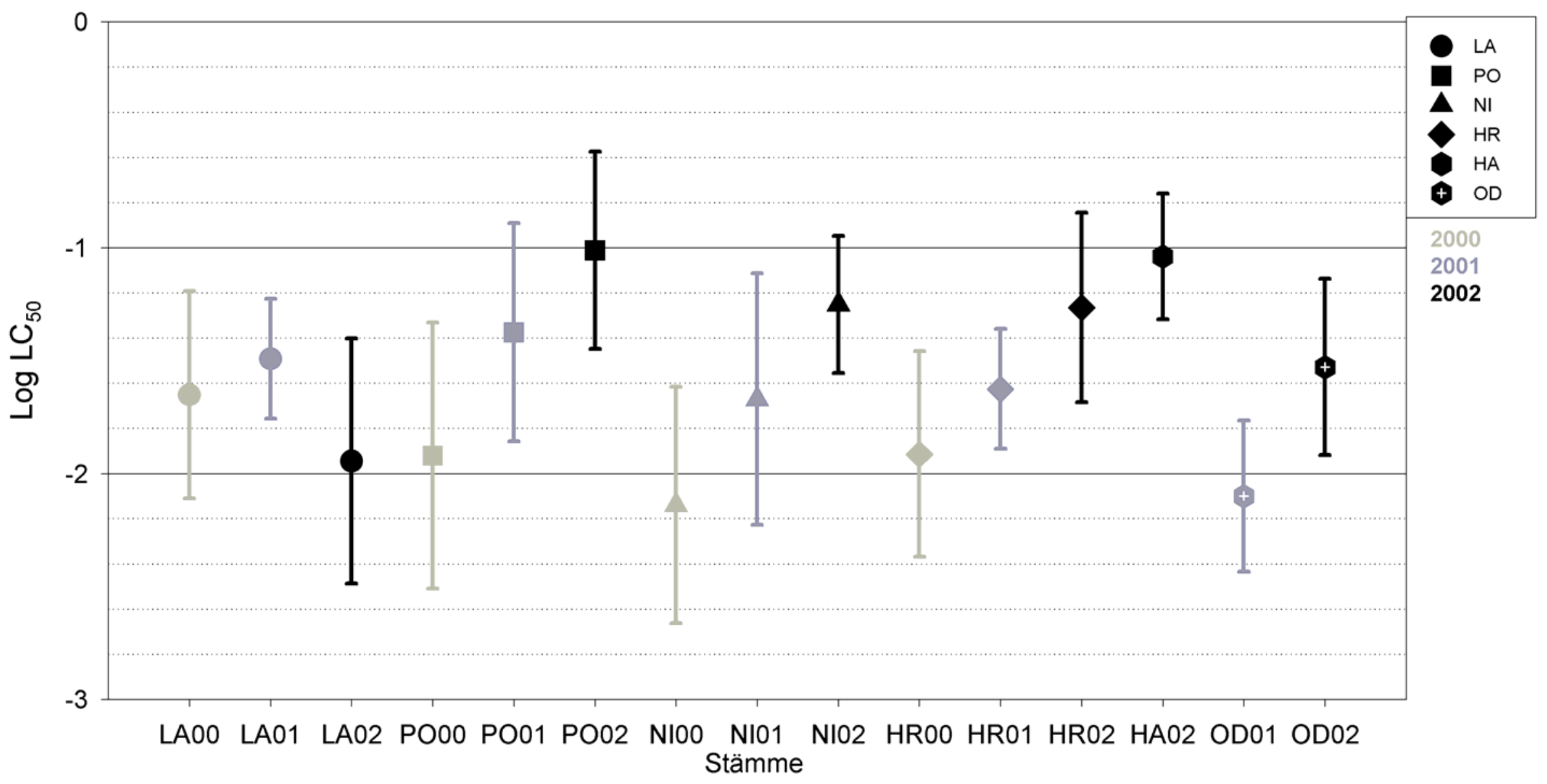

Abb. 1: Basisempfindlichkeit $\left(\log \mathrm{LC}_{50}\right)$ von Ostrinia nubilalis gegenüber Cry1Ab-Toxin in Deutschland in den Jahren 2000 - 2002 über drei Toxinchargen gemittelt.

Standorte Pocking (PO), Niedernberg (NI), Hessisches Ried (HR), Halle (HA) und Oderbruch (OD) sowie der Laborstamm Darmstadt (LA). 
Tab. 17: Angabe der Rangordnung der Empfindlichkeit der verschiedenen Stämme und Versuche

\begin{tabular}{|c|c|c|c|c|}
\hline Versuch & Tabelle & Toxin & Jahr & Rangfolge* \\
\hline Basis 2000; O & Tab. 5 & N1 & 2000 & $\mathbf{N I}^{\mathrm{cd}}<\mathbf{H R}^{\mathrm{bd}}=\mathbf{P O}^{\mathrm{a}}<<\mathrm{LA}^{\mathrm{abc}}$ \\
\hline Basis 2001; O & Tab. 13 & $\mathrm{~J} 1$ & 2001 & $\mathrm{OD}^{\mathrm{abc}}<\mathbf{N I}=\mathbf{H R}^{\mathrm{a}}<\mathbf{P O} \mathbf{O}^{\mathrm{b}}<<\mathrm{LA}^{\mathrm{c}}$ \\
\hline Basis 2001; U & Tab. 13 & $\mathrm{~J} 1$ & 2001 & $\mathbf{N I}<<$ LA $<$ PO $<$ HR \\
\hline Basis 2002; $\mathrm{O}$ & Tab. 14 & $\mathrm{~J} 3$ & 2002 & $\mathrm{LA}^{\mathrm{abcd}}<<\mathrm{OD}^{\mathrm{e}}<\mathbf{H R}^{\mathrm{a}}=<\mathbf{N I}^{\mathrm{b}}<\mathrm{HA}^{\mathrm{c}}=\mathbf{P} \mathbf{O}^{\mathrm{de}}$ \\
\hline Basis 2002; U & Tab. 14 & J3 & 2002 & $\mathbf{N I}<=\mathbf{H R}<\mathbf{P O}<=\mathrm{HA}$ \\
\hline Toxinvergleich; $\mathrm{O}$ & Tab. 19 & N1 & 2001 & $\mathrm{LA}<\mathrm{HR}$ \\
\hline Toxinvergleich; $\mathrm{O}$ & Tab. 19 & $\mathrm{~J} 1$ & 2001 & $\mathrm{LA}<\mathrm{HR}$ \\
\hline Toxinvergleich; $\mathrm{O}$ & Tab. 19 & $\mathrm{~J} 1$ & 2002 & $\mathrm{NI}<\mathrm{HA}$ \\
\hline Toxinvergleich; $\mathrm{O}$ & Tab. 19 & $\mathrm{~J} 3$ & 2002 & $\mathrm{NI}=\mathrm{HA}$ \\
\hline
\end{tabular}

Um die Reproduzierbarkeit der Untersuchungen, unabhängig von den absoluten $\mathrm{LC}_{50^{-}}$ Werten, zu erhalten ist in Tab. 17 die Rangfolge der Empfindlichkeit und ihre statistische Signifikanz angegeben. Werden nur die drei Stämme Pocking, Niedernberg und Hessisches Ried verglichen, erweist sich Pocking in vier von fünf Untersuchungen als der unempfindlichste Stamm. Niedernberg und Hessisches Ried tauschten ihre Reihenfolge bei den unterschiedlichen Untersuchungen. Auffällig ist, dass es innerhalb eines Jahres zwischen den beiden Methoden zu Unterschieden gekommen ist. Der Unterschied zwischen Pocking und dem Oderbruch konnte in zwei Jahren statistisch belegt werden.

\subsubsection{Vergleich der Cry1Ab-Chargen N1, J1 und J3}

Werden die drei Toxinchargen über die drei Jahre und Stämme gemittelt, zeigte die Novartis-Toxincharge (N1) die geringste Wirkung, gefolgt von J1, die doppelt so aktiv war wie N1. Die Charge J3 zeigte die stärkste Wirkung und war gegenüber N1 neunmal und gegenüber J1 4,5-mal aktiver (Tab. 18). Die Versuche mit den Toxinchargen für diese Berechnung wurden nicht parallel durchgeführt, so dass die Unterschiede in der Wirkung zum Teil auch auf Schwankungen zwischen den Jahren und den Stämmen zurückzuführen sind. Im Jahr 2001 und im Jahr 2002 wurden jeweils zwei Toxine paarweise in Parallelversuchen getestet. Im Jahr 2002 stand kein Toxin der Charge N1 zur Verfügung. Auf Grund der Mikrosporidieninfektion im Laborstamm und einer geringeren Reproduktion des Stammes Hessisches Ried wurden die Versuche im Jahr 2002 mit den Stämmen Niedernberg und Halle durchgeführt (Tab. 19). Wie beim Vergleich der Chargen über alle Versuche der Basisempfindlichkeit (Tab. 18), ergibt sich beim Parallelvergleich dieselbe signifikante Wirkungsabstufung (Tab. 19). 
Tab. 18: $\mathrm{LC}_{50}$ für die drei Toxinchargen gemittelt über Orte und Jahre

\begin{tabular}{|c|c|c|c|c|c|}
\hline Jahr & $\begin{array}{l}\text { Toxin- } \\
\text { charge }\end{array}$ & $\mathbf{n}$ & $\begin{array}{l}\mathrm{LC}_{50}\left[\mathrm{ng}^{1} / \mathrm{cm}^{2}\right] \\
(95 \% \mathrm{KI})^{2}\end{array}$ & $\begin{array}{l}\text { Steigung } \\
(95 \% \text { KI) } \\
\end{array}$ & $\begin{array}{l}\text { Wirkungsquotient } \\
(95 \% \text { KI) }\end{array}$ \\
\hline 2000 & $\mathrm{~N} 1$ & 6.931 & $67 \quad(34-137) a$ & $2,53(1,90-3,17)$ & $\begin{array}{l}\mathrm{N} 1 / \mathrm{J} 1=2,1 \\
(0,9-4,9)\end{array}$ \\
\hline 2001 & $\mathrm{~J} 1$ & 12.116 & $(21-52) b$ & $1,75(1,39-2,12)$ & $\begin{array}{l}\mathrm{J} 1 / \mathrm{J} 3=4,5 \\
(2,0-10,1)\end{array}$ \\
\hline 2002 & $\mathrm{~J} 3$ & 14.074 & $(4-14) a b$ & $2,02(1,55-2,49)$ & $\begin{array}{l}\text { N1/J3 = 9,3 (2,8- } \\
30,2)\end{array}$ \\
\hline \multicolumn{6}{|c|}{$\begin{array}{l}\text { Trypsinresistenter Kern des Cry1 Ab-Toxin }(67 \mathrm{kDa}) \text {. } \\
2 \text { Gleicher Buchstabe bedeutet, dass die } \mathrm{LC}_{50} \text { sich signifikant unterscheiden }(\alpha=10 \% \text {, t-Test, Paar- } \\
\text { Vergleich). } \\
3 \text { Gleicher Buchstabe bedeutet, dass die Steigungen nicht parallel sind ( } \alpha=10 \% \text {, t-Test, Paar- } \\
\text { Vergleich). }\end{array}$} \\
\hline
\end{tabular}

Tab. 19: $\mathrm{LC}_{50}$ für die drei Toxinchargen im Paar-Vergleich

\begin{tabular}{|c|c|c|c|c|c|}
\hline Jahr & $\begin{array}{l}\text { Toxin- } \\
\text { charge }\end{array}$ & Stamm & $\mathbf{n}$ & $\begin{array}{l}\mathrm{LC}_{50}\left[\mathrm{ng}^{1} / \mathrm{cm}^{2}\right] \\
(95 \% \mathrm{KI})^{2}\end{array}$ & $\begin{array}{l}\text { Wirkungsquotient } \\
(95 \% \text { KI) }\end{array}$ \\
\hline 2001 & N1 & LA & 1.022 & $67 \quad(31-145)$ & $\mathrm{N} 1 / \mathrm{J} 1=1,2(0,5-3,2)$ \\
\hline 2001 & N1 & HR & 959 & $(38-178)$ & $\mathrm{N} 1 / \mathrm{J} 1=1,2(0,5-3,1)$ \\
\hline 2001 & N1 & & 1.981 & $(43-128) a$ & $\mathrm{~N} 1 / \mathrm{J} 1=1,2(0,6-2,4)$ \\
\hline 2001 & $\mathrm{~J} 1$ & LA & 1.024 & $(25-121)$ & $\mathrm{J} 1 / \mathrm{N} 1=0,8(0,3-2,2)$ \\
\hline 2001 & $\mathrm{~J} 1$ & HR & 959 & $(32-148)$ & $\mathrm{J} 1 / \mathrm{N} 1=0,8(0,3-2,2)$ \\
\hline 2001 & $\mathrm{~J} 1$ & & 1.983 & $(43-128) a$ & $\mathrm{~J} 1 / \mathrm{N} 1=0,8(0,4-1,6)$ \\
\hline 2002 & $\mathrm{~J} 1$ & $\mathrm{NI}$ & 1.000 & $62 \quad(29-136) b$ & $\mathrm{~J} 3 / \mathrm{J} 1=0,4(0,1-0,9)$ \\
\hline 2002 & $\mathrm{~J} 1$ & $\mathrm{HA}$ & 1.416 & $131(68-255) c$ & $\mathrm{~J} 3 / \mathrm{J} 1=0,2(0,1-0,5)$ \\
\hline 2002 & J1 & & 2.416 & $91 \quad(54-151) d$ & $\mathrm{~J} 3 / \mathrm{J} 1=0,3(0,2-0,5)$ \\
\hline 2002 & $\mathrm{~J} 3$ & $\mathrm{NI}$ & 1.004 & $(11-50) \quad b$ & $\mathrm{~J} 1 / \mathrm{J} 3=2,7(1,0-7,1)$ \\
\hline 2002 & $\mathrm{~J} 3$ & HA & 1.418 & $(15-52) \quad c$ & $\mathrm{~J} 1 / \mathrm{J} 3=4,8(2,1-10,7)$ \\
\hline 2002 & $\mathrm{~J} 3$ & & 2.422 & $25 \quad(15-41) \quad d$ & $\mathrm{~J} 1 / \mathrm{J} 3=3,6(1,9-6,7)$ \\
\hline
\end{tabular}

N1 hat eine schwächere Wirkung als J1 und J1 wiederum eine schwächere Wirkung als J3. Werden die Wirkungen der Chargen für einen Stamm verglichen, ist der Unterschied zwischen N1 und J1 nicht signifikant. Der Unterschied zwischen J1 und J3 ist auch auf der Ebene der Stämme signifikant. Beim parallelen Vergleich der Chargen zeigt sich ein geringerer Wirkungsunterschied. Der Wirkungsquotient N1/J1 liegt bei 1,2 und für $\mathrm{J} 1 / \mathrm{J} 3$ bei 3,6. Werden die $\mathrm{LC}_{50}$-Werte für das Toxin $\mathrm{J} 1 \mathrm{im} \mathrm{Jahr} 2001$ und 2002, obwohl die Versuche mit unterschiedlichen Maiszünslerstämmen durchgeführt wurden, verglichen, ergibt sich kein signifikanter Unterschied $(\alpha=10 \%)$. Der Wirkungsquotient für J1 2001/J1 2002 ergab 0,7 (0,3-1,4). Der Vergleich von N1 und J3 resultiert in einem signifikanten Unterschied und einen Wirkungsquotienten von N1/J3 von 2,9 $(1,4$ - 6,2). Dieser liegt unterhalb des berechneten Wirkungsquotienten von 9,3 aus Tab. 18. In beiden Fällen wurden die Untersuchungen nicht parallel und mit 
unterschiedlichen Stämmen durchgeführt, so dass im Wirkungsquotient, neben dem Toxinunterschied, auch den Unterschied der Stämme enthalten ist.

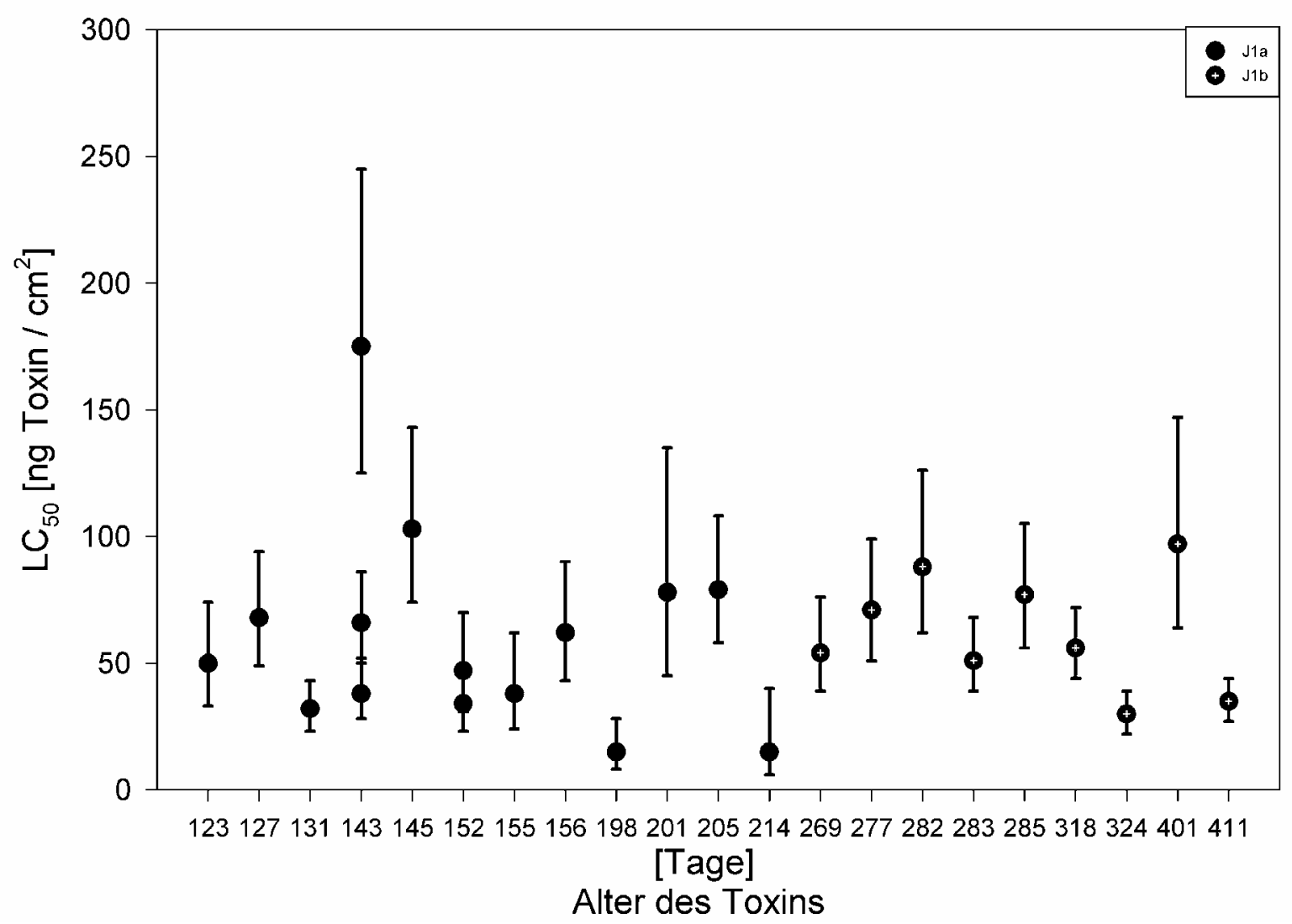

Abb. 2: Untersuchung zum möglichen Abbau des Toxins, $\mathrm{LC}_{50}$-Werte für die Toxincharge J1 und die Laborzucht über 411 Tage nach Herstellung des Toxins. Kreis gefüllt $=$ Charge J1a, Kreis mit Stern $=$ Charge J1b.

Da die Toxinchargen in verschiedenen Jahren produziert worden waren, wurden die Parallelvergleiche der Toxinchargen mit unterschiedlich alten Toxinen durchgeführt. Daher bestand die Möglichkeit, dass der Wirkungsunterschied der Toxinchargen durch einen Abbau in Folge der Lagerdauer verursacht wurde. Um diesen Abbau des Toxins nachzuweisen, wurden die verfügbaren Daten zur Charge J1 aus unterschiedlichen Versuchsreihen des Laborstamms für ca. 13 Monate zusammengefasst (Abb. 2). Für die einzelnen Wiederholungen wurden zum einen die Aliquots (bei $-20^{\circ} \mathrm{C}$ ) und zum anderen die Verdünnungsreihen (bei $4{ }^{\circ} \mathrm{C}$ ) unterschiedlich lang gelagert. Für das Aliquot J1b, das zur Toxincharge J1 gehört, wurde ca. sieben Monate nach Herstellungstermin die Toxinkonzentration nochmals anhand der Bradford-Methode fotometrisch bestimmt (Berlinghof, pers. Mitt.). Diese Bestimmung erbrachte nur noch eine Toxinkonzentration von $18 \mathrm{mg} / \mathrm{ml}$. Der Grund für die Abweichung von der ursprünglichen Toxinkonzentration von $25 \mathrm{mg} / \mathrm{ml}$ konnte nicht geklärt werden. Eine mögliche Ursache für die Abweichung könnte sein, dass es in diesem Aliquot nach der Herstellung zu einem Abbau des Toxins gekommen ist. Die Toxinkonzentrationsbestimmung nach der Bradford-Methode hat eine Präzision von $\pm 15 \%$ (Jehle, pers. Mitt.), so dass der Unterschied auch durch die Messungenauigkeit erklärbar ist. Für die Berechnung der $\mathrm{LC}_{50}$-Werte wurde von der Anfangskonzentration der Toxincharge J1 
von $25 \mathrm{mg} / \mathrm{ml}$ ausgegangen, um die Versuchsreihen vergleichen zu können. Es konnte keine Abnahme der Wirksamkeit der Toxincharge J1 festgestellt werden. Die Larven des Laborstamms zeigten eine Empfindlichkeit, die mit Werten von $15 \mathrm{ng}$ Toxin/ $/ \mathrm{cm}^{2}$ und $175 \mathrm{ng}$ Toxin $/ \mathrm{cm}^{2}$ um das 12 fache schwankte.

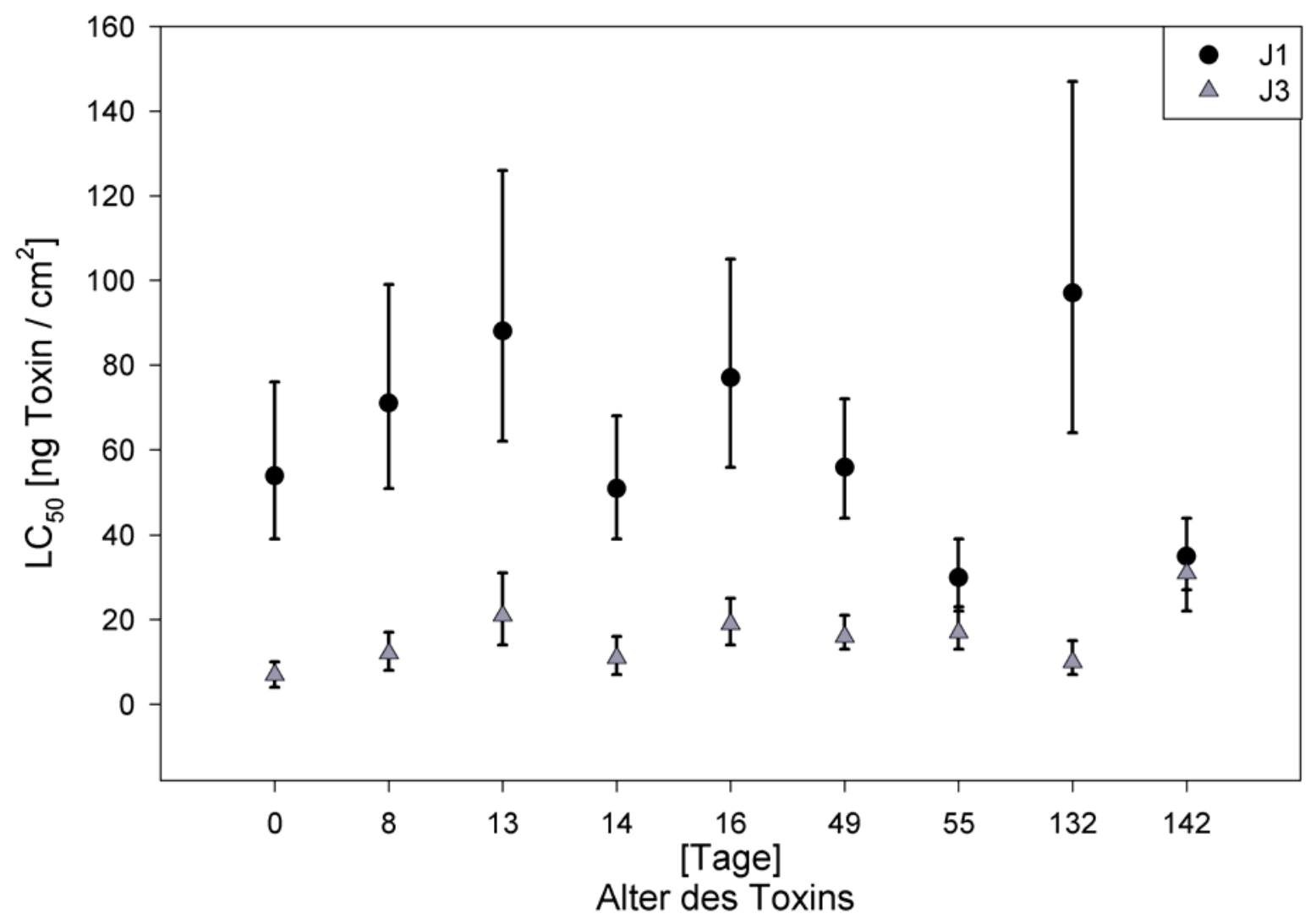

Abb. 3: Untersuchung zum möglichen Abbau des Toxins in der Verdünnungs-Lösung; $\mathrm{LC}_{50}$-Werte für die Toxincharge $\mathrm{J} 1$ und $\mathrm{J} 3$ über einen Zeitraum von 142 Tagen. Lagerung der Verdünnungsreihe bei $4^{\circ} \mathrm{C}$.

Die unterschiedlichen Lager- und Auftauzeiten der Aliquots in Abb. 2 könnten einen Abbau bei $4{ }^{\circ} \mathrm{C}$ verschleiern. Weshalb für zwei Verdünnungsreihen der Chargen J1 und $\mathrm{J} 3$, die frisch aufgetaut angesetzt wurden, über einen Zeitraum von 142 Tagen neun Mal die $\mathrm{LC}_{50}$-Werte bestimmt wurden (Abb. 3). Die $\mathrm{LC}_{50}$-Werte zeigten eine große Schwankungsbreite. Da die Wiederholungen der Chargen parallel mit den Larven des gleichen Ablagetermins durchgeführt wurden, verändern sich die $\mathrm{LC}_{50}$-Werte in den zwei Monaten parallel. Bei den letzten beiden Wiederholungen ist die Entwicklung nicht mehr identisch. $\mathrm{Da} \mathrm{zu}$ diesem Zeitpunkt eine unterschwellige Mikrosporidieninfektion in der Laborzucht nicht ausgeschlossen werden kann, sind diese Änderungen eher auf die Inhomogenität der Larven der letzten beiden Ablagetermine als auf einen unterschiedlichen Abbau der Chargen zurückzuführen. Ein zeitlicher Trend konnte in den Daten statistisch nicht nachgewiesen werden. 


\subsubsection{Vergleich der Oberflächen-Methode und der Untermisch-Methode}

In beiden Jahren zeigte die Untermisch-Methode eine geringere Varianz als die Oberflächen-Methode. Der Unterschied war nicht signifikant $(\alpha=5 \%$, t-Test). Der Wirkungsquotient lag bei 15,4 bzw. 7,0, d. h. es muss die 15 fache bzw. siebenfache Toxinmenge bei der Untermisch-Methode eingesetzt werden um die gleiche Wirkung zu erzielen (Tab. 20). Wird dieses Ergebnis für die Stämme Pocking, Niedernberg und Hessisches Ried aufgeschlüsselt, zeigt sich, dass die $\mathrm{LC}_{50}$-Unterschiede zwischen den beiden Methoden, bedingt durch die Schwankungen in der Empfindlichkeit der Stämme, beträchtlich sind (Tab. 21). So wurde für das Hessische Ried die 33fache Toxinmenge bei der Untermisch-Methode benötigt um eine 50\%ige Mortalität zu erreichen. Im Jahr 2002 waren die Schwankungen innerhalb der Populationen wesentlich geringer, da für alle drei Stämme und Methoden jeweils zwischen 1.953 und 2.688 Larven getestet werden konnten. Wohingegen im Jahr 2001 die Unterschiede in der Anzahl der getesteten Larven zwischen den Stämmen und den Methoden stärker variierten.

Tab. 20: Vergleich Oberflächen-Methode $(\mathrm{O})$ versus Untermisch-Methode (U) für die Jahre 2001 und 2002 gemittelt über die Stämme Pocking, Niedernberg und Hessisches Ried

\begin{tabular}{|c|c|c|c|}
\hline Stamm & 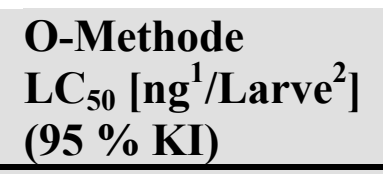 & 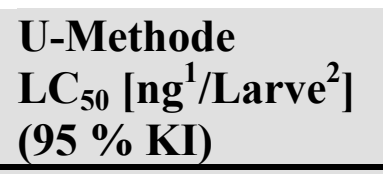 & $\begin{array}{l}\text { Wirkungsquotient } \\
\text { (95\% KI) }\end{array}$ \\
\hline $2001, \mathrm{~J} 1$ & $61(33-112)$ & $942(637-1393)$ & $15,4(6,0-39,5)$ \\
\hline $2002, \mathrm{~J} 3$ & $34(22-54)$ & $240(174-330)$ & $7,0(3,4-14,3)$ \\
\hline Quotient & $1,8(0,6-4,9)$ & $3,93(2,0-7,8)$ & \\
\hline
\end{tabular}

Um die Schwankungen durch die verschiedenen Wiederholungszahlen und die variierende Empfindlichkeit der Stämme zu minimieren, wurden exemplarisch für die Laborzucht Anfang 2002 die Oberflächen-Methode und Untermisch-Methode in Parallelversuchen mit identischer Wiederholungszahl verglichen (Tab. 22). Aus Rationalisierungsgründen wurden bei der Untermisch-Methode mehrere Rasterschalen gegossen, die bis zum Versuch geschützt vor Austrocknung bei $4^{\circ} \mathrm{C}$ im Kühlschrank gelagert wurden. Um einen Einfluss der Lagerung auszuschließen, wurden bei der Oberflächen-Methode zwei Ansätze verfolgt. Zum einen wurde das Toxin jeweils frisch auf das Medium appliziert, d. h. die Applikation erfolgte weniger als drei Tage vor Versuchsbeginn (dies entsprach dem Versuchsdesign der Basisempfindlichkeitsbestimmung). Beim zweiten Ansatz wurde das Toxin auf das Medium gegeben und der Versuch nach mindestens drei Tagen gestartet. Der Verbleib des Toxins auf dem Medium entsprach der Untermisch-Methode.

Zwischen den Ansätzen der Oberflächenapplikation ergab sich kein signifikanter Unterschied. Auch die beiden Untermischansätze zeigten keine signifikanten Unterschiede. In beiden Fällen verursachte das ältere Medium eine nicht signifikant geringere Empfindlichkeit. Die Verdunstung von Wasser bei der Lagerung kann 
möglicherweise zu einer höheren Dichte des Nährmediums führen, so dass Larven auf älteren Medien bei gleich aufgenommener Nahrungsmenge eine höhere Dosis aufnehmen.

Tab. 21: Vergleich Oberflächen-Methode (O) versus Untermisch-Methode (U) für die Stämme Pocking, Niedernberg und Hessisches Ried

\begin{tabular}{|c|c|c|c|c|}
\hline \multicolumn{5}{|c|}{ Jahr 2001, Toxincharge J1 } \\
\hline Stamm & $\begin{array}{l}\text { O-Methode } \\
{\left[\text { ng }^{1} / \text { Larve }^{2}\right]} \\
(95 \% \text { KI })\end{array}$ & $\begin{array}{l}\text { U-Methode } \\
{\left[\mathrm{ng}^{1} / \mathrm{Larve}^{2}\right]} \\
(95 \% \mathrm{KI})\end{array}$ & $\mathbf{n}_{\mathbf{0}} / \mathbf{n}_{\mathrm{u}}$ & $\begin{array}{l}\text { Wirkungsquotient } \\
\text { (95\% KI) }\end{array}$ \\
\hline $\mathrm{PO}$ & $96(32-291)$ & $1.498(824-2.723)$ & $1.011 / 1.510$ & $15,5(3,0-80,2)$ \\
\hline $\mathrm{NI}$ & $49(13-176)$ & $348(150-809)$ & $716 / 827$ & $7,1(1,0-52,5)$ \\
\hline HR & $48(25-95)$ & $1.601(917-2795)$ & $2.429 / 1.915$ & $33,1(10,7-102,6)$ \\
\hline \multicolumn{5}{|c|}{ Jahr 2002, Toxincharge J3 } \\
\hline Stamm & $\begin{array}{l}\text { O-Methode } \\
{\left[\text { ng }^{1} / \text { Larve }^{2}\right]} \\
(95 \% \text { KI) })^{* *}\end{array}$ & $\begin{array}{l}\text { U-Methode } \\
{\left[\text { ng }^{1} / \text { Larve }^{2}\right]} \\
(95 \% \text { KI) }\end{array}$ & $\mathbf{n}_{\mathbf{0}} / \mathbf{n}_{\mathbf{u}}$ & $\begin{array}{l}\text { Wirkungsquotient } \\
\text { (95\% KI) }\end{array}$ \\
\hline $\mathrm{PO}$ & $49(21-11)$ & $289(164-509)$ & $2.027 / 1.953$ & $5,8(1,6-21,9)$ \\
\hline $\mathrm{NI}$ & $30(15-61)$ & $201(115-353)$ & $2.688 / 1.951$ & $6,7(2,1-21,3)$ \\
\hline HR & $27(12-60)$ & $236(137-406)$ & $2.273 / 2.271$ & $8,7(2,5-30,2)$ \\
\hline
\end{tabular}

Trypsinresistenter Kern des Cry1Ab-Toxin $(67 \mathrm{kDa})$.

${ }^{2}$ Die Menge bezieht sich auf die Oberflächen einer Rastervertiefung, in die $1 \mathrm{ml}$ Medium gefüllt und eine Larve gesetzt wurde, was einer Oberfläche von $1,77 \mathrm{~cm}^{2}$ entsprach; bei der Untermisch-Methode bezieht sich die Menge auf $1 \mathrm{ml}$ Medium pro Rastervertiefung, in die eine Larve gesetzt wurde.

Tab. 22: Vergleich Oberflächen-Methode (O) versus Untermisch-Methode (U) im Parallelversuch mit dem Laborstamm und der Toxincharge J3

\begin{tabular}{|c|c|c|c|c|}
\hline Methode & Altersstufe & $\mathbf{n}$ & $\begin{array}{l}\text { LC50 } \\
{\text { [ng } 1 / \text { Larve] }^{2}}^{2} \\
(95 \% \text { KI })^{3} \\
\end{array}$ & $\begin{array}{l}\text { Wirkungsquotient } \\
\text { (95\% KI) }\end{array}$ \\
\hline $\mathrm{O}$ & $<3$ Tage & 1.440 & $16(5-55)$ & $\mathrm{U} / \mathrm{O}<3=7,4(1,3-42,2)$ \\
\hline $\mathrm{O}$ & $>3$ Tage & 1.433 & $10(3-34)$ & $\mathrm{U} / \mathrm{O}>3=12,1(2,1-69,50)$ \\
\hline $\mathrm{U}$ & & 1.405 & $121(35-420) a b$ & \\
\hline $\mathrm{U}$ & $<3$ Tage & 544 & $152(22-1041)$ & $\mathrm{U}<3 / \mathrm{O}<3=9,3(0,9-90,6)$ \\
\hline $\mathrm{U}$ & $>3$ Tage & 861 & $96(19-475)$ & $\mathrm{U}>3 / \mathrm{O}>3=9,6(1,3-72,1)$ \\
\hline \multicolumn{5}{|c|}{$\begin{array}{l}\text { Trypsinresistenter Kern des Cry } 1 \mathrm{Ab} \text {-Toxin }(67 \mathrm{kDa}) \text {. } \\
\text { Die Menge bezieht sich auf die Oberflächen einer Rastervertiefung, in die } 1 \mathrm{ml} \text { Medium gefüllt und } \\
\text { eine Larve gesetzt wurde, was einer Oberfläche von } 1,77 \mathrm{~cm}^{2} \text { entsprach; bei der Untermisch-Methode } \\
\text { bezieht sich die Menge auf } 1 \mathrm{ml} \text { Medium pro Rastervertiefung, in die eine Larve gesetzt wurde. } \\
3 \text { Gleicher Buchstabe bedeutet, dass sich die } \mathrm{LC}_{50} \text { signifikant unterscheiden }(\alpha=10 \% \text {, t-Test, Paar- } \\
\text { Vergleich). }\end{array}$} \\
\hline
\end{tabular}




\subsubsection{Laborvergleich}

Der Stamm Oderbruch wurde von Frau Liebe, BBA Kleinmachnow, gesammelt, gezüchtet und getestet. Bei der Bestimmung der Basisempfindlichkeit zeigten die Larven aus dem Oderbruch die größte Empfindlichkeit. Daher sollte durch einen Laborvergleich mit identischem Material getestet werden, ob Abweichungen in der Handhabung der Biotests zu den geringeren $\mathrm{LC}_{50}$-Werten führten (Abb. 4).

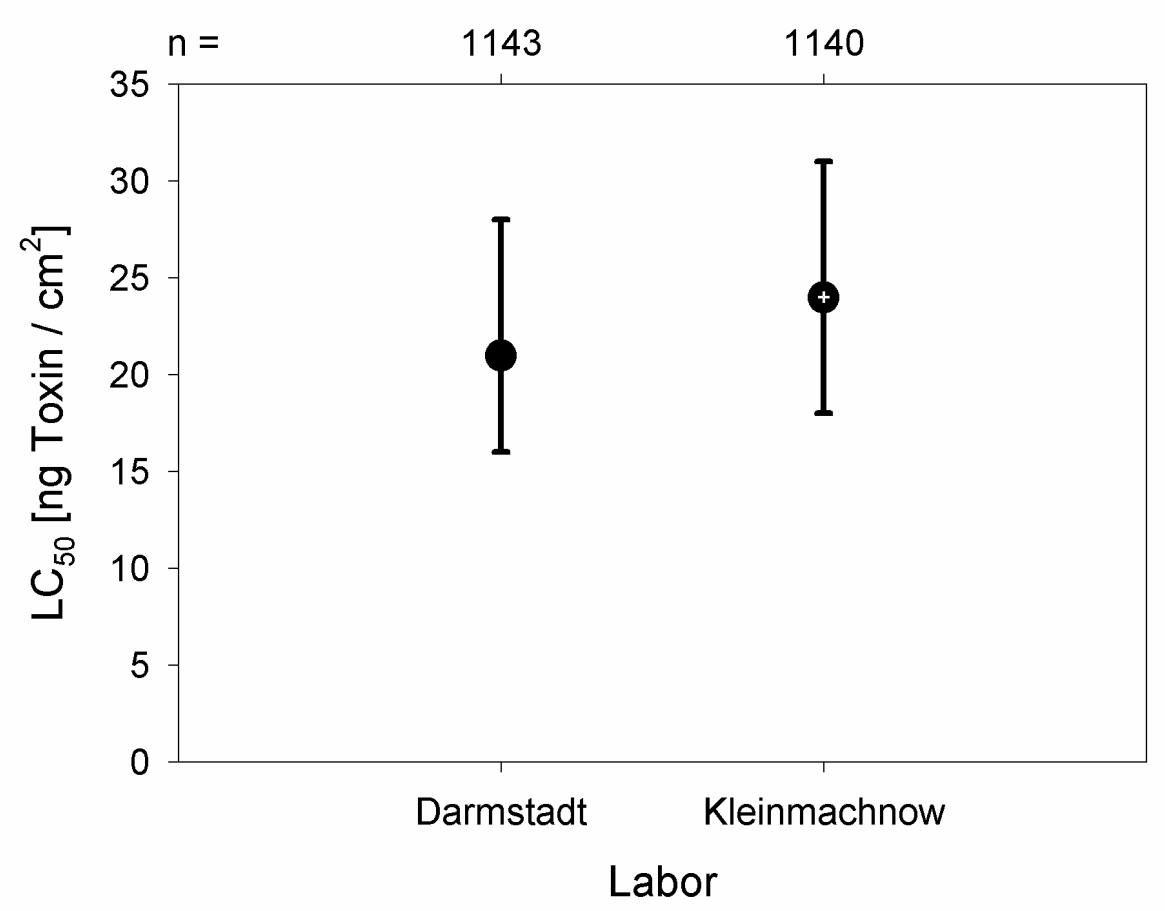

Abb. 4: Laborvergleich BBA Darmstadt und Kleinmachnow, Laborstamm Darmstadt, Larven $<24$ h, Oberflächen-Methode und Toxincharge J3.

Der Laborvergleich bei identischen Larven, Toxin und Versuchsdesign ergab bei vier Wiederholungen eine gute Übereinstimmung der $\mathrm{LC}_{50}$ Werte ohne signifikante Unterschiede (Abb. 4). Im Jahr 2001 wurden in Kleinmachnow zunächst Larven für die Untersuchung verwendet, die zwischen 24 und $48 \mathrm{~h}$ alt waren. In eigenen Vorversuchen wurden Larven verwendet, deren Alter zwischen drei und $48 \mathrm{~h}$ alt war. Larven, die jünger als drei $\mathrm{h}$ Stunden waren, wurden nicht verwendet, um den Larven die Möglichkeit zu geben, einen normalen Enzymhaushalt nach dem Schlupf aufzubauen (Tab. 23).

Die Larven, die älter als 24 Stunden waren, zeigten eine 3,2fach höhere Empfindlichkeit als die jüngeren Larven (Tab. 23). Durch die geringe Wiederholungszahl (3) ist dieser Unterschied nicht statistisch signifikant. Die Larven konnten, bis sie auf das Medium gesetzt wurden, keine Nahrung aufnehmen. Bei den Larven die älter als 24 Stunden waren, führte dies zu einer signifikant erhöhten natürlichen Mortalität. Bei den Larven mit einem Alter über 48 Stunden, lag die Mortalität im Durchschnitt bei $19 \% \pm 5 \%$, wohingegen die jüngeren Larven eine natürliche Mortalität von $1 \% \pm 1 \%$ zeigten. 
Tab. 23: Einfluss des Larvenalters auf die $\mathrm{LC}_{50}$-Bestimmung am Beispiel des Laborstamms Darmstadt

\begin{tabular}{|c|c|c|c|c|c|}
\hline \multirow{2}{*}{$\begin{array}{l}\text { Alter } \\
\text { [h] }\end{array}$} & \multirow[t]{2}{*}{$\mathbf{n}$} & \multirow{2}{*}{$\begin{array}{l}\mathrm{LC}_{50} \\
{\left[\mathrm{ng} / \mathrm{cm}^{2}\right]^{1}} \\
(95 \% \mathrm{KI})^{2}\end{array}$} & \multirow{2}{*}{$\begin{array}{l}\text { Wirkungsquotient } \\
\text { (95\% KI) }\end{array}$} & \multicolumn{2}{|c|}{ Kontrollmortalität ${ }^{3}$} \\
\hline & & & & $\mathbf{n}$ & $\bar{x} \pm s[\%]$ \\
\hline$<24$ & 749 & $(6-54)$ & \multirow{2}{*}{$3,2(0,7-16,2)$} & 192 & $1 \pm 1 \mathrm{a}$ \\
\hline $24-48$ & 750 & $(2-17)$ & & 192 & $19 \pm 5 a$ \\
\hline
\end{tabular}

${ }^{1}$ Trypsinresistenter Kern des Cry1Ab-Toxin $(67 \mathrm{kDa})$, Toxincharge J3.

${ }^{2}$ Gleicher Buchstabe bedeutet, dass sich die $\mathrm{LC}_{50}$ signifikant unterscheiden $(\alpha=10 \%$, t-Test).

${ }^{3}$ Gleicher Buchstabe bedeutet, dass sich die Werte signifikant unterscheiden ( $\alpha=5 \%$, t-Test).

Tab. 24: Vergleich des Einflusses der Kühlung der Larven auf den $\mathrm{LC}_{50}$-Wert

\begin{tabular}{|c|c|c|c|c|c|c|}
\hline \multirow[t]{2}{*}{ Kühlung } & \multirow[t]{2}{*}{ n } & \multirow{2}{*}{$\begin{array}{l}\mathrm{LC}_{50} \\
{\left[\mathrm{ng} / \mathrm{cm}^{2}\right]^{1}} \\
(95 \% \mathrm{KI})^{2}\end{array}$} & \multirow[t]{2}{*}{$\begin{array}{l}\text { Wirkungsquotient } \\
\text { (95 \% KI) }\end{array}$} & \multirow{2}{*}{$\begin{array}{c}\text { Dauer } \\
\text { Eistadium }^{3} \\
\bar{x} \pm s \text { [Tage] } \\
\end{array}$} & \multicolumn{2}{|c|}{$\begin{array}{l}\text { Kontroll- } \\
\text { mortalität }^{3}\end{array}$} \\
\hline & & & & & $\mathbf{n}$ & $\bar{x} \pm s \quad[\%]$ \\
\hline $10^{\circ} \mathrm{C}$ & 749 & $7(4-13)$ & $0,6(0,3-1,5)$ & $10 \pm 0,6 \mathrm{~b}$ & 192 & $9 \pm 1$ \\
\hline $15^{\circ} \mathrm{C}$ & 750 & $4(2-8)$ & $0,5(0,2-1,1)$ & $9 \pm 0,2 \mathrm{a}$ & 192 & $10 \pm 4$ \\
\hline $22^{\circ} \mathrm{C}$ & 750 & $9(5-14)$ & 1 & $7 \pm 0,3 \mathrm{ab}$ & 192 & $5 \pm 1$ \\
\hline
\end{tabular}

Die Kühlung der Eier hatte einen signifikanten Einfluss auf die Dauer des Eistadiums (Tab. 24). Die Mortalität und die Empfindlichkeit gegen das Cry1Ab-Toxin waren bei einem $\alpha=5 \%$ nicht signifikant verschieden. 


\subsection{Diskussion}

Die Bestimmung der Basisempfindlichkeit vor einem Anbau von Bt-Mais dient als Grundlage für ein Resistenzmonitoring. Sie dient der Abgrenzung von Resistenzentwicklungen gegenüber natürlichen Schwankungen. Zusätzlich liefert die Ermittlung der $\mathrm{LC}_{50}$-Werte wichtige Hinweise zur Wahl der diskriminierenden Dosis, die in Tests zur frühzeitigen Entdeckung von Resistenzen verwendet wird (Marçon et al., 2000).

\subsubsection{Unterschiede in der Basisempfindlichkeit der Populationen verschiedener Anbaugebiete in Deutschland}

In der vorliegenden Arbeit wurde die Basisempfindlichkeit in drei Jahren (2000 - 2002) sowie für Maiszünslerpopulationen aus fünf Anbaugebieten und einem Laborstamm bestimmt (Tab. 12 - Tab. 15). Für die Bewertung der Frage, ob sich die Empfindlichkeit der Larven in den Anbaugebieten unterscheidet, müssen sowohl die Unterschiede innerhalb eines Jahres als auch zwischen den Jahren verglichen werden. Im Jahr 2000 wurden die Stämme der Anbaugebiete Pocking, Niedernberg, Hessisches Ried und der Laborstamm mit der Oberflächen-Methode verglichen (Kapitel 4.3.1). Alle drei Standorte unterschieden sich signifikant vom Laborstamm, der die geringste Empfindlichkeit mit $60 \mathrm{ng} / \mathrm{cm}^{2}$ zeigte. Der Wirkungsquotient zwischen dem Laborstamm und dem Stamm Niedernberg, der mit 19 ng die höchste Empfindlichkeit zeigte, betrug 3,1 (1,9 - 4,9). Die Daten des Jahres 2000 lassen sich mit den Daten von Gonzáles-Núñez et al. (2000) vergleichen, da in beiden Untersuchungen dieselbe Applikations-Methode und ein identisches Protoxin eingesetzt wurde. Die spanischen Populationen Ebro und Madrid liegen in ihren Empfindlichkeiten von 55 (38,5 81) $\mathrm{ng} / \mathrm{cm}^{2}$ bzw. 52 (41-70) $\mathrm{ng} / \mathrm{cm}^{2}$ zwischen dem Laborstamm und dem Hessischen Ried sowie Pocking. Für alle fünf Stämme überschneiden sich die Konfidenzintervalle. Dies deutet darauf hin, dass es keinen statistischen Unterschied zwischen den deutschen und den spanischen Populationen gibt. Marçon et al. (1999b) haben für 14 geografisch verschiedene Maiszünslerstämme in den USA und Italien die Basisempfindlichkeit untersucht. Obwohl die Methode und das Protoxin auf den ersten Blick identisch scheinen, liegen die $\mathrm{LC}_{50}$-Werte um eine Zehnerpotenz unter den deutschen und spanischen Werten. Der Grund liegt wahrscheinlich in der Zählung der toten Larven, denn Marçon et al. (1999b) zählten eine Larve unter 0,1 mg Gewicht als tot. Die vorliegende Arbeit und die spanischen Untersuchungen definieren eine Larve als tot, wenn sie sich nicht mehr bei Berührung mit einem Pinsel bewegt. Marcon et al. (1999b) fanden bei gleicher Konzentration mehr tote Tiere, so dass der $\mathrm{LC}_{50}$-Wert sank. Die Daten von Chaufaux et al. (2001) können nicht direkt mit den hier gezeigten Daten verglichen werden, da es sich um $\mathrm{EC}_{50}$-Werte (Effektive Konzentration) handelt. Als Auswertungskriterium wurde nicht der Tod einer Larve, sondern ihr Endgewicht verwendet.

Im Jahr 2001 konnte kein signifikanter Unterschied zwischen den vier Stämmen, die auch 2000 schon getestet wurden, mit der Oberflächen-Methode festgestellt werden. Pocking war in diesem Jahr am unempfindlichsten. Niedernberg und das Hessische Ried zeigten dieselbe niedrige Empfindlichkeit und das Oderbruch wich signifikant von den anderen Stämmen ab und war um das 5,3fache empfindlicher als Pocking. Im Jahr 2001 
wurden die $\mathrm{LC}_{50}$-Werte für vier Stämme (LA, PO, NI, HR) mit der UntermischMethode, wie sie z. B. auch von Bolin et al. (1998) und MacIntosh et al. (1990) verwendet wurde, ermittelt. Bei dieser Methode waren keine statistischen Unterschiede zwischen den Stämmen zu erkennen. Das Hessische Ried zeigte bei dieser Methode die geringste Empfindlichkeit. Da die beiden Methoden mit Larven unterschiedlicher Ablagetermine durchgeführt wurden, kann der Unterschied ein Hinweis auf die Schwankungen der $\mathrm{LC}_{50}$-Werte innerhalb einer Population sein. Dieser Effekt wird in Kapitel 4.4.3 ausführlich diskutiert. Die $\mathrm{LC}_{50}$-Werte schwankten zwischen $0,55(0,1$ $2,3) \mu \mathrm{g}$ Toxin/g Nährmedium für Niedernberg und 1,6 (0,5 - 4,7) $\mu \mathrm{g} / \mathrm{g}$ für das Hessische Ried. Der Wirkungsunterschied betrug ca. das Dreifache. Da $1 \mathrm{ml}$ Medium ca. $1 \mathrm{~g}$ entsprachen, können die Literaturangaben von Bolin et al. (1998) und MacIntosh et al. (1990) verglichen werden, indem sie auf ml Medium umgerechnet und auf den trypsinresistenten Kern bezogen werden. Bolin et al. (1998) führten die Untersuchungen an einem empfindlichen Laborstamm (Mn-Susc) und an fünf Isolinien, den Nachkommen von Larven, die auf Bt-Mais (Bt-176 und Bt-11) gesammelt wurden, durch. Der Laborstamm Mn-Susc besaß einen $\mathrm{LC}_{50}$-Wert von 1,5 $(1,07-2,14) \mu \mathrm{g} / \mathrm{ml}$. Dieser Wert liegt im Bereich der im Jahr 2001 mit der Untermisch-Methode ermittelten $\mathrm{LC}_{50}$-Werte. $\mathrm{Zu}$ berücksichtigen ist, dass die Methoden der Bestimmung der $\mathrm{LC}_{50^{-}}$ Werte voneinander abweichen. Von Bolin et al. (1998) wurde Protoxin eingesetzt, während MacIntosh et al. (1990), wie in der vorliegenden Arbeit, den gereinigten, trypsinresistenten Kern des Cry1 Ab Toxins verwendeten. Die Basisempfindlichkeit des untersuchten Stammes bei MacIntosh (1990) lag mit 3,6 (1,76 - 6,89) doppelt so hoch wie die des Laborstamms von Bolin et al. (1998) und dem unempfindlichsten Stamm der eigenen Untersuchung, Hessisches Ried. Trotzdem überschneiden sich die Konfidenzintervalle deutlich, so dass kein statistisch abgesicherter Unterschied zu erwarten ist. Interessant ist, dass die Testung der Isolinien in der Studie für alle Isolinien eine höhere Empfindlichkeit aufwies als für den empfindlichen Laborstamm. Die Schwankungen zwischen Isolinien von Bolin et al. (1998) entsprachen den Schwankungen zwischen den Populationen in dieser Arbeit.

Im Jahr 2002 wurden, wie im Jahr 2001, die Versuche mit einem trypsinresistenten Kern des Cry1Ab-Toxins durchgeführt, wobei die Chargen sich in der Herstellungsweise unterschieden (4.2.5). Mit der Charge J3 wurden sowohl für die Oberflächen-Methode, als auch für die Untermisch-Methode niedrigere $\mathrm{LC}_{50}$-Werte ermittelt. Das Jahr 2002 war durch eine Mikrosporidieninfektion des Laborstamms Darmstadt gekennzeichnet, die zu einer Erhöhung der Empfindlichkeit in diesem Stamm führte. Pierce et al. (2001) wiesen in ihren Untersuchungen eine höhere Empfindlichkeit von $\mathrm{L}_{1}$-Maiszünslerlarven bei einer Mikrosporidieninfektion nach. Die Empfindlichkeit nimmt mit steigender Sporenzahl der Mikrosporidie Nosema pyrausta zu. Dies ist eine Erklärung, warum das Hessische Ried, trotz einer natürlichen Infektion mit Mikrosporidien, keine erhöhte Empfindlichkeit zeigte. Die Infektionsrate scheint durch die jahrelange Koexistenz der Population mit Mikrosporidien im Freiland oder dadurch, dass durch die Infektion geschwächte Tiere während des Winters gestorben sind, unterhalb eines messbaren Einflusses zu liegen. Parallele Untersuchungen der Toxine an demselben Maiszünslerstamm (4.3.7) sowie die Ergebnisse der Mikrosporidienuntersuchungen (4.2.4.3) und die Untersuchung des Stammes Oderbruch in Kleinmachnow, schließen die Möglichkeit aus, dass die niedrigeren $\mathrm{LC}_{50}$-Werte durch eine unentdeckte Mikrosporidieninfektion aller Stämme oder durch methodische 
Abweichungen hervorgerufen wurden (4.4.2). Wie die Werte von 2001, zeigen die Literaturwerte von MacIntosh et al. (1990) deutliche Unterschiede zu den Werten von 2002. Da die Werte von Bolin et al. (1998) für die Isolinien stark streuen, zeigt sich nur zum Laborstamm Mn-Susc ein deutlicher Unterschied. Werden die Stämme Pocking, Niedernberg, Hessisches Ried, Oderbruch und Halle verglichen, zeigt sich, dass bei der Oberflächen-Methode das Oderbruch am empfindlichsten reagierte, sich aber nur vom Stamm Halle (um das 3 fache) signifikant unterschied. Niedernberg und Hessisches Ried zeigten wie 2001 eine ähnliche Empfindlichkeit und Pocking hatte vor Halle den höchsten $\mathrm{LC}_{50}$-Wert. Bei der Untermisch-Methode ergab sich ein ähnliches Bild, wobei die Unterschiede zwischen Hessisches Ried, Niedernberg sowie Pocking kleiner waren. Halle zeigte bei dieser Methode eine deutlich geringere Empfindlichkeit. Die Unterschiede waren jedoch nicht signifikant. Der maximale Unterschied in der Empfindlichkeit betrug das 1,5fache.

Eine Überprüfung der Stabilität der $\mathrm{LC}_{50}$-Werte über mehrere Jahre wurde durch die unterschiedliche Aktivität der Toxinchargen erschwert. Werden die Daten über die drei Toxine gemittelt, fällt auf, dass für alle Stämme die Empfindlichkeit über die Jahre abnimmt (Abb. 1). Die Ausnahme bildet der Laborstamm, der 2002 die geringste Empfindlichkeit aufwies. Erklärbar ist dies durch die massive Mikrosporidieninfektion des Laborstamms im Jahre 2002. Der Abfall der Empfindlichkeit könnte auf eine Resistenzentwicklung hindeuten. Der Stamm Pocking ist im Jahr 2000 achtmal empfindlicher als der Stamm Pocking 2002. Für Pocking kann ein Kontakt mit Bt-Toxin ausgeschlossen werden, da in den Jahren 2000 bis 2002 in diesem Gebiet kein Bt-Mais angebaut und kein Bt-Spritzmittel eingesetzt wurde. Der Anstieg ist relativ gleichmäßig für alle Stämme lässt auf ein Verrechnungsproblem der Toxinchargen schließen. Bei einer natürlichen Ursache, wie Fitnessunterschieden zwischen den Jahren, ist zu erwarten, dass die Effekte streuen, da die Anbaugebiete in den Jahren 2000 und 2001 unterschiedlichen Umwelteinflüssen ausgesetzt waren (4.2). An den Zuchtbedingungen und dem Versuchsdesign wurde zwischen den Jahren nichts verändert, so dass auch hiermit der Anstieg nicht erklärt werden kann. Die Toxinchargen konnten nicht in allen drei Jahren an allen Stämmen getestet werden, weswegen die Effekte der Jahre und der Stämme in die Berechnung der Toxinchargen eingehen. Werden die $\mathrm{LC}_{50}$-Werte trotz des versuchbedingten Abfalls der Empfindlichkeit über die Jahre verglichen (Tab. 16), zeigte sich, dass sich die Anbaugebiete Pocking, Niedernberg und Hessisches Ried nicht unterschieden. Das Oderbruch war signifikant empfindlicher als Pocking und Halle und die Unterschiede zwischen den Jahren waren wesentlich höher als die Unterschiede zwischen den Populationen innerhalb eines Jahres. 
Tab. 25: Literaturdaten zur Basisempfindlichkeit von Ostrinia nubilalis Stämmen gegenüber Cry1 Ab-Toxin

\begin{tabular}{|c|c|c|c|c|c|c|c|c|}
\hline $\begin{array}{l}\text { Land / } \\
\text { Jahr }\end{array}$ & Toxin & $\begin{array}{l}\text { Methoden- } \\
\text { beschreibung }\end{array}$ & Stamm & $\mathbf{n}$ & $\begin{array}{l}\mathrm{LC}_{50} \\
(95 \% \mathrm{KI})\end{array}$ & $\begin{array}{l}100 \% \\
\text { trypsin- } \\
\text { resistentes } \\
\text { Toxin }\end{array}$ & Einheit & Literatur \\
\hline \multirow{4}{*}{$\begin{array}{l}\mathrm{USA} / \\
1995\end{array}$} & \multirow{4}{*}{$\begin{array}{l}\text { Cry1Ab-Protoxin } \\
\text { Formuliertes Bt- } \\
\text { Produkt } \\
\text { (Mycogen Corp, } \\
\text { San Diego) } \\
\text { P. fluorescens }\end{array}$} & \multirow{4}{*}{$\begin{array}{l}\text { AM: Untermisch } \\
\text { AK : } 9 \\
\text { LK }: 32 \\
\text { AL }: 4 \mathrm{~h} \\
\text { T }: \text { k.A. } \\
D \quad: 7 \text { Tage } \\
\text { G }: F_{2}\end{array}$} & \multirow{2}{*}{ Mn-Susc } & \multirow{2}{*}{512} & \multirow{2}{*}{$\begin{array}{l}3,02 \\
(2,13-4,27)\end{array}$} & \multirow{2}{*}{$\begin{array}{l}1,51 \\
(1,07-2,14)\end{array}$} & \multirow[b]{2}{*}{$\mu \mathrm{g} / \mathrm{ml}$} & \multirow{4}{*}{ Bolin et al., 1998} \\
\hline & & & & & & & & \\
\hline & & & $\mathrm{J} 2$ & 450 & 0,08 & 0,04 & \multirow[t]{2}{*}{$\mu \mathrm{g} / \mathrm{ml}$} & \\
\hline & & & $\mathrm{J} 3$ & 447 & $(1,3-3,45)$ & $(0,65-1,73)$ & & \\
\hline \multirow{2}{*}{$\begin{array}{l}\text { Spanien } \\
\text { / } 1998\end{array}$} & \multirow[b]{2}{*}{$\begin{array}{l}\text { Cry1Ab } \\
\text { Protoxin }{ }^{1} \\
\text { (Novartis USA), } \\
\text { B. t. kurstaki } \\
\text { HD1-9 }\end{array}$} & AM: Oberfläche & Ebro & 430 & $109(77-162)$ & $55(38,5-81)$ & \multirow[t]{2}{*}{$\mathrm{ng} / \mathrm{cm}^{2}$} & \multirow{2}{*}{$\begin{array}{l}\text { Gonzáles-Núñez et al., } \\
2000\end{array}$} \\
\hline & & $\begin{array}{l}\mathrm{AK}: 9 \\
\mathrm{LK}: 48 \\
\mathrm{AL}:<24 \mathrm{~h} \\
\mathrm{~T} \quad: 26^{\circ} \mathrm{C} \\
\mathrm{D} \quad: 7 \text { Tage } \\
\mathrm{G}: \mathrm{F}_{1}\end{array}$ & Madrid & 428 & $104(82-140)$ & $52(41-70)$ & & \\
\hline
\end{tabular}


Tab. 25: Teil II: Literaturdaten zur Basisempfindlichkeit von Ostrinia nubilalis Stämmen gegenüber Cry1Ab-Toxin

\begin{tabular}{|c|c|c|c|c|c|c|c|c|}
\hline $\begin{array}{l}\text { Land / } \\
\text { Jahr }\end{array}$ & Toxin & $\begin{array}{l}\text { Methoden- } \\
\text { beschreibung }\end{array}$ & Stamm & n & $\begin{array}{l}L C_{50} \\
(95 \% \mathrm{KI})\end{array}$ & $\begin{array}{l}100 \% \\
\text { trypsin- } \\
\text { resistentes } \\
\text { Toxin }\end{array}$ & Einheit & Literatur \\
\hline $\begin{array}{l}\text { USA, } \\
\text { Italien / } \\
1994 \text { - } \\
1999\end{array}$ & $\begin{array}{l}\text { Cry1Ab } \\
\text { Protoxin }{ }^{1} \\
\text { Ciba-Geigy } \\
\text { B. } t . \text { kurstaki } \\
\text { HD1-9 }\end{array}$ & $\begin{array}{l}\text { AM : Oberfläche } \\
\text { AK : } 8 \\
\text { LK : k.A. } \\
\text { AL : }<24 \mathrm{~h} \\
\mathrm{~T}: 27^{\circ} \mathrm{C} \\
\mathrm{D}: \mathrm{T}^{\mathrm{Tage}} \\
\mathrm{G} \quad: \mathrm{F}_{2}, \mathrm{~F}_{3}, \mathrm{~F}_{2}\end{array}$ & $\begin{array}{l}\text { Tennessee } \\
\text { N. Carolina } \\
\text { Italien }\end{array}$ & $\begin{array}{l}433- \\
1718 \\
.\end{array}$ & $\begin{array}{l}7,89 \\
(6,04-9,84) \\
2,22 \\
(1,49-3,05) \\
3,16 \\
(2,62-3,70)\end{array}$ & $\begin{array}{l}3,95 \\
(3,02-4,92) \\
1,11 \\
(0,75-1,53) \\
1,58 \\
(1,31-1,85)\end{array}$ & $\mathrm{ng} / \mathrm{cm}^{2}$ & Marçon et al., 1999b \\
\hline
\end{tabular}


Tab. 25: Teil III: Literaturdaten zur Basisempfindlichkeit von Ostrinia nubilalis Stämmen gegenüber Cry1Ab-Toxin

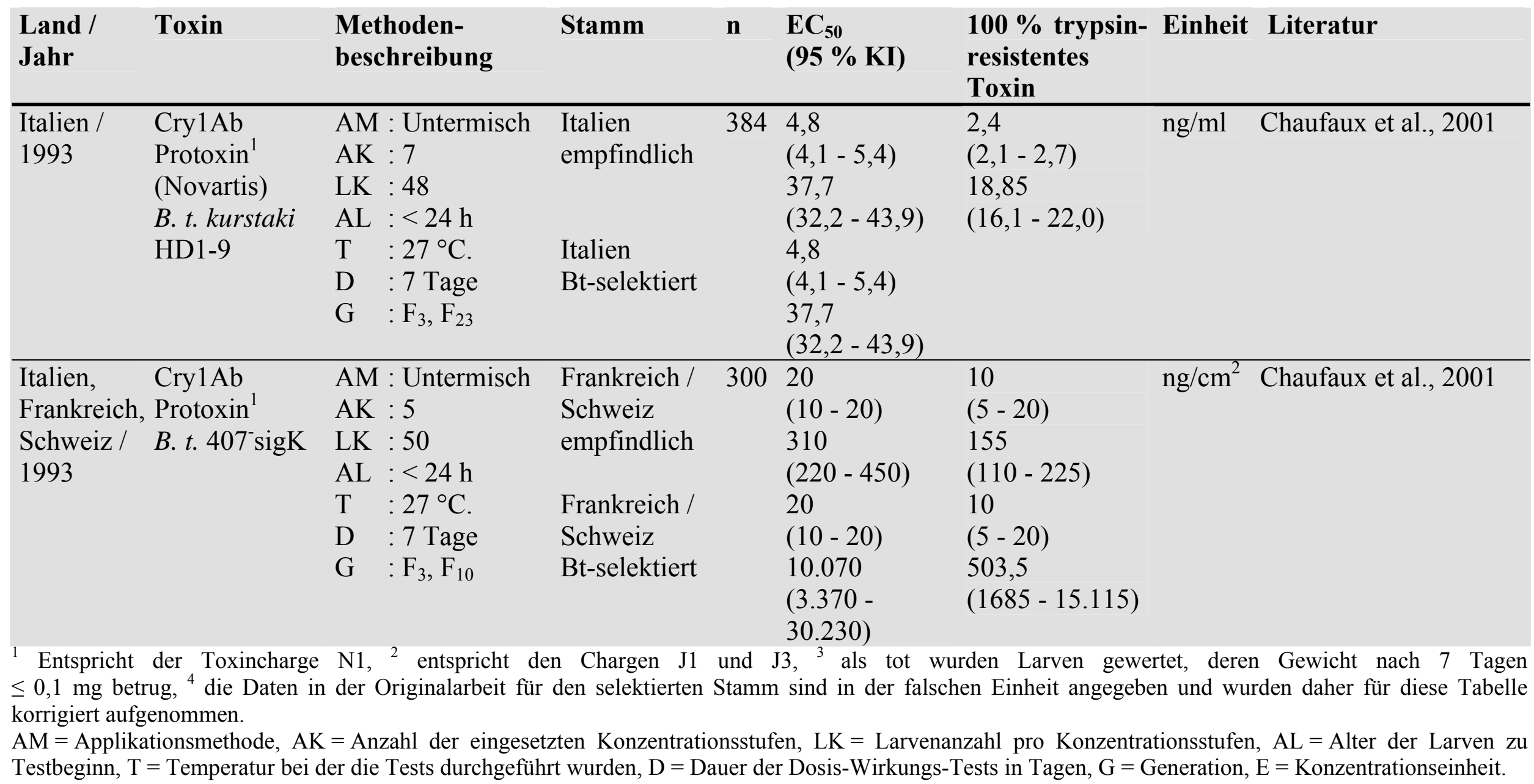




\subsubsection{Bewertung der verwendeten Toxinchargen}

Die für die Basisempfindlichkeit gesammelten Daten lassen sich im Hinblick auf die verwendeten Toxinchargen auswerten. Um die verschiedenen Toxinchargen miteinander vergleichen zu können, wurden die Konzentrationsstufen der Toxinchargen auf $100 \%$ des trypsinresistenten Cry1 Ab-Kerns bezogen, da dieser dem aktiven Teil des Toxins entspricht (Tab. 18). Das Protoxin von Novartis hat eine 2,1 fach geringere Wirkung als die Charge J1. Der Unterschied ist nicht signifikant. Der signifikante Wirkungsunterschied zu J3 beträgt 9,3 bei einem Signifikanzniveau von $\alpha=10 \%$. Die Charge J1 und J3 unterscheiden sich signifikant um das 4,5fache. Da die Versuche mit verschiedenen Stämmen, unterschiedlichen Wiederholungszahlen und in drei verschiedenen Jahren durchgeführt wurden, geben die Werte keine gesicherte Auskunft über die unterschiedliche Effektivität des Toxins. Nur der direkte Vergleich der Toxinchargen mit Larven eines Ablagetermins gibt Aufschluss über den tatsächlichen Wirkungsunterschied. Im Jahr 2001 wurden diese Versuche für die Toxinchargen N1 und J1 mit den Stämmen Labor und Hessisches Ried durchgeführt (Tab. 19). Der Wirkungsquotient war mit 1,2 für beide Stämme geringer als beim Vergleich über die drei Jahre. Wurden die Stämme untereinander verglichen war der Unterschied nicht signifikant. Erst bei gemeinsamer Auswertung der beiden Datensätze wurde ein signifikanter Unterschied nachgewiesen $(\alpha=10 \%)$. Der geringe Unterschied lässt sich evtl. auf die unterschiedliche Toxingröße zurückführen. Das Protoxin der Charge N1 muss im Gegensatz zur Charge J1 zunächst im Darm der Insekten in die aktive Form (trypsinisierten Kern) enzymatisch gespalten werden, so dass eine nicht vollständige Spaltung der Protoxine eine mögliche Erklärung für die geringere Wirkung sein kann. $\mathrm{Zu}$ berücksichtigen ist, dass sowohl die Bestimmung der Reinheit der Toxine als auch die Bestimmung der Proteinkonzentration nach der Bradford-Methode einen versuchsbedingten Toleranzbereich von jeweils $\pm 15 \%$ besitzen. Die Unterschiede zwischen den Jahren 2000 und 2001 sind somit hauptsächlich auf die versuchsbedingten Schwankungen der Empfindlichkeit innerhalb der Stämme sowie auf die unterschiedlichen Wiederholungszahlen und die Ungenauigkeit der Konzentrationsangaben zurückzuführen.

Der Vergleich der Chargen J1 und J3, die beide von Herrn Dr. Jehle und Mitarbeitern (Staatliche Lehr- und Forschungsanstalt, SG Biotechnischer Pflanzenschutz, Neustadt a. d. Weinstraße) mit demselben E. coli Stamm produziert wurden, sich aber im Aufschluss der Zellen unterschieden, ergab einen durchschnittlichen signifikanten $(\alpha=10 \%)$ Wirkungsunterschied von 3,6 (Tab. 19). Erstaunlich sind die Unterschiede im Vergleich der beiden Toxine innerhalb eines Stammes. Der Wirkungsunterschied von Niedernberg lag bei 2,7 und bei Halle betrug er 4,8. Bei der Bestimmung der Basisempfindlichkeit, die mit Charge J3 durchgeführt wurde, hatten Halle und Niedernberg ähnliche $\mathrm{LC}_{50}$-Werte. Der $\mathrm{LC}_{50}$-Wert von Niedernberg war, unter der Annahme gleicher Empfindlichkeit vom Hessischen Ried und Niedernberg (Tab. 17), zu erwarten. Der $\mathrm{LC}_{50}$-Wert für Halle und J1 fällt dagegen sehr hoch aus. Da Halle nur 2002 untersucht wurde, ist eine Bewertung durch einen Vergleich mit anderen Daten nicht möglich. Schwankungen innerhalb der Populationen sind auszuschließen, da die Versuche mit den Toxinchargen J1 und J3 parallel durchgeführt wurden. Die Aufteilung der Larven eines Ablagetermins auf die Raster der beiden Toxinchargen erfolgte nicht vollständig blind randomisiert, so dass ein Einfluss durch das Versuchsdesign möglich 
ist. Es ist unwahrscheinlich, dass ein Versuchsfehler diesen Wert erzeugte, da die Auswahl der Larven für die 12 Rasterwannen der sechs Wiederholungen ohne Schema und von unterschiedlichen Mitarbeiterinnen erfolgte und somit quasi eine Randomisierung darstellte. Ein Teil des Wirkungsunterschiedes lässt sich durch die Toleranzbereiche bei der Bestimmung der Reinheit und der Toxinkonzentration erklären. Wird von einem Toleranzbereich der Messung von jeweils $\pm 15 \%$ ausgegangen (Jehle, pers. Mitt.) ist maximal ein Wirkungsunterschied von 1,8 erklärbar. Die Toxinchargen J1 und J3 zeigten Ende 2002 in der SDS-Polyacrylamidgelelektrophorese (SDS-Page) deutliche Größenunterschiede. Die molekulargenetischen Untersuchungen wurden von Herrn Dr. Wagner (BBA Darmstadt) sowie von Herrn Dr. Jehle und Mitarbeitern durchgeführt, und sind zum Teil bisher nicht abgeschlossen (Wagner und Jehle, pers. Mitt.). Die Toxincharge J1 (2001) und J3 (2002) hatten direkt nach der Produktion, die erwartete Größe des CryIAb-Toxins bei Trypsinbehandlung von ca. $67 \mathrm{kDa}$ (29-607 AS) (Jehle, pers. Mitt.). Bei den Untersuchungen am Ende des Jahres 2002 zeigte die Probe von J1 einen Abbau des Toxins zu einer finalen Größe von ca. $60 \mathrm{kDa}$. J3 zeigte ca. ein Jahr nach Produktion keinen Abbau. Um den Abbau des Toxins während der Lagerung nachzuweisen, wurden die verfügbaren Daten zur Charge J1 und dem Laborstamm in Abb. 2 zusammengefasst. Die Daten stammen aus unterschiedlichen Versuchsreihen, die unter den gleichen Versuchbedingungen durchgeführt wurden. Es konnte keine zeitbedingte Aktivitätsabnahme für die Toxincharge J1 ermittelt werden. Da die ersten Untersuchungen erst vier Monate nach der Produktion der Toxine durchgeführt wurden, kann angenommen werden, dass der größte Teil des Abbaus kurz nach der Produktion geschah und danach stabil blieb. Die Chargen wurden aliquotiert bei $-20^{\circ} \mathrm{C}$ gelagert, bei Bedarf aufgetaut und bei $4{ }^{\circ} \mathrm{C}$ bis zum Verbrauch gelagert. Daher stammen die Daten von Toxinen, die unterschiedliche Lager- und Auftauzeiten besaßen. Dies könnte allerdings einen Abbau bei $4{ }^{\circ} \mathrm{C}$ verschleiern. Aus diesem Grund wurden für zwei Verdünnungsreihen der Chargen $\mathrm{J} 1$ und $\mathrm{J} 3$, die frisch aufgetaut angesetzt wurden, über einen Zeitraum von 142 Tagen neun Mal die $\mathrm{LC}_{50^{-}}$Werte bestimmt (Abb. 3). Die $\mathrm{LC}_{50^{-}}$ Werte zeigten eine große Schwankungsbreite. Da die Wiederholungen der Chargen parallel mit den Larven des gleichen Ablagetermins durchgeführt wurden, veränderteten sich die $\mathrm{LC}_{50}$-Werte in den zwei Monaten parallel. Bei den letzten beiden Wiederholungen ist die Entwicklung nicht mehr identisch. Da zu diesem Zeitpunkt eine unterschwellige Mikrosporidieninfektion in der Laborzucht nicht ausgeschlossen werden kann, sind diese Änderungen eher auf eine Inhomogenität der Larven der letzten beiden Ablagetermine als auf einen unterschiedlichen Abbau der Chargen zurückzuführen. Ein zeitlicher Trend konnte in den Daten statistisch nicht nachgewiesen werden.

Nicht vollständig geklärt ist die Frage, ob der Aufschluss der Zellen durch French Press oder Lysozym einen Einfluss auf den Abbau hatte oder ob die eingesetzte Trypsinmenge, die Einwirkzeit und die Reinigung der Toxinchargen die Unterschiede in den Größen verursachten. Eine Aminosäuresequenzierung erbrachte bisher keinen Aufschluss über die C- und N-terminalen-Enden der beiden Toxin-Chargen. Ein zum Vergleich untersuchtes trypsinisiertes Cry1Ab-Toxin, das von Monsanto am 05.12.1999 hergestellt wurde, hatte eine Größe von ca. $60 \mathrm{kDa}$. MacIntosh et al. (1990) beschreibt in seinen Untersuchungen ebenfalls ein $60 \mathrm{kDa}$ großes Toxin. Die vorgestellten Untersuchungen sind ein deutlicher Hinweis darauf, dass geringe Verschiebungen in der 
Aminosäuresequenz zu Unterschieden in der Effektivität der Toxinfragmente führen. Höfte und Whiteley (1989) zählen sechs Cry1Ab-Toxine auf, die sich in zwei bis sechs Aminosäuren unterscheiden. Wenig ist über den Einfluss der Aminosäurezahl auf die Toxinwirkung bekannt. Beim CrylAb-Toxin des Stammes IC1, das sich vom Standardtoxin um drei Aminosäuren unterscheidet, führt die Änderung zu einer doppelten Wirksamkeit gegenüber Dipteren und Lepidopteren. In der Regel werden die Unterschiede durch die Variabilität der $\mathrm{LC}_{50}$-Werte innerhalb einer Population überdeckt (Visser et al., 1993). Da die vollständige Aminosäuresequenz der beiden Toxine nicht bekannt ist, kann über die Ursache nur spekuliert werden. Nach den vorliegenden Untersuchungen scheint das $60 \mathrm{kDa}-$ Fragment die höchste Effektivität zu besitzen. Die Toxincharge J1 zeigte in der Wirkung einen geringen Unterschied zum Protoxin N1. Daraus kann geschlossen werden, dass das Protoxin im Darmsaft endgültig in ein $60 \mathrm{kDa}$-Fragment gespalten wird. Da die Chargen J1 und J3 mit demselben Plasmid und E. coli Stamm produziert wurden, sollten die zwei Toxinchargen die gleiche Aminosäuresequenz besitzen, so dass der Unterschied nur durch eine unterschiedliche Trypsinisierung entstehen kann. Der unterschiedliche Aufschluss der Zellen kann zu einer Konformationsänderung im Toxin führen, die weitere Trypsinschnittstellen freilegt. Eine Aufklärung des Unterschiedes werden aber erst weitere Untersuchungen erbringen.

\subsubsection{Schwankungen der Basisempfindlichkeit innerhalb und zwischen den Populationen}

In einer Reihe von Veröffentlichungen sind Untersuchungen zu Unterschieden zwischen geografisch verschiedenen Populationen für unterschiedliche Insektenarten vorgelegt worden (Kinsinger und McGaughey, 1979; Wu et al., 1999; Gonzáles-Núñez et al., 2000; Siegfried et al., 2000; Mohan und Gujar, 2002). Für verschiedene Insektenarten konnten einige Autoren geografische Unterschiede feststellen, wohingegen andere Autoren keine Unterschiede fanden. Für Ostrinia nubilalis fanden Gonzáles-Núñez et al. (2000) bei zwei Populationen keine Unterschiede. Siegfried et al. (1995) und Marçon et al. (1999b) stellten dagegen Schwankungen zwischen geografisch verschiedenen Populationen um das Sechsfache bzw. weniger als das Dreifache fest. Beide Autoren führen die Unterschiede auf Schwankungen innerhalb der Populationen, wie sie auch von Robertson et al. (1995) beschrieben wurden, zurück.

Die Schwankungen innerhalb einer Population lassen sich am Konfidenzintervall erkennen. Die Breite des Intervalls ist neben der natürlichen Schwankung von der Anzahl der Wiederholungen abhängig. Die Daten zur Alterung der Toxinchargen (Abb. 2) visualisieren die Schwankungsbreite des Laborstamms. Obwohl der Laborstamm mehrere Jahre in Zucht war und auf die Laborbedingungen selektiert wurde, kam es bei den $\mathrm{LC}_{50}$-Bestimmungen zwischen den verschiedenen Ablageterminen zu natürlichen Schwankungen. Der $\mathrm{LC}_{50}$-Wert stieg innerhalb von 14 Tagen auf das 1,6fache an um einen Tag später auf das Ausgangsniveau zu sinken (Abb. 3). In Abb. 2 sind am 143. Tag nach der Toxinproduktion die $\mathrm{LC}_{50}$-Werte für drei Versuchsansätze dargestellt. Die Empfindlichkeit der Larven des Ansatzes mit dem höchsten $\mathrm{LC}_{50}$-Wert ist um das ca. Sechsfache niedriger als der Ansatz mit dem niedrigsten $\mathrm{LC}_{50}$-Wert. Beide Ansätze wurden mit demselben Versuchsdesign und den gleichen Verdünnungen durchgeführt. Der Ansatz mit dem mittleren $\mathrm{LC}_{50}$-Wert 
unterschied sich von den anderen Ansätzen beiden in der Verwendung der Verdünnungsreihen, aber nicht im Versuchsdesign. Die Larven stammten von demselben Ablagetermin, jedoch nicht von denselben Eltern, so dass der Unterschied im $\mathrm{LC}_{50}$-Wert wahrscheinlich auf die unterschiedliche Empfindlichkeit der Larven zurückzuführen ist.

Die Fitness und damit auch die Empfindlichkeit der Larven hängt zum Teil von der Nährstoffversorgung der Eier ab, die wiederum von dem Fruchtbarkeitsstatus der Eltern abhängt (Robertson et al., 1995). Die Erfahrung aus den Biotests zeigte, dass die Fitness der Larven unzureichend mit der Kontrollmortalität erhoben werden kann, da sich die Larven auf dem Kontrollnährmedium ohne weitere Stressfaktoren erholen können. Die Kontrollmortalität lag bei allen drei Ansätzen zwischen $0 \%$ bis 3,5\%. Ähnliche Beobachtungen finden sich bei Marçon et al. (1999b) und Siegfried et al. (2000). Eine Hypothese zur unterschiedlichen Fitness der Larven und dessen Auswirkungen auf den $\mathrm{LC}_{50}$-Wert ist, dass unterschiedlich fitte Larven unterschiedliche Mengen an Nahrung und damit an Toxin aufnehmen. Die Larven nehmen bei gleicher Toxinkonzentration im oder auf dem Nährmedium unterschiedliche Toxin-Dosen auf. Physiologische Ursachen könnten ebenfalls für die geänderte Empfindlichkeit verantwortlich sein. Es ist vorstellbar, dass die Fitness einen Einfluss auf die Enzymaktivität besitzt, was z. B. eine geringere Spaltung der Protoxine in die aktive Form bewirken könnte. Die Bestimmung der tatsächlich aufgenommenen Toxin-Dosis würde die Schwankungen verringern. Eine Bestimmung der letalen Dosis ist bei $\mathrm{L}_{1}$ Larven vom Maiszünsler nicht möglich, da die aufgenommene Futtermenge nicht praktikabel erfasst werden kann.

Wie in Kapitel 4.4.1 beschrieben, ist die Schwankungsbreite zwischen den Anbauregionen geringer als die Schwankungsbreite innerhalb der Populationen. Da die Populationen in den letzten Jahren keinem Bt-Toxin-Selektionsdruck ausgesetzt waren, sind die geografischen Unterschiede, wie bei Marçon et al. (1999b) und Siegfried et al. (1995) auf die natürlichen Schwankungen der Empfindlichkeit innerhalb der Populationen zurückzuführen. Dies bedeutet für die Basisempfindlichkeit der Maiszünsler in Deutschland, dass mit einer großen Variabilität zu rechnen ist. So sind Empfindlichkeitsunterschiede um das Zehnfache noch als natürliche Schwankungen und nicht als Resistenzunterschiede anzusehen.

\subsubsection{Bewertung der Oberflächen-Methode im Vergleich zur Untermisch- Methode}

In den Jahren 2001 und 2002 wurden die $\mathrm{LC}_{50}$-Werte sowohl für die UntermischMethode als auch für die Oberflächen-Methode bestimmt. Wird der Wirkungsquotient zwischen Methoden für die Jahre und Orte berechnet, zeigt sich, dass für die Untermisch-Methode im Jahr 2001 die ca. 25fache, und im Jahr 2002 die siebenfache Toxinmenge verwendet wurde, um $50 \%$ der Larven zu töten. Die aufzuwendende Toxinmenge schwankte innerhalb der Populationen noch stärker. Für das Hessische Ried wurde 2001 die 33fache und für Pocking 2002 die 5,8fache Menge an Toxin benötigt, um die gleiche Wirkung mit der Untermisch-Methode zu erreichen. Die Unterschiede stammten zum Teil von den Schwankungen innerhalb der Populationen, denn beide Methoden wurden zeitlich versetzt und mit Larven unterschiedlicher Ablagetermine durchgeführt. Diese Schwankungen erlauben somit nicht die 
Berechnung eines Umrechnungsfaktors für die Oberflächen- und Untermisch-Methode. Der Parallel-Test (Tab. 22) zeigte innerhalb der Wiederholungen (Daten wurden nicht gezeigt) keinen konstanten Umrechnungsfaktor. Weiter zeigte die Untersuchung, dass das Untermischen des Toxins und die Lagerung des Toxin-Mediums bis zu 23 Tagen zu keinem signifikanten Toxinabbau führte. Ein Vergleich der Varianzen der beiden Methoden für die Jahre 2001 und 2002 ergab keinen signifikanten Vorteil $(\alpha=10 \%)$ für die Untermisch-Methode. Auf Grund der minierenden Lebensweise des Maiszünslers war mit einem besseren Ergebnis bei der Untermisch-Methode gerechnet worden, da bei der Oberflächen-Methode die Möglichkeit besteht, dass sich die Larve durch die oberen toxinhaltigen Schichten frisst und in den unteren toxinfreien Schichten überlebt. $\mathrm{L}_{1}$-Maiszünslerlarven zeigten in den Untersuchungen keine typisch minierende Lebensweise und auch im Freiland minieren die frisch geschlüpften $\mathrm{L}_{1}$-Larven nicht direkt im Maisblatt. Auch nach mehreren Tagen bohrten sich die Larven auf toxinhaltigem Nährmedium nicht ein. Somit können beide Methoden als gleichwertig für die Bestimmung der $\mathrm{LC}_{50}$-Werte betrachtet werden. In der Literatur werden beide Methoden gleichrangig angewendet (Tab. 25). Ein Nachteil der Untermisch-Methode liegt darin, dass diese ca. das Zehnfache der Toxinmenge im Verhältnis zur Oberflächen-Methode benötigt. Bei großen Wiederholungszahlen und zum Nachweis von resistenten Larven mit einer zehn- bis hundertfach höheren Empfindlichkeit, spielt die Verfügbarkeit großer identischer Mengen an Toxin, dessen Produktion sehr zeitund kostenaufwändig ist, eine entscheidende Rolle. Werden die Besonderheiten der Methoden berücksichtigt, sind beide Methoden einfach durchzuführen und gut zu reproduzieren. Bei der Untermisch-Methode muss darauf geachtet werden, dass das Toxin beim Untermischen unter das warme Medium keine Hitzeschäden erleidet und eine homogene Verteilung des Toxins erreicht wird. Bei der Oberflächen-Methode ist die Reproduzierbarkeit einer planaren gleichgroßen Oberfläche von entscheidender Bedeutung für die Genauigkeit der $\mathrm{LC}_{50}$-Bestimmungen. In vielen Literaturstellen sind die Angaben zur Untermisch-Methode in $\mu \mathrm{g} / \mathrm{ml}$ angegeben, wohingegen in dieser Arbeit die Toxinmenge auf das Gewicht des Nährmediums bezogen wurde, da dieser Wert bei der Herstellung des zähflüssigen Nährmediums einfacher und präziser bestimmt werden kann.

\subsubsection{Bewertung der Untersuchungen in Kleinmachnow und Darmstadt}

Der Stamm Oderbruch zeigte in den Jahren 2001 und 2002 die geringste Empfindlichkeit. Im Jahr 2001 war der Unterschied nur für Niedernberg nicht signifikant. Daher wurden Ende 2001 die Versuchsprotokolle verglichen, wobei kleine Abweichungen in der Interpretation der Versuchsanweisungen festgestellt wurden. In Kleinmachnow wurden die Larven bei $15^{\circ} \mathrm{C}$ gekühlt und für einen Ansatz der Larven mehrerer Eiablagetermine verwendet. Im Jahr 2001 lag das Alter der Larven in den Biotests im Oderbruch im Schnitt bei über $24 \mathrm{~h}$, wohingegen in Darmstadt die Larven jünger als $24 \mathrm{~h}$ waren.

Unter der Kühlung der Eier könnte die Fitness der Larven leiden, da sich die Entwicklungszeit verlängert (Tab. 24). Da die Kontrollmortalität für die beiden Temperaturstufen erhöht war, zeigten die Larven in diesen Ansätzen eine höhere Empfindlichkeit. Beide Unterschiede waren nicht signifikant auf einem Signifikanzniveau von $10 \%$. Bei der Basisempfindlichkeit für das Oderbruch ergab sich keine erhöhte Mortalität im Vergleich zu den Larven der anderen Standorte. Die erhöhte 
Mortalität durch die Kühlung wurde wahrscheinlich durch die Vergrößerung der Stichprobe, die durch das Zusammenfassen von verschiedenen Eiablageterminen entstand, ausgeglichen. Der Einfluss der Kühlung auf den niedrigen $\mathrm{LC}_{50}$-Wert ist daher als gering einzuschätzen.

Das höhere Alter der Larven zeigte dagegen einen deutlich signifikanten Einfluss auf die Kontrollmortalität, der sich in einer erhöhten Empfindlichkeit ausdrückte. Da bei der Bestimmung der Basisempfindlichkeit in Kleinmachnow aber keine erhöhte Mortalität gemessen wurde, ist davon auszugehen, dass die Differenz im Altersunterschied im Jahr 2001 kleiner war als in dem Versuch zum Alter der Larven. Somit hatte dieser Effekt kaum Auswirkungen auf die Bestimmung der Basisempfindlichkeit des Stammes Oderbruch.

Der Vergleich der beiden Labore mit gleicher Toxincharge, gleichem Larvenmaterial und identischem Versuchablauf ergab, dass eine Reproduzierbarkeit der Ergebnisse möglich ist. Beide Versuche belegen die Vermutung, dass geringe Unterschiede in der Fitness der Larven einen Einfluss auf den $\mathrm{LC}_{50}$-Wert besitzen. Eine Summierung von Effekten, die auf die Fitness der Larven einwirkt, kann daher die Schwankung innerhalb der Populationen erklären. Dies hat zur Folge, dass bei der Bestimmung der Basisempfindlichkeiten großen Wert auf eine Einheitlichkeit der Zucht- und Versuchsbedingungen gelegt werden muss.

\subsubsection{Bewertung der Ergebnisse für ein Resistenzmonitoring}

Wie auch von anderen Autoren beschrieben, ist die Schwankung innerhalb der Populationen und zwischen geografischen Populationen ein großes Problem bei der Bewertung von Resistenzentwicklung (Marçon et al., 1999b; Siegfried et al., 2000; Robertson et al., 1995). Erschwert wurde die Bestimmung der Basisempfindlichkeit durch den Wechsel der Toxinproduktion. Abb. 1 zeigt anschaulich über die drei Jahre, wie weit die Empfindlichkeit für die einzelnen Stämme schwanken kann. Eine weitere Schwierigkeit bei der Bestimmung der Basisempfindlichkeit ist die Stichprobengröße sowohl für den initialen Zuchtbeginn als auch für die Wiederholungszahl der DosisWirkungs-Tests und die Anzahl der Larven in einer Wiederholung. Anhand der aus den Daten berechneten Varianz lässt sich die Wiederholungszahl schätzen, die bei einem vorgegebenen tolerierbaren Wirkungsunterschied erreicht werden muss, um eine Äquivalenz der Daten nachweisen zu können. Für einen Wirkungsunterschied zwischen dem empfindlichsten Stamm und dem unempfindlichsten Stamm um den Faktor zehn werden sieben Wiederholungen, bei dem Faktor fünf zwölf Wiederholungen benötigt. Die Wiederholungszahl kann nicht beliebig groß gewählt werden. Im Jahr 2000 war es nicht möglich für Pocking vier Wiederholungen durchzuführen, da durch die kleine Zuchtbasis von 219 Faltern und einem Schlupf der Falter über wenige Tage nicht genügend Larven zum Testen zur Verfügung standen. Große Wiederholungszahlen von mehr als zehn Wiederholungen sind in einer Generation praktisch nicht durchführbar. Besonders bei einem engen Schlupfverlauf besteht die Gefahr, dass die Larven der ersten und letzten Wiederholungen von wenigen Faltern sowie von jungen bzw. alten Faltern stammen, was entsprechende Auswirkungen auf die Fitness der Larven hat. Kleine Stichproben werden wahrscheinlich beim Monitoring von Resistenzen die Regel sein, da auf einem Bt-Maisfeld bei einer beginnenden Resistenzentwicklung wenige Larven im Feld zu finden sind. Eine Kühlung der Eier bietet zwar die Möglichkeit der 
Zusammenfassung bzw. zeitlichen Streckung der Ablagetermine, kann aber, wie in Kapitel 4.3.7 gezeigt, die Basisempfindlichkeit beeinflussen. Auch die Ausweitung der Versuche auf die nächsten Generationen ist keine Lösung, da sich der $\mathrm{LC}_{50}$-Wert zwischen verschiedenen Generation durch die zuchtbedingte Selektion stark unterscheiden kann (Robertson et al., 1995; Marçon et al., 1999b).

Die Basisempfindlichkeit ist somit kein statischer Wert, sondern eine sich verändernde Größe. Für ein Resistenzmonitoring bedeutet dies, dass die Basisempfindlichkeit im Freiland für verschiedene Anbauregionen regelmäßig, d. h. möglichst jährlich oder evtl. im Wechsel alle zwei Jahre ermittelt werden sollte. Ein standardisiertes Cry1Ab-Toxin sollte regelmäßig an einer Referenzzucht überprüft werden. Bei einer regelmäßigen Überprüfung der Basisempfindlichkeiten können resistente Populationen, die eine um den Faktor zehn erniedrigte Empfindlichkeit besitzen, erkannt werden.

Ein direkter Vergleich der ermittelten Werte mit Toxinkonzentrationen in BtMaispflanzen und damit eine Einschätzung inwieweit gefundene Wirkungsunterschiede zwischen Stämmen die "Hoch Dosis"-Strategie überwinden, ist mit dieser Methode nicht möglich. Dies zeigt ein Vergleich der ermittelten Daten mit den Proteinkonzentrationsangaben in Bt-Maispflanzen aus der Literatur. In Bt-Maispflanzen liegen die Toxinkonzentrationen laut Literatur (Tab. 25) je nach Bt-Event und Literaturangabe in den Blättern zwischen 0,4 - 3,0 $\mu \mathrm{g} / \mathrm{g}$ Frischgewicht für Bt-176 und $7,9-12,15 \mu \mathrm{g} / \mathrm{g}$ Frischgewicht für Mon810 sowie in den Maiskörnern bei $<0,005 \mu \mathrm{g} / \mathrm{g}$ Frischgewicht für Bt-176 und 0,2-0,6 $\mu \mathrm{g} / \mathrm{g}$ Frischgewicht für Mon810. Die Untermisch-Methode kommt den Konzentrationsangaben in der Pflanze am nächsten. Beide Angaben beziehen sich auf das Frischgewicht der Pflanze bzw. das Nährmedium. Die $\mathrm{LC}_{50}$-Werte für das Cry1 Ab der Charge J1 liegen zwischen 0,5 $\mu \mathrm{g} / \mathrm{g}(\mathrm{NI}, 2001)$ bis $1,6 \mu \mathrm{g} / \mathrm{g}$ (HR, 2001) und 0,2 $\mu \mathrm{g} / \mathrm{g}$ (NI, 2002) bis $0,32 \mu \mathrm{g} / \mathrm{g}$ (HA, 2002). Die Larven der Laborzucht, Niedernberg und Pocking überlebten die Fütterung mit Blattmaterial von verschiedenen Bt-Maissorten nicht (nicht veröffentliche Daten Lorenz, Fersch, BBA Darmstadt). Ein Vergleich der Werte ist kaum möglich, da die aufgenommene Nahrungsmenge durch Larven auf den Bt-Maispflanzen bzw. auf dem Nährmedium und somit die aufgenommene Dosis unterschiedlich sein kann. Fuchs et al. (1990) zeigten, dass ELISA-Tests, mit denen üblicherweise der Proteingehalt in den Pflanzen gemessen wird, um ein Vielfaches unempfindlicher sind als die Biotests mit gereinigtem Cry $1 \mathrm{Ab}$ Toxin. $\mathrm{LC}_{50}$-Bestimmungen mit Pflanzenmaterial sind auf Grund der geringen Toxinkonzentrationen nicht bzw. schwer möglich (Fuchs et al., 1990). Eigene Versuche zur Verwendung von Pflanzenmaterial in Dosis-Wirkungs-Tests, in dem das Pflanzenmaterial unter Nährmedium bzw. mit Agar-Agar gemischt wird, wurden wegen starker Verpilzung des Mediums und der Schwierigkeit der exakten und stabilen Proteinangabe im Pflanzenmaterial nicht berücksichtigt. Ein Vergleich der Proteinkonzentrationen in der Pflanze mit den Toxinkonzentrationen im Biotest wäre für die Zukunft wünschenswert, um eine Äquivalenz der in Bakterien produzierten Toxine mit den Bt-Maistoxinen nachzuweisen. Die Äquivalenz von trypsinisierten CrylAb und den in den Bt-Maispflanzen verwendetet Toxin wurde in verschiedenen unveröffentlichten Studien anhand der DNA-Sequenz, immunologischen Tests, gelelektrophoretischen Untersuchungen und Biotests gezeigt (U.S. Environmental Protection Agency (EPA), 2000). Da die Daten zur Äquivalenz nicht publiziert und in vielen Studien unterschiedliche Toxinproduktionsweisen verwendeten wurden, ist eine 
Verallgemeinerung der Ergebnisse schwierig. Die in dieser Arbeit vorgestellten Ergebnisse zu den Chargen J1 und J3 zeigen, dass es trotz gleicher Gensequenz und zunächst gleicher Proteingröße zu Wirkungsunterschieden bei Cry1Ab-Toxinen durch bisher noch nicht identifizierte Bedingungen kommen kann. Der Wirkungsunterschied liegt mit einem Faktor von 3,6 im Vergleich zu Schwankungen in der Empfindlichkeit innerhalb einer Population in einem tolerierbaren Rahmen. Die Ergebnisse zu den Chargen J1 und J3 können für die Aussagekraft von Studien über Nicht-Zielorganismen von Bedeutung sein. So unterscheiden sich Subtypen von Bt-Toxinen in nur wenigen Aminosäuren, was aber $\mathrm{zu}$ unterschiedlichen Wirkungsstärken bei verschiedenen Insektenarten führen kann (Höfte et al., 1988). 


\section{$5 \quad$ F $_{2}$-SCREENING}

\subsection{Einleitung}

Die Entstehung von resistenten Populationen und die Geschwindigkeit mit der sich eine Resistenz ausbreitet, hängen von einer Vielzahl von Faktoren ab, u. a. von der Initialfrequenz der Resistenzallele (Gould und Tabashnik, 1998; Tabashnik, 1990; Ferré und Van Rie, 2002) (3.9). Allgemein wird von einem sehr geringen Anteil von resistenten Insekten oder Resistenzallelen in der Population ausgegangen (Venette et al., 2002). Für die Modellierung von Resistenzmanagementplänen werden meist Resistenzallelfrequenzen von $10^{-3}$ bis $10^{-5}$ benutzt, wobei über den wahren Wert wenig bekannt ist (Tabashnik, 1990; Alstad und Andow, 1995). Schätzungen, die auf Mutationshäufigkeiten beruhen, errechnen Frequenzen von $10^{-2}$ bis $10^{-3}$ (Roush und Daly, 1990; Venette et al., 2002). Die Schwierigkeit bei der Bestimmung der Resistenzhäufigkeit liegt darin, dass bei rezessiver Vererbung nur homozygot resistente Larven einen Test auf Resistenz überleben. Bei einer gegeben Resistenzallelhäufigkeit (q) findet sich eine homozygote Larve (x) unter $1 / \mathrm{q}^{2}$ Individuen. Bei einem diagnostischen Konzentrations-Test ergibt sich die notwendige Probengröße (n) aus der Frequenz der resistenten Individuen (f) nach der Formel:

$n=\frac{\log (1-P(x \geq 1))}{\log (1-f)}$ (Roush und Miller, 1986)

Tab. 26 zeigt die Abhängigkeit der notwendigen Probengröße (n) von der Resistenzhäufigkeit. Voraussetzung für die „Refugien/Hoch Dosis“-Strategie zur Verhinderung von Resistenzen (3.9.1) ist eine Frequenz der Resistenzallele von weniger als $10^{-3}$. Für die Überprüfung dieser Voraussetzung müssten mit dem diagnostischen Konzentrations-Test fast drei Millionen Larven auf Resistenz getestet werden.

\section{$F_{2}$-Screening nach Andow und Alstad (1998)}

Aus diesem Grund haben Andow und Alstad (1998) das $\mathrm{F}_{2}$-Screening verwendet, mit dessen Hilfe Resistenzallele bei heterozygoten Individuen und einem rezessiven Erbgang nachgewiesen werden können. Das $\mathrm{F}_{2}$-Screening gliedert sich in sechs Arbeitsabschnitte:

1. Sammeln von Larven einer natürlichen Population.

2. Überwinterung der Larven und Bildung von Isolinien durch Einzelpaarung der geschlüpften Falter $\left(\mathrm{P}_{1}\right)$.

3. Zucht der Nachkommen, Paarung der Falter und Haltung der abgelegten Eier innerhalb einer Isolinie $\left(\mathrm{F}_{1}\right)$.

4. Testung von frisch geschlüpften Larven $\left(\mathrm{F}_{2}\right)$ auf Bt-Maisblattstücken oder auf Nährmedium, das ein Cry1Ab-Toxin enthält.

5. Statistische Auswertung der Daten.

6. Isolinien mit resistenten, überlebenden Larven in der $\mathrm{F}_{2}$-Generation, werden in der $\mathrm{F}_{4}$-Generation nochmals auf Resistenz überprüft. 
Tab. 26: Notwendige Probengröße bei einem diagnostischen Konzentrations-Test für verschiedene Häufigkeiten von resistenten Individuen bzw. Resistenzallelen.

\begin{tabular}{cll}
$\begin{array}{c}\text { Häufigkeit resistenter } \\
\text { Individuen in der } \\
\text { Population } \\
\text { (f) }\end{array}$ & $\begin{array}{c}\text { Häufigkeit } \\
\text { Resistenzallele in } \\
\text { der Population } \\
(\mathbf{q})\end{array}$ & $\begin{array}{c}\text { notwendige } \\
\text { Probengröße }\end{array}$ \\
\hline $10^{-1}=1 / 10$ & 1 & $\mathbf{( n )}$ \\
\hline $10^{-2}=1 / 100$ & $10^{-1}=1 / 10$ & 28 \\
\hline $10^{-4}=1 / 100$ & $10-2=1 / 100$ & 29.956 \\
\hline $10^{-6}=1 / 1.000 .000$ & $10^{-3}=1 / 1.000$ & 2.995 .731 \\
\hline $10^{-8}=1 / 100.000 .000$ & $10^{-4}=1 / 10.000$ & 299.573 .224 \\
\hline $10^{-10}=1 / 1.0000 .000 .000$ & $10^{-5}=1 / 100.000$ & 29.957 .320 .255
\end{tabular}

Bei einer 95\%igen Ereigniswahrscheinlichkeit (P) ein resistentes Individuum im Test zu entdecken.

Als Grundlage für das $\mathrm{F}_{2}$-Screening dient die Tatsache, dass jede Isolinie vier verschiedene haploide Chromosomensätze, zwei vom Weibchen und zwei vom Männchen, trägt. Alle Paarungen mit homozygot sensiblen Paaren (SS x SS) bringen in der $\mathrm{F}_{1}$ - und $\mathrm{F}_{2}$-Generation zu $100 \%$ sensible Nachkommen (SS) hervor. Das sehr seltene Auftreten von Mutation kann vernachlässigt werden. Wird als Ausgangspaarung zufällig ein heterozygot resistentes Elternteil (rS) mit einem homozygoten sensiblen Elternteil (SS) gekreuzt, so enthält die $\mathrm{F}_{1}$-Generation zu $50 \%$ heterozygot resistente Larven (rS) und $\mathrm{zu} 50 \%$ homozygot sensible Larven (SS). Phänotypisch sind alle Larven sensibel gegenüber dem Bt-Toxin. Die Geschwisterkreuzung in der $\mathrm{F}_{1}$ führt zu drei möglichen Kreuzungsprodukten in der $\mathrm{F}_{2}$-Generation: homozygot sensible Larven (SS), heterozygot resistente bzw. sensible Larven (rS) und homozygot resistente Larven (rr) in einem Verhältnis von $9: 6: 1$, d. h. eine von 16 Larven zeigt phänotypisch eine Resistenz gegenüber dem Bt-Toxin und überlebt den Biotest. Die Kreuzung von homozygot resistenten mit homozygot sensiblen Individuen und die Kreuzung von Eltern, die beide homozygot resistent sind, können auf Grund ihrer geringen Wahrscheinlichkeit in den Berechnungen vernachlässigt werden. Bei diesen Kreuzungen würde der Anteil homozygot resistenter Larven auf $1 / 4$ bzw. auf $100 \%$ steigen und sie würden daher im Biotest eindeutig zu erkennen sein.

Andow und Alstad haben 1998 die dem $\mathrm{F}_{2}$-Screening zu Grunde liegende Statistik ausführlich beschrieben. Fehler in den Berechnungen wurden von Schneider (1999) und von Andow und Alstad (1999) korrigiert. Im Artikel Andow et al. (2000) wurden die statistischen Berechnung ergänzt. Eine Zusammenfassung findet sich im Anhang (9.2.1).

Andow und Alstad diskutieren in ihrer Arbeit von 1998 die statistischen Probleme, die mit dem gewählten Ansatz zusammenhängen. Die Präzision ihrer Statistik beruht darauf, dass in der $\mathrm{F}_{2}$-Generation mit einem Höchstma $\beta$ an Genauigkeit die Linien entdeckt werden, die in ihren Ausgangsgenomen der $\mathrm{P}_{1}$-Generation mindestens ein Resistenzallel besaßen. Dabei unterscheiden sie zwei Probleme: erstens eine Falsch-Positiv-Entscheidung und zweitens eine Falsch-Negativ-Entscheidung zu treffen.

\section{Falsch-Positiv-Entscheidung}

Unter einer Falsch-Positiv-Entscheidung wird die Identifizierung einer sensiblen 
Isolinie als Resistente verstanden. Dies ist kein statistisches Problem, sondern hängt davon $a b$, wie genau die Methode zwischen sensiblen und resistenten Larven unterscheiden kann. Durch die Wahl einer hohen Toxin-Konzentration, d. h. einer Konzentration, die $99 \%$ der sensiblen Larven tötet, und durch die ReTestung der Isolinien in der $\mathrm{F}_{3}-\mathrm{bzw}$. in der $\mathrm{F}_{4}$-Generation kann dieses Problem auf ein vernachlässigbares Minimum reduziert werden (Andow und Alstad, 1998).

\section{Falsch-Negativ-Entscheidung}

Eine Falsch-Negativ-Entscheidung zu treffen, d.h. eine resistente Isolinie (mindestens ein $\mathrm{P}_{1}$-Elternteil war heterozygot resistent) als sensibel einzustufen, steht im Zusammenhang mit verschiedenen Abschnitten der Versuchsdurchführung. Die Wahrscheinlichkeit ein Resistenzallel nicht zu entdecken, wird mit $\mathrm{P}_{\text {no }}$ bezeichnet. Drei Gründe für eine Falsch-NegativEntscheidung werden angegeben:
a. Das Allel geht während der $F_{1}$-Generation z. B. durch eine krankheitsbedingte Mortalität verloren.
b. In der $F_{1}$-Generation kommt es nicht zur Kreuzung von Resistenzallelträgern.
c. Das Resistenzallel wurde trotz der Paarung der Resistenzallelträger nicht in die $\mathrm{F}_{2}$-Generation vererbt oder eine homozygot resistente $\mathrm{F}_{2}$-Larve stirbt bevor sie getestet wird.

Abweichend von Andow und Alstad (1998) wurde in dieser Arbeit ein Frequentistischer Ansatz gewählt, der die Entdeckungswahrscheinlichkeit jeder Isolinie berücksichtigt. Die natürliche Resistenzallelhäufigkeit der Maiszünsler kann in Europa, dem Ursprungsland des Maiszünsler, von den in den USA ermittelten Werten abweichen. Für Europa wurden bisher noch keine Untersuchungen zur Resistenzallelhäufigkeit veröffentlicht. Daher wurde die natürliche Resistenzallelhäufigkeit exemplarisch für die Population Niedernberg mit Hilfe eines modifizierten $\mathrm{F}_{2}$-Screenings nach Andow und Alstad (1998) durchgeführt. 


\subsection{Material und Methoden}

\subsubsection{Bestimmung des Flugverlaufes}

Die Daten zur Bestimmung des Flugverlaufes stammen von einer Lichtfalle am Standort Niedernberg. Die Falle war mit einer UV- und einer Weißlicht-Röhre ausgestattet. Die anfliegenden Insekten sammelten sich in einem Käfig ( $\mathrm{H} \mathrm{x} \mathrm{B} \mathrm{x} \mathrm{L}=30 \mathrm{~cm}$ x $30 \mathrm{~cm}$ x 30 $\mathrm{cm})$, der täglich geleert wurde. Die gefangenen Falter wurden gezählt. Im Jahr 1999 wurde die Falle von Dr. Langenbruch (BBA, Darmstadt) und in den Jahren 2000 und 2001 von Dr. Felke (BBA, Darmstadt) und Dr. Fersch (BBA, Darmstadt) betreut.

\subsubsection{Berechnung der Temperatursummen}

Als ungefährer Entwicklungsnullpunkt werden von Ohnesorge und Reh (1987) $9{ }^{\circ} \mathrm{C}$ angegeben. Werden von Tagesdurchschnittstemperaturen, die größer $9{ }^{\circ} \mathrm{C}$ sind, $9{ }^{\circ} \mathrm{C}$ subtrahiert und die Werte addiert, ergibt sich der DD9. Die Tagesdurchschnittstemperaturen (24-Punkt-Methode) stammen von der Wetterstation Großostheim der Bayerische Landesanstalt für Landwirtschaft (2002). Die aufsummierten Tageswertegrade $>9{ }^{\circ} \mathrm{C}$ (DD9) dienen zur Prognose der Schlupfzeitpunkte der Maiszünslerfalter.

\subsubsection{Sammeln der Maiszünsler}

$\mathrm{Da}$ das $\mathrm{F}_{2}$-Screening einen hohen personellen und material-intensiven Einsatz erfordert, wurde es nur exemplarisch an der Population Niedernberg (4.2.1.1) für die Jahre 2000 und 2001 durchgeführt. Im Herbst 1999 bzw. 2000 wurden auf 10 bzw. 12 Maisfeldern 1.232 bzw. 1.083 Larven gesammelt. In den Gebieten gab es nur eine 0,5 ha große Fläche mit Bt-Mais. Die Felder, auf denen gesammelt wurde, lagen in einem Sicherheitsabstand von mindestens $500 \mathrm{~m}$ von dem Bt-Maisfeld entfernt, so dass ein Kontakt der Larven mit Bt-Mais ausgeschlossen werden kann.

\subsubsection{Haltung und Zucht von Maiszünslern im Labor}

Die Zucht der Maiszünsler richtete sich nach den Erfahrungen der Abteilung Dr. Hassan, BBA Darmstadt. Im Verlaufe der Dissertation wurden die Zuchtbedingungen optimiert und den Versuchbedingungen angepasst.

\subsubsection{Elterngeneration $P_{1}$}

Die im Herbst im Freiland gesammelten $\mathrm{L}_{5}$-Larven wurden zunächst in Plastikboxen (B x L x H $=20 \mathrm{~cm} \times 20 \mathrm{~cm}$ × $8 \mathrm{~cm}$ ) aufbewahrt. Um Kondenswasserbildung $\mathrm{zu}$ vermeiden, waren in die Deckel ca. $10 \mathrm{~cm}$ x $10 \mathrm{~cm}$ und in den Seiten im Durchmesser $4,5 \mathrm{~cm}$ große Gazestücke eingesetzt, was einen ausreichenden Luftaustausch gewährleistete. Als Versteckmöglichkeit wurde den Larven im Jahr 2000 Maisstängel, die jedoch stark verpilzten, und im folgenden Jahr zerknülltes Handtuchpapier angeboten. In jede Box wurden maximal 50 Larven gesetzt. Die Lagerung der Boxen erfolgte in gelüfteten, nicht beheizten und nicht beleuchteten Gewächshäusern, so dass die Licht- und Temperaturverhältnisse weitgehend den natürlichen Bedingungen in Darmstadt in den Jahren 1999 bis 2001 entsprachen. Ab April wurden die Larven ein 
Mal pro Woche mit Wasser besprüht, damit sie tropfbares Wasser aufnehmen konnten (Beck, 1967). Die Puppen wurden in Plastikbecher mit perforiertem Deckel $(\varnothing \times \mathrm{x}=$ $4,5 \mathrm{~cm} \times 7 \mathrm{~cm}$ ) mit einem Stück Filter- oder Handtuchpapier gelegt.

Im Folgenden richtete sich die Zucht nach den in Kapitel 4.2.4.1 beschriebenen Bedingungen. Die Paarung der Falter erfolgte unter natürlichen Licht- und Temperaturverhältnissen in Gewächshäusern. Ab Juni wurden die Gewächshäuser durch ein Schattiergewebe beschattet und bei hohen Temperaturen wurde für eine ausreichende Ventilation gesorgt. Die Falter der Eltern-Generation wurden jeweils paarweise in Plexiglaszylinder gesetzt. Die Nachkommen eines Paares wurden gemeinsam weitergezüchtet und strikt von den Nachkommen der anderen Isolinien getrennt.

\subsubsection{2 $\mathrm{F}_{1}$ und $\mathrm{F}_{2}$-Generation}

Die Eier und Larven wurden i. d. R. wie in Kapitel 4.2.4.1 beschrieben in Lichtthermostaten bei $25{ }^{\circ} \mathrm{C}, 18: 6 \mathrm{~h}$ (H : D) gehalten. Zur Synchronisation der Schlupfzeitpunkte wurden früh abgelegte Eigelege und Puppen für maximal sieben Tage bei $10{ }^{\circ} \mathrm{C}$ gehalten. Die Entwicklung von spät abgelegten Eigelegen und sich langsam entwickelnden Larven wurde durch Temperaturerhöhung auf $30{ }^{\circ} \mathrm{C}$ beschleunigt. Die Paarung der Falter der $\mathrm{F}_{1}$-Generation erfolgte in beheizbaren Gewächshäusern bei Langtagbedingungen $18: 6 \mathrm{~h}(\mathrm{H}: \mathrm{D})$. Alle zwei bis drei Tage wurden die Behälter auf geschlüpfte Falter einer Isolinie kontrolliert und die Falter gepaart. Gleichzeitig wurden die Zylinder auf Eiablage überprüft.

Im Jahr 2000 wurden die Falter einer Isolinie in der Reihenfolge des Schlupfes in einem Zylinder zusammengesetzt. Bei einem starken Ungleichgewicht im Geschlechterverhältnis wurden die überzähligen Falter eines Geschlechts in einem separaten Zylinder oder Schlupfgefäß bei $10{ }^{\circ} \mathrm{C}$ für maximal zehn Tage gehalten. Im Jahr 2001 wurden die frisch geschlüpften Falter einer Isolinie zunächst in einem Zylinder A bis zur ersten Eiablage gesammelt. Nach der ersten Eiablage in Zylinder A wurden neu schlüpfende Falter in einem zweiten Zylinder B, wieder bis zur ersten Eiablage dieser Gruppe, gesammelt. Die zweite und dritte Eiablage von Zylinder A wurde für die Testung der Resistenz verwendet, um allen Faltern die Möglichkeit zu geben sich an der Eiproduktion zu beteiligen. Nachdem die Falter in Zylinder B zum ersten Mal Eier abgelegt hatten, wurden die Falter in Zylinder A abgetötet, um Platz für die neu geschlüpften Falter zu erhalten. Die folgende Eiablage der Gruppe aus Zylinder B wurde wiederum für die Biotests verwendet. Dies wurde solange wiederholt, bis insgesamt 10 Paare einer Isolinie mit je 10 Larven getestet waren. Durch diese Methode könnten die Eier Kleingruppen von Weibchen zugeordnet und der Platz sowie der Arbeitaufwand minimiert werden.

\subsubsection{Versuch zum Paarungsverhalten der Maiszünsler Männchen}

Für die statistischen Untersuchungen musste geklärt werden mit wie vielen Weibchen ein Männchen kopulieren kann. Die Versuche wurden mit Tieren aus der Laborzucht durchgeführt und richteten sich nach den Zuchtbedingungen, wie sie im Kapitel 4.2.4.1 beschrieben sind $\left(\mathrm{L}: \mathrm{D}=18: 8\right.$; Temperatur $23 \pm 2{ }^{\circ} \mathrm{C}$; relative Luftfeuchte von $90 \pm 10 \%$ ). Es wurden 20 Zylinder mit je einem frisch geschlüpften Männchen und einem frisch geschlüpften Weibchen angesetzt. Die Weibchen und Männchen hatten 
vorher noch keine Möglichkeit zur Kopulation. Hatte das Weibchen Eier abgelegt, wurden die Eier und das Weibchen aus dem Zylinder entfernt und ein neues frisch geschlüpftes Weibchen zu dem Männchen gesetzt. Dies wurde so lange wiederholt bis das Männchen starb. Die Eier wurden so lange gehalten bis an ihrer Entwicklung zu erkennen war, dass sie befruchtet waren. Starb ein Männchen vor der ersten Kopulation wurde ein neuer Zylinder angesetzt.

\subsubsection{Test auf Resistenz}

Für die Testung einer Isolinie auf Resistenz wurden frisch geschlüpfte Larven der $\mathrm{F}_{2}$ bzw. $F_{4}$-Generation, die jünger als 24 Stunden waren und noch keine Nahrung aufgenommen hatten, verwendet.

\subsubsection{Testung auf Maispflanzen}

In Vorversuchen wurden $10 \mathrm{~L}_{1}$-Larven bzw. fünf Larven im $\mathrm{L}_{2}$-bis $\mathrm{L}_{3}$-Stadium auf zehn Bt-Maispflanzen im Zweiblattstadium der Sorte Pactol CB, der Firma Novartis gesetzt sowie zur Kontrolle auf Pactol gegeben. Die Pflanzen standen jeweils einzeln in einem Blumentopf in einem Plexiglaszylinder $(\varnothing \times \mathrm{H}=12 \mathrm{~cm} \times 30 \mathrm{~cm})$, der mit einer feinen Gaze bespannt war, damit keine Larven entweichen konnten. Pro Ansatz wurden vier Wiederholungen durchgeführt. Die Pflanzen standen im Gewächshaus bei Temperaturen zwischen $22^{\circ} \mathrm{C}$ bis $28^{\circ} \mathrm{C}$. Das Verhalten der Larven wurde täglich für 10 min kontrolliert und nach 7 Tagen die Mortalität bestimmt.

\subsubsection{Testung der Larven paarweise auf Blattstücken}

Da bei den Vorversuchen mit Bt-Maispflanzen methodische Probleme auftraten (5.3.3), wurden für die weitere Testung auf Resistenz Biotests in Plastikwürfeln (L x B x H = 2 $\mathrm{cm} \times 2 \mathrm{~cm} \times 2 \mathrm{~cm}$ ) im dunklen Lichtthermostat bei $25{ }^{\circ} \mathrm{C}$ durchgeführt. In jedem Plastikwürfel befanden sich zwei $\mathrm{L}_{1}$-Larven, die jünger als 24 Stunden waren. Bonitiert wurde nach 7 und 21 Tagen. Im Jahr 2000 erfolgte die Testung auf Resistenz mit Hilfe von Bt-Maisblattstücken, da in diesem Jahr nur eine geringe Menge an Bt-Toxin zur Verfügung stand. Dazu wurde in die Plastikwürfel $2 \mathrm{ml}$ Wasser-Agar (2,5 \%) gefüllt, auf das ein ausgestanztes Blattstück $(\varnothing=12 \mathrm{~mm})$ gelegt wurde. Die Blattstücke stammten von Bt-Mais der Sorte Pactol CB (Linie Bt-176; Firma Novartis), der im Labor angezogen und im Vier- bis Sechs-Blattstadium geerntet wurde. Alle zwei bis drei Tage wurde das Blattstück gewechselt und die Mortalität bestimmt. Nach 21 Tagen wurden die überlebenden Larven auf Nährmedium (9.1.2) umgesetzt und die Nachkommen der Isolinie in der $\mathrm{F}_{4}$-Generation erneut getestet. 


\subsubsection{Testung der Larven paarweise auf toxinhaltigem Medium}

Nachdem im Jahr 2001 ausreichend Bt-Toxin zur Verfügung stand, wurde anstelle der Blattstücke und des Wasser-Agars $2 \mathrm{ml}$ Nähmedium verwendet, dem das Bt-Toxin (Charge J1a, Tab. 10) untergemischt war (Untermisch-Methode, Anhang 9.1.2). Die BtToxinkonzentration wurde im Jahr 2001 entsprechend der Konzentration des Bt-Toxins von Bt-Maispflanzen der Linie Mon810 der Firma Monsanto mit 10,34 $\mu \mathrm{g} / \mathrm{g}$ (Cry1 Ab pro Gramm Blattfrischgewicht) (Tab. 1) gewählt, da zu diesem Zeitpunkt keine Daten zur $\mathrm{LC}_{50}$ vorlagen. Weiterhin wurde davon ausgegangen, dass das zur Verfügung stehende Cry1 Ab-Toxin mit dem Cry1 Ab-Toxin aus der Pflanze identisch ist. Da beim Untermischen große Mengen an Toxin verbraucht wurden, wurde im Laufe der Untersuchung auf eine Oberflächen-Methode (4.2.6.1) umgestellt. Nachdem die ersten Ergebnisse zur Basisempfindlichkeit durchgeführt worden waren, wurde die Toxinkonzentration zur Toxineinsparung weiter herabgesetzt. Die Toxinkonzentration war ausreichend um $100 \%$ der empfindlichen Maiszünslerarven abzutöten.

Tab. 27: Toxinkonzentrationen beim $\mathrm{F}_{2}$-Screening für die Jahre 2000 bis 2002

\begin{tabular}{lllll} 
Jahr & Toxin & Applikation & $\begin{array}{l}\text { Menge } \\
\text { [Toxin/ } \\
\text { Frischgewicht] }\end{array}$ & $\begin{array}{l}\text { Larven- } \\
\text { mortalität } \\
\text { nach 7 Tagen }\end{array}$ \\
\hline 2000 & Bt-Mais, Bt-176 ${ }^{2}$ & Blattstücke & $\begin{array}{l}(\varnothing 12 \mathrm{~mm}) \\
1,4 \mu \mathrm{g} / \mathrm{g}{ }^{1}\end{array}$ & $100 \%$ \\
\hline 2001 & Cry1Ab, Charge J1 ${ }^{4}$ & $\begin{array}{l}\text { Untermisch- } \\
\text { Methode }\end{array}$ & $10 \mu \mathrm{g} / \mathrm{g}^{3}$ \\
\hline 2001 & Cry1Ab, Charge J3 ${ }^{4}$ & $\begin{array}{l}\text { Oberflächen- } \\
\text { Methode }\end{array}$ & $0,312 \mu \mathrm{g} / \mathrm{cm}^{2}$ \\
\hline
\end{tabular}

\subsubsection{Statistik zum $F_{2}$-Screening}

Die statistische Auswertung erfolgte durch Professor Piepho von der Universität Hohenheim, Fachgebiet Bioinformatik, und weicht von der Auswertung, die Andow und Alstad (1998) vorgeschlagen haben, ab.

Im Gegensatz zu Andow und Alstad (1998), die eine Baye'sche Analyse verwendeten, wird in dieser Arbeit ein Frequentistischer Ansatz zur Berechnung der Resistenzallelfrequenz (q) verwendet. Für die Berechnung werden folgende Annahmen festgelegt.

1. Die Allelfrequenz $q$ des rezessiven Resistenzallels ( $\mathrm{r}$ ) ist klein. Daher dominieren Kreuzungen von sensiblen Eltern, die homozygot für das sensible Allel (S) sind, so dass näherungsweise ausschließlich die beiden Eltern $\left(\mathrm{P}_{1}\right)$-Kreuzungen SS x, 
SS und SS x rS betrachten werden. Diese beiden Arten von Paarungen haben die approximativen Frequenzen $1-4 q$ und $4 q$ (Andow und Alstad, 1998).

2. Die Kreuzungen der Eltern und $F_{1}$-Generation sind unabhängig und zufällig. Es werden Annahmen über die Verteilung der Genotypen auf die Nachkommenschaft getroffen (Anhang 9.2.2).

Die Wahrscheinlichkeit aus einer gegebenen Isolinie keine resistenten Nachkommen in $\mathrm{F}_{2} \mathrm{zu}$ bekommen, sofern die Parental-Paarung SS x rS stattgefunden hat, wird mit $\mathrm{P}_{\text {no }}$ bezeichnet. Sie kann durch die Aufsummierung der bedingten Wahrscheinlichkeiten der einzelnen Kreuzungen berechnet werden. Für i-te Isolinie beträgt die Likelihood $\mathrm{L}_{\mathrm{i}}=4 \times \mathrm{q} \times \mathrm{P}_{\text {no }}+(1-4 \times \mathrm{q})$. Für die gesamte Nachkommenschaft lässt sich die Likelihood als $\Pi L_{i}$ angeben. Da keine resistenten Larven aufgetreten sind, wurde ein Vertauensintervall für $\mathrm{q}$ berechnet. Die Herleitung der Formeln und eine genau Beschreibung der Statistik befindet sich im Anhang 9.2.2. 


\subsection{Ergebnis}

Die Bestimmung der Häufigkeit der Resistenzallele in der Population Niedernberg wurde 2000 und 2001 mit einem hohen $\mathrm{Ma} ß$ an Arbeits- und Materialeinsatz durchgeführt.

\subsubsection{Daten zum Arbeitsaufwand}

Der Arbeitsaufwand bei der Durchführung des $\mathrm{F}_{2}$-Screenings ist stark vom Versuchszeitpunkt abhängig, denn durch die Zuchtbedingungen traten hohe Arbeitsspitzen auf. Das Sammeln der Larven im Herbst hatte den Vorteil, dass zu diesem Zeitpunkt die Zuchtaktivitäten abgenommen hatten. Im Jahr 2000 wurde an fünf Tagen von einem Team bestehend aus zwei bis fünf Personen insgesamt in 58,5 Arbeitsstunden 1083 Maiszünsler bei einem Befall von 20 - 30\% gesammelt, d. h. pro Larve wurden ca. drei Minuten benötigt. Pausen und Fahrtzeiten sind dabei nicht berücksichtigt. Für die Zuchten und die Testung der $\mathrm{F}_{2}$-Generation wurden pro Jahr ca. 600 Stunden an Aushilfskräften und eine halbe bis eine ganze Stelle für eine technische Assistentin benötigt. Besonders während der Schlupfzeiten der $\mathrm{P}_{1}$-Falter und der $\mathrm{F}_{1^{-}}$Falter konnten die hohen Arbeitszeitspitzen nur durch die Einstellung von Aushilfskräften abgedeckt werden.

\subsubsection{Zucht-Daten}

Für das $\mathrm{F}_{2}$-Screening ist von besonderer Bedeutung, dass Resistenzallele während der Zucht bis zur $\mathrm{F}_{2}$-Generation verloren gehen. Die Larven, die in den Jahren 1999 und 2000 gesammelt wurden, mussten für das $\mathrm{F}_{2}$-Screening über zwei Generationen im Labor gezüchtet werden. Dabei wurde die Ausgangspopulation durch Krankheiten und Parasitoide, die durch Larven aus dem Freiland in die Zucht eingeschleppt wurden, stark reduziert. Die Umstellung auf ein künstliches Nährmedium und auf die spezifischen Laborbedingungen führten im Zuchtverlauf $\mathrm{zu}$ einer weiteren Reduktion der Ausgangspopulation.

\subsubsection{Vergleich des Schlupfverlaufes im Labor mit Lichtfallenfängen am Standort Niedernberg}

Abb. 5 zeigt den Verlauf des Schlupfes der $\mathrm{P}_{1}$-Generation. Im Jahr 2000 schlüpften im Labor die ersten Falter in der ersten Juni-Pentade, eine Pentade, bevor die ersten Falter im Freiland gefangen wurden. Der erste Flughöhepunkt zeigte sich in der dritten JuniPentade. Zu diesem Zeitpunkt lag der DD9 bei $501{ }^{\circ} \mathrm{C}$. Der Flugverlauf erstreckte sich bis zur letzten Juli Pentade und war durch einen mehrgipfeligen Verlauf gekennzeichnet, der durch drei Kälteperioden, mit Temperaturen unter $15{ }^{\circ} \mathrm{C}$, in der letzten Mai-, letzten Juni- und letzten Juli- Pentade hervorgerufen wurde. Der Schlupf der Falter endet aber nicht im Juli, sondern die letzten Falter schlüpften Ende August. Die Temperaturen im Gewächshaus lagen über den Werten aus Niedernberg, wodurch der mehrgipfelige Verlauf abgemildert wurde.

Im Jahr 2001 zeigte sich ein anderer Flug- und Schlupfverlauf. Ein Kälteeinbruch in der ersten Juni-Pentade führte dazu, dass der Falterflug erst in der dritten Pentade begann. Mit wieder langsam ansteigenden Temperaturen erhöhte sich die Anzahl der 
gefangenen Falter. In der sechsten Juni-Pentade kam es zu einem rasanten Anstieg der Falterfänge. Zu diesem Zeitpunkt lag der DD9 bei $542{ }^{\circ} \mathrm{C}$. Im Jahr 2000 war dieser Wert fast zwei Pentaden früher erreicht worden. Der Schlupfverlauf im Gewächshaus zeigte ein ähnliches Bild. Der erste Schlupf von Faltern war wie 2000 in der ersten JuniPentade. In den nächsten drei Pentaden schlüpften keine weiteren Falter und in der sechsten Pentade schlüpften parallel zum Flugverlauf sehr viele Falter im Gewächshaus. Nach dem Schlupfhöhepunkt in der sechsten Juni-Pentade nahm der Schlupfverlauf stark ab. Die letzten Falter erschienen Ende Juli. Die Schlupfzeiträume der Elterngeneration in den Jahren 2000 und 2001 unterschieden sich um ca. einen Monat.

Im Jahr 1999 wurden bei 65 Weibchen, aus einer Lichtfalle im Gebiet Niedernberg, das Eiablageverhalten bestimmt. 36 Weibchen wurden zusammen mit Männchen in einen Zylinder gesetzt, um den Weibchen, die vor der Kopulation gefangen wurden, die Möglichkeit zur Befruchtung zu geben. Von den 36 Weibchen legten acht $(22 \%)$ keine Eier ab. Bei 29 Weibchen wurde das Eiablageverhalten untersucht, ohne dass ein weiteres Männchen für die Paarung zur Verfügung stand. Von diesen Weibchen legten 7 (24\%) keine Eier ab. Die Weibchen wurden nicht auf das Vorhandensein von Spermatophoren untersucht, so dass nicht angegeben werden kann, ob die Weibchen nicht befruchtet wurden oder ob sie nicht fertil waren. Die Mehrzahl der Weibchen hatte sich aber bereits vor dem Fang in der Lichtfalle gepaart. 

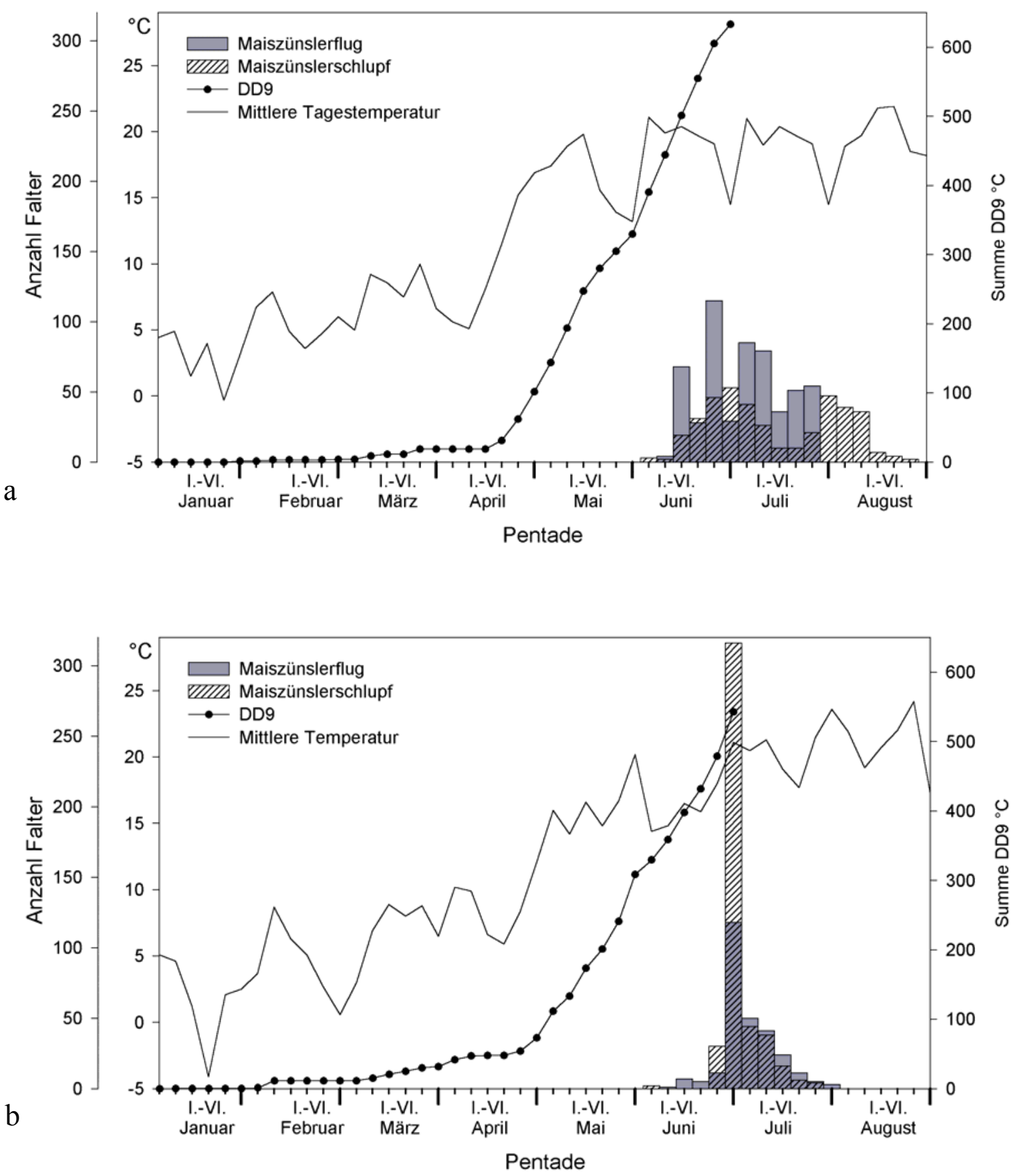

Abb. 5: Flugverlauf der Maiszünsler am Standort Niedernberg und Schlupfverlauf der Maiszünsler des Standortes Niedernberg im Gewächshaus in Darmstadt in Abhängigkeit vom Temperaturverlauf im Jahr 2000 (a) und 2001 (b).

Die Daten sind als Pentadenwerte berechnet; die Temperaturdaten stammen von der Wetterstation Großostheim der Bayerische Landesanstalt für Landwirtschaft (2002); die Temperatur wurde $2 \mathrm{~m}$ über dem Boden gemessen. DD9 $=$ aufsummierte Tagesgrade $>9{ }^{\circ} \mathrm{C}$ bis zur 3 . Juni-Pentade. 


\subsubsection{Kenndaten zur Zucht der $\mathrm{F}_{1}$-Generation}

Die Tab. 28 zeigt die durchschnittliche Lebenserwartung von Faltern der $\mathrm{P}_{1}$-Generation in den Jahren 1999 bis 2001 unter den in Kapitel 5.2.4 genanten Haltungsbedingungen. Anzumerken ist, dass die Daten nicht für alle Falter vollständig erhoben werden konnten und besonders im Jahr 2001 Falter frühzeitig abgetötet wurden, um Platz für schlüpfende Falter zu schaffen. Im Jahr 2000 haben die Weibchen im Durchschnitt fünf Tage länger gelebt. In den kühlen Perioden in den letzten Pentaden der Monate Mai bis Juli stellten die Falter die Kopulation und die Eiablage ein. Erst beim Anstieg der Temperaturen setzten die Falter die Eiablage fort, so dass sich auch der Eiablagezeitraum innerhalb einer Isolinie über mehrere Pentaden ausdehnen konnte. Erstaunlich ist die maximale Überlebensrate eines einzelnen Weibchens von 61 Tagen.

Tab. 28: Kenndaten zur Zucht der $\mathrm{P}_{1}$-Falter vom Standort Niedernberg in den Jahren 1999 bis 2001

\begin{tabular}{|c|c|c|c|}
\hline & $\begin{array}{l}\text { NI-99 } \\
\text { Lichtfalle }\end{array}$ & NI-00 & NI-01 \\
\hline Lebensdauer Männchen [d] & $\mathrm{N}=35$ & $\mathrm{~N}=181$ & $\mathrm{~N}=168$ \\
\hline$($ Median $\pm s)$ & $7 \pm 3,6$ & $21 \pm 10,4$ & $7 \pm 5,6$ \\
\hline Maximum & 14 & 54 & 26 \\
\hline Lebensdauer Weibchen [d] & $\mathrm{N}=56$ & $\mathrm{~N}=189$ & $\mathrm{~N}=218$ \\
\hline$($ Median $\pm s)$ & $10 \pm 7,1$ & $16 \pm 13,3$ & $11 \pm 6,6$ \\
\hline Maximum & 31 & 61 & 29 \\
\hline $\begin{array}{l}\text { Anzahl der Paare ohne Eiablage } \\
(\%)\end{array}$ & $\begin{array}{l}N=65 \\
15(23 \%)\end{array}$ & $\begin{array}{l}\mathrm{N}=193 \\
157(19 \%)\end{array}$ & $\begin{array}{l}\mathrm{N}=233 \\
74(32 \%)\end{array}$ \\
\hline $\begin{array}{l}\text { Dauer bis zur Ablage des } \\
\text { 1. Eipakets [Tage] }\end{array}$ & $\mathrm{N}=50$ & $\mathrm{~N}=157$ & $\mathrm{~N}=144$ \\
\hline$($ Median $\pm s)$ & $4 \pm 3,4$ & $4 \pm 3,2$ & $4 \pm 3,8$ \\
\hline Maximum & 14 & 22 & 32 \\
\hline $\begin{array}{l}\text { Mittlere Anzahl der Kontrolltage } \\
\text { mit Eipakete pro Isolinie }\end{array}$ & $\mathrm{N}=51$ & $\mathrm{~N}=157$ & $\mathrm{~N}=147$ \\
\hline$($ Median $\pm s)$ & $2 \pm 1,7$ & $5 \pm 2,4$ & $2 \pm 1,0$ \\
\hline Maximum & 8 & 10 & 5 \\
\hline $\begin{array}{l}\text { Mittlere Zeit zwischen 1. Eigelege } \\
\text { und letzten Eigelege [d] }\end{array}$ & $\mathrm{N}=32$ & $\mathrm{~N}=154$ & $\mathrm{~N}=91$ \\
\hline$($ Median $\pm s)$ & $7 \pm 4,2$ & $12 \pm 8,6$ & $5 \pm 2,1$ \\
\hline Maximum & 17 & 38 & 10 \\
\hline
\end{tabular}

Der unterschiedliche Schlupfverlauf und das Eiablageverhalten in der Elterngeneration hatte natürlich auch Auswirkungen auf den weiteren Verlauf der Zucht. So zog sich der Eiablagezeitraum der $F_{1}$-Generation 2000 bis Mitte März des nächsten Jahres hin, wohingegen die $F_{1}$-Generation 2001 ihre Eier bis zum 28.11.2001 abgelegt hatte. 
Tab. 29: Schlupfzeitraum und Eiablagezeitraum der $F_{1}$-Generation, Standort Niedernberg, für die Jahre 2000 und 2001

\begin{tabular}{lll} 
& $\mathbf{2 0 0 0}$ & $\mathbf{2 0 0 1}$ \\
\hline Schlupfzeitraum ${ }^{\uparrow}$ & 07.08 .00 bis 12.03 .00 & 07.08 .01 bis 16.11 .01 \\
\hline Schlupfzeitraum + & 07.08 .00 bis 12.03 .00 & 07.08 .01 bis 19.11 .01 \\
\hline Eiablagezeitraum & 15.08 .00 bis 14.03 .01 & 10.08 .01 bis 28.11 .01
\end{tabular}

Der lange Schlupfzeitraum im Jahr 2000 lässt sich dadurch erklären, dass einige Larven trotz der Einstellung von Langtagbedingungen in Diapause gegangen sind. Um die Diapause zu brechen, wurden die Larven ab Ende November für 100 Tage bei $10{ }^{\circ} \mathrm{C}$ in Dunkelheit gehalten, bevor sie wieder bei $25^{\circ} \mathrm{C}$ und Langtagbedingungen $18: 6 \mathrm{~h}(\mathrm{H}$ : D) gehalten wurden. Von den Witterungs- und den Zuchtbedingungen hing auch die Wintermortalität in den Jahren 2001 und 2002 ab.

\subsubsection{Versuch zum Paarungsverhalten der Männchen}

Die Männchen der Maiszünsler kopulierten im Durchschnitt 2,6 0,3 Mal. Das Maximum betrug in diesem Versuch 5 Kopulationen pro Männchen. Durchschnittlich wurden die Männchen 12,8 $\pm 3,3$ Tage alt.

\subsubsection{Verlauf der Zucht der Isolinien}

Die Wintermortalität betrug im Jahr 2000 27,1 \% und im Jahr 2001 39,6 \%. Zusätzlich wurden in den Jahren 2000 bzw. 200140 bzw. 120 Larven für PCR- bzw. Mikrosporidienuntersuchungen entnommen. Von den im Frühjahr lebenden Larven verpuppten sich aber wiederum nur ein Teil bzw. die Lebensspanne reichte nicht für eine erfolgreiche Paarung, so dass im Jahr 2000 trotz der geringen Wintermortalität prozentual weniger Falter für die Zucht zur Verfügung standen als 2001. Das Geschlechterverhältnis lag in beiden Jahren bei $1: 1$ ( $\widehat{\jmath}:$ 우우).

Tab. 30: Reduktion der gesammelten Larven bis zur Bildung der Isolinien im Jahr 2000 und 2001

\begin{tabular}{|c|c|c|}
\hline & 2000 & 2001 \\
\hline & $\begin{array}{l}\text { Anzahl der Larven } \\
{[\mathrm{n}(\%)]}\end{array}$ & $\begin{array}{l}\text { Anzahl der Larven } \\
{[\mathrm{n}(\%)]}\end{array}$ \\
\hline Gesammelte Larven & $1232(100 \%)$ & $1083(100 \%)$ \\
\hline Im Frühjahr lebende Larven & $938(76 \%)$ & $654(60 \%)$ \\
\hline $\begin{array}{l}\text { Geschlüpfte Falter } \\
\mathrm{P}_{1} \text {-Generation }\end{array}$ & $398(32 \%)$ & $467(43 \%)$ \\
\hline Davon $\hat{0} \hat{0}$ & 201 & 223 \\
\hline Davon $+9+$ & 197 & 244 \\
\hline $\begin{array}{l}\text { Gepaarte Falter } \\
{\left[\mathrm{P}_{1} \text {-Isolinie }\right]}\end{array}$ & $\begin{array}{l}386(31 \%) \\
{[193]}\end{array}$ & $\begin{array}{l}466(43 \%) \\
{[233]}\end{array}$ \\
\hline
\end{tabular}


Tab. 31: Reduktion der Isolinien von der Elterngeneration $\left(\mathrm{P}_{1}\right)$ bis zur $\mathrm{F}_{2}$-Generation im Jahr 2000 und 2001

\begin{tabular}{lll} 
& $\mathbf{2 0 0 0}$ & $\mathbf{2 0 0 1}$ \\
\hline & Isolinie [n (\%)] & Isolinie [n (\%)] \\
\hline $\mathrm{P}_{1}$-Generation & $193(100 \%)$ & $233(100 \%)$ \\
\hline $\mathrm{F}_{1}$-Generation & $115(60 \%)$ & $128(55 \%)$ \\
\hline $\mathrm{F}_{2}$-Generation & $74(38 \%)$ & $126(53 \%)$
\end{tabular}

Die 115 Isolinien des Jahres 2000 führten in der $F_{1}$-Generation zum Schlüpfen von 791 $\partial^{\lambda} \partial^{\lambda}$ und 919 우, aus denen 686 Paare angesetzt wurden. Von den 115 Isolinien der $F_{1}$ Generation konnten Nachkommen von 74 Isolinien in der $\mathrm{F}_{2}$-Generation getestet werden. Auf Resistenz wurden in der $\mathrm{F}_{2}$-Generation 12.249 Larven getestet. Im Jahr 2001 wurden auf Grund der Erfahrung aus dem Jahr 2001, trotz einer geringeren Ausgangspopulation, 128 Isolinien angesetzt. Die Anzahl an $\mathrm{F}_{1}$-Falter konnte mit 1.703

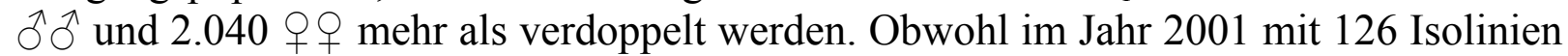
fast doppelt so viele Isolinien getestet wurden wie im Jahr 2000, konnte durch die Verwendung der Zwei-Zylinder-Methode die Anzahl an getesteten Larven in der $\mathrm{F}_{2}-$ Generation auf 11.821 reduziert werden, da die Zugehörigkeit der Larven zu einem Pärchen besser überprüfbar wurde. Jede Larve, die im Herbst gesammelt wurde, steht für ein Genom. Durch die Kreuzung werden mit einer Isolinie zwei Genome getestet. Wird die Isolinie auf die Larven, die im Herbst gesammelt wurden, bezogen, so konnte im Jahr 2000 das Genom von $12 \%$ und im Jahr 2001 das Genom von $23 \%$ der ursprünglich gesammelten Larven (Genome) getestet werden.

\subsubsection{Vorversuch zur Mortalität von Larven auf Bt-Maispflanzen}

Aus Beobachtungen in der Zucht und aus dem Freiland war bekannt, dass frisch geschlüpfte Maiszünslerlarven einen starken Drang zur Ausbreitung besitzen. So können sich $\mathrm{L}_{1}$-Larven durch das Abspinnen eines Seidenfadens auf benachbarte Pflanzen verwehen lassen. Daher wurde in einem Vorversuch geklärt, ob Larven, die auf Bt-Maispflanzen und auf Nicht-Bt-Maispflanzen gesetzt werden, auf diesen nach 7 Tagen wieder gefunden werden. Tägliche Beobachtungen bestätigten den Eindruck aus dem Freiland, dass frisch geschlüpfte Larven sich auf der Pflanze verteilen. Kurz nach der künstlichen Investierungen verließen die Larven die Investierungsstelle. Ein Teil der Larven seilte sich dabei über einen Seidenfaden auf den Boden ab. $\mathrm{L}_{2-3}$-Larven zeigten eine geringe Mobilität. Sie vermieden aber die Nähe ihrer Artgenossen. 
Tab. 32: Mortalität von $\mathrm{L}_{1}$ - und $\mathrm{L}_{2-3}$-Larven nach sieben Tagen auf Bt- und Nicht-BtMaispflanzen

\begin{tabular}{llllll} 
Pflanze & Larvenstadium & $\mathbf{N}$ & $\begin{array}{l}\text { Tote Larven } \\
(\mathbf{n} / \%)\end{array}$ & $\begin{array}{l}\text { Lebende } \\
\text { Larven } \\
(\mathbf{n} / \%)\end{array}$ & $\begin{array}{l}\text { Larven nicht } \\
\text { wiedergefunden } \\
(\mathbf{n} / \%)\end{array}$ \\
\hline $\mathrm{BT}$ & $\mathrm{L}_{1}$ & 40 & $32(80 \%)$ & $0(0 \%)$ & $8(20 \%)$ \\
\hline $\mathrm{Nicht}-\mathrm{Bt}$ & $\mathrm{L}_{1}$ & 40 & $10(25 \%)$ & $12(30 \%)$ & $18(45 \%)$ \\
\hline $\mathrm{BT}$ & $\mathrm{L}_{2-3}$ & 20 & $16(80 \%)$ & $0(0 \%)$ & $4(20 \%)$ \\
\hline Nicht-Bt & $\mathrm{L}_{2-3}$ & 20 & $6(30 \%)$ & $14(70 \%)$ & $0(0 \%)$ \\
\hline
\end{tabular}

Tab. 33: Aufenthaltsort der Larven nach sieben Tagen

\begin{tabular}{|c|c|c|c|c|c|c|}
\hline \multirow[t]{3}{*}{ Pflanze } & \multirow{3}{*}{\multicolumn{2}{|c|}{$\begin{array}{l}\text { Larven- N } \\
\text { stadium }\end{array}$}} & \multicolumn{2}{|c|}{$\begin{array}{l}\text { Auf bzw. in der } \\
\text { Pflanze }\end{array}$} & \multicolumn{2}{|c|}{$\begin{array}{c}\text { Nicht auf bzw. in der } \\
\text { Pflanze }\end{array}$} \\
\hline & & & Tote & Lebende & Tote & Lebende \\
\hline & & & $\begin{array}{l}\text { Larven } \\
(\mathrm{n} / \%)\end{array}$ & $\begin{array}{l}\text { Larven } \\
(\mathrm{n} / \%)\end{array}$ & $\begin{array}{l}\text { Larven } \\
(\mathrm{n} / \%)\end{array}$ & $\begin{array}{l}\text { Larven } \\
(\mathrm{n} / \%)\end{array}$ \\
\hline $\mathrm{BT}$ & $\mathrm{L}_{1}$ & 32 & $8(25 \%)$ & $0(0 \%)$ & $24(75 \%)$ & $0(0 \%)$ \\
\hline Nicht-Bt & $\mathrm{L}_{1}$ & 22 & $8(36 \%)$ & $8(36 \%)$ & $2(9 \%)$ & $4(18 \%)$ \\
\hline BT & $\mathrm{L}_{2-3}$ & 16 & $8(50 \%)$ & $0(0 \%)$ & $8(50 \%)$ & $0(0 \%)$ \\
\hline Nicht-Bt & $\mathrm{L}_{2-3}$ & 20 & $4(20 \%)$ & $10(50 \%)$ & $2(10 \%)$ & $4(20 \%)$ \\
\hline
\end{tabular}

Bei den Bt-Pflanzen konnte nach sieben Tagen bei keinem Larvenstadium überlebende Larven gefunden werden. $20 \%$ der Larven konnten aber weder tot noch lebendig wiedergefunden werden, da besonders tote $\mathrm{L}_{1}$-Larven bei der Auswertung in der Pflanzerde übersehen werden können. Bei den Nicht-Bt-Pflanzen lag die Mortalität bei den $\mathrm{L}_{1}$-Larven bei $36 \%$ und bei den $\mathrm{L}_{2-3}$-Larven bei $20 \%$. Werden zu den wiedergefunden toten Larven noch die nicht wiedergefundenen Larven gezählt, liegt die Mortalität bei $70 \%$. Bei den Versuchen mit Bt-Maispflanzen wurden $75 \%$ der toten $\mathrm{L}_{1}$ Larven und $50 \%$ der toten $\mathrm{L}_{2-3}$-Larven nicht auf den Maispflanzen wiedergefunden. Bei diesen Larven ist nicht auszuschließen, dass die Larven verhungert sind und nicht durch das Toxin gestorben sind.

\subsubsection{Mortalität bei den Blattversuchen und in den Nährmedium-Versuchen}

Aus Vorversuchen war bekannt, dass Maiszünslerlarven bei hoher Populationsdichte zum Kannibalismus neigen. Erst bei zwei Larven pro Dose konnte kein Kannibalismus mehr festgestellt werden, da die Larven genügend Platz zum Ausweichen hatten. Die Kontrollmortalität lag bei den Versuchen mit Blattstücken im Durchschnitt aller Versuche bei $25 \pm 1,9 \%(\mathrm{~N}=1.257$ Larven $)$, bei den Versuchen mit Nährmedium lag die Mortalität bei $15 \pm 1,1 \%(\mathrm{~N}=1.424$ Larven).

Die Kontrollmortalitäten wurden nicht für die einzelnen Isolinien berechnet und wurden auch für die einzelnen Versuche nur stichprobenartig erhoben. Daher erfolgte keine Korrektur nach Abbott (1925). Die Endauswertung der Versuche erfolgte aber erst nach 7 bzw. 21 Tagen, um Falsch-Positive-Entscheidungen auszuschließen. 


\subsubsection{Resistenzhäufigkeit}

Von den getesteten Larven überlebten im Jahr 2000 bei einer Isolinie vier Individuen, die ein geringeres Wachstum zeigten, so dass von einer fehlerhaften Toxin-Dosierung im Test ausgegangen werden konnte. Die Nachkommen dieser Isolinie wurden in der $\mathrm{F}_{4}$-Generation nochmals getestet und zeigten keine Resistenz. Damit wurde in keiner der 189 getesteten Isolinien ein Resistenzallel nachgewiesen, so dass ein Wert für die Resistenzhäufigkeit nicht berechnet werden konnte. Aus diesem Grund wurde das Clopper-Pearson-Intervall mit einem $\alpha$ von $5 \%$ berechnet (Anhang 9.2).

Tab. 34: Anzahl der Isolinien und die Entdeckungswahrscheinlichkeit $\left(\mathrm{P}_{\text {no }}\right)$, berechnet anhand der getesteten $\mathrm{F}_{2}$-Larven und Paare der $\mathrm{F}_{1}$-Generation

\begin{tabular}{lll} 
& $\mathbf{2 0 0 0}$ & $\mathbf{2 0 0 1}$ \\
\hline $\mathrm{P}_{\text {no }}$ & $\begin{array}{c}\text { Anzahl der Isolinien } \\
{[\mathrm{n}(\%)]}\end{array}$ & $\begin{array}{c}\text { Anzahl der Isolinien } \\
{[\mathrm{n}(\%)]}\end{array}$ \\
\hline$<10 \%$ & $46(62 \%)$ & $94(75 \%)$ \\
\hline $10-20 \%$ & $15(20 \%)$ & $8(6 \%)$ \\
\hline$>20 \%$ & $13(17 \%)$ & $24(19 \%)$
\end{tabular}

Bereits im Jahr 2000 erwies es sich als schwierig, die von Andow und Alstad verlangte

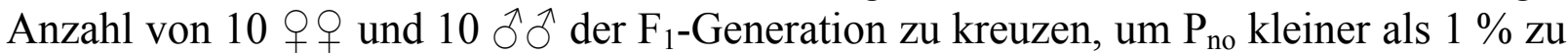
erhalten. Durch die Statistik von Professor Piepho wurde für jede Isolinie ein eigenes $\mathrm{P}_{\text {no }}$ berechnet. Die Isolinien wurden bei der Gesamtberechnung der Resistenzhäufigkeit entsprechend gewichtet.

Tab. 35: Clopper-Pearson der Resistenzallelfrequenz in Niedernberg 2000 und 2001

\begin{tabular}{llll} 
& $\mathbf{2 0 0 0}$ & $\mathbf{2 0 0 1}$ & Gesamt \\
\hline Isolinie getestet & 73 & 126 & 199 \\
\hline Larven & 12.249 & 11.821 & 24.070 \\
\hline $\begin{array}{l}\text { Clopper-Pearson Intervall } \\
\text { der Resistenzallelfrequenz, }\end{array}$ & $0-0,011171$ & $0-0,006416$ & $0-0,0041974$ \\
$\alpha=5 \%$. & & \\
& & & \\
& &
\end{tabular}

Die Stichproben sind im Vergleich zur Gesamtpopulation als sehr klein anzusehen, d. h. es ist äußerst unwahrscheinlich, dass Nachkommen von Geschwistern der 1999 gesammelten Larven in der Stichprobe von 2000 auftauchen. Da außerdem die Häufigkeit der Resistenzallele für die zwei Jahre als konstant anzusehen ist, können die Werte von 2000 und 2001 zur Berechnung des Clopper-Pearson-Gesamtintervall addiert werden. Die Frequenz der Resistenzallele (q) liegt mit einer Sicherheit von $95 \%$ somit zwischen 0 und 0,0041974. Zu beachten ist, dass das Intervall 0,001 mit einschließt. Es kann also anhand dieser Stichprobe nicht ausgeschlossen werden, dass die Resistenzfrequenz über $10^{-3}$ liegt. 


\subsection{Diskussion}

Für die Durchführung und Planung des Resistenzmanagements ist die Kenntnis der initialen Resistenzallelfrequenz in einer Population von großer Bedeutung (Roush und Miller, 1986; Andow und Hutchison, 1998; Andow und Alstad, 1998; Venette et al., 2002). Verschiedene Methoden zur Bestimmung der Resistenzallelfrequenz wurden vorgeschlagen (Kapitel 3.8). Gould et al. (1997) erweiterten den diskriminierenden Konzentrationstest in dem sie die natürliche Population von Heliothis virescens mit einem resistenten Laborstamm kreuzten. Ein weiterer Ansatz ist der in diesem Kapitel beschriebene Ansatz von Andow und Alstad von 1998. Einen dritten Ansatz, der auf ein Monitoring resistenter Larven auf Bt-Maisflächen beruht, schlugen Venette et al. (2000) vor (Kapitel 3.8). Für Deutschland lagen bisher keine Informationen über die initiale Resistenzhäufigkeit bei Ostrinia nubilalis gegenüber dem Cry1Ab vor. Eine Übertragung der Daten aus Amerika ist nicht möglich, da sich in Deutschland die Anbaustruktur im Vergleich zu der in den USA stark unterscheidet. So liegt in den USA 1997 die durchschnittliche Farmgröße bei 200 ha (Economic Research Service U.S. Department of Agriculture, 1997). In Deutschland lag die durchschnittliche Betriebsgröße bei 38 ha. In den neuen Bundesländern lag die durchschnittliche Flächengröße bei 184 ha (Statistisches Bundesamt, 2003). In Europa, als Ursprungsgebiet des Maiszünslers, ist mit einer größeren genetischen Variabilität zu rechnen und damit auch mit einer anderen Resistenzfrequenz (Flacke, 1982; Marçon et al., 1999a). Im Folgenden soll die Methode des $\mathrm{F}_{2}$-Screening kritisch beleuchtet werden. Besonders werden die durchgeführten Methoden im Vergleich zu den Untersuchungen von Andow und Alstad von 1998 und 2000 diskutiert.

\subsubsection{Effizienz des $\mathrm{F}_{2}$-Screenings}

\subsubsection{Sammelstrategie}

Die Sammlung der Maiszünsler für das $\mathrm{F}_{2}$-Screening erfolgte im Gegensatz zu Andow et al. (1998a) nicht mit Hilfe von Lichtfallen, sondern im Herbst wurden auf zehn verschiedenen Feldern kurz vor der Ernte ca. 100 Maiszünslerlarven pro Feld gesammelt. Lichtfallen haben den Vorteil, dass diese durch ihre Fernwirkung innerhalb von wenigen Tagen bis Wochen eine große Anzahl an Maiszünslern bei einem geringen Personaleinsatz fangen. Während der Fangperiode 2000 und 2001 schwankte die Gesamtzahl der Falter zwischen 500 und 1.000 Individuen. Das Geschlechterverhältnis lag bei ca. 1:2 [ठぇ: 우이 und die maximale Anzahl der Falter pro Pentade lag bei 120. Andow et al. (2000) geben an, dass ca. $31 \%$ der Weibchen, die durch eine Lichtfalle gefangen wurden, keine Eier ablegen. Eine im Jahr 1999 verwendete Lichtfalle erbrachte einen ähnlichen Wert von $23 \%$ Weibchen ohne Eibablage. Pro Lichtfalle hätten also in den Jahren 2000 - 2001 ca. 200 - 460 Isolinien maximal angesetzt werden können. Werden die durch den Transport und die Lagerung getöteten Falter berücksichtigt und die Tatsache, dass nicht während der gesamten Flugperiode Isolinien angesetzt werden können, so ergibt sich ein realistischer Wert von ca. 50 - 100 Isolinien pro Lichtfalle und Flugperiode. Um eine möglichst repräsentative Stichprobe zu erhalten, müssten an einem Standort ca. 3 - 4 Lichtfallen aufgestellt und betreut werden. Im Jahr 1999 konnten in einem Vorversuch mit einer Lichtfalle 65 Isolinien 
angesetzt werden. Ein Nachteil der Lichtfalle liegt darin, dass in Gebieten in denen die Z-Rasse und die E-Rasse gemeinsam vorkommen mit der Lichtfalle auch Weibchen der E-Rasse gefangen werden. Hybriden von E- und Z-Rasse sind zwar bekannt (Peña et al., 1988), es ist aber nicht bekannt inwieweit die Hybride stabile Populationen aufbauen und somit als Refugium im Rahmen eines Resistenzmanagements eingesetzt werden kann, so dass es nicht sinnvoll wäre die Initialfrequenz einer Mischpopulation zu ermitteln. Mehrere Autoren sind der Ansicht, dass die E-Rasse bzw. alternative Wirtspflanzen nicht als Refugium verwendet werden können (Bourguet et al., 2000a; Alstad und Andow, 1995; Gould, 1998). Es ist anzumerken, dass die E-Rasse ihren Flughöhepunkt ca. 18 Tage vor der Z-Rasse hat (Lorenz, 1993), und dass die Populationsdichte der Z-Rasse in einem Maisanbaugebiet der Populationsdicht der ERasse um ein Vielfaches übersteigt. Durch die richtige Wahl des Standortes der Lichtfalle und durch die Beschränkung auf Fänge ab dem Zeitpunkt des Flughöhepunktes können somit die Beifänge der E-Rasse vermindert werden.

Das Sammeln der Maiszünsler im Herbst ist zeitlich aufwändiger als das Fangen mit Lichtfallen. Es hatte aber den Vorteil, dass es in einem Zeitraum lag, in der der Arbeitsaufwand in den Zuchten heruntergefahren werden konnte und so freiwerdende Mitarbeiter beim Sammeln eingesetzt werden konnten. Die Überwinterung der Larven verursacht keinen weiteren Bedarf an Arbeitszeit. Durch die Vereinzelung der Larven bzw. frisch geschlüpfte Falter nach der Überwinterung im Labor kann die Monogamie der $\mathrm{P}_{1}$-Weibchen, die eine Voraussetzung für die Statistik ist, gewährleistet werden. Bei Bedarf lässt sich auch der Schlupfzeitpunkt der $\mathrm{P}_{1}$-Falter steuern. Es muss beachtet werden, dass durch die hohe Wintermortalität und durch Paare die im Labor keine Eier legen (Tab. 30 und Tab. 31) die Anzahl angesetzter Isolinien nur einem Viertel der Anzahl der gesammelten Larven entspricht, d. h. für 750 Isolinien müssen ca. 3.000 Larven im Herbst gesammelt werden. Das Gebiet Niedernberg umfasst eine Fläche von ca. $15 \mathrm{~km}^{2}$. In diesem Gebiet ist ein genetischer Austausch von Maiszünslern möglich, so dass trotz der Möglichkeit zur Bildung von Subpopulationen von einer homogenen Population in Bezug auf die Resistenzallele auszugehen ist. Durch das Sammeln von Maiszünslern auf zehn Feldern à 100 Larven wird im Vergleich zur Lichtfalle ein ähnlicher bzw. sogar höherer Abdeckungsgrad in der Fläche erreicht. Beide Sammelstrategien können als gleichwertig angesehen werden und stellen eine zufällige Stichprobennahme aus einem Untersuchungsgebiet dar. Die Bevorzugung einer Strategie hängt von den lokalen Gegebenheiten ab, wie z. B. der Entfernung zum Sammelgebiet, dem Befallsgrad, dem Anteil der E-Rassenpopulation, den Synergien mit anderen Forschungsprojekten und der Auslastung der Mitarbeiter.

\subsubsection{Zucht}

Jede Larve, die im Herbst gesammelt wurde, steht für ein Genom (= ein diploider Chromosomensatz). In der $\mathrm{F}_{2}$-Generation werden 2 Genome, je einer von Vater und Mutter, getestet, d. h. 4 haploide Chromosomensätze. Von den ursprünglich 2.315 Genomen bzw. 2.155 (abzüglich 160 Larven, die für weitere Untersuchungen entnommen wurden), die 2000 und 2001 gesammelt wurden, sind $18 \%$ auf das Vorhandensein eines Resistenzallels getestet worden. An mehreren Stellen des Zuchtverlaufes werden die Zahlen der ursprünglich vorhandenen Chromosomensätze verringert. Die Effektivität des $\mathrm{F}_{2}$-Screenings nimmt durch die starke Reduktion der 
Isolinien während der Zucht ab. Daher werden im Folgenden die Abschnitte des Zuchtverlaufes diskutiert, die zu einer Reduktion der Isolinien führen.

\subsection{Wintermortalität}

Die Wintermortalität mit 27,1 \% bzw. 39,6 \% hatte den größten Einfluss auf die Reduktion der Larven und damit auf die zu testenden Chromosomensätze. Die Wintermortalität, wird sie mit den Populationen Hessisches Ried und Pocking (4.2) verglichen, liegt im erwarteten Rahmen. Die Wintermortalität dieser Populationen, die unter gleichen Bedingungen überwintert wurden, betrug 1999 bis 2002 minimal $22 \%$ bis maximal $42 \%$ (4.2.1). Lorenz (1993) stellte für Maiszünsler, die in Stängeln unter ähnlichen Bedingungen überwinterten, eine Mortalität von $55 \%$ fest. Die Wintermortalität der Maiszünslerlarven ist von verschiedenen Faktoren abhängig, so z. B. von dem Temperatur- und Niederschlagsverlauf während der Diapause, von der Parasitierung der Larven bzw. von den eingeschleppten Krankheiten und der allgemeinen Fitness der gesammelten Larven.

\section{Temperatur und Luftfeuchtigkeit}

In den vorliegenden Versuchen wurden die Maiszünsler weitgehend den natürlichen Temperaturen ausgesetzt. Es erfolgte lediglich ein Schutz gegen Niederschlag und Räuber. Maiszünsler gelten während der Diapause als sehr widerstandsfähig gegenüber tiefen Temperaturen (Lorenz, 1993). Die Temperaturverläufe im Jahr 2000 und 2001 unterschieden sich beträchtlich. Der Winter im Jahr 2000 war relativ mild. Zum Frühjahr stieg die Durchschnittstemperatur aber nur langsam ohne größere Temperatursprünge an. Das Jahr 2001 war im Januar und Februar durch einen schnellen Wechsel von Phasen mit tiefen Temperaturen und für die Jahreszeit ungewöhnlich hohen Temperaturen gekennzeichnet. Leichtere Larven, die einen geringeren DD9 bis zum Schlupf benötigen, sind im Jahr 2001 wahrscheinlich durch den Temperaturwechsel frühzeitig aus der Diapause erwacht und haben dadurch Energiereserven schneller verbraucht, was zu einer erhöhten Mortalität führte. Dies würde den starken Anstieg der Schlupfrate erst in der 6. Juni-Pentade erklären. Im Jahr 2000 überwinterten die Larven in Stoppeln. Aus hygienischen Gründen wurde den Larven 2001 nur Handtuchpapier zur Überwinterung angeboten. Stoppeln können aber wahrscheinlich ungünstige Temperaturverhältnisse besser abpuffern als Handtuchpapier, so dass dies ein weiterer Grund für die geringere Mortalität im Jahr 2000 sein kann. Die Alternative bei der Überwinterung der Maiszünsler wäre gewesen, die Larven bei konstanten Temperaturen im Klimaschrank überwintern zu lassen. Aus der Literatur (Beck und Hanec, 1960; Lynch et al. 1972; Lavialle, 1988) ist bekannt, dass das Schlupfverhalten der Maiszünsler von einem genauen Zusammenspiel von Temperatur, Licht und Feuchtigkeit abhängig ist. Durch die künstliche Einstellung dieser Parameter kann der Einfluss von ungünstigen Temperaturverläufen minimiert werden, wobei die Gefahr einer Selektion von Faltern, die sich an diese speziellen Bedingungen anpassen, besteht, was für die Untersuchungen der natürlichen Resistenzhäufigkeit verhindert werden sollte. 


\section{Parasitierung, Krankheiten und Fitness der Larven}

Die Parasitierung von Maiszünslerlarven wurde nicht separat ermittelt, da diese bei den Larven aus dem Freiland auch nicht beeinflusst werden kann. Maiszünslerlarven werden auch durch die Mikrosporidie Nosema pyrausta befallen. Durch die Untersuchung der Isolinien können befallene Linien frühzeitig aus der Zucht entfernt werden und so eine Ausbreitung verhindert werden. Nosema pyrausta kann bei einem Massenauftreten die Empfindlichkeit der Maiszünsler gegenüber dem Bt-Toxin vermindern (4.2.4.3). Regelmäßige Untersuchungen zeigten, dass die Larven aus Niedernberg nicht mit Nosema pyrausta infiziert waren. Die Infektion mit bakteriellen Krankheiten führt bei einer Massenhaltung immer wieder zu Problemen. Durch die Verwendung von Plastikboxen und Handtuchpapier als Versteckmöglichkeit, das eine regelmäßige Kontrolle der Überwinterungsgefäße sowie die Reinigung der Gefäße erleichterte, wurde der starken Ausbreitung von bakteriellen Infektion entgegengewirkt. Im Herbst 2000 hatten die in Niedernberg gesammelten Larven ein durchschnittliches Gewicht von $101 \mathrm{mg} \pm 20 \mathrm{mg}$, was als typisch für Larven vor der Diapause angesehen werden kann (Lorenz, 1993). Dies deutet darauf hin, dass die Larven sich auf die Diapause eingestellt hatten und eine normale Fitness besaßen.

\subsection{Paarung der $\mathrm{P}_{1}$-Generation}

Die Paarung der Maiszünsler wurde weitgehend unter natürlichen Licht- und Temperaturverhältnissen durchgeführt. Das hatte den Vorteil, dass das sensible Zusammenspiel von Temperatur und Licht, das bei Maiszünslern das Paarungsverhalten auslöst, nicht aufwändig simuliert werden musste. Im Gegensatz zu den Laborzuchten, die über Jahre auf Laborbedingungen selektiert wurden, reagieren die Zuchten aus dem Freiland meist mit einer verminderten Fertilität, wenn die Zuchtbedingungen nicht optimal sind. Die Verwendung von Plexiglaszylindern (4.2.4.1), die auf Gittern über Wasserschalen standen und mit Folie abgeschlossen waren, ermöglichte es, eine hohe Luftfeuchtigkeit in den Zuchtgefäßen $(80-90 \%$ ) zu erreichen, um so optimale Fortpflanzungbedingungen zu schaffen. Die Falter lebten im Durchschnitt zwischen 7 und 21 Tagen. Ähnliche Werte zur Lebensdauer von Weibchen im Labor (12 bis 17 Tage) erzielten Fadamiro und Baker (1999). Durch Synchronisation des Falterschlupfs ließe sich der Ansatz von Isolinie noch erhöhen. Lorenz (1993) gibt an, dass schwere Postdiapause-Larven eine höhere Temperatursumme als leichtere Larven benötigen. Er schränkt aber ein, dass die Streuung innerhalb einer Gewichtsklasse beträchtlich ist. Für die Synchronisation wären somit genauere Untersuchungen zum Einfluss der Temperatur und des Gewichtes auf das Schlupfverhalten notwendig, um die große Variabilität der Larven aus dem Freiland zu reduzieren, ohne unfreiwillig besondere phänotypische Eigenschaften in der Zucht zu selektieren und damit evtl. Resistenzallelträger zu entfernen.

\subsection{Zucht der Larven der $\mathrm{F}_{1}$-Generation}

Bei den Zuchten der $\mathrm{F}_{1}$-Generation wurde von den weitgehend natürlichen Bedingungen auf künstliche Laborbedingungen umgestellt. Dadurch konnte die Zucht beschleunigt werden. Um eine ungewollte Selektion zu verhindern, wurden alle Eigelege eines $\mathrm{P}_{1^{-}}$ Paares weitergezüchtet. Die Mortalität der Larven während der $\mathrm{F}_{1}$-Generation wurde nicht separat erhoben. Sie schwankte zwischen den einzelnen Isolinien beträchtlich. 
Besonders während des $\mathrm{L}_{1}$-Stadiums sank die Larvenanzahl erheblich. Dies ist auf die besondere Empfindlichkeit der $\mathrm{L}_{1}$-Larven gegenüber Temperaturschwankungen und Trockenheit zurückzuführen. Außerdem nahm nur ein Teil der Larven das künstliche Medium an und der Drang der Larven sich zu verteilen führte dazu, dass einige Larven im Papier, das die Petrischalen abschloss und zur Luftfeuchtigkeitsregulation diente, verhungerten. Eine Reduktion der Larvenzahl durch Kannibalismus konnte beobachtet werden. Andow und Alstad (1998) berichteten davon, dass sie eine Vielzahl von Isolinien durch Verpilzung des Mediums verloren haben und schlugen die Zugabe von Konservierungsmitteln in das Nährmedium vor. Trotz der Zugabe von Konservierungsstoffen kam es zu Beginn der Versuche im Jahr 2000 zur Verpilzungen von Zuchtmaterial. Durch eine wöchentliche Kontrolle der Zuchtgefäße konnte die Verpilzung gestoppt werden, so dass keine Isolinie durch Verpilzung verloren gegangen ist. Die aufwändige Betreuung der $\mathrm{F}_{1}$-Larven erhöht allerdings wesentlich die Kosten der Zucht. Die Zucht der $\mathrm{F}_{1}$-Larven birgt damit ein großes Einsparpotential, wenn es gelingt die Zuchtbedingungen zu optimieren.

\subsubsection{Statistische Analyse}

In der vorliegenden Arbeit wurde für die Berechnung der initialen Resistenzfrequenz von Prof. Piepho abweichend von dem Baye'schen Ansatz von Andow und Alstad (1998) mit einem Frequentistischen Ansatz gerechnet. Der Vorteil des Baye'schen Ansatz ist, dass eine direkte Aussage über die Stichprobenpopulation gemacht wird, wobei eine Annahme einer Prior-Verteilung gemacht werden muss. Der Frequentistische Ansatz eine Aussage über die Wahrscheinlichkeitsverteilung der Resistenzfrequenz unter der Annahme der Wiederholung der Untersuchung bei ähnlichen Populationen macht (Andow und Alstad, 1998; Gould et al., 1997; Robert, 1994; Wilrich, 2001). Einerseits soll zwar eine Aussage über die Stichprobe, d. h. die Population Niedernberg, gemacht werden, andererseits ist die Stichprobe nur eine Möglichkeit der Charakterisierung der Population Niedernberg unter unendlich vielen ähnlichen Stichproben, so dass je nach Sichtweise beide Ansätze gewählt werden können. Andow und Alstad (1998) verwenden einerseits eine nicht-informative a-prioriVerteilung, nehmen aber gleichzeitig bei der Entwicklung ihrer Methode implizit an, dass q nahe Null ist. Diese Annahmen widersprechen sich diametral. Bei dem hier gewählten Frequentistischen Ansatz wird auch die Resistenzfrequenz nahe Null angenommen, ohne aber eine weitere widersprechende Annahme treffen zu müssen.

Die hier verwendete Statistik wurde nach der Durchführung des $F_{2}$-Sreenings basierend auf der Erfahrung der Zucht der Maiszünsler in den Jahren 2001 und 2002 entwickelt. Sie ermöglicht es, dass jede Iso-Familie, gewichtet nach dem Informationsgehalt, in die Berechnung eingeht. Wohingegen bei Andow und Alstad die Berechnung der Entdeckungswahrscheinlichkeit zu einer Durchführungsvorschrift bei den Zuchten führt. Die sich daraus ergebenden Unterschiede werden in den folgenden Kapiteln diskutiert.

\subsection{Diskriminierende Dosis}

Die Wahl der diskriminierenden Dosis spielt bei der Unterscheidung von resistenten und nicht-resistenten Isolinien und damit für die Genauigkeit des $\mathrm{F}_{2}$-Screenings eine wichtige Rolle. Resistente und sensible Insekten sollten theoretisch eine parallele DosisWirkungskurve zeigen (ffrench-Constant und Roush, 1990). Überschneiden sich die 
Dosis-Wirkungskurven nicht, kann als diskriminierende Dosis der $\mathrm{LC}_{99}$ der sensiblen Population gewählt werden. Überschneiden sich die Dosis-Wirkungskurven, ist es schwierig eine eindeutig diskriminierende Dosis zu finden. Wird sie zu niedrig gewählt, überleben auch einige wenige sensible Insekten (Falsch-Positiv-Entscheidung); wird sie zu hoch gewählt, stirbt ein Teil der resistenten Larven (Falsch-Negativ-Entscheidung). $\mathrm{Zu}$ Beginn des $\mathrm{F}_{2}$-Screenings liegen meist noch keine resistenten Stämme und damit keine Daten über die Dosis-Wirkungskurve vor. Daher ist die Wahl der diskriminierenden Dosis eine meist "willkürliche" Entscheidung und richtet sich nach dem $\mathrm{LC}_{99}$ eines sensiblen Stammes bzw. der Konzentration in den transgenen Maispflanzen, die in der Praxis von den Larven überwunden werden muss.

Während der zwei Jahre wurde die Methode der Toxinverabreichung und die diskriminierende Dosis hauptsächlich aus praktischen Erwägungen verändert. Zunächst wurde mit Blattmaterial gearbeitet, das eine 20 fach höhere Konzentration als der $\mathrm{LC}_{99}$ eines sensiblen Stamms hatte, um möglichst nahe an den praxisrelevanten Bedingungen zu bleiben. Die Methode hatte durch die Verpilzung bzw. die Austrocknung von Blattstücken und durch das Einbohren von Larven in den Wasser-Agar eine erhöhte Kontrollmortalität zur Folge (5.3.4) und durch das Wechseln der Blattstücke alle zwei bis drei Tage den Nachteil eines sehr hohen Arbeitaufwandes. Deshalb wurde auf eine Oberflächenapplikation umgestellt und die Toxin-Konzentration so gewählt, dass sie der $\mathrm{LC}_{99}$ nach sieben Tagen für sensible Larven entsprach. Unterstützt wird die Reduzierung der Toxinkonzentration durch Untersuchungen von Zhao et al. (2002), die das $\mathrm{F}_{2}$-Screening für einen Plutella xylostella Stamm mit einer bekannten Resistenzfrequenz durchgeführt haben und feststellten, dass sehr hohe Toxinkonzentrationen bzw. die Verwendung von transgenen Pflanzen im Biotest zu einem hohen Prozentsatz an Falsch-Negativ-Entscheidungen führen (5.4.2.1.3).

\subsection{Falsch-Positiv-Entscheidung}

Eine Falsch-Positiv-Entscheidung tritt dann auf, wenn eine sensible Linie als resistent in der $\mathrm{F}_{2}$-Generation eingestuft wird. Wie Andow (1998) erwähnt, ist dies im engeren Sinn kein statistisches Problem, sondern beruht auf der Methodik des diskriminierenden Dosistests. Niedrige Dosen können zu einer hohen Anzahl von Falsch-PositivEntscheidungen führen (Zhao et al., 2002). Um die Gefahr einer Falsch-PositivEntscheidung zu reduzieren, wurden die Larven aber nicht wie üblich nur 7 Tage dem Toxin ausgesetzt, sondern über 21 Tage, wobei das Toxinmedium nach 7 bzw. 14 Tagen gewechselt wurde. Eine Isolinie, die eine überlebende Larve in der $\mathrm{F}_{2}$-Generation hatte, wurde nochmals in der $\mathrm{F}_{4}$-Generation getestet, so dass eine Falsch-Positiv-Entscheidung ausgeschlossen werden kann. In Vorversuchen stellte sich heraus, dass besonders der Kannibalismus unter den Larven zu Falsch-Positiv-Entscheidungen nach 7 Tagen führen kann. Die Larven fraßen ihren Partner, aber kein Bt-haltiges Medium. Deshalb wurden nur zwei Larven pro Dose eingesetzt, da hier nur sehr selten Kannibalismus bemerkt wurde. 


\subsection{Falsch-Negativ-Entscheidung}

Eine Falsch-Negativ-Entscheidung wird getroffen, wenn eine resistente Isolinie nicht als resistent bei der Testung in der $\mathrm{F}_{2}$-Generation erkannt wird.

Mehrere Schritte während der Zucht können zu einer Falsch-Negativ-Entscheidung führen:

1. Vererbung der Resistenzallele von der $\mathrm{P}_{1}$-Generation auf die $\mathrm{F}_{1}$-Generation.

2. Vererbung der Resistenzallele von der $\mathrm{F}_{1}$-Generation auf die $\mathrm{F}_{2}$-Generation.

3. Keine $\mathrm{F}_{2}$-Larve überlebt den Biotest.

\section{Vererbung der Resistenzallele von der $\mathbf{P}_{\mathbf{1}}$-Generation auf die $\mathbf{F}_{\mathbf{1}}$-Generation}

Während der Meiose werden die Chromosomen normalerweise zufällig auf die Spermien bzw. auf die Eizellen verteilt. Die Verteilung folgt einer Binomialverteilung und wurde in den Berechnungen unter Punkt 4 (i) berücksichtigt (siehe Anhang 9.2.2).

\section{Vererbung der Resistenzallele von der $F_{1}$-Generation auf die $F_{2}$-Generation}

Die Vererbung der Resistenz hängt von der Anzahl der heterozygoten Weibchen und Männchen in der $F_{1}$-Generation und der Anzahl von Kreuzungen ab. Die Paarung der $\mathrm{F}_{1}$-Falter kann nicht als Einzelpaarung durchgeführt werden, denn dadurch würde der Arbeits- und Platzbedarf um das Zehnfache gesteigert. Über die genaue Anzahl an Paarungen der Falter in der $\mathrm{F}_{1}$-Generation können somit nur Annahmen getroffen werden. Aus dem Versuch zum Paarungsverhalten (5.3.2.3) ist bekannt, dass die Männchen sich in diesem Versuch im Durchschnitt 2,6 Mal gepaart haben und das Maximum bei 5 Kopulationen lag. Die Ergebnisse unterschätzen aber die Häufigkeit der Paarung der Männchen, da das mehrmalige Paaren mit einem Weibchen nicht mit aufgenommen wurde und da neue Paarungen erst nach Ablage der Eier stattfinden konnten. Bei der $\mathrm{F}_{1}$-Kreuzung stehen den Männchen, allerdings in Konkurrenz mit anderen Männchen, gleichzeitig mehrere Weibchen zur Paarung zur Verfügung. Deshalb wurde für die Statistik angenommen, dass ein Männchen mit jedem Weibchen kopulieren kann und somit von den Weibchen eine Zufallsauswahl unter allen Männchen getroffen wird. Von den Weibchen ist nach Untersuchungen von Fadamiro und Baker (1999) bekannt, dass Weibchen bis zu drei Spermatophoren aufnehmen können, aber $78 \%$ der Weibchen nur ein Mal kopulieren. Aus diesen beiden Annahmen kann für die Paarungen in der $\mathrm{F}_{1}$-Generation eine Binomialverteilung angenommen werden. Die Menge der Nachkommen pro Weibchen kann zum Teil beträchtlich schwanken. Es ist aber bei der $F_{1}$-Kreuzung nicht möglich die Eigelege einzelnen Weibchen zu zuordnen, da hierfür eine Einzelpaarzucht notwendig wäre. Durch die Verwendung des Zwei-Zylinder-Systems kann aber dieser Fehler minimiert werden. Dabei werden die Paare zufällig in Gruppen von ein bis vier Paaren aufgeteilt, so dass die abgelegten Eier einer geringeren Anzahl an Paaren zu zuordnen sind. Die Eier bzw. die Nachkommen der Gruppen wurden anteilig der Zahl der Paare an der Gesamtzahl der Paare in der $\mathrm{F}_{1}$-Generation getestet. Daher wird zur Vereinfachung der Statistik angenommen, dass die Nachkommen sich gleichmäßig auf die Weibchen verteilen. Für die Paarungswahrscheinlichkeit in der $\mathrm{F}_{1}$-Generation lässt sich somit eine hypergeometrische Verteilung berechnen. 


\section{Keine $\mathbf{F}_{2}$-Larve überlebt den Biotest}

Wie in Kapitel 5.4.2.1.1 schon erwähnt, führen zu hoch gewählte Toxinkonzentrationen im Biotest zu einer Erhöhung der Falsch-Negativ-Entscheidungen (Zhao et al., 2002). Ein weiterer Punkt, der zu einer Falsch-Negativ-Entscheidung im Biotest führt, ist die natürliche Mortalität, die mit Hilfe der Kontrollgruppe erfasst wird. Bei den ersten Versuchen im Jahr 2000 lag die Kontrollmortalität bei den Blattversuchen (über alle Versuche berechnet) bei $22 \%$ und bei den Nährmediumversuchen bei $15 \%$, was einen Grund für den Wechsel der Methode darstellte. Die Nachkommen der $\mathrm{F}_{2}$-Generation wurden in der zeitlichen Abfolge ihres Schlupfes getestet. Dadurch wurden pro Versuch unterschiedliche Anzahlen an Larven getestet. Die Kontrollgruppe schwankte daher für die einzelnen Versuche beträchtlich. Deshalb war es nicht möglich, für die einzelnen Versuche bzw. Paare die Mortalität nach Abbott (1925) zu korrigieren. Da nur eine beschränkte Anzahl an Larven zur Verfügung steht, würde eine konstante Kontrollgruppe pro Isolinie und $\mathrm{F}_{1}-\mathrm{Paar}$ dazu führen, dass zum Teil weniger Larven auf Toxin getestet würden, was wiederum zu einer Erhöhung der Falsch-NegativEntscheidung führen könnte. Die Kontrollgruppe konnte daher nur dazu dienen Totalausfälle im Biotest zu erkennen und eine Schätzung über die Kontrollmortalität aller Versuche zu geben. Da meist mehr als 100 Larven pro Isolinie getestet wurden, ist es unwahrscheinlich, dass keine resistente Larve den Biotest überlebt hätte. Die angegebene Resistenzhäufigkeit wird aber durch die fehlende Korrektur der Kontrollmortalität $\mathrm{zu}$ günstig geschätzt. Für weitere Untersuchungen ist darauf zu achten, dass die Kontrollmortalität weiter reduziert wird bzw. die Anzahl zu testender Larven pro Isolinie entsprechend erhöht wird.

\subsubsection{Berechnung der Resistenzhäufigkeit}

Jede Isolinie hat je nach Anzahl der Paarung und Nachkommen in der $\mathrm{F}_{1}$-Generation eine Wahrscheinlichkeit, mit der ein resistentes Allel entdeckt wird.

Durch das Aufsummieren der verschiedenen bedingten Wahrscheinlichkeiten lässt sich für jede Isolinie, unter der Annahme eines Resistenzallels in der $\mathrm{P}_{1}$-Generation, die Wahrscheinlichkeit $P_{\text {no }}$ (bei dieser Isolinie keine resistente Larve in $F_{2}$ zu entdecken) bzw. die Entdeckungswahrscheinlichkeit (1-P $\left.\mathrm{P}_{\text {no }}\right)$ in die Berechnungen mit einbeziehen. Im Jahr 2000 und 2001 lag die Wahrscheinlichkeit ein Resistenzallel zu entdecken $\left(\mathrm{P}_{\text {no }}\right)$ bei $62 \%$ bzw. $75 \%$ der Isolinien bei mehr als $90 \%$ und bei $33 \%$ bzw. $25 \%$ der Isolinien lag die Entdeckungswahrscheinlichkeit unter $90 \%$. Für die Gesamtberechnung der Resistenzallelfrequenz geht jede Isolinie mit der tatsächlichen Entdeckungswahrscheinlichkeit in die Berechnung mit ein. Andow und Alstad (1998) gehen bei der Berechnung der Resistenzhäufigkeit einen anderen Weg. Sie nehmen an, dass eine Entdeckungswahrscheinlichkeit von $99 \%$ für jede Isolinie erreicht wird. Sie weisen in ihren Berechnungen nach, dass bei 10 Nachkommen von $10{ }^{\widehat{\lambda}} \delta^{\lambda}$ und 10 우우 der $F_{1}$-Generation einer Isolinie $P_{n o}$ unter $1 \%$ liegt. In den hier dargestellten Versuchen zeigte sich, dass es nicht möglich war, die Larven einer Isolinie so zu synchronisieren, dass das Schlüpfen von 10 Paaren an einem Tag erreicht wurde. Das zunächst getrennte Sammeln von Männchen und Weibchen hatte den Nachteil, dass die Falter frühzeitig starben bevor sie zur Paarung zusammengesetzt wurden. Untersuchungen von Fadamiro und Baker (1999) zeigten außerdem, dass Weibchen, die erst nach mehr als drei Tagen nach dem Schlupf kopulieren konnten, eine geringere Fertilität aufweisen. Wurde den 
Weibchen die Kopulation erst nach sieben Tagen ermöglicht, sank die Fertilität auf Null. Werden nun Falter zunächst einzeln nach Geschlecht getrennt gesammelt und beim Erreichen von 10 Paaren zusammengesetzt, so sollten jüngere Weibchen stärker an der Eiproduktion beteiligt sein als ältere, was aber dem Ansatz der Gleichverteilung der Eigelege unter den $F_{1}$-Paaren widerspricht. Durch die Zwei-Zylinder-Methode ist es nun möglich jedem geschlüpften Weibchen sofort eine Paarung zu ermöglichen, sobald ein Männchen zur Verfügung steht. Außerdem wird die Gefahr verringert, dass nur einzelne Weibchen in einer Gruppe von 10 Paaren die Haupteiproduktion leisten und die getesteten Nachkommen in der $\mathrm{F}_{2}$-Generation tatsächlich nur von zwei oder drei Paaren abstammen.

Die Entscheidung ob eine Isolinie hoch informativ ist oder nur einen geringen Beitrag zur Frequenzschätzung bringt, da nur wenige Nachkommen in der $\mathrm{F}_{2}$ Generation getestet wurden, steht zumeist erst während der Paarung der $\mathrm{F}_{1^{-}}$ Generationen, also zu einem Zeitpunkt zu dem schon ein hoher Arbeitseinsatz für die Linie angefallen ist, fest. Werden Isolinien mit niedrigem Informationsgehalt aus den Berechnungen herausgenommen, geht der bis dahin geleistete Arbeitsaufwand verloren. Werden sie wie hoch informative Linien behandelt, wird die Frequenzhäufigkeit unterschätzt und die Vorhersagesicherheit des $\mathrm{F}_{2}$-Screenings leidet. Die hier vorgestellte Statistik ermöglicht es, alle Isolinien in die Auswertung mit ihrem tatsächlichen Informationsgehalt aufzunehmen. Für das $\mathrm{F}_{2}$-Screening ist es aber immer noch wünschenswert eine Vielzahl von Nachkommen in der $F_{1}$ - und $F_{2}$-Generation $z u$ züchten und zu testen, da nur hoch informative Isolinien ein günstiges Kosten/NutzenVerhältnis aufweisen.

\subsubsection{Resistenzhäufigkeit}

In den Jahren 2000 und 2001 konnten in den 24.070 getesteten Larven von 199 Isolinien keine Resistenzallele nachgewiesen werden. Bei einer Irrtumswahrscheinlichkeit von $5 \%$ lag die Resistenzhäufigkeit somit, fasst man die beiden Jahre zusammen, zwischen Null und $0,0042=4,2 \times 10^{-3}$. Das Intervall umschließt somit auch die Resistenzfrequenz von $10^{-3}$, die in der Literatur als Grenze angegeben wird und über der die "Hoch Dosis"Strategie nicht mehr durchführbar ist (Andow und Hutchison, 1998). Die untersuchten 199 Isolinien reichten somit nicht aus, das Clopper-Pearson-Intervall so zu verkleinern, dass eine Aussage über die Durchführbarkeit der "Hoch Dosis"-Strategie gemacht werden kann. Zusätzlich muss beachtet werden, dass die natürliche Mortalität bei den Biotests nicht berücksichtigt wurde und somit die Intervallgrenze zu positiv geschätzt wurde. Andow und Alstad (1998) errechneten ein Intervall für die Resistenzhäufigkeit von Null bis $0,013=1,3 \times 10^{-2}$ bei 91 getesteten Isolinien ohne ein Resistenzallel nachweisen zu können. Die Entdeckungswahrscheinlichkeit lag dabei im Durchschnitt bei $89 \%$. Bei $53 \%$ der Isolinien lag die Entdeckungswahrscheinlichkeit bei über $90 \%$, aber auch bei $28 \%$ der Isolinien unter $80 \%$. Das Konfidenzintervall ist somit zu positiv geschätzt. Im Jahr 2000 konnten Andow und Alstad 188 Isolinien testen. Sie fanden keine Larve mit Resistenzallel. Bei zwei Linien schlossen sie aber auf eine partielle Resistenz. Die Entdeckungswahrscheinlichkeit konnten sie stark erhöhen. $90 \%$ der Isolinien hatte eine Entdeckungswahrscheinlichkeit von $95 \%$ und nur noch $2 \%$ eine von unter $2 \%$. Sie berechneten, dass die Resistenzallelfrequenz der untersuchten Population $<3,9 \times 10^{-3}$ ist, was dem in dieser Arbeit errechneten Wert entspricht. Andow und Alstad (1998) gehen aber weiterhin von einem gleichen Informationsgehalt 
der Isolinien aus, was aber nach den oben beschriebenen Erfahrungen zu positiv gedacht ist. Zhao et al. (2002) wiesen in ihren Untersuchungen auf die Schwachstellen des $\mathrm{F}_{2^{-}}$ Screenings hin. Für einen Plutella xylostella Stamm mit einer künstlich erzeugten Resistenzfrequenz von $3 \%$ berechnen sie im günstigen Fall mit Hilfe des $\mathrm{F}_{2}$-Screenings einen Wert von $1 \%$. Da bei einer natürlichen Resistenzfrequenz von $1 \mathrm{zu} 1.000$ die Fehler durch Falsch-Negativ-Entscheidungen noch ansteigen, wird klar, dass die mit dem $\mathrm{F}_{2}$-Screening ermittelten Werte die Resistenzhäufigkeit unterschätzen. Trotzdem bleibt dass $\mathrm{F}_{2}$-Screening ein starkes Werkzeug, um in einer Population resistente Larven bei einem rezessiven Erbgang aufzufinden.

Nach Berechnungen von Andow und Alstad (1998) wären bei optimalem Zuchtverlauf, d.h. keine Falsch-Negativ-Entscheidungen und keine Falsch-PositivEntscheidungen, 750 Isolinien nötig um die Resistenzfrequenz unterhalb von $10^{-3} \mathrm{zu}$ bestimmen, also die drei- bis vierfache Anzahl der in 2000 und 2001 getesteten Isolinien und damit auch der drei- bis vierfache Kosten und Arbeitsaufwand. Dieser logistische und personelle Aufwand war innerhalb dieses Projektes nicht möglich. Für eine weitere Durchführung des $\mathrm{F}_{2}$-Screenings müssen daher folgende Punkte optimiert und berücksichtigt werden:

1. Das $\mathrm{F}_{2}$-Screening sollte kontinuierlich von einer Einrichtung durchgeführt werden, um die Zuchtbedingungen optimieren zu können und um dadurch eine maximale Ausbeute zu erhalten.

2. Eine Wiederholung der Untersuchungen alle vier bis fünf Jahre, evtl. durch unterschiedliche Einrichtungen, wird zu kaum vergleichbaren Ergebnissen führen.

3. Bei der Planung des $\mathrm{F}_{2}$-Screenings sind die enormen Arbeitszeitspitzen, die von festangestellten Kräften nicht zu leisten sind, und der kurzfristig enorme Platzbedarf während der Paarungszeiten der $\mathrm{P}_{1^{-}}$und $\mathrm{F}_{2}$-Generation $\mathrm{zu}$ berücksichtigen. 


\section{MONITORING RESISTENTER MAISZÜNSLER AUF BT- MAISFELDERN}

\subsection{Einleitung}

Auf einem Maisfeld von 1 ha stehen abhängig vom Reihenabstand und dem Abstand innerhalb der Reihe ca. 80.000 bis 120.000 Maispflanzen (Zscheischler et al., 1990). Bei einem rezessiven Erbgang sollten in einem Bt-Maisfeld nur homozygot resistente Larven (rr) überleben. Bei einem dominanten Erbgang sollten zusätzlich heterozygote Larven (sR) überleben. Maiszünslerlarven schädigen die Maispflanze, an der sie fressen i. d. R. erheblich, so dass vor der Ernte eine resistente Larve in einem Bt-Maisfeld durch die deutlichen Schadsymptome leicht zu entdecken sein sollte. Ein Bt-Maisfeld stellt somit einen natürlich diskriminierenden Dosistest dar. Bei einem sehr starken Maiszünslerbefall, wie z. B. im Oderbruch mit ca. $100 \%$, ist kurz vor der Ernte im Durchschnitt in jeder Pflanze mindestens eine Larve anzutreffen. Auf einem Maisfeld von 10 ha und einem Befall von $100 \%$ können ca. 800.000 bis 1,2 Millionen Maiszünsler erwartet werden. Für den optimalen diskriminierenden Dosistest müssen bei einer Resistenzallelfrequenz von $10^{-3}$ ca. 3 Millionen Larven getestet werden, um bei einem $\alpha$ von $5 \%$ eine resistente Larve zu entdecken. In einem $100 \%$-Befallsgebiet sollten ca. 30 ha Bt-Mais ausreichen, um mit 95\%iger Sicherheit eine resistente Larve zu finden.

Diese Überlegungen führten zur Entwicklung des In-Field-Screening von Venette et al. (2000). Diese Methode verwendet zwei benachbarte Parzellen von einer Bt-SüßmaisLinie und der isogenen Nicht-Bt-Maislinie, um die Resistenzhäufigkeit zu ermitteln. Unter der Voraussetzung, dass sich die Bt-Maislinie nicht von der isogenen Nicht-BtMaislinie in Hinsicht auf das Ablegeverhalten der Weibchen und auf die Überlebenswahrscheinlichkeit der Larven (abzüglich der Toxinwirkung) unterscheidet, wird die benachbarte Nicht-Bt-Maislinie zur Bestimmung der Populationsdichte verwendet. Anhand der untersuchten Pflanzen sowie der gefundenen resistenten Larven im Bt-Mais und aus der Populationsdichte, die in der isogenen Linie ermittelt wurde, lässt sich die Resistenzallelhäufigkeit schätzen.

In den Jahren 2000 bis 2002 wurden in Deutschland einige hundert Hektar Bt-Mais angebaut (Degenhardt et al., 2003). Ein Teil der Flächen sollte im Rahmen des BMBFProjektes "Sicherheitsforschung und Monitoring-Methoden zum Anbau von Bt-Mais" unter anderem genutzt werden, um resistente Larven für physiologische Untersuchungen zum Resistenzmechanismus beim Maiszünsler zu sammeln. Daher entstand die Überlegung, ob die Methode von Venette auf die im Jahr 2001 in Deutschland angebauten Bt-Maisfelder, die auf resistente Maiszünsler untersucht wurden, angepasst werden kann, um eine initiale Resistenzfrequenz in Deutschland zu ermitteln. 


\subsection{Material und Methoden}

\subsubsection{Sammeln der Maiszünsler}

Maislinien, die in der Sortenprüfung stehen, dürfen bis zur Erteilung der Sortenzulassung in begrenztem Umfang (12 t Saatgut) vertrieben und angebaut werden (BRD, 1985; Bundessortenamt, pers. Mitt.). Seit dem Frühjahr 2000 ruht für Bt-176Mais die seit 1997 laufende Sortenprüfung. Ein Anbau von maximal $12 \mathrm{t}$ ist $\mathrm{zu}$ Versuchszwecken weiterhin erlaubt (Bundesregierung, 2000). Nachkommen des Events Mon810 stehen seit dem Jahr 2000 in der Sortenprüfung und dürfen in diesem Rahmen unter praxisüblichen Bedingungen angebaut werden.

Ein Teil dieser Flächen wurde zur Suche nach resistenten Maiszünslern genutzt. Da die Felder nicht speziell für die Untersuchungen angelegt wurden, stand nicht in allen Fällen eine isogene Vergleichslinie zur Verfügung. Die Größe der Felder und die Größe der Stichprobe konnte meist nicht beeinflusst werden. Für das Jahr 2000 wurden Larven auf Feldern des Events Bt-176 gesammelt. Da bei diesen Versuchen meist nur der Kolbenbefall ermittelt wurde, reichten die Befallsdaten im Nicht-Bt-Mais nicht für eine Berechnung der Resistenzhäufigkeit aus. Die Felder wurden zum Teil konventionell bearbeitet oder waren Standorte von Sortenversuchen oder von Untersuchungen, die sich mit der Auswirkung von Bt-Mais auf Nicht-Zielorganismen befassten. Von einigen Landwirten wurde der Wunsch geäußert, die genaue Lage der Felder nicht preiszugeben, da sie mit Nachteilen für ihren Betrieb rechneten, so dass alle Daten zu Bt-Maisfeldern durch eine Kodierung mit einer groben geografischen Einordnung angegeben wurden. Nach den Erfahrungen aus dem Jahr 2000 wurden im Jahr 2001 nur Bt-Maisfelder des Events Mon810 nach überlebenden Larven untersucht und Befallsdaten in isogenen Vergleichsflächen ermittelt. Zwei Standorte lagen im Oderbruch und waren konventionell bearbeitet worden. Die Daten des Befallsdrucks am Standort 9 stammen von einem Sortenversuch des Pflanzenschutzdienstes Brandenburg und wurden von Frau Götzke (pers. Mitt.), Pflanzenschutzdienst Brandenburg, zur Verfügung gestellt. Am Standort 8 wurden die Daten von Herrn Dr. Magg, Universität Hohenheim, ermittelt (Magg et al., 2002). Beide Versuche lagen direkt benachbart zu den Bt-Maisflächen. Der Standort 10 bei Halle gehörte zu Forschungsprojekten des BMBF-Programms "Sicherheitsforschung und Monitoring" und der Standort 11 bei Freiburg war ein Versuch des Regierungspräsidiums Freiburg und wurde von Herrn Dannemann (pers. Mitt.) durchgeführt. Die Ermittlung von resistenten Maiszünslern erfolgte mittels der für die weiteren Untersuchungen gezogenen Stichproben. 
Tab. 36: Kenndaten der Bt-Maisflächen 2000

\begin{tabular}{llll} 
Nr. & Ort & Lage & Herkunft \\
\hline 1 & Griesheim & westliches Süd-Hessen & Sortenversuch \\
\hline 2 & Groß-Gerau & westliches Süd-Hessen & Herbizidversuch \\
\hline 3 & $\begin{array}{l}\text { Bad Nauheim } \\
\text { Wölfersheim }\end{array}$ & $\begin{array}{l}\text { Mittel-Hessen, süd- } \\
\text { westlich des Vogelsbergs }\end{array}$ & Praxisanbau \\
\hline 4 & Schweinfurt & $\begin{array}{l}\text { Unterfranken, süd- östlich } \\
\text { der Rhön }\end{array}$ & Praxisanbau \\
\hline 5 & Heidelberg & $\begin{array}{l}\text { nördliches Baden- } \\
\text { Württemberg, westlich des } \\
\text { Naturparks Neckertal- } \\
\text { Odenwald }\end{array}$ & Praxisanbau \\
\hline 6 & Aschaffenburg & Unterfranken, Maintal & $\begin{array}{l}\text { Versuch zu Nicht- } \\
\text { Zielorganismen, } \\
\text { Sortenversuch }\end{array}$ \\
\hline 7 & Bad Neustadt & $\begin{array}{l}\text { Unterfranken, } \\
\text { östlich der Rhön }\end{array}$ & Praxisanbau \\
& a. d. S. & & \\
\hline
\end{tabular}

Tab. 37: Kodierung der Standorte, Felder und Sorten 2000

\begin{tabular}{|c|c|c|c|c|c|}
\hline Ort & Sammelzeitraum & $\begin{array}{l}\text { Bt-Mais- } \\
\text { Id.-Nr. }\end{array}$ & $\begin{array}{l}\text { Bt-Mais- } \\
\text { Sorte/-Linie }\end{array}$ & $\begin{array}{l}\text { Nicht-Bt- } \\
\text { Id.-Nr. }\end{array}$ & $\begin{array}{l}\text { Nicht-Bt- } \\
\text { Maissorte }\end{array}$ \\
\hline Griesheim & $\begin{array}{l}04.08 .00-29.08 .00 \\
12.09 .00\end{array}$ & $\begin{array}{l}\text { AA.1 } \\
1 \mathrm{~B} .1\end{array}$ & Bt6369 & $\begin{array}{l}\text { A. } 2 \\
1 \mathrm{~B} .2\end{array}$ & Textos \\
\hline Griesheim & $\begin{array}{l}04.08 .00-29.08 .00 \\
12.09 .00\end{array}$ & $\begin{array}{l}1 \mathrm{~A} .3 \\
1 \mathrm{~B} .3\end{array}$ & $\begin{array}{l}\text { Prelude Bt } \\
\text { (Bt6262) }\end{array}$ & $\begin{array}{l}1 \mathrm{~A} .4 \\
1 \mathrm{~B} .4\end{array}$ & Prelude \\
\hline Griesheim & $\begin{array}{l}04.08 .00-29.08 .00 \\
12.09 .00\end{array}$ & $\begin{array}{l}1 \mathrm{~A} .5 \\
1 \mathrm{~B} .5\end{array}$ & Pactol CB & $\begin{array}{l}1 \mathrm{~A} .6 \\
1 \mathrm{~B} .6\end{array}$ & Pactol \\
\hline Groß-Gerau & $04.08 .00-29.08 .00$ & $2 \mathrm{~A} .5$ & Pactol CB & $2 \mathrm{~A} .6$ & Pactol \\
\hline Bad Nauheim & $\begin{array}{l}04.08 .00-29.08 .00 \\
25.09 .00\end{array}$ & $\begin{array}{l}3 \text { A. } 5 \\
\text { 3B.5 }\end{array}$ & Pactol CB & $\begin{array}{l}3 \text { A.6 } \\
\text { 3.B.6 }\end{array}$ & Pactol \\
\hline Schweinfurt & $04.08 .00-29.08 .00$ & 4A.7 & Navares & 4 4A.0 & k.A. \\
\hline Heidelberg & 24.08 .00 & $5 \mathrm{~A} .3$ & Prelude Bt & 5 A. 6 & Pactol \\
\hline Heidelberg & 24.08 .00 & $5 \mathrm{~A} .7$ & Navares & $5 \mathrm{~A}$ & k.A. \\
\hline Heidelberg & 19.09 .00 & 5 B.7 & Navares & $5 \mathrm{~B} .0$ & k.A. \\
\hline Heidelberg & 19.09 .00 & $5 B .3$ & Prelude Bt & $5 \mathrm{~B} .0$ & k.A. \\
\hline Aschaffenburg & $29.08 .00-21.11 .00$ & 6B.5 & Pactol CB & 6B.6 & Pactol \\
\hline $\begin{array}{l}\text { Bad Neustadt } \\
\text { a.d.S. }\end{array}$ & 29.08 .00 & 7B.7 & Navares & 7B.0 & k.A. \\
\hline
\end{tabular}


Tab. 38: Kenndaten der Bt-Maisflächen 2001

\begin{tabular}{llll} 
Nr. & Ort & Lage & Herkunft \\
\hline 8 & Bad Freienwalde & nördliches Oderbruch & Praxisanbau \\
\hline 9 & Wriezen & $\begin{array}{l}\text { nord-westliches } \\
\text { Oderbruch }\end{array}$ & Praxisanbau \\
\hline 10 & Halle & $\begin{array}{l}\text { nord-westlicher Teil der } \\
\text { Leipziger Bucht }\end{array}$ & BMBF-Projekt \\
\hline 11 & Freiburg & $\begin{array}{l}\text { südliches oberrheinisches } \\
\text { Tiefland }\end{array}$ & Sortenversuch \\
& & &
\end{tabular}

Tab. 39: Kodierung der Standorte und Felder sowie Sorten 2001

\begin{tabular}{|c|c|c|c|c|c|}
\hline Ort & Sammelzeitraum & $\begin{array}{l}\text { Bt-Id- } \\
\text { Nr. }\end{array}$ & $\begin{array}{l}\text { Bt-Mais- } \\
\text { Sorte/-Linie }\end{array}$ & $\begin{array}{l}\text { Nicht-Bt } \\
\text {-Id.-Nr. }\end{array}$ & $\begin{array}{l}\text { Nicht-Bt- } \\
\text { Maissorte } \\
\end{array}$ \\
\hline Bad Freienwalde & $26+27.09 .2001$ & 8.9 & Novelis & $\begin{array}{l}8.10 \\
8.12\end{array}$ & $\begin{array}{l}\text { Nobilis } \\
\text { Alle Sorten: } \\
\text { Clarica, } \\
\text { Monumental, } \\
\text { Nobilis, } \\
\text { Pactol, } \\
\text { Prelude, } \\
\text { Symphonie }\end{array}$ \\
\hline Wriezen & 25.09 .01 & 9.13 & Bacila & 9.14 & Clarica \\
\hline Halle & 09.10 .01 & 10.9 & Novelis & 10.10 & Nobilis \\
\hline Freiburg & 26.09 .01 & $\begin{array}{l}11.9 \\
11.13\end{array}$ & $\begin{array}{l}\text { Novelis } \\
\text { Bacila }\end{array}$ & $\begin{array}{l}11.10 \\
11.14\end{array}$ & $\begin{array}{l}\text { Nobilis } \\
\text { Clarica }\end{array}$ \\
\hline
\end{tabular}

\subsubsection{PCR-Untersuchungen von Bt-Maisblattstücken}

Den Pflanzen mit Larvenfund und Fraßschäden wurde ein Blattstück für die späteren PCR-Untersuchungen entnommen und bei $-20^{\circ} \mathrm{C}$ gelagert. Die Untersuchungen wurden von Frau Metke, Biologische Bundesanstalt in Kleinmachnow (Abteilung Dr. Hommel), durchgeführt. Die Extraktion der Blätter erfolgte nach der Methode von Dellaporta et al. (1983) die von Liebe und Sick (pers. Mitt.) angepasst wurde. Die spezifische PCR erfolgte mit den Primern mg3 und mg4 der Firma MWG, welche Cry1Ab spezifisch sind. Eine genaue Beschreibung der PCR-Bedingungen befindet sich im Anhang (9.3.1). 


\subsubsection{Statistik zum Resistenz-Screening}

Die statistische Auswertung erfolgte durch Professor Piepho von der Universität Hohenheim, Fachgebiet Bioinformatik. Die Resistenzallelhäufigkeit q in einem BtMaisfeld errechnet sich nach der Formel:

$q=\sqrt{\frac{\pi_{0} n_{1}}{\left(1-\pi_{0}\right) n_{2}}}$

Wobei $\mathrm{n}_{1}$ die Zahl der untersuchten Pflanzen im Nicht-Bt-Maisfeld und $\mathrm{n}_{2}$ die Zahl der untersuchten Pflanzen im Bt-Maisfeld kennzeichnet.

$\pi_{0}$ ist die Wahrscheinlichkeit des Anteils der Larven aus dem Bt-Feld an der Gesamtlarvenzahl $\left(\frac{\pi_{0}}{\left(1-\pi_{0}\right)} \approx \frac{m_{2}}{m_{1}} ; m_{1}, m_{2} \rightarrow \infty\right)$.

Da keine resistenten Larven gefunden wurden, wird für $q$ ein 95\%iges Konfidenzintervall angegeben, dessen untere Grenze 0 ist.

Eine Herleitung der Statistik und die verwendeten Prozeduren finden sich im Anhang (9.3.2). Für die Berechnung wurde das Statistikprogramm SAS in der Windows Version 8 verwendet.

\subsubsection{Haltung und Zucht von Maiszünslern im Labor}

Die Zucht der Maiszünsler entspricht der Zucht des $F_{2}$-Screenings (5.2.4). Die Abweichungen werden im Folgenden kurz beschrieben.

\subsubsection{Elterngeneration $\mathrm{P}_{1}$}

Die im Herbst im Freiland gesammelten $\mathrm{L}_{5}$-Larven wurden in einzelnen Plastikbechern ( $\varnothing \times \mathrm{H}=4,5 \mathrm{~cm} \times 7 \mathrm{~cm}$ ) aufbewahrt. Um Kondenswasserbildung zu vermeiden, waren die Deckel perforiert. Als Versteckmöglichkeit wurde zerknülltes Handtuchpapier angeboten. Die Lagerung der Becher erfolgte in unbeheizten Gewächshäusern, die im Sommer schattiert wurden. Die Licht- und Temperaturverhältnisse entsprachen den natürlichen Bedingungen in Darmstadt in den Jahren 2000 bis 2002. Ab April wurden die Larven einmal pro Woche mit Wasser besprüht, damit sie tropfbares Wasser aufnehmen konnten (Beck, 1967). Die Maiszünsler blieben bis zum Schlupf der Falter in den Bechern. Im Folgenden richtete sich die Zucht nach den im Kapitel 4.2.4.1 beschriebenen Bedingungen. Die Paarung der Falter erfolgte unter natürlichen Lichtund Temperaturverhältnissen in Gewächshäusern. Ab Juni wurden die Gewächshäuser durch ein Schattiergewebe beschattet und bei hohen Temperaturen wurde für eine ausreichende Ventilation gesorgt. Die Falter der Eltern-Generation wurden paarweise in Plexiglaszylinder gesetzt. Es wurden zunächst die Falter von einem Bt-Feld untereinander gekreuzt. Stand kein Partner von demselben Bt-Feld zur Verfügung, wurde ein Falter von einem Nicht-Bt-Maisfeld zur Kreuzung verwendet. War auch dies nicht möglich, so fand die Kreuzung mit einem Partner aus der Laborzucht statt. Die Nachkommen eines Paares wurden gemeinsam weitergezüchtet und strikt von den Nachkommen der anderen Isolinien getrennt. 


\subsubsection{2 $\mathrm{F}_{1}$ - und $\mathrm{F}_{2}$-Generation}

Die Eier und Larven wurden i. d. R., wie in Kapitel 4.2.4.1 beschrieben, in Lichtthermostaten bei $25^{\circ} \mathrm{C}$ und $18: 6 \mathrm{~h}$ (Licht $[\mathrm{H}]$ : Dunkel [D]) gehalten. Zur Synchronisation der Schlupfzeitpunkte wurden früh abgelegte Eipakete und Puppen für maximal sieben Tage bei $10{ }^{\circ} \mathrm{C}$ gehalten. Die Entwicklung von spät abgelegten Eipaketen und sich langsam entwickelnden Larven wurde durch Temperaturerhöhung auf $30{ }^{\circ} \mathrm{C}$ beschleunigt. Die Eier wurden in Lichtthermostaten und die Larven in Lichtthermostaten oder in beheizbaren Räumen mit separater Lichtsteuerung gehalten. Die Paarung der Falter der $\mathrm{F}_{1}$-Generation erfolgte in beheizbaren Gewächshäusern bei Langtagbedingungen $18: 6 \mathrm{~h}(\mathrm{H}: \mathrm{D})$. Alle zwei bis drei Tage wurden die Behälter auf geschlüpfte Falter einer Isolinie kontrolliert und die Falter gepaart. Gleichzeitig wurden die Zylinder auf Eiablage überprüft. Die Paarung der $\mathrm{F}_{1}$-Falter erfolgte nach der ZweiZylinder-Methode (5.2.4.2).

\subsubsection{Testung der Larven auf Bt-Blattstücken bzw. auf toxinhaltigem Medium}

Larven von August 2000, aus der frühen Sammelperiode, wurden direkt auf Resistenz getestet. In würfelförmige Plastikgefäße (L x B x H = $2 \mathrm{~cm}$ x $2 \mathrm{~cm}$ x $2 \mathrm{~cm})$ wurden $2 \mathrm{ml}$ Wasser-Agar (2,5\%) gefüllt, auf das ein ausgestanztes Blattstück $(\varnothing=12 \mathrm{~mm})$ gelegt wurde. Die Blattstücke stammten vom Bt-Mais Pactocl CB (Linie Bt-176; Firma Novartis), die im Labor angezüchtet und im Vier- bis Sechs-Blattstadium geerntet wurden. Alle zwei bis drei Tage wurde das Blattstück gewechselt und die Mortalität bestimmt. Nach 21 Tagen wurden überlebende Larven auf Nährmedium umgesetzt und die Nachkommen dieser Isolinie in der $\mathrm{F}_{4}$-Generation erneut getestet. Die Larven der $\mathrm{F}_{2}$-Generation wurden analog der Methode des $\mathrm{F}_{2}$-Screenings getestet (5.2.5). Die Biotests wurden in den o. g. Plastikgefäßen im Lichtthermostat bei $25^{\circ} \mathrm{C}, 0: 24 \mathrm{~h}(\mathrm{H}$ : D) durchgeführt (4.2.6). In jedem Plastikwürfel wurden zwei $\mathrm{L}_{1}$-Larven, die jünger als 24 Stunden waren, gesetzt. Bonitiert wurde nach 7 und 21 Tagen. Pro Plastikbox wurden 2 ml Nährmedium (Anhang 9.1.2) verwendet. Das Toxin, dessen Konzentration zwischen $0,1 \mu \mathrm{g} / \mathrm{cm}^{2}$ und $0,3 \mu \mathrm{g} / \mathrm{cm}^{2}$ lag, wurde auf die Oberfläche des Medium appliziert (Tab. 27). Die Toxinkonzentration war ausreichend, um $100 \%$ der empfindlichen Maiszünslerlarven abzutöten. 


\subsection{Ergebnis}

\subsubsection{Daten zum Arbeitsaufwand}

Der Arbeitsaufwand ist wie bei der Durchführung des $F_{2}$-Screenings stark vom Versuchszeitpunkt abhängig. Unterschiede in den Methoden liegen vor allem im Aufwand der Maiszünslersammelaktionen. Für das Jahr 2000 konnten keine Daten zum Arbeitsaufwand der Sammelaktionen erhoben werden. Der Arbeitsaufwand im Bt-176 war aber im Vergleich zu Mon810 und Bt-176 höher, da besonders zu einem frühen Sammelzeitpunkt mehr nicht-resistente Larven im Kolben von Bt-176 (geringe Toxinkonzentration) gefunden wurden.

Tab. 40: Zeitaufwand für das Sammeln von Larven im Bt-Maisfeld in Abhängigkeit vom Maiszünslerbefall (MzB) im Jahr 2001

\begin{tabular}{|c|c|c|c|c|c|c|c|}
\hline Ort & $\begin{array}{c}\text { MzB im } \\
\text { Nicht-BT- } \\
\text { Mais [\%] }\end{array}$ & $\begin{array}{c}\text { Sammler } \\
\text { n }\end{array}$ & $\begin{array}{c}\text { Bt- } \\
\text { Pflanzen } \\
\text { n }\end{array}$ & $\begin{array}{c}\text { gesammelte } \\
\text { Larven } \\
n\end{array}$ & $\begin{array}{c}\text { Gesamt- } \\
\text { Zeit } \\
{[\mathrm{h}]}\end{array}$ & $\begin{array}{l}\text { Zeit/ } \\
\text { Larve } \\
\text { [min] }\end{array}$ & $\begin{array}{c}\text { Zeit/ } \\
\text { Pfl. } \\
\text { [s] }\end{array}$ \\
\hline 8 & 129 & 4 & 154.000 & 68 & 40 & 35 & 1 \\
\hline 9 & 80 & 5 & 37.410 & 73 & 30 & 23 & 3 \\
\hline 10 & 24 & 3 & 116.400 & 3 & 18 & 360 & 0,6 \\
\hline
\end{tabular}

Die Daten verdeutlichen den hohen Zeitaufwand für das Auffinden der Larven in BtMaisfeldern und die Abhängigkeit des Sammelaktivität vom Befall. Die benötigte Sammelzeit pro Larve hängt neben dem Befallsdruck, der "Verunreinigung" im Bt-Feld mit Nicht-Bt-Mais und der Effektivität der Bt-Maislinie in der Maiszünslerbekämpfung besonders von der Erfahrenheit der Sammler ab. Zusätzlich müssen die Zeiten und Kosten für einen Proteinschnelltest oder einer PCR-Untersuchung berücksichtigt werden. Diese Daten wurden in dieser Arbeit nicht erhoben, da die Ergebnisse der PCRUntersuchungen nicht zum Ausschluss von Larven und somit von Isolinien führten. Der Arbeitsaufwand der Weiterzucht der Larven als Isolinien und der Testung der Larven auf Resistenz ist mit dem Arbeitsaufwand beim $\mathrm{F}_{2}$-Screening vergleichbar (5.3.1).

\subsubsection{Daten zu den Maiszünslerstandorten}

Seit 1997 bzw. 1998 besitzen die Events Bt-176 und Mon810 die Genehmigung zum Inverkehrbringen in der EU (3.2.1). Seit April 2000 ruht auf Anweisung des Bundesministeriums für Gesundheit (BMG) in Deutschland die Genehmigung für den Anbau und den Vertrieb von Bt-176 Mais (Bundesregierung, 2000). Derzeit ist der Anbau zu Zwecken der Erforschung und Erprobung erlaubt.

Im Jahr 2000 wurden an sieben Standorten insgesamt 493 überlebende Larven auf Bt-Maisfeldern des Events Bt-176 gesammelt. Dazu wurden ca. 50.000 Pflanzen abgesucht. Der Schwerpunkt der Arbeit lag in diesem Jahr auf der Entdeckung resistenter Larven, daher hatte sich die Sammelaktivität weitgehend auf die BtMaisfelder beschränkt und es wurden kaum Daten zum Befallsdruck erhoben. Die gesammelten Larven wurden im Biotest auf Resistenz getestet. Da für die Berechnung der Resistenzhäufigkeit der Befallsdruck in den untersuchten Gebieten entscheidend ist, 
konnte keine Resistenzhäufigkeit für das Jahr 2000 ermittelt werden. Im Jahr 2001 wurden die Untersuchungen zur Resistenzhäufigkeit an zwei Standorten mit Praxisanbau sowie an zwei Standorten unter Versuchsbedingungen durchgeführt. Der Befall schwankte zwischen $129 \%$ im Oderbruch (8.9) und $4 \%$ in Freiburg (11.10) (Tab. 41). Am Standort 8 wurden neben der isogenen Vergleichssorte (8.11) auch sechs weitere Nicht-Bt-Sorten (8.12) auf Befall untersucht. Das Befallsmittel lag über allen sieben Sorten (Tab. 39) bei 76,3\% und damit deutlich unter dem Befall der isogenen Sorte zu Novelis.

Tab. 41: Maiszünslerbefall auf den Maisfeldern im Jahr 2001

\begin{tabular}{|c|c|c|c|c|c|c|}
\hline \multirow[b]{2}{*}{ Id-Nr } & \multicolumn{3}{|c|}{ Bt-Mais } & \multicolumn{3}{|c|}{ Nicht-Bt-Mais } \\
\hline & $\begin{array}{l}\text { Pflanzen } \\
\text { (n) }\end{array}$ & $\begin{array}{c}\text { Larven } \\
\text { (n) }\end{array}$ & $\begin{array}{c}\text { Befall } \\
{[\%]}\end{array}$ & $\begin{array}{l}\text { Pflanzen } \\
\text { (n) }\end{array}$ & $\begin{array}{c}\text { Larven } \\
\text { (n) }\end{array}$ & $\begin{array}{c}\text { Befall } \\
{[\%]}\end{array}$ \\
\hline 8.11 & 154.000 & 68 & 0,044 & 100 & 129 & $129^{1}$ \\
\hline 8.12 & & & & 600 & 458 & $76,3^{2}$ \\
\hline 9 & 37.410 & 73 & 0,195 & 50 & 40 & 80 \\
\hline 10 & 116.400 & 3 & 0,0025 & 300 & 72 & 24 \\
\hline \multirow[t]{2}{*}{11} & $200^{3}$ & 0 & & $200^{3}$ & 8 & 4 \\
\hline & $200^{4}$ & 0 & & $200^{4}$ & 18 & 9 \\
\hline
\end{tabular}

Trotz des meist hohen Befallsdrucks im Nicht-Bt-Feld konnten im Jahr 2001 auf den Flächen der Linie Mon810 weniger Larven gefunden werden als auf den Flächen mit Bt-176 im Jahr 2000. Bt-176 expremiert im Kolben kein bzw. nur im geringen Maße das Bt-Toxin (Tab. 1). Die Larven die $2000 \mathrm{zu}$ einem frühen Termin gesammelt wurden, wurden zu annährend $100 \%$ im Kolben gefunden. Je länger die Vegetationszeit andauerte, umso mehr Larven wurden im Stängel gefunden. Bei den Versuchen in Freiburg (Feld 11.9 und 11.13) wurden keine Larven im Bt-Mais gefunden, was auf Grund der geringen Stichprobe und des geringen Befalls der isogenen Sorte zu erwarten war. Das Feld 9.13 zeigte im Vergleich zum Feld 8.9 einen hohen Befall mit 0,195 \%. Bei diesem Feld war versehentlich während der Aussaat Nicht-Bt-Mais unter das BtMaissaatgut gemischt worden. Die Stellen im Feld, in denen Nicht-Bt-Mais ausgesät worden war, waren durch den stärkeren Befall leicht zu erkennen und konnten durch einen Bt-Toxin-Schnelltest (Firma Gene Scan) auch bestätigt werden. In die Auswertung von Feld 9.13 wurde der Teil des Feldes aufgenommen, der eine geringe bzw. keine „Verunreinigung“ mit Nicht-Bt-Mais zeigte.

\subsubsection{1 "Verunreinigung" von Bt-Maisfeldern mit Maispflanzen, die kein oder nur eine geringe Bt-Expression aufweisen}

Um bei den überlebenden Larven auf Bt-Maisfeldern Falsch-Positive-Ergebnisse möglichst auszuschalten, wurden von den Bt-Maispflanzen mit Larven bzw. mit Fraßspuren Blattproben entnommen und vom Institut für integrierten Pflanzenschutz (Abteilung Dr. Hommel) der BBA Kleinmachnow mit Hilfe der PCR untersucht. Da der Arbeitsaufwand durch die unerwartet hohe Anzahl von überlebenden Larven im Jahr 2000 und 2001 den veranschlagten Aufwand überschritt, konnten nicht alle Proben 
untersucht werden. Eine Quantifizierung der „Verunreinigung“ mit Nicht-BtMaispflanzen durch die PCR konnte auf Grund der nötigen hohen Probenzahl nicht durchgeführt werden. Um eine Verunreinigung von $5 \%$ statistisch abzusichern, müssten ca. 1.800 Blattstücke untersucht werden, wohingegen bei einer Verunreinigung von $0,025 \% 380.000$ Blattstücke zu untersuchen wären.

Tab. 42: Ergebnisse der PCR-Untersuchungen im Jahr 2000

\begin{tabular}{|c|c|c|c|c|c|}
\hline Feld-Nr. & Linien & $\begin{array}{l}\text { Untersuchte } \\
\text { Blattstücke } \\
\text { (n) }\end{array}$ & $\begin{array}{c}\text { PCR } \\
\text { Bt-Positiv } \\
\text { (n) }\end{array}$ & $\begin{array}{c}\text { PCR } \\
\text { Bt-Negativ } \\
\text { (n) }\end{array}$ & $\begin{array}{l}\text { Bt-Pflanzenanteil an } \\
\text { den untersuchten } \\
\text { Pflanzen [\%] }\end{array}$ \\
\hline 1A.1 & Bt-176-(6369) & 42 & 19 & 23 & 45,2 \\
\hline 1A. 3 & $\begin{array}{l}\text { Bt-176-Prelude } \\
\text { Bt (6262) }\end{array}$ & 57 & 46 & 11 & 80,7 \\
\hline $5^{1}$ & $\begin{array}{c}\text { Bt-176-Pactol } \\
\text { CB }\end{array}$ & 27 & 24 & 3 & 88,9 \\
\hline 5 A. 7 & $\begin{array}{c}\text { Bt-176- } \\
\text { Navares }\end{array}$ & 18 & 16 & 2 & 88,9 \\
\hline 7B.7 & $\begin{array}{l}\text { Bt-176- } \\
\text { Navares }\end{array}$ & 45 & 39 & 6 & 86,7 \\
\hline
\end{tabular}

Tab. 43: Ergebnisse der PCR-Untersuchungen im Jahr 2001

\begin{tabular}{cccccccc}
$\begin{array}{c}\text { Feld- } \\
\text { Nr. }\end{array}$ & $\begin{array}{c}\text { Linien } \\
\text { Befall im Befall im Untersuchte } \\
\text { Nicht-Feld } \\
{[\%]}\end{array}$ & $\begin{array}{c}\text { Bt-Feld } \\
{[\%]}\end{array}$ & $\begin{array}{c}\text { PCR } \\
\text { Bn) }\end{array}$ & $\begin{array}{c}\text { PCR } \\
\text { Bt- } \\
\text { Positiv } \\
\text { (n) }\end{array}$ & $\begin{array}{c}\text { Negativ } \\
\text { (n) }\end{array}$ & $\begin{array}{c}\text { Bt-Pflanzen- } \\
\text { anteil an den } \\
\text { untersuchten Pfl. } \\
{[\%]}\end{array}$ \\
\hline 8.9 & $\begin{array}{c}\text { Mon810- } \\
\text { Novelis }\end{array}$ & 129 & 0,044 & 67 & 7 & 60 & 10,4 \\
\hline 9.13 & $\begin{array}{c}\text { Mon810- } \\
\text { Bacila }\end{array}$ & 80 & 0,195 & 43 & 3 & 40 & 7,0 \\
\hline 10.9 & $\begin{array}{c}\text { Mon810- } \\
\text { Novelis }\end{array}$ & 24 & 0,0025 & $\begin{array}{c}3 \\
(29)\end{array}$ & $\begin{array}{c}1 \\
(13)\end{array}$ & $\begin{array}{c}2 \\
(16)\end{array}$ & $\begin{array}{c}33,3 \\
(44,8)\end{array}$ \\
\hline
\end{tabular}

(..) Blätter mit deutlichen Fraßspuren.

Aus den Ergebnissen kann keine Aussage über die tatsächliche "Verunreinigung" im BtMaisfeld getroffen werden, da nur Blattstücke mit Fraßspuren untersucht und somit die Stichprobe vorselektiert war. Zusätzlich bewirkt die Biologie der beiden Events eine unterschiedliche Vorselektion, wodurch die PCR-Daten von 2000 und 2001 nicht direkt verglichen werden können. Frisch geschlüpfte Larven verteilen sich je nach Ablagetermin unterschiedlich auf den Maispflanzen (3.3). Einige Larven suchen zunächst den Kolben auf. Bt-176 produziert kein oder nur kaum Toxin im Kolben, so dass Larven, die dort fressen, nicht in Kontakt mit dem Toxin kommen. Es erfolgt somit nur teilweise eine Vorselektion. Daher liegt der Prozentsatz an Bt-Maispflanzen im Jahr 2000 mit $45 \%$ bis $89,9 \%$ sehr hoch. Im Gegensatz dazu haben überlebende Larven im Mon810-Feld entweder auf Maispflanzen überlebt, die kein Bt-Toxin expremieren, oder 
sie sind resistent. Bei den Feldern 8.9 und 9.13 handelt es sich bei $7 \%$ bzw. $10 \%$ der Pflanzen, auf denen Larven überlebt haben, um Bt-Mais. Der PCR-Nachweis gibt keine Auskunft über die tatsächliche Expremierung des Toxins in der Pflanze, so dass der Anteil an Pflanzen, die kein Bt-Toxin expremieren, höher liegt. Im Feld 10.9 wurden neben den drei Pflanzen, in denen Larven gefunden wurden, auch Pflanzen mit deutlichen Fraßschäden untersucht. Der Prozentsatz liegt mit 45 \% Bt-Maispflanzen deutlich höher als auf den beiden anderen Feldern.

Bei den Feldern 8 und 9 war der Befall in den Nicht-Bt-Feldern mit $80 \%$ bzw. $129 \%$ sehr hoch. Wird dieser Wert auf das Bt-Maisfeld übertragen, so steht jede überlebende Larve für eine Nicht-Bt-Maispflanze im Bt-Maisfeld. Homozygote resistente Larven können vernachlässigt werden, da ihr Auftreten sehr selten ist und keine resistenten Larven nachgewiesen werden konnten. Unter der Annahme, dass nur eine Larve pro Pflanze gefunden wurde, dienen die Larven als Indikator für die „Verunreinigung“ der Bt-Maisfelder mit nicht Bt-Toxin expremierender Maispflanzen, wodurch die "Verunreinigung", wie in Kapitel 9.3.3 beschrieben, berechnet werden kann. Für das Feld 9.13 liegt die "Verunreinigung" bei 0,3544\% mit einem 95\%igem Konfidenzintervall von 0 bis 1,01 und für das Feld 8.9 liegt der Wert bei 0,0609 \% $(0: 0,16)$.

6.3.2.2 Gewichte der Larven zum Sammelzeitpunkt als Maß für die Fitness der Larven im Bt-Maisfeld des Jahres 2000

Im Jahr 2000 wurde von den gesammelten Larven das Gewicht bestimmt. Da die Anzahl der Larven von Feld zu Feld schwankte, wurden nur für Felder mit ausreichender Anzahl an Larven im Bt- und im Nicht-Bt-Feld die Gewichte mit Hilfe eines t-Test auf signifikante Unterschiede untersucht (Abb. 6). Das Larvengewicht zeigte eine große Schwankungsbreite. Durch den mehrere Wochen andauernden Falterflug kam es zu einer Überschneidung von Larvenstadien im Feld, so dass im August auf einem Maisfeld mehrere Larvenstadien mit unterschiedlichem Gewicht angetroffen wurden. Zum Herbst nahm die Schwankungsbreite der Gewichte ab, da immer mehr Larven ihr Überwinterungsgewicht von über $100 \mathrm{mg}$ erreicht hatten. Kurz vor der Ernte nahm das Larvengewicht wieder leicht ab, da die Larven vor der Überwinterung Wasser ausscheiden. Im August lassen sich signifikante Unterschiede in der Gewichtsverteilung der Larven nachweisen; dabei zeigt sich der Trend, dass Larven auf Bt-Maisfelder leichter als solche auf Nicht-Bt-Maisfeldern sind. Eine Erklärung für diesen Unterschied könnte eine subletale Wirkung des Toxins darstellen. Wahrscheinlicher ist, dass in einem Bt-176-Maisfeld, also in allen im Jahr 2000 untersuchten Bt-Maisfeldern, überproportional häufig Larven überleben, die am Kolben fressen. Das Aufsuchen der Kolben ist vom Ablagetermin und von der Witterung abhängig (3.3). Durch Bt-176-Pflanzen werden bestimmte Ablagetermine selektiert, wodurch es nicht mehr zu einer starken Überschneidung von Larvenstadien kommt. Die Toxinwirkung führt somit indirekt zu einem unterschiedlichen Verteilungsmuster der Larvenstadien und der Gewichte im Bt-Feld bzw. im Nicht-Bt-Feld. 


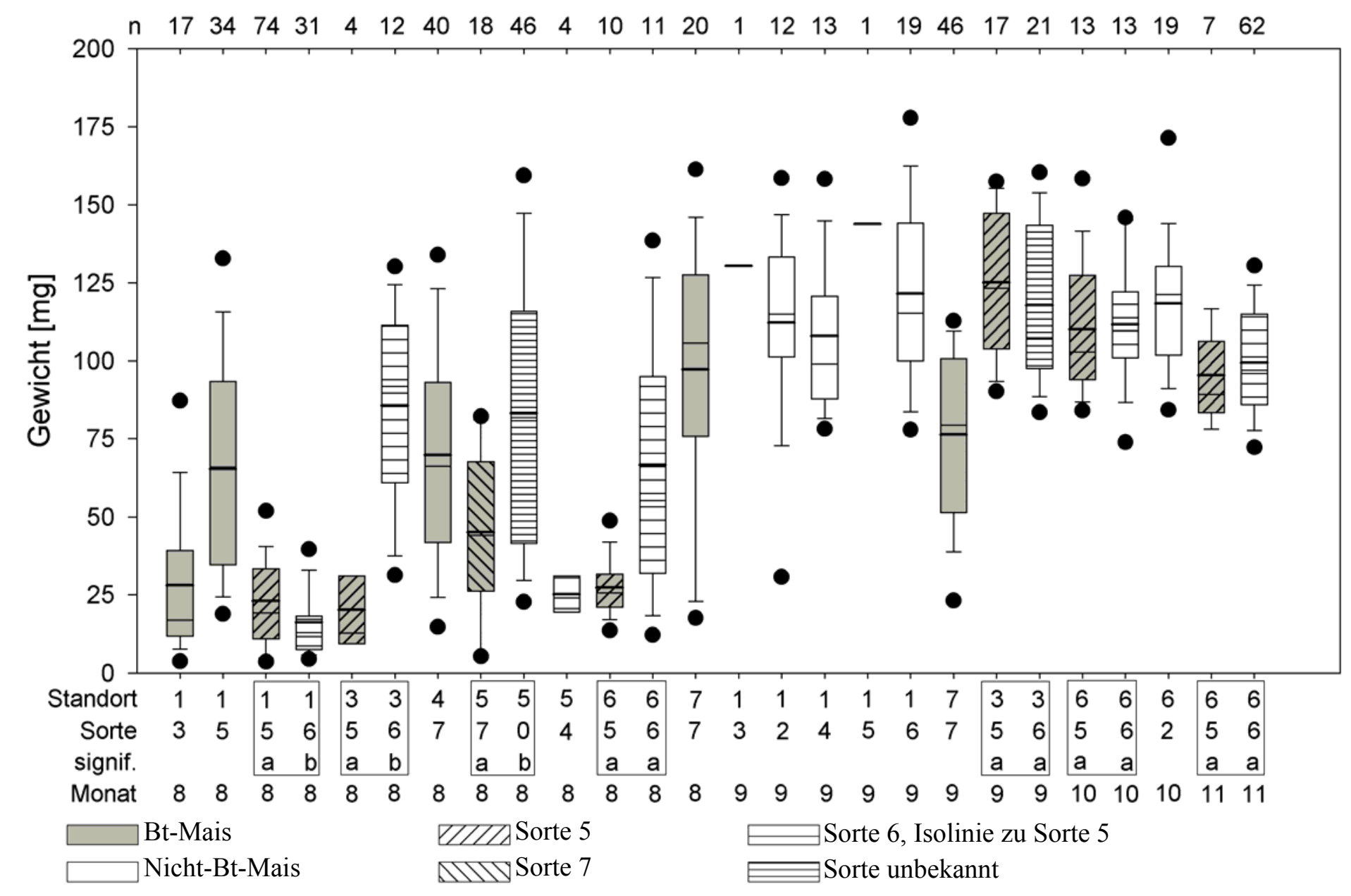

Abb. 6: Gewichte der Larven aus Bt-Maisfeldern und Nicht-Bt-Mais-Feldern zu unterschiedlichen Sammelzeitpunkten im Jahr 2000. $\mathrm{n}=$ Anzahl der gewogenen Larven; $\mathrm{D}=$ umklammerte Felder wurden durch einen $\mathrm{t}$-Test auf signifikante Unterschiede getestet; $\mathrm{a}, \mathrm{b}=$ gleicher Buchstabe bedeutet keine signifikanten Unterschiede im paarweisen Vergleich $\alpha=5 \%$. 


\subsubsection{Zucht}

Im Jahr 2000 konnten bei der Sammelaktion ein früher (bis Ende August) und ein später Sammeltermin (ab September) unterschieden werden. Larven, die im August gesammelt wurden, zeigten eine hohe Mortalität, wenn sie im Labor ohne Diapause in eine Dauerzucht überführt werden sollten. Aus diesem Grund wurden diese Larven direkt auf Bt-Maisblattstücken getestet. Während der Testung der Larven vom Sammeltermin 29.08.2000 zeigte sich aber, dass diese Larven kaum noch Blattmaterial aufnahmen. Einige Larven bohrten sich in den Wasser-Agar ein und verpuppten sich. Dies führte zu einer hohen Mortalität, die somit auf die Versuchsbedingungen und nicht auf eine BtToxin-Wirkung zurückzuführen ist. Von den direkt getesteten Larven überlebten einige den Testzeitraum von 21 Tagen. Meist waren es Larven im $\mathrm{L}_{3}-$ bis $\mathrm{L}_{4}$-Stadium, bei denen auf Grund der gestiegenen Unempfindlichkeit das Toxin nicht tödlich wirkte. Die subletale Wirkung des Toxins führte dazu, dass sich keine Larve zum Falter entwickeln konnte. Diese Larven wurden als nicht resistent gewertet.

$\mathrm{Ab}$ September wurden die Larven mit einem Maisstängelstück in einzelnen Plastikbechern zur Überwinterung in das Gewächshaus gestellt. Im Jahr 2001 wurden alle Larven kurz vor der Ernte gesammelt, so dass sie direkt in die Gewächshäuser zur Überwinterung gebracht wurden.

Tab. 44: Reduktion der Larven des Sammelzeitpunktes im Jahr 2000 bis zur Testung auf Resistenz für Larven

Anzahl (n) bzw. Prozent (\%) der gesammelten Larven im Bt-Maisfeld

\begin{tabular}{|c|c|c|c|c|c|c|c|c|}
\hline Feld-Nr. & 1B.1 & 1B.3 & $1 \mathrm{~B} .5$ & $3 \mathrm{~B} .5$ & $6 \mathrm{~B} .5$ & $5 B .3$ & 5B.7 & 7B.7 \\
\hline Gesammelte Larven & 0 & 1 & 1 & 15 & 19 & 23 & 31 & 46 \\
\hline $\begin{array}{l}\text { Im Frühjahr lebende } \\
\text { Larven }\end{array}$ & & 1 & 1 & 15 & 18 & 18 & 20 & 39 \\
\hline Wintermortalität & & & & & & & & \\
\hline Bt-Larven & & $0 \%$ & $0 \%$ & $0 \%$ & $5 \%$ & $22 \%$ & $35 \%$ & $39 \%$ \\
\hline Nicht-Bt-Larven $^{1}$ & & $27 \%$ & $12 \%$ & $4 \%$ & $25 \%$ & k.A. & $45 \%$ & k.A. \\
\hline Auf Resistenz in der $\mathrm{F}_{2^{-}}$ & & 0 & 0 & 4 & 5 & 5 & 4 & 14 \\
\hline Generation getestet & & & & $27 \%$ & $26 \%$ & $22 \%$ & $13 \%$ & $30 \%$ \\
\hline
\end{tabular}

Tab. 45: Reduktion der Larven des Sammelzeitpunktes im Jahr 2001 bis zur Testung auf Resistenz für Larven

Anzahl (n) bzw. Prozent (\%) der gesammelten Larven im Bt-Maisfeld

\begin{tabular}{lccccc}
\hline Feld-Nr. & 8.9 & 9.13 & 10.9 & 11.9 & 11.13 \\
\hline Gesammelte Larven & 68 & 73 & 3 & 0 & 0 \\
\hline Im Frühjahr lebende Larven & 53 & 49 & 3 & & \\
\hline Wintermortalität & & & & & \\
Bt-Larven & $28 \%$ & $33 \%$ & $0 \%$ & & \\
Nicht-Bt-Larven & k.A. & k.A. & k.A. & & \\
\hline Auf Resistenz in der $\mathrm{F}_{2^{-}}$ & 31 & 35 & 3 & & \\
Generation getestet & $46 \%$ & $48 \%$ & $100 \%$ & &
\end{tabular}


Im Jahr 2000 konnten durch die Wintermortalität keine Larven der Felder 1.B.3 und 1.B.5 untersucht werden. Für die anderen Felder schwankte die Wintermortalität zwischen 5 und $39 \%$. Bei den Feldern 6B.5 und 5B.7 war die Wintermortalität der Larven niedriger oder gleich der Wintermortalität der Larven aus den Nicht-BtVergleichsfeldern, was auf eine gleiche oder bessere Fitness der Larven schließen lässt. Einschränkend ist aber zu sagen, dass die Larven aus den Bt-Feldern im Gegensatz zu denen aus den Nicht-Bt-Maisfeldern einzeln gehalten wurden, so dass hier die Infektionsgefahr niedriger war. Ein weiterer Mortalitätsanstieg könnte durch die Konkurrenz in den Dosen und damit einem erhöhten Stressfaktor bewirkt worden sein. Wie beim $\mathrm{F}_{2}$-Screening spielte die Wintermortalität eine entscheidende Rolle bei der Reduktion der Isolinien.

\subsubsection{Resistenzhäufigkeit}

Die Larven von den Bt-Maisfeldern konnten nicht direkt als resistente Larven angenommen werden. Auf den Maislinien Bt-176 konnten Larven am Kolben, der kaum Toxin enthält, überleben, ohne mit dem Toxin in Kontakt gekommen zu sein. Des Weiteren führen möglicherweise Stressfaktoren wie Nährstoffmangel oder Trockenheit $\mathrm{zu}$ einer geringeren Toxinproduktion der Bt-Maispflanzen. Außerdem können die Saatgutfirmen aus technischen Gründen keine 100\%ige Reinheit des Saatguts gewährleisten. Für die Linie Mon810 im Feld 9.13 wurde die Verunreinigung mit Pflanzen, die den Larven ein Überleben ermöglichen, auf Grund keiner bzw. zu geringer Toxinproduktion auf $0,35 \%$ geschätzt, d. h. auf 1.000 untersuchte Bt-Pflanzen kommen drei bis vier Nicht-Bt-Pflanzen. Durch die PCR können die Pflanzen, die keine BtMaisgene enthalten, herausgefiltert werden und durch den Proteinnachweis lassen sich Pflanzen ohne Bt-Maisgene und solche ohne Bt-Produktion eliminieren. Beide Verfahren sind aufwändig und haben eine bestimmte methodenbedingte Genauigkeit, so dass ein Biotest der Larven auf Resistenz notwendig ist. Während der Zucht bis zur $\mathrm{F}_{2^{-}}$ Generation und durch die Wintermortalität ist es möglich, dass Isolinien mit resistenten Larven verloren gehen. Für die Berechnung der Resistenzhäufigkeiten wurde daher die untersuchte Pflanzenzahl entsprechend dem Anteil der untersuchten Larven an der Gesamtzahl der gesammelten Larven korrigiert. Für das Jahr 2001 wurden die Daten zusammengefasst. Die Anzahl der untersuchten Pflanzen im Bt-Maisfeld wurde auf einen theoretischen Befall von $100 \%$ umgerechnet und anschließend summiert. 
Tab. 46: Berechnung der Resistenzhäufigkeit [q] für die Standorte im Jahr 2001

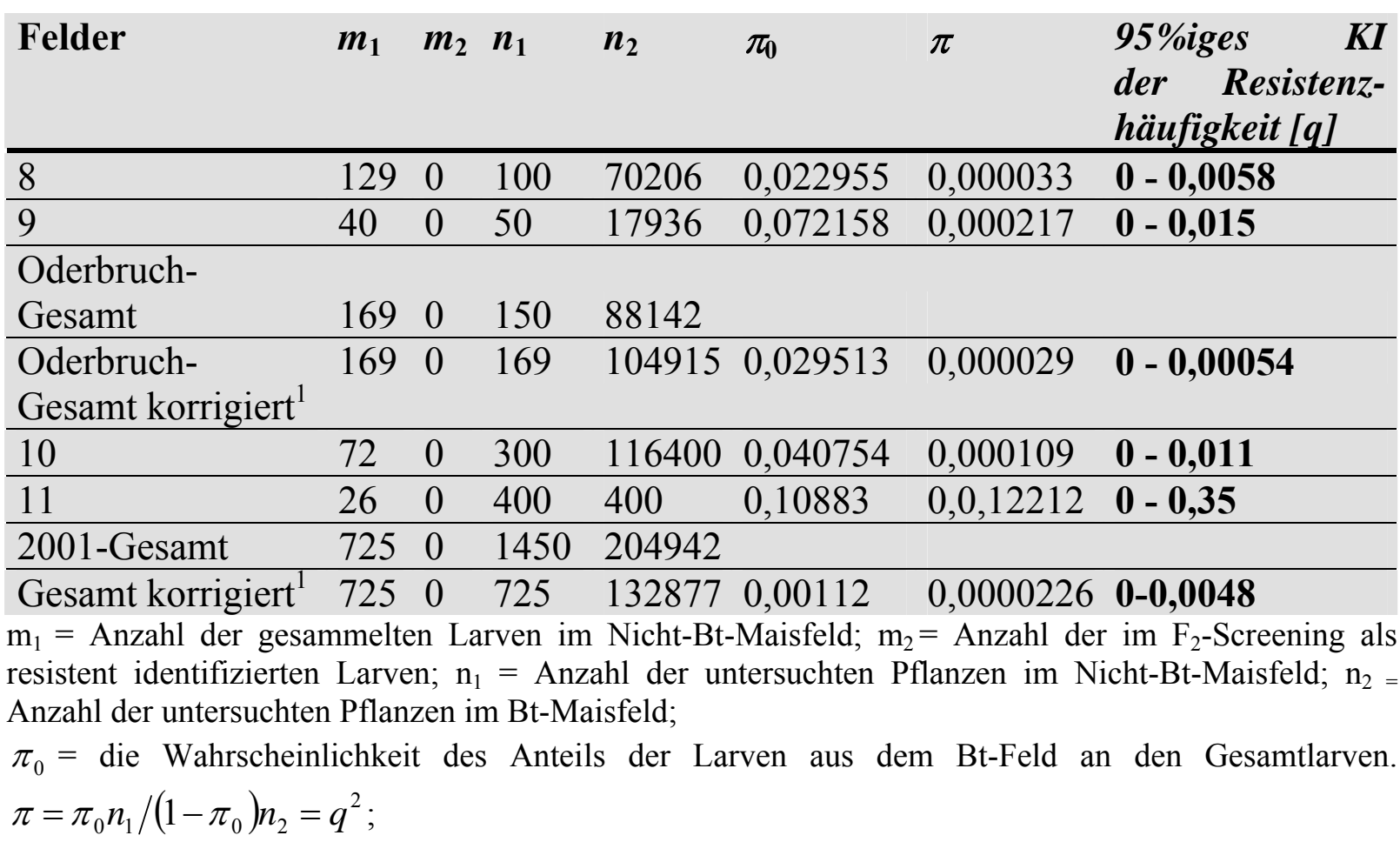

${ }^{1}$ Für das Jahr 2001 wurden die Daten zusammengefasst. Die Anzahl der untersuchten Pflanzen im BtMaisfeld wurde auf einen theoretischen Befall von $100 \%$ umgerechnet und anschließend summiert.

\subsubsection{Vergleich der Methoden $F_{2}$-Screening und Screening auf Bt-Maisfeldern}

Der Arbeitsaufwand pro Isolinie wird durch das Sammeln der Larven sowie durch die Zucht und die Testung bestimmt.

Durch den geringen Befall im Bt-Mais ist der Aufwand beim Sammeln im Bt-Mais pro Isolinie, trotz der angepassten Sammelstrategie, höher als im Nicht-Bt-Maisfeld. Die Testung und Zucht ist für das Screening auf Nicht-Bt-Maisfelder aufwändiger pro Isolinie als für das Screening auf Bt-Maisfeldern, da durch die Selektion homozygoter Larven im Bt-Mais die Entdeckungswahrscheinlichkeit resistenter Larven in der $\mathrm{F}_{2}$ Generation höher ist. Werden beide Vor- und Nachteile zusammengefasst, ist der Arbeitsaufwand pro Isolinie für beide Methoden annährend gleich. Die effizientere Methode sollte bei gleicher Anzahl untersuchter Isolinien (x) eine kleinere Varianz für die Resistenzallelfrequenz (q) besitzen.

Die Effizienz lässt sich somit als Quotient der Varianzen der Methode A (Screening auf Nicht-Bt-Maisfelder) durch die Methode B (Screening auf Bt-Maisfeldern) bei gleicher Resistenzfrequenz und gleicher Isolinienzahl berechnen (Piepho, pers. Mitt.):

Effizienz $=\operatorname{Varianz}(\mathrm{A}) / \operatorname{Varianz}(\mathrm{B})=\frac{\frac{q(1-4 q)}{4 x}}{\frac{q^{2}\left(1+\beta / q^{2}\right)}{8 x}}=\frac{2 q(1-4 q)}{q^{2}\left(1+\beta / q^{2}\right)}=\frac{2(1 / q-4)}{\left(1+\beta / q^{2}\right)}$

(Anlage 9.3.3)

Die Anzahl der zu untersuchenden Isolinien von Bt-Maisfeldern hängt von der „Verunreinigung“ dieser Felder mit Pflanzen, die kein Toxin produzieren, und von der Resistenzhäufigkeit ab. Für die Abb. 7 wurde die Effizienz (E) auf einer logarithmischen Skala angegeben. 


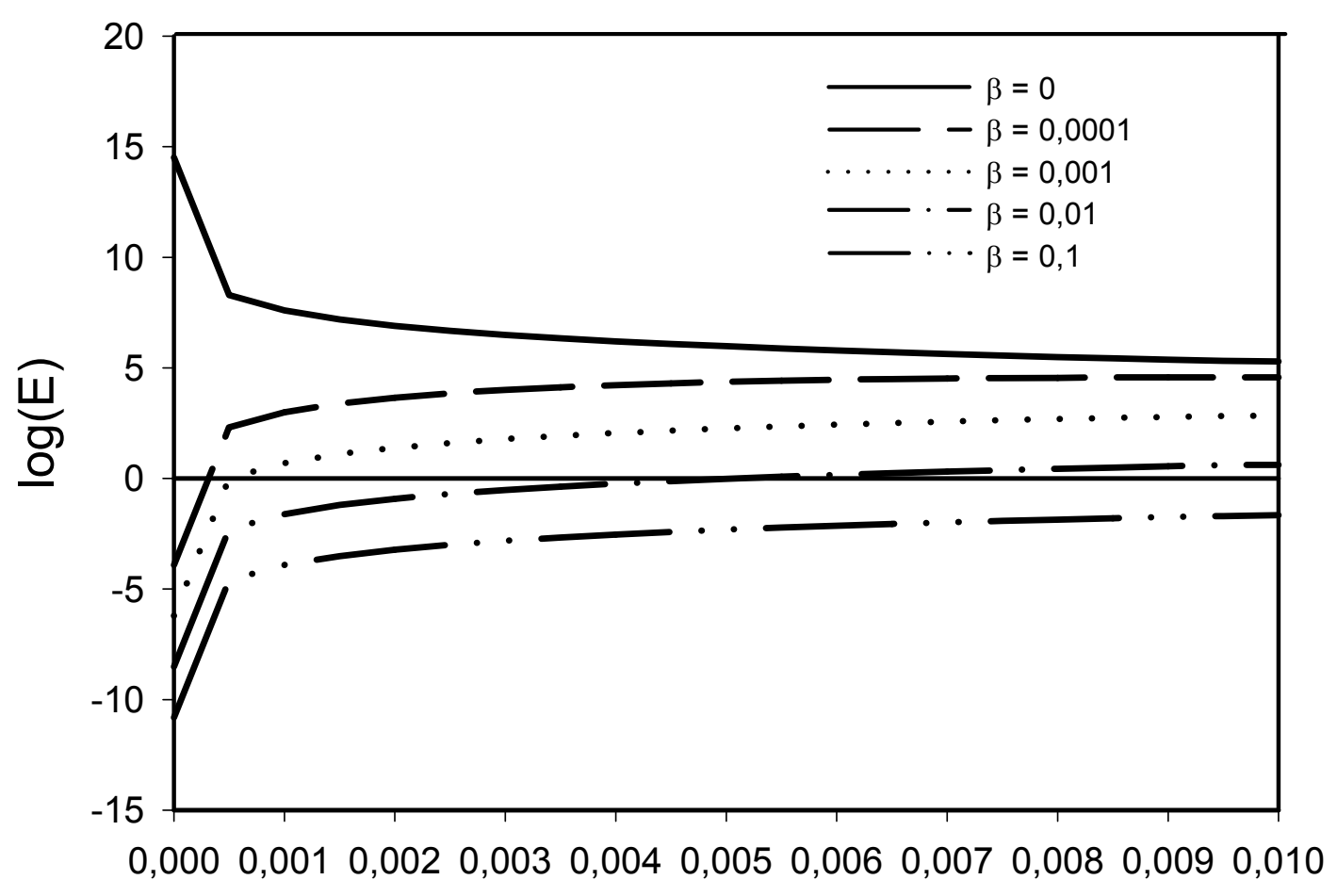

q

Abb. 7: Effizienz der Methoden $\mathrm{F}_{2}$-Screening auf Nicht-Bt-Maisfeldern und Screening auf Bt-Maisfeldern für vier Verunreinigungs-Stufen ( $\beta$ ) der Bt-Maisfelder.

Anteil Nicht-Bt-Pflanzen in Prozent der Gesamtpflanzen auf einem Bt-Maisfeld:

$\beta=0,1 \% ; \beta=0,01 \% ; \beta=0,001 \% ; \beta=0,0001 \% ; \beta=0 \%$.

$\mathrm{q}=$ Resistenzfrequenz, $\mathrm{E}=\mathrm{Effizienz}=\operatorname{Varianz}(\mathrm{A}) / \operatorname{Varianz}(\mathrm{B})$.

Ist der $\log (\mathrm{E})>0$, besitzt das $\mathrm{F}_{2}$-Screening auf Nicht-Bt-Maisfelder (Methode A) eine größere Varianz und eine geringere Effizienz. Ist der $\log (\mathrm{E})<0$, hat das Screening auf Bt-Maisfeldern (Methode B) eine größere Varianz.

Für die Durchführung des "Refugien/Hoch Dosis"-Resistenzmanagements sollte eine Resistenzfrequenz von $0,001=10^{-3}$ nicht überschritten werden. Unterhalb dieser Resistenzfrequenz ist das $\mathrm{F}_{2}$-Screening auf Nicht-Bt-Maisfeldern dem Screening auf BtMaisfeldern bis zu einer „Verunreinigung“ von $0,001 \%$ in der Bestimmung der Resistenzallelfrequenz überlegen. Bei keiner Verunreinigung der Bt-Felder ist es effizienter im Bt-Maisfeld zu sammeln. 


\subsection{Diskussion}

Das Screening von Bt-Maisfeldern auf homozygot resistente Maiszünslerlarven wurde von Venette et al. (2000) als Alternative bzw. Ergänzung zum $\mathrm{F}_{2}$-Screening von rezessiven Resistenzallelen auf Nicht-Bt-Maisfeldern entwickelt.

In Deutschland wurden in den Jahren 2000 und 2001 einige hundert Hektar Bt-Mais angebaut (Degenhardt et al., 2003). Auf diesen Feldern sollten resistente Maiszünsler gesammelt werden, die für die Untersuchung der physiologischen Ursachen der Resistenzentstehung verwendet werden sollten. Daher bot es sich an die Resistenzfrequenz mit einer angepassten Methode von Venette zu bestimmen.

\subsubsection{Vergleich der Monitoring-Methode von Venette (2000) mit der in dieser Arbeit durchgeführten Methode}

In einigen wichtigen Punkten weicht die in dieser Arbeit durchgeführte Untersuchung von der von Venette et al. (2000) vorgeschlagen Methode ab. In den folgenden Abschnitten werden die Ergebnisse dieser Untersuchungen und der Einfluss der unterschiedlichen Methodik diskutiert.

\subsubsection{Parzellen-Versuch versus Praxisanbau}

Venette (2000) führte die Versuche in Parzellen-Anlagen durch, wobei die Nicht-BtSorte direkt benachbart lag. In den eigenen Untersuchungen wurden an den Standorten 10 und $11 \mathrm{im}$ Jahr 2001 Parzellen-Versuche mit benachbarten isogenen Nicht-Bt-Sorten durchgeführt, wobei der Standort 10 als randomisierte Blockanlage angelegt war. Bei den anderen Feldern lagen die Vergleichsflächen in einem Umkreis von maximal 50 Metern. Im Gegensatz zu Venette (2000) wurden die Untersuchungen auf verschiedenen Feldern mit unterschiedlichen Größen durchgeführt. Die sich hieraus ergebenden Unterschiede in der Befallserhebung werden in Kapitel 6.4.7 diskutiert.

\subsubsection{Süßmais versus Futter- bzw. Stärkemais}

Die Untersuchungen von Venette (2000) wurden mit Bt-Süßmais durchgeführt, wobei über das verwendete Bt-Mais-Event keine Angaben gemacht wurden. Aus den Angaben lässt sich der Rückschluss ziehen, dass Linien, die in allen Pflanzenteilen das Toxin produzieren, verwendet wurden. In den eigenen Versuchen wurden im Jahr 2000 Linien des Events Bt-176 untersucht, die im Kolben kein oder nur geringe Mengen an Bt-Toxin produzieren. Im Jahr 2001 wurde mit Linien des Events Mon810 gearbeitet, die im Kolben eine hohe Toxinkonzentration expremieren. Bt-Süßmais wurde nicht untersucht, da dieser in Deutschland nicht angebaut wird. Eine Bewertung der verwendeten MaisEvents erfolgt in Kapitel 6.4.3.

\subsubsection{Sammelstrategie zur Entdeckung resistenter Larven}

Die Untersuchungen von Venette (2000) wurden während des Befalls der 2. Generation durchgeführt. Für die Maiszünsler der 2. Generation auf Süßmais stellt der Kolben die attraktivste Nahrungsquelle dar, so dass sich Venette (2000) auf die Kontrolle der Kolben konzentrieren konnte. In Deutschland kommt es zur Ausbildung von nur einer Maiszünslergeneration und der Kolben ist nicht das attraktivste Ziel für die 
Maiszünslerlarven. Aus diesem Grund wurde im Jahr 2001 nach den Erfahrungen des Vorjahres die gesamte Pflanze auf Schadsymptome untersucht. Da für das Aufschneiden der Pflanzen ca. drei Minuten benötigt werden, schied diese Untersuchungsmethode bei der benötigten Pflanzenboniturzahl aus. Die visuelle Bonitur der Gesamtpflanze benötigt weniger als 5 s/Pflanze, wobei beim Auftreten von Schadsymptomen ein Aufschneiden der Pflanzen notwendig war. Der Befallsdruck wird im Nicht-Bt-Mais durch das Aufschneiden von Pflanzen erhoben. Die Stichprobengröße sollte sich nach der Gesamtzahl der im Bt-Maisfeld untersuchten Pflanzen richten, um den Arbeitsaufwand zu minimieren. In dieser Arbeit wurde zum Teil auf externe Befallserhebung in benachbarten Versuchsanlage zurückgegriffen. Dies ermöglichte eine Konzentration auf das Sammeln im Bt-Mais. Der Nachteil ist, dass die Stichprobengröße nicht beeinflusst werden kann und es zu einem Ungleichgewicht in der Anzahl der untersuchten Bt-Mais-Pflanzen und der für den Befallsdruck untersuchten Nicht-Bt-Maispflanzen kommt.

\subsubsection{Statistik}

Die Statistik in dieser Arbeit geht von einem Frequentistischen Ansatz aus, während Venette einen Baye'schen Ansatz wählte (vergleiche Kapitel 5.4.2). Zur Vereinfachung der Berechnung wurde angenommen, dass der Befall im Nicht- und im Bt-Mais einer Poisson-Verteilung entspricht. Die Vererbung der Resistenzallele wurde als vollständig rezessiv angenommen, so dass der Dominanzgrad $h=0$ ist und nicht weiter berücksichtigt wurde. Venette diskutiert die Möglichkeit der Verwandtschaft zweier Larven, die im Bt-Maisfeld und besonders auf einer Bt-Maispflanze gefunden wurden und berechnet einen Korrekturfaktor. Da in den eigenen Untersuchungen keine resistenten Larven gefunden wurden, erübrigte sich die Korrektur der Daten.

\subsubsection{Bewertung des Sammelzeitpunktes für die Bestimmung der Resistenzhäufigkeit}

Im Jahr 2000 wurden die Sammeltermine in einen frühen und in einen späten Zeitpunkt unterschieden. Durch einen frühen Sammeltermin und eine direkte Testung der Larven ließen sich die Kosten für das Screening reduzieren. Zum einen entfiel die aufwändige Zucht bis zur $\mathrm{F}_{2}$-Generation und zum anderen konnte über alle gesammelten Larven eine Aussage zur Resistenz gemacht werden. Beim späten Sammeltermin musste die gefundene Larvenanzahl nach unten korrigiert werden, da während der Zucht die Larven durch die hohe Wintermortalität reduziert wurden. Im Durchschnitt konnte für die Hälfte bis zu einem Drittel der gesammelten Larven eine Aussage über ihre Resistenz anhand der $\mathrm{F}_{2}$-Generation gemacht werden. Der Nachteil des frühen Sammelzeitpunktes liegt darin, dass Fraßspuren, die erst schwach ausgeprägt sind, und damit auch resistente Larven im Feld übersehen werden. Für die Berechnung der Resistenzhäufigkeit ist die Annahme einer möglichst vollständigen Auffindung von resistenten Larven ausschlaggebend. Bei einem späten Sammeltermin können die Schadsymptome wie abgeknickte Stängel, Bohrmehl in den Blattachseln, Lochfraß an den Blättern und am Stängel und zum Teil eine Rotverfärbung der Blätter leicht erkannt werden. Durch das Aufschneiden der Pflanzen mit Schadsymptomen können die Symptome dem Verursacher direkt zugeordnet werden. 
Die Streuung der Larvenstadien zu einem frühen Sammelzeitpunkt (Abb. 6) führte dazu, dass die Toxinkonzentration hoch gewählt werden musste, da ältere Larvenstadien eine geringere Empfindlichkeit als jüngere Larven besitzen (Huang et al., 1999a). Die Gefahr von Falsch-Positiv-Entscheidungen nimmt daher stark zu.

Um die beiden Sammeltermine abschließend bewerten zu können, müssten Tests über die Wiederauffindrate im Bt-Maisfeld gemacht werden. Um einen Befall von $5 \pm 5 \%$ mit einem $\alpha=5 \%$ abzusichern, müssten ca. 70 Pflanzen abgesucht und nachträglich aufgeschnitten werden. Bei einem Befall von $0,5 \pm 0,5 \%$ wären dazu fast 800 Pflanzen nötig. Da die Hauptintention der Sammelaktion das Auffinden resistenter Maiszünsler war, konnte dieser Aufwand nicht geleistet werden.

\subsubsection{Eignung des Bt-Events zur Bestimmung der Resistenzhäufigkeit}

Werden die Bt-Nachweise mit Hilfe der PCR der Pflanzen mit Larven von Bt-176Feldern mit denen von Mon810-Felder verglichen, so zeigt sich, dass Bt-176 mit $45 \%$ bis $89 \%$ einen höheren Bt-Nachweis als Mon810 mit $7 \%$ bis 10,4\% hatte (siehe Tab. 43, Feld 10 mit $33 \%$ kann wegen der geringen Zahl untersuchter Pflanzen ( $n=3)$ nicht gewertet werden). Werden bei Mon810 die Pflanzen mit Schadsymptomen untersucht, steigt der Anteil der Bt-Nachweise auf 44,8 \%. Da keine Resistenz bei den Larven nachgewiesen wurde, wurden im Bt-176-Maisfeld ca. sechs Mal mehr Falsch-PositiveEntscheidungen getroffen, d. h. es wurden Larven gefunden, die nicht resistent sind. Der Unterschied ist durch die geringe Toxinkonzentration im Kolben von Bt-176 zu erklären, der den Larven ein Überleben auf Bt-Maispflanzen ermöglicht hatte (Meise und Langenbruch, 1999). Ob das Aufsuchen der Kolben bzw. Pflanzen oder Pflanzenteile mit geringer Toxinproduktion eine aktive Vermeidung des Toxins durch die Larven ist und somit einer Verhaltensresistenz gleich kommt, konnte nicht nachgewiesen werden. Versuche mit einem Teil der Larven aus den Bt-176-Feldern zeigten keine Hinweise, da durch die große Variabilität der Larvenstadien und Larvengröße sowie durch die spezifische Toxinwirkung, die zunächst zu einem Fraßstopp führte, ein möglicher Effekt einer Verhaltensresistenz überlagert wurde (nicht veröffentlichte Daten, Meise 2000).

Für die Bestimmung der Resistenzhäufigkeit ist die Minimierung von Falsch-PositivenEnscheidungen und damit die Reduzierung des Arbeitsaufwandes sinnvoll. Daher sind Maislinien zu bevorzugen, die möglichst alle empfindlichen Larven abtöten und nur homozygot resistenten Larven ein Überleben ermöglichen. Die Reinheit des Saatgutes und die Stabilität der Toxinexpression spielten hierbei eine wichtige Rolle. Je größer die Reinheit und je größer die Stabilität umso weniger Falsch-Positive-Entscheidungen werden im Feld getroffen und müssen durch ein aufwändiges $\mathrm{F}_{2}$-Screening oder durch Bt-Toxinschnelltests eliminiert werden.

\subsubsection{Reinheit der Bt-Maisfelder}

Bt-Maisfelder sind mit nicht Bt-Toxin-expremierenden Pflanzen "verunreinigt". Es gibt verschiedene Möglichkeiten die zu dieser "Verunreinigung" führen können. Konventioneller Mais kann durch Reste in der Sämaschine oder durch Verwechselungen von Saatgut ausgebracht werden, wie es im Jahr 2001 bei Feld 9 vorgefallen ist (Tab. 41). Die Saatgutvermehrung kann keine 100\%ige Reinheit gewähren und laut Sortenschutzgesetzt werden $2 \%$ Verunreinigungen toleriert 
(BRD, 1997). Neben dem Nicht-Bt-Maissaatgut kann es bei Bt-Maispflanzen zu Störungen in der Expression kommen, so dass Maispflanzen zwar das Gen für die Toxinproduktion besitzen, das Protein aber nicht oder in geringer Konzentration expremieren. So ist denkbar, dass Stressfaktoren wie Trockenheit oder Nährstoffmangel eine Toxinproduktion verhindern. Genaue Daten zu diesem Phänomen liegen nicht vor, da die meisten Autoren in ihren Veröffentlichungen zur Stabilität und Expression Mittelwerte angeben. Der Fokus dieser Untersuchungen liegt meist im Nachweis der durchschnittlichen Stabilität und nicht im Nachweis der sehr seltenen Ausfälle einzelner Pflanzen. Ostlie et al. (1997, in Venette et al., 2000) schätzen den Prozentsatz von Pflanzen, die aus den oben genannten Gründen kein oder nur wenig Toxin enthalten, auf bis zu $4 \%$. In Kapitel 6.3.2.1 wurde die Verunreinigung mit Hilfe der gefundenen Larven (jede Larve steht für eine Pflanze mit keiner oder $\mathrm{zu}$ geringer Toxinkonzentration) für das Event Mon810 bestimmt. Für das Feld 9, indem auch aus Versehen geringe Mengen Nicht-Bt-Mais ausgesät wurden, lag die Verunreinigung bei $0,3544 \%$ und für das Feld 8 bei $0,0609 \%$. Beide Werte liegen weit unter dem vom Sortengesetz geforderten Wert von $2 \%$. Die Werte unterschätzen wahrscheinlich die Verunreinigung, da die Berechnung stark vom Befallsdruck abhängig ist. Für die Berechnungen der Resistenzhäufigkeiten wurden die Pflanzenzahlen nicht mit Hilfe der geschätzten Verunreinigung korrigiert, da die Schätzung selbst eine zu große Unsicherheit in sich trägt und nicht für alle Felder möglich war. Die Resistenzhäufigkeit wird hierdurch zu niedrig geschätzt.

Neben Nicht-Bt-Toxin-expremierenden-Maispflanzen können für junge Larven Wildkräuter im Feld oder am Feldrand eine Nahrungsquelle bieten (Losey et al., 2001). Durch Herbizidspritzungen ist diese Möglichkeit in der Praxis aber sehr unwahrscheinlich. Bei Bt-Linien, die nicht in allen Pflanzenteilen das Toxin produzieren wie z. B. Bt-176, können diese Pflanzenteile ebenfalls als Nahrungsquelle für Larven dienen.

Venette et al. (2000) versuchten die "Verunreinigung" durch einen Bt-ToxinSchnelltest zu verringern, indem sie die Pflanzen, auf denen Larven gefressen hatten, auf das Toxin testeten. Es ist fraglich, ob der Schnelltest eine sichere Aussage über die Resistenz der Larven gibt. Die Nachweisgrenze der Teststäbchen liegt weit unter der toxischen Konzentration des Bt-Toxins. Eine Verdünnung des Pflanzenextraktes um 1:1000 ergibt immer noch ein deutliches Signal (Kaiser-Alexnat, pers. Mitt.), so dass sich mit diesem Test praktisch nur Fremdsaatgut ausschließen lässt. Pflanzen mit geringer Toxinproduktion oder Larven, die an Pflanzenteilen ohne Toxinexpression gefressen haben, werden nicht identifiziert. Weiterhin wechseln die Larven während der Vegetationszeit die Maispflanzen, so dass bei einer starken "Verunreinigung" vor der Ernte ein Wechsel von resistenten Larven auf eine Nicht-Bt-Maispflanze möglich ist. Da dieser Fall selten ist, spielt er für die Berechnungen der Resistenzhäufigkeit bei einer geringen Verunreinigung keine Rolle. Bei der Bestimmung anhand der PCR gelten die gleichen Überlegungen wie für den Protein-Test. Beide Methoden liefern einen Hinweis auf welche Larven man sich bei der Testung konzentrieren sollte, aber nicht darauf, ob die gefundenen Larven tatsächlich phänotypisch resistent sind. 


\subsubsection{Bewertung der Annahmen zum Befallsdruck}

Für die Berechnung der Resistenzhäufigkeit werden in dieser Arbeit und von Venette et al. (2000) verschiedene Annahmen zum Befallsdruck getroffen.

6.4.5.1 Vergleich des Eiablageverhaltens der Maiszünsler in Bt-Mais- und Nicht-BtMaisfeldern

Für den Befallsdruck ist unter anderem das Eiablageverhalten ausschlaggebend. Verschiedene Studien zeigten, dass es keine Unterschiede im Eiablageverhalten zwischen Bt-Mais und isogener Nicht-Bt-Maissorten in kleinparzelligen Versuchen gibt (Orr und Landis, 1997, Hellmich et al., 1999). Langenbruch (pers. Mitt.) ermittelte am Standort 1 sowohl zwischen den Bt-Sorten und den isogenen Sorten, als auch innerhalb der Nicht-Bt-Sorten bzw. der Bt-Linien Unterschiede im Ablageverhalten. Da die Anlage nicht randomisiert angelegt war, konnten die Unterschiede zum Teil mit der Nähe zum benachbarten Vorjahres-Maisfeld, von dem die Neubesiedlung startete, erklärt werden. Aber auch die unterschiedliche Wuchshöhe zum Zeitpunkt des Falterflugs kann die Attraktivität der Maispflanzen beeinflussen. Da es schon bei kleinparzelligen Versuchen zu Unterschieden im Befallsdruck kommt, sind bei praxisnah bewirtschafteten Feldern die Daten zum Befallsdruck mit großer Zurückhaltung zu bewerten. Noch unsicherer ist die Verwendung des Befalls von nichtisogenen Maisfeldern. Magg (pers. Mitt.) ermittelte 2001 am Standort acht in einer randomisierten Versuchsanlage den höchsten Befallsdruck bei der Nicht-Bt-Sorte Nobilis mit $129 \%$ und den niedrigsten bei Prelude mit $25 \%$. Der Unterschied wurde wahrscheinlich durch die Stängelhärte der Sorten und der Pflanzenattraktivität während des Maiszünslerfluges verursacht. Ohnesorge und Reh (1987) stellten in ihren Untersuchungen starke Schwankungen im Befall von $50 \mathrm{~m}$ entfernten Maisfeldern fest und vermuteten einen Einfluss des Entwicklungsstadiums. Die gewählte Sorte hat somit einen entscheidenden Anteil an der Bestimmung der Resistenzhäufigkeit. Bei einem um die Hälfte niedrigeren Befallsdruck sinkt die berechnete Resistenzhäufigkeit um das 0,7-fache. Trotz dieser Schwierigkeiten wurde in dieser Arbeit eine Vergleichbarkeit der Befallsdrücke angenommen, was bei der Interpretation berücksichtigt werden muss.

\subsubsection{2 Ähnlichkeit des Verteilungsmusters der Maiszünslerlarven zwischen Bt-Mais- und Nicht-Bt-Maisfeldern}

Venette (2000) nimmt weiter an, dass das Verteilungsmuster in einem Bt-Maisfeld dem im Nicht-Bt-Maisfeld entspricht. Bei einem hohen Befall von $100 \%$ trifft diese Annahme sicher zu. Bei einem sehr geringen Befall z. B. unter $10 \%$ kann nicht mehr von einem gleichmäßigen Befall ausgegangen werden, da sich die Larven um ihre Ablegepflanze verteilen und es so zu Befallsinseln kommen kann. In einem Bt-Maisfeld werden sich die Larven weniger verteilen, da sie evtl. auf ihrer Ablegepflanze durch die Toxinwirkung sterben. Da die meisten Untersuchungen durch den hohen Befallsdruck einen Befall ohne Befallsinseln zeigten bzw. bei geringem Befallsdruck die Erhebung in Parzellenversuchen durchgeführt wurde, wurden für die Verteilung der Larven im BtMais eine Poisson-Verteilung angenommen. 
6.4.5.3 Unterschiede in der natürlichen Mortalität der Larven zwischen Bt-Mais- und Nicht-Bt-Maisfeldern

Unterschiede in der natürlichen Mortalität von Maiszünslerlarven im Bt-Mais und Nicht-Bt-Mais sind umstritten. Es gibt einige Literaturstellen die einen negativen Einfluss von Bt-Toxin auf Predatoren postulieren (Hilbeck et al., 1999), während andere keine Unterschiede bzw. eine höhere Predatorendichte im Bt-Mais in ihren Untersuchungen nachgewiesen haben (Orr und Landis, 1997). Unterschiedliche Predatorendichte bzw. Schädigung der Predatoren können den Faktor der natürlichen Mortalität beeinflussen. Übersichten zu Untersuchungen auf Nicht-Zielorganismen inklusive der Predatoren finden sich bei Hilbeck et al. (2000) und Novartis (1999). Insgesamt kann angenommen werden, dass die natürliche Mortalität inklusive der Predatoren zwischen Bt-Mais und isogener Linie ähnlich ist, da die postulierten Effekte meist chronischer Natur sind und erst bei längeren Untersuchungsintervallen von mehreren Jahren zum Tragen kommen würden. Größere Unterschiede können sich beim Vergleich Nicht-isogener-Sorten ergeben bzw. wenn die Vergleichsflächen andere zeitliche und räumliche Strukturen aufweisen.

\subsubsection{Bestätigung der Resistenz der auf Bt-Mais gesammelten Larven}

In Kapitel 6.4.3 und 6.4.4 wurde diskutiert, dass durch die "Verunreinigung" der BtMaisfelder nicht bei allen Larven, die in einem Bt-Maisfeld gesammelt wurden, von einer Resistenz ausgegangen werden kann. Daher ist es nötig, die Resistenz der Larven durch einen Biotest nachzuweisen. Wie in Kapitel 5.4.1.1 beschrieben, erlaubt nur ein früher Sammeltermin eine direkte Testung der Larven, wobei die Testung von $\mathrm{L}_{2-3}-$ Larven eine höhere Toxinkonzentration als von $\mathrm{L}_{1}$-Larven benötigt. Huang et al. (1999a) geben für $\mathrm{L}_{3-5}$ gegenüber den $\mathrm{L}_{1}$-Larven eine bis $\mathrm{zu}$ hundertfach niedrigere Empfindlichkeit gegenüber dem Bt-Präparat DIPEL ${ }^{\circledR}$ an. Weswegen die Resistenz bei den meisten Larven nur anhand der nächsten Generationen getestet wurde. Da bei keiner gesammelten Larve bekannt ist, ob sie tatsächlich resistent ist, und da keine homozygot resistenten Larven als Kreuzungspartner zur Verfügung standen, wurden die verpaarten Larven als Isolinien gehalten und in der $\mathrm{F}_{2}$-Generation auf Resistenz getestet. Bei der Kreuzungsvariante eines homozygot resistenten Falters (rr) mit einem homozygot empfindlichen Falter (ss) sind alle Nachkommen in der $\mathrm{F}_{1}$-Generation uniform (1. Mendelsches Gesetz), und in der $F_{2}$-Generation treten mit einer Wahrscheinlichkeit von 1/3 homozygot resistente Larven auf (2. Mendelsches Gesetz). Bei der Kreuzung rs x ss liegt die Wahrscheinlichkeit in der $F_{2}$-Generation bei 1/16 (5.1). Bei der Durchführung der Biotests wurde versucht sich an die Vorgaben des $\mathrm{F}_{2}$ Screenings für heterozygote Individuen $\mathrm{zu}$ halten, so dass bei allen Isolinien eine Entdeckungswahrscheinlichkeit von fast $100 \%$ erreicht wurde. Bei der Weiterzucht der Larven kommt es, wie schon in 5.4.1.2 beschrieben, durch die Wintermortalität und durch die Einstellung von Isolinien während der Zucht zur Reduktion der Larvenanzahl. Die Wintermortalität lag für die Larven aus dem Jahr 2000 zwischen 0 und $39 \%$ und für die Larven aus dem Jahr 2001 zwischen 0 und $33 \%$ und damit unter der Wintermortalität der Larven aus dem $\mathrm{F}_{2}$-Screening für den Standort Niedernberg (5.3.2.2). Venette et al. (2000) rechneten in Minnesota mit einer Mortalität der $\mathrm{L}_{5^{-}}$ Larven aus natürlichen Gründen von $40 \%$. Kritisch anzumerken ist, dass die Wintermortalität nur über alle Larven ermittelt werden konnte. Carrière et al. (2001) 
konnten für Bt-Baumwolle-resistente Pectinophora gossypiella-Stämme einen Fitnessnachteil während der Überwinterung feststellen. Ein ähnlicher Effekt bei Ostrinia nubilalis wäre durch die große Anzahl der nicht-resistenten Larven in den hier vorgestellten Untersuchungen überdeckt worden, wodurch die Resistenzhäufigkeit zu niedrig geschätzt worden wäre. Auffällig bei den Versuchen ist, dass der Paarungserfolg in der Eltern- und $\mathrm{F}_{1}$-Generation sehr gering ist. $27 \%$ der Larven des Jahres 2000, die den Winter überlebt hatten, und $67 \%$ der Larven des Jahres 2001 wurden erfolgreich in der Elterngeneration verpaart. Die Gründe für diesen hohen Prozentsatz wurden nicht ermittelt. $\mathrm{Zu}$ vermuten ist, dass die nicht schwankenden Temperaturbedingungen in den Gewächshäusern und die künstliche Paarungssituation einen großen Anteil hatten. Eine Selektion bei der Partnerwahl, die nicht unbedingt resistenzspezifisch sein muss, und Fertilitätsprobleme, die unabhängig von der übrigen Fitness sind, können nicht ausgeschlossen werden und können bei den Faltern, die keine Wahlmöglichkeit hatten, zu einer reduzierten bzw. keiner Reproduktion geführt haben. Führen subletale Effekte zu einer geringen Fitness der resistenten Larven, so wird die Resistenzhäufigkeit in der Stichprobe unterschätzt.

Da die direkte Testung, wie in Kapitel 6.4.2 beschrieben, keine optimale Lösung für die Testung der Resistenz ist und eine Kreuzung mit einem resistenten Stamm in den meisten Fällen nicht durchgeführt werden kann, weil bisher keine resistenten Stämme vorliegen bzw. nur der im Laborstamm vorliegende Resistenzmechanismus entdeckt würde, sollte besonders Wert auf die Zuchtbedingungen und das Paarungsverhalten der Maiszünsler gelegt werden. Bei der Berechnung werden die untersuchten Pflanzen mit dem Quotienten "auf Resistenz untersuchte Larven/gesammelte Larven" korrigiert, so dass ein Teil des Aufwandes beim Sammeln verloren geht. Sollte bei zukünftigen Versuchen die Zucht weiter optimiert und der Quotient nahe eins gehalten werden, steigt sich die Effizienz dieser Methode.

\subsubsection{Bewertung der Resistenzhäufigkeit}

Bei keiner der Larven, die auf Bt-Maisflächen gefunden wurde, konnte im Biotest eine Resistenz nachgewiesen werden. Für die Resistenzhäufigkeit wird daher ein Konfidenzintervall angegeben, indem mit 95\%iger Sicherheit die Resistenzfrequenz liegt. Die obere Grenze des Intervalls, das mit der unteren Grenze die 0 einschließt, kann dazu dienen, höhere Resistenzhäufigkeiten auszuschließen. Die Breite des Konfidenzintervalls ist abhängig von der Anzahl der untersuchten "tatsächlichen" BtMaispflanzen und dem Befallsdruck, der im benachbarten Nicht-Bt-Maisfeld erhoben wird. Um die Resistenzhäufigkeit auf unter $10^{-3}$ schätzen zu können, müssen bei einem 100\%igen Befall im Nicht-Bt-Mais über 3.000.000 Bt-Maispflanzen, d. h. mehr als 37,5 ha abgesucht werden. Da für die meisten Flächen im Jahr 2000 keine Daten zum Befallsdruck vorhanden waren bzw. die Stichprobengröße auf den Pazellenversuchen nicht ausreichte, konnte für das Jahr 2000 keine Resistenzhäufigkeit angegeben werden. Im Jahr 2001 konnten insgesamt 204.942 (bzw. korrigiert 132.877) Bt-Maispflanzen untersucht werden. Für die Zusammenfassung der Befallswerte wurde die Anzahl der zu untersuchenden Pflanzen auf einen theoretischen Befall von $100 \%$ korrigiert, so dass Standorte mit einem schwachen Befall mit wesentlich weniger Pflanzen in die Berechnung eingehen als tatsächlich abgesucht wurden. Damit ist die Resistenzfrequenz der Allele kleiner als 4,8 x $10^{-3}$. Homozygot resistente Larven treten mit einer Häufigkeit von weniger als $6,9 \times 10^{-2}$ in den untersuchten Populationen auf. Bei den 
Untersuchungen des Jahres 2001 konnte die Anzahl von drei Millionen untersuchten Pflanzen nicht erreicht werden, so dass keine Aussage darüber, ob die natürliche Resistenzhäufigkeit tatsächlich unterhalb des für das Gelingen der "Refugien/Hoch Dosis"-Strategie notwendigen Wertes liegt, getroffen werden kann. Die berechnete Intervallgrenze lässt den Schluss $\mathrm{zu}$, dass keine akute Resistenzentwicklung bei Einführung von Bt-Maispflanzen zu befürchten ist, da ein direkter wirtschaftlicher Schaden erst bei einer Frequenz von $50 \%$ resistenter Larven eintritt (Andow und Hutchison, 1998). Bei weiteren Untersuchungen ist eine Konzentration auf Flächen mit einem hohen Befall von mindestens $100 \%$ und einer hohen Sortenreinheit wünschenswert.

Wie oben beschrieben, können die meist optimistisch gewählten Annahmen zu einer Unterschätzung der Resistenzhäufigkeit führen, so dass dies beim Nachweis von resistenten Larven bzw. bei der Interpretation der Intervallgrenzen zu berücksichtigen ist. Venette et al. (2000) machen in ihrem Artikel keine Angaben über die tatsächlich untersuchten Pflanzen und die berechnete Resistenzhäufigkeit. Weinzierl et al. (1998) verwendet in Illinois eine ähnliche Methode wie die hier Beschriebene. Sie durchschritten konventionelle Bt-Maisfelder auf der Suche nach überlebenden Larven und durchsuchten ca. 150 ha mit 5,18 Millionen Pflanzen und einem durchschnittlichen Befalldruck von $50 \%$. Von 200 gefundenen Larven hatten zwei auf Bt-Mais überlebt. Da beide Larven während der weiteren Zucht gestorben sind, konnten ihre Nachkommen nicht auf Resistenz getestet werden.

Der Gesamtbefall in den Bt-Maisflächen inklusive der "Verunreinigung" lag in den Untersuchungen von Weinzierl bei einer optimalen Entdeckungsrate und einem Befallsdruck von $50 \%$ bei 0,000039\%. Dieser Wert liegt deutlich unter dem Wert von Standort 10 mit $0,0025 \%$ bei einem geringeren Befall im Nicht-Bt-Maisfeld von $24 \%$. Der große Unterschied lässt sich mit einer genaueren Kontrolle und höheren Entdeckungswahrscheinlichkeit in der hier vorliegenden Arbeit erklären, da der Standort 10 als Versuchsstandort optimale Bedingungen in Hinblick auf die Sortenreinheit und die Befallerhebung im Nicht-Bt-Mais gewährleistet hat. Interessant ist ein Vergleich der Resistenzhäufigkeit. Unter der Annahme, dass die Larven, die in den "tatsächlichen" Bt-Maispflanzen überlebt haben, resistent sind, lassen sich für das Oderbruch 2001 sowie für die Daten von Weinzierl vergleichbare Resistenzhäufigkeiten berechnen. Die Verunreinigung mit Nicht-Bt-Maispflanzen wird bei der Anzahl der untersuchten Pflanzen im Bt-Maisfeld vernachlässigt. Im Oderbruch wurden nach den PCR-Untersuchungen 10 Larven auf "tatsächlichen" Bt-Maispflanzen gefunden. Untersucht wurden 88.142 Bt-Maispflanzen bei einem Befall von $113 \%$. Die Allelfrequenz liegt bei $10^{-4}$ und die Häufigkeit resistenter Larven beträgt somit $10^{-2}$. Für die Daten von Weinzierl ergibt sich eine Häufigkeit resistenter Larven von 7,7 x $10^{-7}$ bzw. eine Resistenzallelfrequenz von $8,7 \times 10^{-4}$. Hieraus wird deutlich, wie wichtig eine hohe Wiederauffindrate im Bt-Maisfeld und eine Bestätigung der Resistenz im Biotest ist.

\subsubsection{Vergleich des $\mathrm{F}_{2}$-Screenings und des Screenings auf Bt-Maisfeldern}

Die Bestimmung der initialen Resistenzfrequenz und die Beobachtung von Resistenzentwicklung sind entscheidende Punkte eines Resistenzmanagements. Die Suche nach Resistenzallelen bzw. resistenten Individuen ist auf Grund der Seltenheit ein 
aufwändiges Unterfangen. Methoden wie der diskriminierende Konzentrationstest oder die Bestimmung von $\mathrm{LC}_{50^{-}}$bzw. $\mathrm{LC}_{90^{-}}$Werten sind auf Grund der meist geringen Probenanzahl von 100-300 Tieren nicht effizient genug frühzeitig eine Resistenzentwicklung vorherzusagen. Das $\mathrm{F}_{2}$-Screening nach Andow und Alstad (1998) und das Screening auf resistente Larven auf Bt-Maisfeldern sind zwei adäquate Methoden frühzeitig eine Resistenzfrequenz zu entdecken. In den Kapiteln 5.4 und 6.4 werden die Grenzen dieser Methoden aufgezeigt. Die Probleme des $\mathrm{F}_{2}$-Screenings liegen vor allem in der Vermeidung von Falsch-Negativ-Entscheidungen während der Zucht und bei der Testung auf Resistenz in der $\mathrm{F}_{2}$-Generation. Beim Screening auf BtMaisflächen liegen die Probleme in der Übertragbarkeit der Befallsdaten des Nicht-BtMaisfeldes auf die Bt-Maisfläche, in der Entdeckungs-Wahrscheinlichkeit von Larven im Bt-Maisfeld, in der Eliminierung von Falsch-Positiv-Entscheidungen im Maisfeld sowie in der "Verunreinigung" mit Nicht-Bt-Toxin-expremierenden Pflanzen im BtMaisfeld. Für beide Methoden ist die Anzahl der untersuchten Isolinien auf Resistenz ein limitierender Faktor, da der Sammelaufwand annährend gleich ist bzw. im Vergleich zur Weiterzucht eine untergeordnetere Rolle spielt. Die Methode, die bei gleicher Isolinienzahl eine geringere Varianz bei der Bestimmung der Resistenzhäufigkeit erreicht, ist die effizientere Methode und sollte daher bevorzugt werden. Da die Anzahl der zu untersuchenden Isolinien für das Bt-Mais-Screening von der "Verunreinigung" Nicht-Bt-Toxin-expremierender-Pflanzen in der Bt-Maisfläche abhängt, wurde in Abb. 7 (6.3.5) der Logarithmus des Varianzquotienten gegen die Frequenzhäufigkeit und für verschiedene "Verunreinigungen" aufgetragen. Die Grafik zeigt, dass oberhalb einer Resistenzallelfrequenz von $0,001 \%$ und einer "Verunreinigung" unter 0,001\% das Screening auf Bt-Maispflanzen effizienter ist. Bei Resistenzallelfrequenzen $<0,001$ $=10^{-3}$ ist das $\mathrm{F}_{2}$-Screening überlegen. Kommt keine "Verunreinigung" im Bt-Maisfeld vor, ist ein Screening im Bt-Feld effizienter. Dieses Ergebnis weist auf die Wichtigkeit der Beachtung und der möglichen Verringerung der "Verunreinigung" in einem BtMaisfeld hin. 


\section{ZUSAMMENFASSUNG}

Ziel dieser Arbeit war es, Daten zur Basisempfindlichkeit und zur Resistenzhäufigkeit der Maiszünsler in Deutschland zu erheben und die Methoden und Ergebnisse in Hinblick auf ein Resistenzmonitoring zu diskutieren. Die Basisempfindlichkeit $\left(\mathrm{LC}_{50}\right)$ wurde mit verschiedenen Methoden und zum Teil für drei Jahre für Maiszünslerpopulationen der Anbaugebiete Niedernberg, Halle, Hessisches Ried, Pocking und Oderbruch ermittelt. Zusätzlich wurde ein Laborstamm als mögliche Referenz in die Untersuchungen miteinbezogen. Die Untersuchungen wurden mit gereinigtem Cry1Ab-Toxin, das in E. coli produziert wurde, durchgeführt. Sowohl das CrylAb-Protoxin als auch trypsinisierte Toxine wurden verwendet.

Im Jahr 2000 wurden die größten Unterschiede in den $\mathrm{LC}_{50}$-Werten zwischen dem Stamm Niedernberg $\left(19 \mathrm{ng} / \mathrm{cm}^{2}\right)$ und Laborstamm Darmstadt $\left(60 \mathrm{ng} / \mathrm{cm}^{2}\right) \mathrm{mit}$ einem Wirkungsquotient von 3,1 ermittelt. Im Jahr 2001 lag der maximale Wirkungsunterschied zwischen den Stämmen Oderbruch $\left(10 \mathrm{ng} / \mathrm{cm}^{2}\right)$ und Pocking mit $55 \mathrm{ng} / \mathrm{cm}^{2}$ bei einem Faktor von 5,3. Im Jahr 2002 zeigte der nur in diesem Jahr getestete Stamm aus Halle $\left(25 \mathrm{ng} / \mathrm{cm}^{2}\right)$ und Pocking $\left(28 \mathrm{ng} / \mathrm{cm}^{2}\right)$ die geringste Empfindlichkeit. Der Stamm aus Halle war um das Dreifache unempfindlicher als der empfindlichste Stamm aus dem Oderbruch $\left(9 \mathrm{ng} / \mathrm{cm}^{2}\right)$. Die Stämme wiesen eine große Schwankungsbreite innerhalb der Untersuchungen eines Jahres und zwischen den Jahren auf. Diese waren größer als die Unterschiede zwischen den Maiszünslerpopulationen der verschiedenen Maisanbauregionen. Da die Populationen in den letzten Jahren keinem Bt-Toxin-Selektionsdruck ausgesetzt waren, sind die geografischen und jährlichen Unterschiede auf die natürlichen Empfindlichkeitsschwankungen der Populationen zurückzuführen. Dies bedeutet für ein Resistenzmonitoring in Deutschland, dass mit einer großen Variabilität der Basisempfindlichkeit der Maiszünsler zu rechnen ist. Empfindlichkeitsunterschiede um das Zehnfache sind noch als natürliche Schwankungen und nicht als Resistenzunterschiede anzusehen. Die Untersuchungen zeigten, dass das Untermischen des Toxins unter das Nährmedium als auch die Applikation des Toxins auf die Nährmediumoberfläche vergleichbare Ergebnisse erzielen. Ausschlaggebend für die Wahl der Methode kann somit der Verbrauch an Toxin sein, der bei der UntermischMethode um das Zehnfache höher liegt. Der Dosis-Wirkungs-Test erwies sich als sehr empfindlich gegenüber Unterschieden in der Toxinwirkung verschiedener Produktionschargen. So konnten mit dieser Methode die Wirkungsunterschiede zweier Toxinchargen um den Faktor 3,6 nachgewiesen werden. Nachfolgende gelelektrophoretische Untersuchungen ergaben, dass die Toxine der Chargen durch unterschiedliche Produktionsmethoden einen Größenunterschied von ca. $7 \mathrm{kDa}$ aufwiesen. Die Produktionsfaktoren bei der Herstellung der CrylAb-Toxine scheinen einen Einfluss auf die Wirkungsstärke zu besitzen.

Die Resistenzallelfrequenz kann durch mehrere Methoden ermittelt werden. In dieser Arbeit wurden das $\mathrm{F}_{2}$-Screening und das Monitoring resistenter Maiszünsler auf Bt-Maisflächen verwendet um die Resistenzhäufigkeiten zweier Populationen in Deutschland zu ermitteln. In den Jahren 2000 und 2001 wurden 398 Maiszünslern der Population Niedernberg mit Hilfe des $\mathrm{F}_{2}$-Screenings auf das Vorhandensein von Resistenzallelen getestet. In der Stichprobe wurde kein Resistenzallel nachgewiesen. Für die Resistenzallelhäufigkeit der Population Niedernberg kann bei einer 
Irrtumswahrscheinlichkeit von $5 \%$ ein Konfidenzintervall von Null bis $4,2 \times 10^{-3}$ berechnet werden. In den Anbaugebieten Oderbruch und Halle wurden im Herbst des Jahres 2001 ca. 204.942 Mon810 Bt-Maispflanzen auf überlebende Maiszünslerlarven untersucht. Die gefundenen Larven wurden in Biotests auf Resistenz getestet. Bei keiner Larve konnte eine Resistenz nachgewiesen werden. Für beide Standorte ließ sich mit dieser Methode eine Resistenzallelhäufigkeit von über $4,8 \times 10^{-3}$ ausschließen. Die Stichprobenumfänge beider Versuche reichten nicht aus, um die Resistenzallelhäufigkeit unter $10^{-3} \mathrm{zu}$ schätzen, was eine Voraussetzung für die "Refugien/Hoch Dosis"-Strategie ist. Für Empfehlungen zur Größe von Refugienflächen sind weitere Untersuchungen nötig. Eine Resistenzentwicklung bei einem großflächigen Einsatz von Bt-Mais innerhalb von wenigen Jahren kann ausgeschlossen werden. Das Monitoring der Resistenz auf Bt-Maisflächen wird durch die "Verunreinigung" der Bt-Maisfelder mit Nicht-Bt-Toxin-expremierenden Maispflanzen erschwert. Die Verunreinigung konnte bei zwei Feldern auf 0,35 bzw. $0,06 \%$ geschätzt werden. Ein Vergleich der Effizienz der Methoden $\mathrm{F}_{2}$-Screening und Monitoring der Resistenz auf Bt-Maisflächen ergab, unter Berücksichtigung der "Verunreinigung" im Bt-Maisfeld, Vorteile für das $\mathrm{F}_{2}$-Screening. Bei Resistenzallelfrequenzen von $10^{-3}$ und Verunreinigungen von weniger als $0,001 \%$ ist das $\mathrm{F}_{2}$-Screening auf Nicht-Bt-Maisflächen effektiver als das Monitoring auf BtMaisflächen.

Die hier vorgestellten Ergebnisse können für die Planung und Durchführung von Resistenzmanagement-Programmen in Deutschland eingesetzt werden. Sie sind erste Schritte auf dem Weg zu einem Resistenzmonitoring des Maiszünslers. Weitere Untersuchungen müssen und werden hoffentlich in den nächsten Jahren folgen, um eine nachhaltige Nutzung von Bt-Mais zu gewährleisten und damit eine Resistenzentwicklung des Maiszünslers zu vermeiden. 


\section{LITERATUR}

Abbott, W. S. (1925): A method of computing the effictiveness of an insecticide. J. Econ. Entomol. 18: 265-267.

agbios (1.8.2001a): GM Database, Bt-11. <http://www.agbios.com/dbase.php/ $(06.07 .2003)>$.

agbios (6.8.2001b): GM Database, Bt-176. < http://www.agbios.com/dbase.php.html $(03.06 .2003)>$.

agbios (6.8.2001c): GM Database, MON810. < http://www.agbios.com/dbase.php/ $(06.07 .2003)>$.

Agresti, A. (2002): Categorical data analysis, 2 ed. Wiley, New York.

Alstad, D. N. und Andow, D. A. (1995): Managing the evolution of insects resistance to transgenic plants. Science 268: 1894-1896.

Andow, D. A. (2001): Pattern of feeding and mortality of adult European corn borer (Lepidoptera: Crambidae) in the laboratory. Ann. Entomol. Soc. Am. 94 (4): 563-565.

Andow, D. A. und Alstad, D. N. (1998): The $F_{2}$ Screen for rare resistance alleles. J. Econ. Entomol. 91 (3): 572-578.

Andow, D. A. und Alstad, D. N. (1999): Credibility interval for rare resistance allele frequencies. J. Econ. Entomol. 92: 755-756.

Andow, D. A., Alstad, D. N., Pang, Y.-H., Bolin, P. C. und Hutchison, W. D. (1998a): Using an $\mathrm{F}_{2}$ Screen to search for resistance alleles to Bacillus thuringiensis toxin in European corn borer (Lepidoptera: Carambidae). J. Econ. Entomol. 91 (3): $579-584$.

Andow, D. A., Ferro, D., Gould, F. L., Hutchison, W. D., Tabashnik, B. E., und Whalon, M. N. (1998b): Now or Never. Union of Concerned Scientist, Cambridge.

Andow, D. A. und Hutchison, W. D. (1998): Bt-corn resistance management. In: Mellon, M. und Rissler, J., Now or Never. Union of Concerned Scientist, Cambridge, 19-66.

Andow, D. A. und Ives, A. R. (2002): Monitoring and adaptive resistance management. Ecol. Applic. 12 (5): 1378-1390.

Andow, D. A., Olson, D. M., Hellmich, R. L., Alstad, D. N. und Hutchison, W. D. (2000): Frequency of resistance to Bacillus thuringiensis toxin Cry $1 \mathrm{Ab}$ in an Iowa population of European corn borer (Lepidoptera: Crambidae). J. Econ. Entomol. 93 (1): 26-30. 
Bayerische Landesanstalt für Landwirtschaft (15.4.2002): Agrarmeterologisches Messnetz Bayern - Wetterdatenabruf -. < http://www.stmlf.bayern.de $(05.06 .2002)>$.

Bayerisches Staatsministerium für Landwirtschaft und Forsten (10.4.2002a): Landwirtschaftsamt - Aschaffenburg/Karlstadt. < $\quad$ http://www.stml.bayern.de (15.06.2002)>.

Bayerisches Staatsministerium für Landwirtschaft und Forsten (10.4.2002b): Landwirtschaftsamt - Passau/Rotthalmünster. $\quad<\underline{\text { http://www.stml.bayern.de }}$ (15.06.2002)>.

Beck, S. D. (1967): Water intake and the termination of diapause in the European corn borer, Ostrinia nubilalis. J. Ins. Physiol. 13 : 739-750.

Beck, S. D. und Hanec, W. (1960): Diapause in the European Corn Borer, Pyrausta nubilalis (Hübn.). J. Ins. Physiol. 4: 304-318.

Benbrook, C. M. (1.12.2001): When does it pay to plant Bt corn? Farm-level economic impacts of Bt corn, 1996-2001. <http://www.biotech-info.net/ Bt corn FF final.pdf $(13.09 .2003)>$.

Biologische Bundesanstalt für Land- und Forstwirtschaft (2003): Ausbreitung und Bekämpfung des Maiszünslers (Ostrinia nubilalis). $<$ http://www.bba.de/mitteil/aktuelles/maiszuensler/maiszstart.htm (09.07.2003)>.

BMVEL (2001): Gute fachliche Praxis der landwirtschaftlichen Bodennutzung. Bundesministerium für Verbraucherschutz, Ernährung und Landwirtschaft (BMVEL), Bonn.

Bolin, P. C., Hutchison, W. D., Andow, D. A. und Ostlie, K. R. (1998): Monitoring for European corn borer (Lepidoptera: Crambidae) resistance to Bacillus thuringiensis: logistical considerations when sampling larvae. J. Agric. Entomol. 15 (3): 231-238.

Bourguet, D., Bethenod, M. T., Trouvé, C. und Viard, F. (2000a): Host-plant diversity of the European corn borer Ostrinia nubilalis: what value for sustainable transgenic insecticidal Bt maize? Proc. R. Soc. Lond. B 267: 1177-1184.

Bourguet, D., Pasteur, N., und Viard, F. (2000b): Gene flow in the European corn borer Ostrinia nubilalis: implications for the sustainability of transgenic insecticidal maize. Proc. R. Soc. Lond. B 267 (1439 ): 117-122.

BRD (20-8-1985): Saatgutverkehrsgesetz. BGBI I (31.03.2002), www.juris.de.

BRD (1997): Sortenschutzgesetz. BGBI I (23.07.2002).

Bundesministerium für Verbraucherschutz, E. u. L. (2001): Statusbericht "Biologischer Pflanzenschutz", Bonn, BMVEL, Referat 518 (Pflanzenschutz), http://www.verbraucherministerium.de (23.05.03). 
Bundesregierung (18.5.2000): Keine Zulassung von gentechnisch verändertem Mais. $<$ http://www.bundesregierung.de/dokumentechnisch_veraenderter_Mais/ix801_ 9 $\underline{232 . h \operatorname{tm}}(21.11 .00)>$.

Carrière, Y., Ellers-Kirk, C., Patin, A. L., Sims, M. A., Meyer, S. K., Liu, Y.-B., Dennehy, T. J. und Tabashnik, B. E. (2001): Overwintering cost associated with resistance to transgenic cotton in the pink bollworm (Lepidoptera: Gelechiidae). J 94 (4): 935-941.

Caussade Saaten GmbH (2002): Versuchsführer 2002, Versuchsstation Görzig in der Domäne Görzig.

Chaufaux, J., Seguin, M., Swanson, J. J., Bourguet, D. und Siegfried, B. D. (2001): Chronic exposure of the European corn borer (Lepidoptera: Crambidae) to Cry1Ab Bacillus thuringiensis toxin. J. Econ. Entomol. 94 (6): 1564-1570.

Crickmore, N., Zeigler, D., Bravo, A., Schnepf, H. E., Lereclus, D., Baum, J., Van Rie, J., und Dean, D. H. (2002): The Bt delta-endotoxin nomenclature. $<$ www.biols.susx.ac.uk/home/Neil_Ckrickmore/Bt/commitee.html(31.06.2003)>.

Crickmore, N., Zeigler, D. R., Feitelson, J., Schnepf, E., Van Rie, J., Lereclus, D., Baum, J. und Dean, D. H. (1998): Revision of the nomenclature for the Bacillus thuringiensis pesticidal crystal proteins. Microbiol. Mol. Biol. Rev. 62 (3): 807813.

Davis, P. M. und Onstad, D. W. (2000): Seed mixtures as a resistance management strategy for European corn borers (Lepidoptera: Crambidae) infesting transgenic corn expressing Cry1Ab protein. J. Econ. Entomol. 93 (3): 937-948.

Degenhardt, H., Horstmann, F. und Mülleder, N. (2003): Bt-Mais in Deutschland. Mais 31 (2): 75-77.

Dellaporta, S. L., Wood, J. und Hicks, J. B. (1983): A plant DNA minipreparation: version II. Plant Molecular Biology Reporter 1 (4): 19-21.

Deutscher Wetterdienst (DWD) (2002): Temperaturdaten. < http://www.dwd.de/de $(12.06 .2002)>$.

Dowd, P. F. (2000): Indirect reduction of ear molds and associated mycotoxins in Bacillus thuringiensis corn under controlled and open field conditions: utility and limitations. J. Econ. Entomol. 93(6): 1669-1679.

Economic Research Service U.S. Department of Agriculture (1997): Farm structure: overview. <http://www.ers.usda.gov/Data (16.08.2003)>.

Elliot, W. M. (1977): Mating frequency of the female European corn borer, Ostrinia nubilalis (Lepidoptera:Pyralidae) in Southwestern Ontario. Can. Entomol. 109: 117-122. 
EU-RAT (2002): Richtlinie 2001/18/EG des Europäischen Parlaments und des Rates vom 12. März 2001 über die absichtliche Freisetzung gentechnisch veränderter Organismen in die Umwelt und zur Aufhebung der Richtlinie 90/220/EWG des Rates. 2001/18/EG.

Fadamiro, H. Y. und Baker, T. C. (1999): Reproductive performance and longevity of female European corn borer, Ostrinia nubilalis: effects of multiple mating, delay in mating, and adult feeding. J. Insect Physiol. 45: 385-392.

Ferré, J. und Van Rie, J. (2002): Biochemistry and genetics of insect resistance to Bacillus thuringiensis. Annu. Rev. Entomol. 47: 501-533.

ffrench-Constant, R. H. und Roush, R. T. (1990): Resistance detection and documentation: the relative roles of pesticidal and biochemical assays. In: Roush, R. T. und Tabashnik, B. E., Pesticide Resistance in Arthropods. Chapman and Hall, London, 38.

Flacke, W. (1982). Ein Modell zur phänologischen Entwicklungssimulation von Maiszünslerpopulationen (Ostrinia nubilalis Hbn.) im Freiland als Beitrag zur Arealsystemforschung. Universität Saarland.

Frutos, R., Rang, C. und Royer, M. (1999): Managing insect resistance to plants producing Bacillus thuringiensis toxins. Crit. Rev. Biotechnol. 19 (3): 227-276.

Fuchs, R. L., MacIntosh, S. C., Dean, D. A., Greenplate, J. T., Perlak, F. J., Pershing, J. C., Marrone, P. G., und Fischhoff, D. A. (1990): Quantification of Bacillus thuringiensis insect control protein as expressed in transgenic plants. In: Fitch, W. L. und Hickle, L. A., Analytical chemistry of Bacillus thuringiensis. American Chemical Society, Washington D.C., 105-113.

Genius Biotechnology GmbH (2000): Übersicht zum Anbau genetisch veränderter Pflanzen mit Part C-Genehmigung nach RL 90/220/EWG, Beispiel Mais, Standort Deutschland und EU, Darmstadt, Genius GmbH.

Gonzáles-Núñez, M., Ortego, F. und Castañera, P. (2000): Susceptibility of spanish populations of the corn borers Sesamia nonagrioides (Lepidoptera: Noctuidae) and Ostrinia nubilalis (Lepidoptera: Crambidae) to a Bacillus thuringiensis endotoxin. J. Econ. Entomol. 93 (2): 459-463.

Gould, F. L. (1998): Sustainability of transgenic insecticidal cultivars: integrating pest genetics and ecology. Annu. Rev. Entomol. 43: 701-726.

Gould, F. L., Anderson, A., Jones, D., Summerford, D., Heckel, D. G., Lopez, J., Micinski, S., Leonard, R., und Laster, M. (1997): Initial frequency of alleles for resistance to Bacillus thuringiensis toxins in field populations of Heliothis virescens. Proc. Natl. Acad. Sci. USA 94: 3519-3523. 
Gould, F. L. und Tabashnik, B. E. (1998): Bt-cotton resistance management. In: Mellon, M. und Rissler, J., Now or Never. Union of Concerned Scientist, Cambridge, 67105.

Greenpeace (25.5.2001): Gentechnisch veränderter Mais in Deutschland 2001. $<$ www.gene.ch/genpost/2001/Jan-Jun/doc00000.doc (18.12.2002)>.

Hase, A. (1929): Beobachtungen über Verbreitung und Verhalten des Maiszünslers (Pyrausta nubilalis Hbn. Lepidopt.)., Band 17 ed. Biologische Reichsanstalt für Land- unf Forstwirtschaft, Berlin-Dahlem.

Heckel, D. G. (1994): The complex genetic basis of resistance to Bacillus thuringiensis toxin in insects. Biocontrol Science and Technology 4: 405-417.

Heckel, D. G., Gahan, L. J., Liu, Y.-B. und Tabashnik, B. E. (1999): Genetic mapping of resistance to Bacillus thuringiensis toxins in diamondback moth using biphasic linkage analysis. Proc. Natl. Acad. Sci. USA 96: 8373-8377.

Heitefuß, R., Klingauf, F., Meinert, G., Plate, H.-P., Schmidt, H., Schütte, F., Thiede, H., und Wachendorff, R. (1986): Integrierter Pflanzenschutz. AID, Bonn.

Hellmich, R. L., Higgins, L. S., Witkowski, J. F., Campbell, J. E. und Lewis, L. C. (1999): Oviposition by European corn borer (Lepidoptera: Crambidae) in response to various transonic corn events. J. Econ. Entomol. 92 (5): 1014-1413.

Hessisches Dienstleistungszentrum für Landwirtschaft, G. u. N. (12.5.2002): Statistische Grundlagen für den Landkreis Groß-Gerau, Landwirtschaft, $<$ http://www.hdlgn-hessen.de/landwirtschaft/oekologischerlandbau/ index_oekologischerlandbau.htm (03.04.2003)>.

Hilbeck, A., Meier, M. S., und Raps, A. (2000): Review on non-target organsims and bt-plants, Zürich, EcoStrat GmbH, < www.greenpeace.org/ geneng/reports/gmo lecostratbt.pdf (19.05.03)>.

Hilbeck, A., Moar, W. J., Pusztai-Carey, M., Filippini, A. und Bigler, F. (1999): Preymediated effects of Cry1Ab toxin and protoxin and Cry2A protoxin on the predator Chrysoperla carnea. Entomol. exp. appl. 91: 305-316.

Hofstetter, M. (2000): Genetisch veränderter Mais in Deutschland. $<$ http://archiv. greenpeace.de/GP_DOK 3P/HINTERGR/C05H85.pdf $(18.12 .2002)>$.

Hogg, R. V. und Craig, A. T. (1995): Introduction to mathematical statistics, 5 ed. Prentice-Hall, Upper Saddle River.

Höfte, H., Van Rie, J., Jansens, S., Van Houtven, A., Vanderbruggen, H. und Vaeck, M. (1988): Monoclonal antibody analysis and insecticidal spectrum of three types of Lepidopterean-specific insecticidal crystal protein of Bacillus thuringiensis. Appl. Environ. Microbiol. 54 (8): 2010-2017. 
Höfte, H. und Whiteley, H. R. (1989): Insecticidal crystal proteins of Bacillus thuringiensis. Microbiological Reviews 53: 242-255.

Hua, G., Masson, L., Jurat-Fuentes, J. L., Schwab, G. und Adang, M. J. (2001): Binding analysis of Bacillus thuringiensis Cry $\delta$-endotoxins using brush border membrane vesicles of Ostrinia nubilalis. Appl. Environ. Microbiol. 67 (2): 872879 .

Huang, F., Buschman, L. L. und Higgins, R. A. (1999a): Susceptibility of different instars of European corn borer (Lepidoptera: Crambidae) to diet containing Bacillus thuringiensis. J. Econ. Entomol. 92 (3): 547-550.

Huang, F., Buschman, L. L., Higgins, R. A. und McGaughey, W. H. (1999b): Inheritance of resistance to Bacillus thuringiensis toxin (DIPEL ES ${ }^{\circledR}$ ) in the European corn borer. Science 284: 965-967.

Huang, F., Higgins, R. A. und Buschman, L. L. (1997): Baseline susceptibility and changes in susceptibility to Bacillus thuringiensis subsp. kurstaki under selection pressure in European corn borer (Lepidoptera: Pyralidae). J. Econ. Entomol. 90 (5): 1137-1143.

Huang, F., Higgins, R. A. und Buschman, L. L. (1999c): Heritability and stability of resistance to Bacillus thuringiensis in Ostrinia nubilalis (Lepidoptera: Pyralidae). Bull. ent. Res. 89: 449-454.

Hugger, H. (1998): Was ist von transgenen Maissorten zu erwarten? Mais 26: 112-113.

Insecticide Resistance Action Commitee (IRAC) (7.6.2000): Insecticide resistance: The Facts. $<$ http://plantprotection.org/IRAC/general_resources/facts.html (13.05.03)>.

James, C. (2002): Global status of commercialized transgenic crops: 2002, ISAAAReport. The International Service for the Acquisition of Agri-biotech Applications (ISAAA), New-York.

Johnson, N. L., Kotz, S., Kemp, A.W. (1993): Univariate discrete distributions. Wiley, New York.

King, E. G. und Leppla, N. C. (1984): Advances and challenges in insect rearing. Agricultural Research Services, New Orleans.

Kinsinger, R. A. und McGaughey, W. H. (1979): Susceptibility of population of indianmeal moth and almond moth to Bacillus thuringiensis. J. Econ. Entomol. 73: 346-349.

Kira, M. T., Guthrie, W. D. und Huggans, J. L. (1969): Effect of drinking water on production of eggs by the European corn borer. J. Econ. Entomol. 62 (6): 13661368. 
Kluge, E., Enzian, S., und Gutsche, V. (1999): Befallsatlas; Atlas der potentiellen Befallsgefährdung durch wichtige Schadorganismen im Ackerbau Deutschlands. Biologische Bundesanstalt für Land- und Forstwirtschaft Berlin und Braunschweig, Braunschweig.

Klun, J. A. (1968): Isolation of a sex pheromone of the European corn borer. J. Econ. Entomol. 61 (2): 484-487.

Klun, J. A. und Brindley, T. A. (1970): cis-11-tetradecenyl acetate, a sex stimulant of the European corn borer. J. Econ. Entomol. 63 (3): 779-780.

Knowles, B. H. (1994): Mechanism of action of Bacillus thuringiensis insecticidal $\delta$ endotoxins. In: Evans, P. D., Advances in Insect Physiology. Academic Press, London, 275-308.

Kofod, M., Schüring, J., Merz, C., Winkler, A., Liedholz, T., Sieckmann, I. und Isenbeck-Schröter, M. (1997): Der geochemische Einfluss von Sickerwasser aus landwirtschaftlich genutzten Flächen auf das Grundwasser im Oderbruch. Z. dt. geol. Ges. 148 (3-4): 389-403.

Koziel, M. G., Beland, G. L., Bowman, C., Carozzi, N. B., Crenshaw, R., Crossland, L., Dawson, J., Desai, N., Hill, M., Kadwell, S., Launis, K., Lewis, K., Maddox, D. , McPherson, K., Meghji, M. R., Merlin, E., Rhodes, R., Warren, G. W., Wright, M. und Evola, S. V. (1-2-1993a): Field performance of elite transgenic maize plants expressing an insecticidal protein derived from Bacillus thuringiensis. Bio/Technology 11 (February): 194-200.

Koziel, M. G., Carozzi, N. B., Currier, T. C., Warren, G. W. und Evola, S. V. (1993b): The insecticidal crystal proteins of Bacillus thuringiensis: past, present and future use. Biotechnol. Genet. Eng. Rev. 11: 171-228.

Krieg, A. (1986): Bacillus thuringiensis ein mikrobielles Insektizid. Paul Parey, Berlin und Hamburg.

Krieg, A., Huger, A. M., Langenbruch, G. A. und Schnetter, W. (1983): Bacillus thuringiensis var. tenebrionis: ein neuer, gegenüber Larven von Coleopteren wirksamer Pathotyp. Z. ang. Ent. 96: 500-508.

Langenbruch, G. A. (2002): Die Ausbreitung des Maiszünslers in Deutschland. Mitt. Biol. Bundesanst. Land- Forstwirtsch. 390, 2002, 96-97.

Langenbruch, G. A. (2003): Wer nicht pflügt, züchtet Maiszünsler. Mais aktuell Frühjahr 2003: 44-47.

Langenbruch, G. A., Hommel, B., und Burgermeister, W. (1999): Monitoring der Anpassung des Maiszünslers an transgenen Bacillus thuringiensis-Mais Populationsgenetische Untersuchungen in ausgewählten Anbauregionen Deutschlands, Schiemann, J., Braunschweig. 5-10. 
Langenbruch, G. A. und Kleespies, R. G. (1998): Die Ausbreitung des Maiszünslers und die Verbreitung seiner Mikrosporidien. Mitt. a. d. Biol. Bundesanst.: 345.

Langenbruch, G. A. und Lorenz, N. (1989): Maiszünslerreduzierung bei der Körnermaisernte. Nachrichtenbl. Deut. Pflanzenschutzd. 41(8/9): 140-144.

Langenbruch, G. A. und Lorenz, N. (1992): Zehnjährige Untersuchungen zur Eignung von Pheromonfallen zur Überwachung des Maiszünslers (Ostrinia nubilalis Hbn.) in der Bundesrepublik Deutschland. Zeitschrift für Pflanzenkrankheiten und Pflanzenschutz 99 (1): 80-92.

Lavialle, M. (1988): La symétrie des résponses photopériodiques dans l'induction et la terminaison de diapause chez Ostrinia nubilalis Hbn. (Lep., Pyralidae). J. Appl. Ent. 105: 516-524.

Lereclus, D., Delecluse, A., und Lecadet, M. M. (1993): Diversity of Bacillus thuringiensis toxins and genes. In: Entwistle, P. F., Cory, J. S., Bailey, M. J., and Higgs, S., Bacillus thuringiensis, An Environmental Biopesticide: Theory and Practice. John Wiley \& Sons Ltd, West Sussex, 37-60.

Liu, Y.-B., Tabashnik, B. E., Dennehy, T. J., Patin, A. L. und Bartlett, A. C. (1999): Development time and resistance to Bt crops. Nature 400 (5): 519.

Lorenz, N. (1993): Untersuchungen zur Verbreitung des Maiszünslers (Ostrinia nubilalis Hbn.) in Beifuß (Artemisia vulgaris L.) und Mais (Zea mays L.) zu Überwinterung und Falterschlupf sowie zur Überwachung seiner Z-Rasse mittels Pheromonfallen. Institut für Pflanzenpathologie und Pflanzenschutz der GeorgAugust-Universität zu Göttingen.

Lorenz, N. und Langenbruch, G. A. (1989): Untersuchungen zur Verbreitung des Maiszünslers (Ostrinia nubilalis Hbn.; Lepidoptra: Pyralidae) in der Bundesrepublik Deutschland. Mitt. Dtsch. Ges. Allg. Angew. Ent. 7: 289-294.

Losey, J. E., Calvin, D. D., Carter, M. E. und Mason, C. E. (2001): Evaluation of noncorn host plants as a refuge in a resistance management program for European corn borer (Lepidoptera: Crambidae) on Bt-corn. Environ. Entomol. 30 (4): 728-735.

Lynch, R. E., Brindley, T. A. und Lewis, L. C. (1972): Influence of photophase and temperature on survival and oxygen consumption of diapausing European corn borers. Ann. Entomol. Soc. Am. 65 (2): 433-436.

MacIntosh, S. C., Stone, T. B., Sims, S. R., Hunst, P. L., Greenplate, J. T., Marrone, P. G., Perlak, F., Fischhoff, D. A. und Fuchs, R. L. (1990): Specificity and efficacy of purified Bacillus thuringiensis proteins against agronomically important insects. Journal of Invertebrate Pathology 56: 258-266.

Magg, T., Melchinger, A. E., Klein, D. und Bohn, M. (2002): Relationship between European corn borer resistance and concentration of mycotoxins produced by 
Fusarium spp. in grains of transgenic Bt maize hybrids, their isogenic counterparts and commercial varieties. Plant Breeding 121: 146-154.

Marçon, P. C. R. G., Siegfried, B. D., Spencer, T. und Hutchison, W. D. (2000): Development of diagnostic concentrations for monitoring Bacillus thuringiensis resistance to European corn borer (Lepidoptera: Crambidae). J. Econ. Entomol. 93 (3): 925-930.

Marçon, P. C. R. G., Taylor, D. B., Mason, C. E., Hellmich, R. L. und Siegfried, B. D. (1999a): Genetic similarity among pheromone and voltinism races of Ostrinia nubilalis (Hübner) (Lepidoptera: Pyralidae). Insect Mol. Biol. 8 (2): 213-221.

Marçon, P. C. R. G., Young, L. J., Steffey, K. L. und Siegfried, B. D. (1999b): Baseline susceptibility of European corn borer (Lepidoptera: Crambidae) to Bacillus thuringiensis toxins. J. Econ. Entomol. 92 (2): 279-235.

Masson, L., Préfontaine, G., Péloquin, L., Lau, P. C. K. und Brousseau, R. (1989): Comparative analysis of the individual protoxin components in $\mathrm{P} 1$ crystals of Bacillus thuringiensis subsp. kurstaki isolates NRD-12 and HD-1. J. Biol. Chem. 269: 507-512.

McGaughey, W. H. und Beeman, R. W. (1988): Resistance to Bacillus thuringiensis in colonies of indianmeal moth and almond moth (Lepidoptera: Pyralidae). J. Econ. Entomol. 81 (1): 28-33.

McGaughey, W. H. und Whalon, M. N. (1992): Managing insect resistance to Bacillus thuringiensis toxins. Science 258: 1451-1455.

McKenzie, J. A. (1996): Ecological and evolutionary aspects of insecticide resistance. R. G. Landes Company and Academic Press, Georgetown, Texas, USA; San Diego, California, USA.

Meise, T. und Langenbruch, G. A. (1999): Überprüfung der transgenen Maissorten Kenn-Nr.: M8329, M5606, M7956, M4633. Bericht Bundessortenamt.

Melander, A. L. (1914): Can insects become resistant to sprays? J. Econ. Entomol. 7: 167-173.

Mohan, M. und Gujar, G. T. (2002): Geographical variation in larval susceptibility of the diamondback moth, Plutella xylostella (Lepidoptera: Plutellidae) to Bacillus thuringiensis spore-crystal mixtures and purified crystal proteins and associated resistance development in India. Bull. ent. Res. 92: 489-498.

Monsanto (2002): Safety Assesment of YieldGard ${ }^{\circledR}$ Insect-Protected Corn Event Mon 810, < http://www.agbios.com/docroot/decdocs/02-269-010.pdf (27.02.03)>.

Müller, W. (2001): Handbuch zu Monitoring und Resistenzmanagement für Bt-Mais. Umweltbundesamt GmbH, Wien. 
Novartis (1999): Bt-maize and non-target organisms, Compilation of available data, Basel, Novartis.

Ohnesorge, B. und Reh, P. (1987): Untersuchungen zur Populationsdynamik des Maiszünslers Ostrinia nubilalis Hbn. (Lep. Pyralidae) in Baden Württemberg; I. Populationsstruktur, Apparenz, Verteilung im Habitat. J. Appl. Ent. 103: 288304.

Onstad, D. W. und Guse, C. A. (1999): Economic analysis of transgenic maize and nontransgenic refuges for managing European corn borer (Lepidoptera: Pyralidae). J. Econ. Entomol. 92 (6): 1256-1265.

Orr, D. B. und Landis, D. A. (1997): Oviposition of European corn borer (Lepidotera: Pyralidae) and impact of natural enemy populations in transgenic versus isogenic corn . J. Econ. Entomol. 90 (4): 905-909.

Peña, A., Arn, H., Buser, H.-R., Rauscher, S., Bigler, F., Brunetti, R., Maini, S. und Tóth, M. (1988): Sex pheromone of European corn borer, Ostrinia nubilalis: polymorphism in various laboratory and field strains. Journal of Chemical Ecology 14 (5): 1359-1366.

Pierce, C. M. F., Solter, L. F. und Weinzierl, R. A. (2001): Interactions between Nosema pyrausta (Microsporidia: Nosematidae) and Bacillus thuringiensis subsp. kurstaki in the European corn borer (Lepidoptera: Pyralidae). J. Econ. Entomol. 94 (6): 1361-1368.

Popko, R. (1988): Beobachtungen zum Auftreten des Maiszünslers (Ostrinia nubilalis Hbn.) an Silomais. Nachrichtenbl. Pflanzenschutz DDR 42: 110-112.

Rice, M. E. und Pilcher, C. D. (1998): Potential benefits and limitations of transgenic Bt corn for management of the European corn borer (Lepidoptera: Crambidae). American Entomologist: 75-78.

Robert Koch Institut (7.7.2003): Produkte, für die ein Inverkehrbringen in der Europäischen Union (EU) gemäß Richtlinie 90/220/EWG bzw. Richtlinie 2001/18/EG beantragt oder genehmigt wurde. <http://www.rki.de /GENTEC/INVERKEHR/INVKLIST.HTM (12.09.2003)>.

Robert, C. P. (1994): The Bayesian Choice - A decision-theoretic motivation. Springer Verlag, New York.

Robertson, J. L., Preisler, H. K., Ng, S. S., Hickle, L. A. und Gelernter, W. D. (1995): Natural variation: a complicating factor in bioassays with chemical and microbial pesticides. J. Econ. Entomol. 88 (1): 1-10.

Roush, R. T. und Daly, J. C. (1990): The role of population genetics in resistance research and management. In: Roush, R. T. und Tabashnik, B. E., Pesticide Resistance in Arthropods. Chapman and Hall, New York, 97-152. 
Roush, R. T. und Miller, G. L. (1986): Considerations for design of insecticide resistance monitoring programs. J. Econ. Entomol. 79: 293-298.

Savin, N. E., Robertson, J. L. und Russell, R. M. (1977): A critical evaluation of bioassay in insecticide research: likelihood ratio tests of dose-mortality regression. Bull. Ent. Soc. Amer. 23: 257-266.

Schmitz, G., Mücher, T., Saeglitz, C., Bartsch, D., Rothemeier, I., Mölle, J., Stanke, B. und Greib, G. (2001): Zur Ausbreitung des Maiszünslers (Ostrinia nubilalis Hbn.) im südlichen Rheinland. Nachrichtenbl. Deut. Pflanzenschutzd. 53: 63-64.

Schneider, J. C. (1999): Confidence interval for Bayesian estimates of resistance allele frequencies. J. Econ. Entomol. 92 (4): 755.

Scientific Commitee on Plants at the EU-Commission (30.3.1998): Protokol for the monitoring of European corn borer resistance to Bt-maize, Doc.: XI/157/98.

Siegfried, B. D., Marçon, P. C. R. G., Witkowski, J. F., Wright, R. J. und Warren, G. W. (1995): Susceptibility of field populations of the European corn borer, Ostrinia nubilalis (Hübner) (Lepidoptera: Pyralidae), to Bacillus thuringiensis (Berliner). J. Agric. Entomol. 12 (4): 267-273.

Siegfried, B. D., Spencer, T. und Nearman, J. (2000): Baseline susceptibility of corn earworm (Lepidoptera: Noctuidae) to the Cry1 Ab toxin from Bacillus thuringiensis . J. Econ. Entomol. 93 (4): 1265-1268.

Statistisches Bundesamt (1.1.2003): Landwirtschaft Deutschlands weiterhin im strukturellem Wandel. $<$ http://www.destatis.de/download/d/forst/ergtxt.pdf (11.01.2003)>.

Tabashnik, B. E. (1990): Modeling and evaluation of resistance management tactics. In: Roush, R. T. und Tabashnik, B. E., Pesticide Resistance in Arthropods. Chapman and Hall, London, 153-182.

Tabashnik, B. E. (1994): Evolution of resistance to Bacillus thuringiensis. Annu. Rev. Entomol. 39: 47-97.

Tabashnik, B. E., Cushing, N. L., Finson, N. und Johnson, M. W. (1990): Field development of resistance to Bacillus thuringiensis in diamondback moth (Lepidoptera: Pyralidae). J. Econ. Entomol. 83 (5): 1671-1676.

The Database of Arthropods Resistant to Pesticide (30.4.2003): Ostrinia nubilalis resistant to Bacillus thuringiensis subsp. kurstaki (Dipel). $<\underline{\text { http://www.cips.msu.edu/resistance/rmdb/index.html }}(13.05 .2003)>$.

TransGen e.V. (31.10.2002): Bt-Mais in Spanien: 25.000 ha Anbau seit 1998. $<$ http://www.transgen.de/?link=/Anwendung/Pflanzen/anbau spanien.html $(12.09 .2003)>$. 
U.S. Environmental Protection Agency (EPA) (16.10.2000): EPA advisors assess risks,

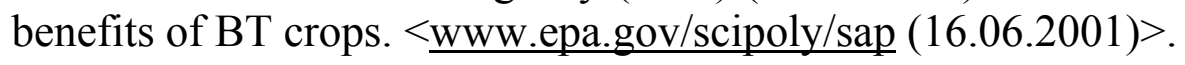

U.S. Environmental Protection Agency (EPA) (16.10.2001): Biopesticides registration action document - Bacillus thuringiensis plant-incorporated proctectants.

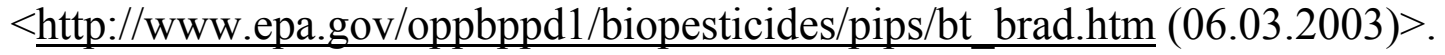

Unkelbach, H. D. und Wolf, T. (1985): Qualitative Dosis-Wirkungs-Analysen. Gustav Fischer, Stuttgart.

Van Frankenhuyzen, K. (1993): The challenge of Bacillus thuringiensis. In: Entwistle, P. F., Cory, J. S., Bailey, M. J. und Higgs, S., Bacillus thuringiensis, An Environmental Biopesticide: Theory and Practice. John Wiley \& Sons, Chichester, 1-35.

Venette, R. C., Hutchison, W. D. und Andow, D. A. (2000): An in-field screen for early detection and monitoring of insect resistance to Bacillus thuringiensis in transgenic crops. J. Econ. Entomol. 93 (4): 1055-1064.

Venette, R. C., Moon, R. D. und Hutchison, W. D. (2002): Strategies and statistics of sampling for rare individuals. Annu. Rev. Entomol. 47: 143-174.

Visser, B., Bosch, D., und Honée, G. (1993): Domain-function studies of Bacillus thuringiensis crystal proteins: a genetic approach. In: Entwistle, P. F., Cory, J. S., Bailey, M. J. und Higgs, S., Bacillus thuringiensis, An Environmental Biopesticide: Theory and Practice. John Wiley \& Sons Ltd, West Sussex, 71231.

Weinzierl, R. A., Steffey, K. L., und Pierce, C. M. F. (1998): Field survey for Bt resistant in European corn borer. $<$ http://www.ag.uiuc.edu/cespubs/pest/ articles/v988i.html (02.08.2003)>.

Weis, J. (1961): Die Mikrosporidien als Parasiten der Insekten. Paul Parey, Hamburg und Berlin.

Wilrich, P.-T. (2001): Bayes-Verfahren versus frequentistische Verfahren? In: Kaufmann, J. und Weiß, H., Statistische Methoden in der empirischen Forschung. Schering Ag, Berlin, 212-254.

Witkowski, J. F., Wedberg, J. L., Steffey, K. L., Sloderbeck, P. E., Siegfried, B. D., Rice, D. A., Pilcher, C. D., Onstad, D. W., Mason, C. E., Lewis, K., Landis, D. A., Keaster, A. J., Huang, F., Higgins, R. A., Haas, M. J., Gray, M., Giles, K. L., Foster, J. E., Davis, P. M., Calvin, D. D., Buschman, L. L., Bolin, P. C., Barry, B. D., Andow, D. A., und Alstad, D. N. (1997): Bt corn \& European corn borer, long-term success through resistance management, <http://www.extension. umn.edu/distribution/cropsystems/DC7055.html (19.05.2003)>. 
Wu, K., Guo, Y. und Lv, N. (1999): Geographic variation in susceptibility of Helicoverpa armigera (Lepidoptera: Noctuidae) to Bacillus thuringiensis insecticidal protein in China. J. Econ. Entomol. 92 (2): 273-278.

Zhao, J. Z., Li, Y.-X., Collins, H. L. und Shelton, A. M. (2002): Examination of the $F_{2}$ screen for rare resistance alleles to Bacillus thuringiensis toxins in the diamondback moth (Lepidoptera: Plutellidae). J. Econ. Entomol. 95 (1): 14-21.

Zscheischler, J., Estler, D. M. C. , Staudacher, W., Groß, F., Burgstaller, G., Streyl, H., und Rechmann, T. (1990): Handbuch Mais, 4 ed. DLG-Verl., Frankfurt (Main).

Zwölfer, W. (1926): Bericht über die Untersuchung zur Biologie und Bekämpfung des Maiszünslers (Pyrausta nubilalis Hübn.) in Süddeutschland 1926. Arbeiten aus der Biologischen Reichsanstalt für Land- und Forstwirtschaft 15: 356-402.

Zwölfer, W. (1928): Ergebnisse der Maiszünsleruntersuchungen Süddeutschland. Mitt. Deutsch. Landw. Ges. 43: 268-271. 
Quellen der Persönlichen Mitteilungen

Herr Dannemann, Regierungspräsidiums Freiburg, Pflanzliche und tierische Erzeugung, Kaiser-Joseph-Straße 167, 79098 Freiburg i.Br.

Herr Fassauer, Amt für Landwirtschaft und Flurneuordnung Anhalt, Ferdinand-von-Schill-Straße 24, 06844 Dessau.

Frau Götzke, Landwirtschaftsamt Landkreis Märkisch-Oderland, Pflanzenschutzdienst, Puschkinplatz 12, 15301 Seelow.

Herr Grundwürmer, Landwirtschaftsamt Passau-Rotthalmünster, Franz-Gerauer-Str. 23, 94094 Rotthalmünster.

Herr Dr. Hassan, Biologische Bundesanstalt für Land- und Forstwirtschaft, Institut für biologischen Pflanzenschutz, Heinrichstraße 243, 64287 Darmstadt.

Herr Dr. Jehle und Mitarbeiterinnen, Staatliche Lehr- und Forschungsanstalt, SG Biotechnischer Pflanzenschutz, Breitenweg 71, 67435 Neustadt.

Frau Dr. Kaiser-Alexnat, Biologische Bundesanstalt für Land- und Forstwirtschaft, Institut für biologischen Pflanzenschutz, Heinrichstraße 243, 64287 Darmstadt.

Herr Dr. Langenbruch, Biologische Bundesanstalt für Land- und Forstwirtschaft, Institut für biologischen Pflanzenschutz, Heinrichstraße 243, 64287 Darmstadt.

Frau Liebe, Biologische Bundesanstalt für Land- und Forstwirtschaft, Institut für integrierten Pflanzenschutz Stahnsdorfer Damm 81, 14532 Kleinmachnow.

Herr Dr. Magg, Universität Hohenheim, Institut für Pflanzenzüchtung, Saatgutforschung und Populationsgenetik, Fruwirthstraße 21, 70599 Stuttgart

Frau Metke, Biologische Bundesanstalt für Land- und Forstwirtschaft, Institut für integrierten Pflanzenschutz, Stahnsdorfer Damm 81, 14532 Kleinmachnow.

Herr Dr. Moll, Biologische Bundesanstalt für Land- und Forstwirtschaft, Zentrale EDV-Gruppe, Stahnsdorfer Damm 81, 14532 Kleinmachnow.

Herr Prof. Piepho, Universität Hohenheim, Fachgebiet Bioinformatik, Fruwirthstr. 23, 70599 Stuttgart.

Frau Sick, Biologische Bundesanstalt für Land- und Forstwirtschaft, Institut für integrierten Pflanzenschutz, Stahnsdorfer Damm 81, 14532 Kleinmachnow.

Herr Dr. Wagner, Biologische Bundesanstalt für Land- und Forstwirtschaft, Institut für biologischen Pflanzenschutz, Heinrichstraße 243, 64287 Darmstadt. 


\section{ANHANG}

\subsection{Anhang Basisempfindlichkeit}

\subsubsection{Toxinproduktion der Chargen J1 und J3}

Die Informationen zur Toxinproduktion der Charge J1 und J3 stammen von Herrn Dr. Jehle, Staatliche Lehr- und Forschungsanstalt, SG Biotechnischer Pflanzenschutz, Neustadt/Weinstraße (Jehle, pers. Mitt.). Als Ausgangsmaterial zur Produktion des Cry1Ab-Protoxins, das eine Länge von 1155 AS und ein vorhergesagtes Molekulargewicht von 130616,76 Daltons hat, diente ein in Escherichia coli expremierendes Plasmid pMP, welches das offene Leseraster von Cry $1 \mathrm{Ab}$ enthält (Masson et al., 1989). Dieses Plasmid wurde in E. coli HB101-Zellen vermehrt und in Terrific Broth (TB)-Medium mit Ampicillin bei $37^{\circ} \mathrm{C}$ zur Expression gebracht. Die Zellen wurden unter Verwendung einer French Press $(\mathrm{J} 1 \mathrm{a}+\mathrm{b})$ aufgeschlossen oder mit Lysozym lysiert (J3a-c). Anschließend wurden die Kristalle abzentrifugiert. Zur Aktivierung des Protoxins wurde dieses mit pankreatischem Trypsin (TPCK treared) behandelt. Dadurch soll vom Protoxin ein Rest von 594 Aminosäuren $(66,7 \mathrm{kDa})$ übrig bleiben. Durch Ultrafiltration wurde das Toxin gereinigt und konzentriert. Die Reinheit des Toxins betrug ca. $90 \%$.

\subsubsection{Nährmedium Maiszünsler}

Die Herstellung des Mediums richtet sich weitestgehend nach den Anweisungen des Protokolls einer EU-Expertenkommission zum Monitoring des Maiszünslers (Scientific Commitee on Plants at the EU-Commission, 1998). Um eine glatte Oberfläche des Nährmediums für die Biotests zu erhalten, wurde die Agar-Menge reduziert.

\subsubsection{Herstellungsanweisung des Nährmediums für die Zucht}

1. Wasser $(340 \mathrm{ml})$ kochen. Benzoesäure, Sorbinsäure und Nipagin in geringer Menge Alkohol lösen und in das Wasser geben. Das Gemisch gut aufkochen, bis der Alkohol verdampft ist. Wasser auf $340 \mathrm{ml}$ auffüllen [Gemisch 1].

2. Parallel Maisgrieß, Weizenkeime, Hefe, kaltes Wasser $(340 \mathrm{ml})$ gut mit Pürierstab mischen [Gemisch 2].

3. Agar in das Gemisch 1 einrühren und nochmals aufkochen lassen.

4. Wenn sich der Agar gelöst hat, das Gemisch von der Herdplatte nehmen und Gemisch 2 unterrühren.

5. Ascorbinsäure in Wasser lösen.

6. Vitamine, Friesomycin, Ascorbinsäurelösung zugeben und gut mischen (nach dem Zusammenrühren ist das Gemisch auf unter $45^{\circ} \mathrm{C}$ abgekühlt.

7. Nährmedium in Plastikboxen ( $\mathrm{L} \times \mathrm{B} \times \mathrm{H}=18 \mathrm{~cm} \times 14 \mathrm{~cm} \times 6 \mathrm{~cm}$ ) geben.

8. Nährmedium ca. $1 / 2$ - 1 Stunde unter den Abzug stellen, bis das Medium trocken ist.

9. Nährmedium in Plastiktüten bei $4{ }^{\circ} \mathrm{C}$ aufbewahren. 
Tab. 47: Bestandteile für das Maiszünsler-Nährmedium

\begin{tabular}{llrr} 
& Firma & Versuch & Zucht \\
\hline $\mathrm{H}_{2} \mathrm{O}$ & & $340 \mathrm{ml}$ & $340 \mathrm{ml}$ \\
\hline Agar-Agar & Fritz Götte \& CIE. Köln & $9 \mathrm{~g}$ & $12 \mathrm{~g}$ \\
\hline $\begin{array}{l}\mathrm{H}_{2} \mathrm{O} \text { (für restlich } \\
\text { Bestandteile) }\end{array}$ & $340 \mathrm{ml}$ & $340 \mathrm{ml}$ \\
\hline Maisgrieß & $\begin{array}{l}\text { Hammermühle, Darmstadt } \\
\text { Hatthis \& Söhne }\end{array}$ & $112 \mathrm{~g}$ & $112 \mathrm{~g}$ \\
\hline Weizenkeime & $\begin{array}{l}\text { Hammermühle, Darmstadt } \\
\text { Hatthis \& Söhne }\end{array}$ & $28 \mathrm{~g}$ & $28 \mathrm{~g}$ \\
\hline Hefe & $\begin{array}{l}\text { (Lactiva) } \\
\text { Raiffeisen Darmstadt }\end{array}$ & $30 \mathrm{~g}$ & $30 \mathrm{~g}$ \\
\hline Benzoesäure & Merck & $2 \mathrm{~g}$ & $2 \mathrm{~g}$ \\
\hline Ascorbinsäure & Merck & $6 \mathrm{~g}$ & $6 \mathrm{~g}$ \\
\hline $\begin{array}{l}\text { Vitaminmixtur } \\
\text { Nipagin } \\
\text { (Methyl-4- } \\
\text { hydroxybenzoat) }\end{array}$ & Sigma & $2 \mathrm{~g}$ & $2 \mathrm{~g}$ \\
\hline $\begin{array}{l}\text { Sorbinsäure } \\
\text { [Fumidil B] }{ }^{1}\end{array}$ & Merck & $1 \mathrm{~g}$ & \\
\hline $\begin{array}{l}\text { Frisomycin } \\
\text { (Tetra-Cyclin- }\end{array}$ & Sanofi-Synthelabo & & $1 \mathrm{~g}$ \\
$\begin{array}{l}\text { Hydro-Chlorid) } \\
\text { bei einer Infektion mit }\end{array}$ & Mikrosporidien (Nosema pyrausta) eingesetzt werden. &
\end{tabular}

\subsubsection{Herstellungsanweisung des Nährmediums für die Biotests}

Die Herstellung des Mediums für die Biotests entspricht weitgehend dem Nährmedium für die Zucht. Bei dem Nährmedium für die Biotests wurde die Agar-Menge auf dreiviertel reduziert und kein Frisomycin sowie Fumidil B verwendet (siehe Tab. 47).

Für die Oberflächen-Methode wurden jeweils $1 \mathrm{ml}$ Medium mit einer EppendorfMultipipette in jede Wanne der Bioba128-Raster (Firma: Color-Dec-Italy) gefüllt, so dass sich eine planare Oberfläche bildete. Einen Tag vor den Versuchen wurden die Toxinkonzentrationen auf das Medium mit einer Eppendorf-Multipipette ${ }^{\circledR}$ appliziert. Für die Untermisch-Methode wurde das Toxin am Punkt 5 der Herstellungsbeschreibung des Nährmediums nach Zugabe der Vitamine und Ascorbinsäure bei einer Temperatur unter $45^{\circ} \mathrm{C}$ untergemischt. Dazu wurde das Nährmedium auf 8 Bechergläser $(100 \mathrm{ml})$ à $50 \mathrm{ml}$ aufgeteilt und in ein Wärmebad (45 $\left.50^{\circ} \mathrm{C}\right)$ gestellt. Pro Gramm Nährmedium wurden $100 \mu 1$ der entsprechenden Toxinlösung bzw. Wasser für die Kontrollgruppe dazugegeben und mit einem Mixer gut durchgemischt. Danach wird $1 \mathrm{ml}$ des Toxin-Nährmediums in die Wannen der Bioba128-Raster gefüllt und wie unter 9.1.2.1 beschrieben fortgefahren. 


\subsubsection{SAS Prozedur zur Berechnung und zum Vergleich der $\mathrm{LC}_{50}$-Werte}

data piepho;

input Konz n r Ort Jahr Nr;

cards;

$\begin{array}{lrrrrr}0.000000 & 64 & 11 & 0 & 2002 & 59 \\ 0.002260 & 31 & 18 & 0 & 2002 & 59 \\ \ldots \ldots \ldots \ldots \ldots \ldots . . & \text { etc. }\end{array}$

;

/*1. Probitanalyse*/

/*Sortieren für ED50 Berechnung je Assay*/

proc sort data=piepho out=piepho;

by ort nr;

/*logED50 berechnen für jedes Assay*/

ods output AdditionalEstimates=AddEst;

proc nImixed data=piepho;

parms alpha=2 beta $=2$ gamma $=-2$;

delta=probnorm(gamma);

if konz>0 then do;

eta $=$ alpha+beta* $\log 10$ (konz);

$\mathrm{p}=$ delta $+(1-\text { delta })^{*}$ probnorm $($ eta $)$;

end;

else $p=d e l t a ;$

model $r \sim \operatorname{binomial}(n, p)$;

estimate 'logED50' -alpha/beta;

estimate 'alpha ' alpha;

estimate 'beta ' beta;

by ort nr; run;

/*2. Gewichtete Varianzanalyse und 3. Äquivalenzintervalle für ED50*/

proc print data=addest; run;

$I^{*}$ Gewichte aus Standardfehlern berechnen*/

data logED50;

set addest;

if label = 'logED50';

weight=1/standardError ${ }^{* *}$;

$\log \mathrm{ED} 50=$ estimate;

proc print data=logED50; var ort nr; run;

/*Nebenrechnung: alpha für Äquivalenztest in MIXED berechnen*/

data;

$p=2^{*} 0.05 / 15$; run;

proc print; run;

/*Gewichtete Analyse*/

ods output Ismeans=Ismeans;

proc mixed data=logED50;

class ort nr;

weight weight;

model logED50=ort/ddfm $=\mathrm{kr}$;

Ismeans ort/pdiff cl alpha $=\mathbf{0 . 0 0 0 9 5 2 3 8 1 ;}$

random $\mathrm{nr}$;

parms $(0.01)(1) /$ hold=2;

repeated; run;

/*ED50 aur originalskala*/

data ED50_originalskala;

set Ismeans; 
ed50 $=10^{* *}$ estimate;

ed50_Lower $=10^{\star *}$ lower;

ed50_Upper $=10^{* *}$ upper;

drop Effect Estimate StdErr DF tValue Probt Alpha Lower Upper; run;

/*alpha und beta berechnen*/

I*alpha*I

/*Gewichte aus Standardfehlern berechnen*/

data alpha;

set addest;

if label = 'alpha';

weight=1/standardError ${ }^{* *}$;

alpha=estimate;

/*Gewichtete Analyse*/

ods output Ismeans=Ismeans;

proc mixed data=alpha;

class ort nr;

weight weight;

model alpha $=$ ort $/ \mathrm{ddfm}=\mathrm{kr}$;

Ismeans ort/pdiff $\mathrm{cl}$ alpha $\mathbf{0} \mathbf{0} \mathbf{0 0 6 6 6 6 6 6 7}$;

random $\mathrm{nr}$;

parms $(0.01)(1) /$ hold $=2$;

repeated; run;

I*Alpha *I

data Abschnitt_LU;

set Ismeans;

Abschnitt=estimate;

a_Lower=lower;

a_Upper=upper;

drop Effect Estimate StdErr DF tValue Probt Alpha Lower Upper; run;

I*beta*/

/*Gewichte aus Standardfehlern berechnen*/

data beta;

set addest;

if label = 'beta';

weight $=\mathbf{1} /$ standardError $^{* *} \mathbf{2}$;

beta=estimate;

/*Gewichtete Analyse*/

ods output Ismeans=Ismeans;

proc mixed data=beta;

class ort nr;

weight weight;

model beta $=$ ort $/ \mathrm{ddfm}=\mathrm{kr}$;

Ismeans ort/pdiff cl alpha $\mathbf{0 . 0 0 0 9 5 2 3 8 1}$

random $\mathrm{nr}$

parms $(0.01)(1) /$ hold $=2$;

repeated; run;

I*Alpha */

data Steigung_LU;

set Ismeans;

Steigung=estimate;

b_Lower=lower;

b_Upper=upper;

drop Effect Estimate StdErr DF tValue Probt Alpha Lower Upper; run;

proc print data=Steigung_LU;run;

proc print data=Abschnitt_LU;run;

proc print data=ed50_originalskala;run; 


\subsection{Anhang $\mathrm{F}_{2}$-Screening}

\subsection{1 $F_{2}$-Screening nach Andow und Alstad (1998)}

Andow und Alstad haben 1998 die dem $\mathrm{F}_{2}$-Screening zu Grunde liegende Statistik ausführlich beschrieben. Fehler in den Berechnungen wurden von Schneider (1999) und von Andow und Alstad (1999) korrigiert. Im Artikel Andow et al. (2000) wurden die statistischen Berechnungen ergänzt. Grundlage der Berechnung von Andow und Alstad ist die Baye 'sche-Statistik. Jede Isolinie repräsentiert einen Bernoulli-Versuch, bei dem ein Treffer [R] definiert ist als der Nachweis einer resistenten Larve in der $\mathrm{F}_{2}$ Generation. $\mathrm{R}$ wird als binomial verteilt mit dem Parameter P und der Konstante N angenommen, wobei $\mathrm{N}$ die Anzahl untersuchter Linien in der $\mathrm{F}_{2}$ ist, und $\mathrm{P}$ die Wahrscheinlichkeit einen Treffer zu erhalten, d. h. eine Linie zeigt phänotypisch in der $\mathrm{F}_{2}$ eine Resistenz.

Für die Wahrscheinlichkeit einen Treffer zu erhalten (P), d.h. eine Linie zeigt phänotypisch in der $\mathrm{F}_{2}$ eine Resistenz muß eine a priori Verteilung angenommen werden. Als a-priori-Verteilung wurde zu Beginn eine Gleichverteilung gewählt, die im Jahr 2000 durch eine Beta-Verteilung ersetzt wurde. Jede Iso-Familie steht für 4 haploide Chromosomensätze, zwei vom Vater und zwei von der Mutter, wobei davon ausgegangen wird, dass das Weibchen monogam ist. Daraus kann Beta $(\mathrm{R}+u, \mathrm{~N}-\mathrm{R}+v)$ die posterior Verteilung für $\mathrm{P}$ angegeben werden. Das Mittel der posterior Verteilung ist $\mathrm{E}(\mathrm{P})=(\mathrm{R}+u, \mathrm{~N}-\mathrm{R}+v)$ und gleichzeitig gilt $\mathrm{E}(\mathrm{P})=4 \mathrm{x} \mathrm{p}_{\mathrm{r}} \mathrm{p}_{\mathrm{r}}$ ist die tatsächliche Resistenzallelfrequenz und $u$ bzw. $v$ sind Parameter, die sich aus der gewählten priorVerteilung von P ergeben. Nach Umrechnung lautet die Formel für den Erwartungswert für eine Resistenzallefrequenz $\mathrm{E}\left(\mathrm{p}_{\mathrm{r}}\right)$ :

bei einem kleinen $P$ :

$E\left(p_{r}\right)=\frac{(R+u)}{4(N+u+v+1)}$

und für ein großes P:

$E\left(p_{r}\right)=1-\left[1-\frac{(R+u)}{4(N+u+v+1)}\right]^{1 / 4}$

Formel [ 1 \& $\&$ 2] stammen aus Andow et al. (2000) (S wurde durch R ersetzt) und die Berechnungen des $95 \%$ "credibility interval" finden sich in den Artikel Andow et al. (2000) sowie Andow und Alstad (1999).

Andow und Alstad diskutieren in ihrer Arbeit von 1998 die statistischen Probleme, die mit dem gewählten Ansatz zusammenhängen. Die Genauigkeit ihrer Statistik beruht darauf, dass in der $\mathrm{F}_{2}$-Generation mit einem Höchstmaß an Genauigkeit die Linien entdeckt werden, die in ihren Ausgangsgenomen der $\mathrm{P}_{1}$-Generation mindestens ein Resistenzallel besaßen. Dabei unterscheiden sie zwei Probleme: erstens eine Falsch-Positiv-Entscheidung und zweitens eine Falsch-Negativ-Entscheidung zu treffen. 


\section{Falsch-Positiv-Entscheidung}

Unter einer Falsch-Positiv-Entscheidung wird die Identifizierung einer sensiblen Isolinie als Resistente verstanden. Dies ist kein statistisches Problem, sondern hängt davon $\mathrm{ab}$, wie genau die Methode zwischen sensiblen und resistenten Larven unterscheiden kann. Durch die Wahl einer hohen Toxin-Konzentration, d. h. einer Konzentration, die $99 \%$ der sensiblen Larven tötet, und durch die ReTestung der Isolinien in der $\mathrm{F}_{3}$ bzw. in der $\mathrm{F}_{4}$ kann dieses Problem auf ein vernachlässigbares Minimum reduziert werden (Andow und Alstad, 1998).

\section{Falsch-Negativ-Entscheidung}

Eine Falsch-Negativ-Entscheidung zu treffen, d.h. eine resistente Isolinie (mindestens ein $\mathrm{P}_{1}$-Elternteil war heterozygot resistent) als sensibel einzustufen, steht im Zusammenhang mit verschiedenen Abschnitten der Versuchsdurchführung. Die Wahrscheinlichkeit ein Resistenzallel nicht zu entdecken wird mit $\mathrm{P}_{\text {no }}$ bezeichnet. Drei Gründe für eine Falsch-NegativEntscheidung werden angegeben:

a. Das Allel geht während der $F_{1}$-Generation z. B. durch eine krankheitsbedingte Mortalität verloren.

b. In der $F_{1}$-Generation kommt es nicht zur Kreuzung von Resistenzallelträgern.

c. Das Resistenzallel wurde trotz der Paarung Resistenzallelträger nicht in die $\mathrm{F}_{2}$-Generation vererbt oder eine homozygot resistente $\mathrm{F}_{2}$-Larve stirbt bevor sie getestet wird.

Andow und Alstad berechneten für die einzelnen Schritte die Wahrscheinlichkeiten und ermittelten, wie viele Larven getestet werden müssen. Um die Wahrscheinlichkeit ein Resistenzallel $\mathrm{zu}$ übersehen $\mathrm{P}_{\text {no }}$ unter $1 \% \mathrm{zu}$ halten, müssen von jeder Isofamilie mindesten 100 Larven getestet werden, die von der Paarung von $10 \mathrm{~F}_{1}$-Männchen und $10 \mathrm{~F}_{2}$-Weibchen abstammen. 


\subsubsection{Statistik zum $\mathbf{F}_{2}$-Screening}

Die statistische Auswertung erfolgte durch Professor Piepho von der Universität Hohenheim, Fachgebiet Bioinformatik, und weicht von der Auswertung, die Andow und Alstad (1998) vorgeschlagen haben, ab. Im folgenden gebe ich die statistischen Überlegungen von Herrn Professor Piepho wieder (pers. Mitt.).

Für die Berechnung werden folgende Annahmen festgelegt:

1. Die Allelfrequenz $q$ des rezessiven Resistenzallels $(*)$ ist klein. Daher dominieren Kreuzungen von sensiblen Eltern, die homozygot für das sensible Allel $(+)$ sind, so dass näherungsweise ausschließlich die beiden Eltern $\left(\mathrm{P}_{1}\right)$ Kreuzungen SS, SS und SS, rS betrachten werden. Diese beiden Arten von Paarungen haben die approximativen Frequenzen $1-4 q$ und $4 q$ (Andow und Alstad, 1998).

2. Die Nachkommen einer $P_{1}$-Kreuzung werden untereinander gepaart. Mit $m$ wird die Zahl der männlichen Nachkommen der $i$-ten $\mathrm{P}_{1}$-Kreuzung und mit $w$ die Zahl der weiblichen Nachkommen der $i$-ten $\mathrm{P}_{1}$-Kreuzung (Index $i$ der Einfachheit halber weggelassen) bezeichnet.

3. Wenn die $\mathrm{P}_{1}$-Kreuzung SS $\mathrm{x}$ SS ist, was mit einer Wahrscheinlichkeit $\mathrm{P}(\mathrm{SS}, \mathrm{SS})=1-4 q$ geschieht, so sind alle Nachkommen in $\mathrm{F}_{1}$ und $\mathrm{F}_{2}$ gleich SS,SS, also anfällig.

4. Für $\mathrm{F}_{1}$-Generation wird angenommen:

(i) Wenn die $\mathrm{P}_{1}$-Kreuzung SS $\mathrm{x}$ rS ist, was mit einer Wahrscheinlichkeit $\mathrm{P}(\mathrm{SS}, \mathrm{rS})=4 q$ geschieht, so liegt die Wahrscheinlichkeit, dass ein $\mathrm{F}_{1}$ Nachkommen SS ist, bei $50 \%$, während die Wahrscheinlichkeit für rS ebenfalls bei $50 \%$ ist. Die Verteilung der Zahl $a$ der männlichen SS-Nachkommen ist binomial mit einer Wahrscheinlichkeit von 0,5 und Konstante $m$. Die Zahl $b$ der weiblichen SS-Nachkommen folgt einer Binomialverteilung mit einer Wahrscheinlichkeit von 0,5 und Konstante $w$.

Tab. 48: Verteilung der $\mathrm{F}_{1}$-Nachkommen einer $\mathrm{P}_{1}$-Kreuzung der $i$-ten Isolinie

\begin{tabular}{llll} 
& $\mathrm{SS}$ & $\mathrm{rS}$ & \\
\hline männlich & $a$ & $m-a$ & $a \sim B(m ; 0,5)$ \\
\hline weiblich & $b$ & $w-b$ & $b \sim B(w ; 0,5)$
\end{tabular}

$[B(n ; \pi)$ ist die Binomialverteilung mit Konstante $n$ und Parameter $\pi]$.

(ii) Annahme über die Anpaarung der Männchen und Weibchen der $F_{1}$ : Es sei angenommen, dass jedes Weibchen von genau einem Männchen befruchtet wird. Hierbei kann ein Männchen mehrere Weibchen befruchten. Es sei angenommen, dass für ein gegebenes Weibchen das angepaarte Männchen eine Zufallsauswahl aus allen Männchen darstellt. Die Wahrscheinlichkeit, dass das angepaarte Männchen SS ist, beträgt $a / m$. Unter den $b$ SS-Weibchen folgt die Zahl $d$ der Paarungen SS $x$ SS einer Binomialverteilung mit der Wahrscheinlichkeit $a / m$ und der Konstanten $b$. Unter den $(w-b)$ rS-Weibchen folgt die Zahl der Paarungen rS,SS einer Binomialverteilung mit Wahrscheinlichkeit $a / m$ und Konstanten $w-b$. Zusammengefasst: 
Tab. 49: Verteilung der $F_{1}$-Paarungen der $i$-ten Isolinie

\begin{tabular}{|c|c|c|c|c|}
\hline & \multicolumn{2}{|c|}{ Männchen } & \\
\hline & & & $\mathrm{rS}$ & \\
\hline \multirow{2}{*}{ Weibchen } & SS & & $b-d$ & $\begin{array}{l}d \sim B(b ; a / m) \text { falls } b>0 ; \\
\text { sonst } P(b-d=0)=1\end{array}$ \\
\hline & $\mathrm{rS}$ & $e$ & $\begin{array}{c}w-b- \\
e\end{array}$ & $\begin{array}{l}e \sim B(w-b ; a / m) \text { falls } w-b>0 ; \\
\text { sonst } P(w-b-e=0)=1\end{array}$ \\
\hline
\end{tabular}

(iii) Annahme über die Verteilung der $F_{1}$-Nachkommen auf die $w$ Weibchen in $\mathrm{F}_{1}$ :

Es wird angenommen, dass die Zahl der Nachkommen sich möglichst gleichmäßig auf die Weibchen verteilt, so dass sich die Zahl der Nachkommen zwischen zwei Weibchen höchstens um eins unterscheidet. Hierbei stellt sich die Frage, wie die unterschiedlich großen Nachkommenschaften auf die $F_{1}$ Paarungen zu verteilen sind. Man kann z. B. annehmen, dass die Anzahl der kleineren Nachkommenschaften bei den vier verschiedenen $F_{1}$-Paarungen einer multiplen hypergeometrischen Verteilung folgt.

Tab. 50: Verteilung der F1-Paarungen

\begin{tabular}{lr|cccc} 
& & \multicolumn{4}{|c}{$\mathrm{F}_{1}$-Paarung } \\
& $w$ & $\mathrm{SS} \times \mathrm{SS}$ & $\mathrm{SS} \times \mathrm{rS}$ & $\mathrm{rS} \times \mathrm{SS}$ & $\mathrm{rS} \times \mathrm{rS}$ \\
\hline & $d$ & $b-d$ & $e$ & $w-b-e$ \\
$n_{j}=z$ & $x_{1}$ & $x_{2}$ & $x_{3}$ & $x_{4}$ \\
$n_{j}=z+1$ & $w-s$ & $y_{1}$ & $y_{2}$ & $y_{3}$ & $y_{4}$
\end{tabular}

Verteilung der Zahl von Paarungen mit $n_{j}=z$, wobei $z$ die kleinere der beiden Größen der $F_{2}$ Nachkommenschaften ist und $n_{j}$ die Zahl der Nachkommen in der $j$-ten $F_{1}$-Paarung

$n_{j}=$ Zahl der Nachkommen der $j$-ten $F_{2}$-Paarung in der $i$-ten Isolinie. $w=$ Gesamtzahl von $\mathrm{F}_{1}$-Weibchen $i$-ten Isolinie.

$\left(x_{1}, x_{2}, x_{3}\right)$ folgt multipler hypergeometrischer Verteilung. $\left(x_{4}, \quad y_{1}, \quad y_{2}, \quad y_{3}, y_{4}\right)$ folgt aus $\left(x_{1}, \quad x_{2}, x_{3}\right)$ und Randverteilung Randverteilung ist fix für gegebenes $w$ und $\mathrm{F}_{1}$-Paarungen! Formel für multiple hypergeometrische Verteilung:

$P\left(x_{1}, x_{2}, x_{3} \mid w, s, d, b, e\right)=\frac{d !(b-d) ! e !(w-b-e) ! s !(w-s) !}{w ! x_{1} ! x_{2} ! x_{3} ! x_{4} ! y_{1} ! y_{2} ! y_{3} ! y_{4} !}$

Für das Auffinden von Resistenten ist nur eine Unterscheidung der Kreuzung $\mathrm{rS} x \mathrm{rS}$ oder Kreuzungen, die nicht dem Schema rS x rS entsprechen, wichtig, so dass die Betrachtung einer $2 \times 2$ Tafel und der einfachen hypergeometrischen Verteilung ausreicht: 
Tab. 51: Verteilung der $\mathrm{F}_{1}$-Paarung

\begin{tabular}{lr|cc} 
& & \multicolumn{2}{|c}{$\mathrm{F}_{1}$-Paarung } \\
& $w$ & Nicht rS x rS & rS x rS \\
\hline$n_{j}=z$ & $S$ & $x_{0}=x_{1}+x_{2}+x_{3}$ & $w-b-e$ \\
$n_{j}=z+1$ & $w-s$ & $y_{0}=y_{1}+y_{2}+y_{3}$ & $x_{4}$ \\
& & & $y_{4}$ \\
\cline { 2 - 2 } & $P\left(x_{0} \mid w, s, d, b, e\right)=\frac{(b+e) !(w-b-e) ! s !(w-s) !}{w ! x_{0} ! x_{4} ! y_{0} ! y_{4} !}$
\end{tabular}

Zwei Unbekannte: $z$ und $s$

Bedingungen:

(a) $z=\operatorname{FLOOR}(N / w)$

(b) $s^{*} z+(w-s)^{*}(z+1)=N \Leftrightarrow s z+w z-s z+w-s=w(z+1)-s=N \quad \Leftrightarrow s=N-$ $w(z+1)$

$N=$ Gesamtzahl der $\mathrm{F}_{2}$-Nachkommen der $i$-ten Isolinie

(iv) Die Zahl der anfälligen Nachkommen folgt einer Binomialverteilung mit Konstante $n_{j}$ und Wahrscheinlichkeit $u$, die von der Art der Paarung abhängt. Es gibt vier verschiedene Paarungen:

Tab. 52: Wahrscheinlichkeit $u$ anfälliger Nachkommen in Abhängigkeit von der $F_{1^{-}}$ Paarung

\begin{tabular}{l|l} 
Paarung & $\begin{array}{l}\text { Wahrscheinlichkeit } u \\
\text { anfälliger Nachkomme }\end{array}$ \\
\hline SS x SS & $u_{1}=1$ \\
\hline SS x rS & $u_{2}=1$ \\
\hline $\mathrm{rS} \mathrm{x} \mathrm{SS}$ & $u_{3}=1$ \\
\hline $\mathrm{rS} \mathrm{x} \mathrm{rS}$ & $u_{4}=3 / 4$
\end{tabular}

Insgesamt $n_{j}=x_{4} Z+y_{4}(z+1) \quad F_{2}$-Nachkommen von $r S, r S$. Für diese gilt: $P\left(\right.$ keine Resistenten unter diesen $\mathrm{F}_{2}$-Nachkommen $)=(3 / 4)^{n i j}$

Für andere Paarungen in $F_{1}$ ist diese Wahrscheinlichkeit gleich $1\left(u_{1}\right.$ bis $\left.u_{3}\right)$. Die Berechnung der Likelihood erfordert eine Summation über verschieden bedingte Wahrscheinlichkeiten (ähnlich wie bei Andow und Alstad 1998). Hierbei arbeitet man sich von (iv) nach (i) vor, und zwar für jede $\mathrm{F}_{2}$-Nachkommenschaft.

(iv) Eine Nachkommenschaft:

$\Pi_{\text {alle }} \quad$ F2-Nachkommenschaften $\mathrm{P}\left(0\right.$ resistente Nachkommen $\mid F_{1}$-Nachkommen $\quad F_{1}$-Paarung, $\left.n_{j}\right) * \mathrm{P}\left(\mathrm{F}_{1}\right.$-Paarung $)=\Pi u^{n_{j}}$

+(iii): gewichtetes Mittel über hypergeometrische Verteilung:

$\Sigma_{\text {mögliche Verteilung der nj auf F1-Paarungen }}\left\{\mathrm{P}\left(n_{j} \mid \mathrm{F}_{1}\right.\right.$-Paarungen, $\mathrm{F}_{1}$-Nachkommen $\left.) \Pi u^{n_{j}}\right\}=\mathrm{v}$ $+\left(\right.$ ii): gewichtetes Mittel über Verteilung der $\mathrm{F}_{1}$-Paarungen

$\Sigma_{\text {mögliche Verteilung der F1-Paarungen }} \mathrm{P}\left(\mathrm{F}_{1}\right.$-Paarung $\left.\mid \mathrm{F}_{1}-\mathrm{Nachkommen}\right) \mathrm{v}=\mathrm{k}$

$+(\mathrm{i})$ gewichtetes Mittel über Verteilung der $\mathrm{F}_{1}$-Nachkommen

$\Sigma_{\text {mögliche Verteilung der F1-Nachkommen }} \mathrm{P}(\mathrm{F} 1-\mathrm{Nachkommen})^{\mathrm{k}}$ 
Die Wahrscheinlichkeit aus einer gegebenen Isolinie keine resistenten Nachkommen in $\mathrm{F}_{2} \mathrm{zu}$ bekommen, sofern die Parental-Paarung SS,rS stattgefunden hat, wird mit $\mathrm{P}_{\text {no }}$ bezeichnet. Die Likelihood der $i$-ten Isolinie ist dann $L=4^{*} q^{*} P_{n o}+(1-4 * q)$, die gesamte Likelihood über die Nachkommenschaften (Isolinien) ist demnach $\Pi L_{i}$.

In Anlehnung an das exakte Clopper-Pearson Intervall bei einfacher Binomialverteilung wird ein frequentistisches Vertrauensintervall berechnet. Da keine Resistenzen beobachtet wurden, ist die untere Grenze $q=0$. Die obere Grenze ergibt sich durch Auflösen der Gleichung $\Pi L_{i}=\alpha / 2$, wobei $\alpha$ die Irrtumswahrscheinlichkeit ist (Agresti, 2002, S. 18). Da hier die Unbedenklichkeit nachzuweisen ist, ist ein einseitiger Test als Grundlage des Vertrauensintervalls angemessen, wodurch sich die Gleichung $\Pi L_{i}=\alpha$ ergibt. Diese führt zu einem engeren Vertrauensintervall. 


\subsection{Monitoring resistenter Maiszünsler auf Bt-Maisfeldern}

\subsubsection{PCR-Untersuchungen von Bt-Maisblattstücken}

Die Extraktion der Blätter erfolgte nach der Methode von Dellaporta et al. (1983) die von Liebe und Sick (pers. Mitt.) angepasst wurde. Die spezifische PCR erfolgte mit den Primern mg3 und mg4 der Firma MWG, die CryIAb spezifisch sind. mg3 hat die Sequenz 5'-d(ACT-ATC-CTT-CGC-AAG-ACC-CTT-CCT-C)-3' und mg4 die Sequenz 5'-d(GCA-TTC-AGA-GAA-ACG-TGG-CAG-TAA-C)-3'. Die Reagenzien (Firma Quiagen) des Reaktionansatzes für die PCR hatten folgende Konzentrationen:

Tab. 53: Konzentrationen der Reagenzien der PCR zum Bt-Nachweis

\begin{tabular}{l|l} 
Reagenz & $\begin{array}{l}\text { Konzentration bzw. } \\
\text { Menge im Ansatz }(25 \mu \mathrm{l})\end{array}$ \\
\hline Primerkonzentration & $0,5 \mu \mathrm{M}$ \\
\hline Taq-Polymerase & $1 \mathrm{U}$ \\
\hline $\mathrm{MgCl} 2$ & $1,5 \mathrm{mM}$ \\
\hline dNTP & $0,2 \mathrm{mM}$ \\
\hline Probe & $1 \mathrm{ng}$ DNA
\end{tabular}

Tab. 54: Thermocycler-Programm

\begin{tabular}{lll} 
Schritt & Temperatur & Zeit $[\mathrm{h}]$ \\
\hline 1.Vordenaturierung & $95^{\circ} \mathrm{C}$ & $04: 30$ \\
\hline 2. Denaturierung & $95^{\circ} \mathrm{C}$ & $01: 30$ \\
\hline 3. Primer-Anlagerung & $60^{\circ} \mathrm{C}$ & $01: 50$ \\
\hline 4. Polymerase-Reaktion & $72^{\circ} \mathrm{C}$ & $01: 50$ \\
\hline 5. Polymerisierung & $72^{\circ} \mathrm{C}$ & $04: 15$ \\
\hline 6. Abkühlung und Konservierung & $4^{\circ} \mathrm{C}$ &
\end{tabular}

Die PCR erfolgte im MultiCycler PTC 200 der Firma BIOZYM.

40 Zyklen der Schritte 2-4 wurden durchgeführt. Das PCR-Produkt wurde in einem 1,5\% igen Agarosegel (Laufzeit 1,5 h bei $120 \mathrm{~V}$ ) elektrophoretisch getrennt und mit Ethidiumbromid gefärbt.

\subsubsection{Statistik zum Screening auf Bt-Maisfeldern}

Die statistische Auswertung erfolgte durch Professor Piepho, Universität Hohenheim Fachgebiet Bioinformatik (Piepho, pers. Mitt.). Sei $\lambda$ die erwartete Larvenzahl je Pflanze im Nicht-Bt-Maisfeld und $\pi$ der Anteil homozygot resistenter Larven, was dem Quadrat der Resistenzallelfrequenz $\left(\mathrm{q}^{2}\right)$ entspricht, dann ist $\lambda^{*} \pi$ die erwartete Anzahl resistenter Larven je Pflanze. Mit $\mathrm{m}_{1}$ wird die Zahl der gefundenen Larven und mit $\mathrm{n}_{1}$ die Zahl der untersuchten Pflanzen im Nicht-Bt-Maisfeld bezeichnet. Mit $\mathrm{m}_{2}$ wird die Zahl der gefundenen resistenten Larven und mit $\mathrm{n}_{2}$ die Anzahl der untersuchten Pflanzen im Bt-Maisfeld bezeichnet. Da eine tatsächliche homozygote Resistenz der auf Bt-Maisfelder gesammelten Larven nicht nachgewiesen ist, wurden sie durch das $\mathrm{F}_{2}$ Screening oder falls möglich direkt auf Resistenz getestet. Dabei wurde die Annahme getroffen, dass alle homozygot resistenten Larven zweifelsfrei identifiziert wurden. $\mathrm{m}_{1}$ und $\mathrm{m}_{2}$ können als Poisson-verteilt angenommen werden. 


$$
\begin{aligned}
& \operatorname{Poisson}\left(n_{1} \lambda\right)=\frac{\exp \left(-n_{1} \lambda\right)}{m_{1} !}\left(n_{1} \lambda\right)^{m_{1}} \\
& \operatorname{Poisson}\left(n_{2} \lambda \pi\right)=\frac{\exp \left(-n_{2} \lambda \pi\right)}{m_{2} !}\left(n_{2} \lambda \pi\right)^{m_{2}}
\end{aligned}
$$

Für die beiden Werte $m_{1}$ und $m_{2}$ lässt sich eine bivariate Verteilungsfunktion (joint density function) berechnen:

$$
\begin{aligned}
& f\left(m_{1}, m_{2} \mid \lambda, \pi, n_{1}, n_{2}\right)=\frac{\exp \left(-n_{1} \lambda\right)}{m_{1} !}\left(n_{1} \lambda\right)^{m_{1}} \frac{\exp \left(-n_{2} \lambda \pi\right)}{m_{2} !}\left(n_{2} \lambda \pi\right)^{m_{2}} \\
& =\lambda^{m_{1}+m_{2}} \exp \left[-\left(n_{1}+n_{2} \pi\right) \lambda\right] \frac{1}{m_{1} ! m_{2} !} n_{1}^{m_{1}} n_{2}^{m_{2}} \pi^{m_{2}}
\end{aligned}
$$

Für $\mathrm{p}=\mathrm{m}_{1}+\mathrm{m}_{2}=$ die Gesamtzahl an Larven, die in beiden Feldern gefunden wurden, lässt sich die folgende Poisson-Verteilung annehmen:

$\mathrm{p} \sim$ Poisson $\left[\left(\mathrm{n}_{1}+\mathrm{n}_{2} \pi\right) \lambda\right]$ (Hogg und Craig, 1995, S. 166)

$$
\text { Poisson }\left[(\mathrm{n} 1+\mathrm{n} 2 \pi \lambda]=\frac{\exp \left(-\left(n_{1}+n_{2} \pi\right) \lambda\right)}{(p) !}\left(\left(n_{1}+n_{2} \pi\right) \lambda\right)^{p}\right.
$$

Hieraus ergibt sich eine konditionale Dichtefunktion für $m_{1}$ und $m_{2}$ bei einem gegeben p. Folgende Annahmen können für die Berechnung getroffen werden:

Das Ereignis $\mathrm{M}_{1}=\mathrm{m}_{1}$ und $\mathrm{M}_{2}=\mathrm{m}_{2}$ wird als $\mathrm{B}$ bezeichnet und das Ereignis $\mathrm{P}=\mathrm{p}$ als A. Wenn $\mathrm{p} \neq \mathrm{m}_{1}+\mathrm{m}_{2}$ ist, dann ist die konditionale Wahrscheinlichkeit $\mathrm{P}(\mathrm{A} \mid \mathrm{B})$ gleich 0 , da $\mathrm{A} \cap \mathrm{B}=\varnothing$.

Wenn $\mathrm{p}=\mathrm{m}_{1}+\mathrm{m}_{2}$ ist, so ist $\mathrm{A} \subset \mathrm{B}$ und $\mathrm{A} \cap \mathrm{B}$ ergibt $\mathrm{A}$. Die konditionale Wahrscheinlichkeit ist $\mathrm{P}(\mathrm{A} \mid \mathrm{B})=\mathrm{P}(\mathrm{A}) / \mathrm{P}(\mathrm{B})$ (Hogg und Craig, 1995, S. 315).

$P(A / B)=\frac{\frac{\left(m_{1}+m_{2}\right) !}{m_{1} ! m_{2} !} n_{1}{ }^{m_{1}} n_{2}{ }^{m_{2}} \pi^{m_{2}}}{\left(n_{1}+n_{2} \pi\right)^{m_{1}+m_{2}}}$

Dies ist eine Binomial-Verteilung für $\mathrm{m}_{2}$ bei konstantem $\mathrm{p}$ und den Parameter $\pi_{0}$ :

$\pi_{0}=\frac{n_{2} \pi}{n_{1}+n_{2} \pi}$

$\pi_{0}$ ist die Wahrscheinlichkeit des Anteils der Larven aus dem Bt-Feld an den Gesamtlarven. $\pi_{0}$ ist abhängig von $\mathrm{n}_{1}$ und $\mathrm{n}_{2}$. Es lässt sich eine bedingte Schlussfolgerung für $\pi$ auf der Grundlage der suffizienten Statistik für $\lambda$ angeben, indem die exakten Konfidenzintervalle für $\pi_{0}$ verwendet und nach $\pi$ aufgelöst werden: $\pi=\frac{\pi_{0} n_{1}}{\left(1-\pi_{0}\right) n_{2}}$

Für die Berechnung des Konfidenzintervalls von $\mathrm{q}$ wird $\pi$ durch $\mathrm{q}^{2}$ ersetzt. Die Konfidenzgrenzen basieren auf einem einseitigen Test, da nur gezeigt werden soll, dass q unter dem Grenzwert liegt.

$$
q=\sqrt{\frac{\pi_{0} n_{1}}{\left(1-\pi_{0}\right) n_{2}}}
$$


9.3.2.1 SAS-Programm zur Berechnung der Resistenzallelfrequenz bei einem Screening auf Bt-Maisfeldern

data;

input field $\mathrm{m}$;

datalines;

20

158 ;

proc freq order=data;

weight $\mathrm{m}$;

tables field/binomial alpha $=0.1$;

exact binomial;

output out=ci binomial;

run;

proc print data $=\mathrm{ci}$;

run;

data final;

set ci;

upper_pi $0=x u \_b i n$;

if abs(upper_pi0-1)<1e-10 then upper_pi0 $=1-\mathrm{xl} \_$bin; $/{ }^{*}$ no cases in bt-field $->^{*} /$

$\mathrm{n} 1=1000$;

$\mathrm{n} 2=1000$;

$I^{\star} \mathrm{F} R E Q$ computes proportion*/

upper_pi=upper_pi $0 /\left(1-u p p e r \_p i 0\right)^{*} \mathrm{n} 1 / \mathrm{n} 2$;

upper_q=sqrt(upper_pi);

proc print;

var upper_pi0 upper_pi upper_q;

run; 


\subsubsection{Schätzen des Anteils von Nicht-Bt-Pflanzen im Bt-Feld}

Definitionen:

$\lambda=$ erwartete Anzahl Larven je Pflanze

$\beta=$ erwarteter Anteil von Nicht-Bt-Pflanzen im Bt-Feld

$n_{1}=$ Anzahl Pflanzen im Nicht-Bt-Feld

$m_{1}=$ Anzahl Larven im Bt-Feld

$n_{2}=$ Anzahl Pflanzen im Bt-Feld

$k_{2}=$ Anzahl von Nicht-Bt-Pflanzen mit mindestens einer Larve im Bt-Feld

Annahmen:

Die Zahl der Larven je Bt-Pflanze folgt einer Poisson-Verteilung mit dem Parameter $\lambda$. Homozygot Resistente sind zu vernachlässigen

$\mathrm{P}($ keine Larve $\mid$ Nicht-Bt-Pflanze $)=\exp (-\lambda) \quad$ (folgt aus Poisson-Verteilung)

$\mathrm{E}\left(k_{2}\right)=n_{2} \beta[1-\exp (-\lambda)]$

$k_{2} \sim \operatorname{binomial}\left\{n_{2}, \beta[1-\exp (\lambda)]\right\}=\left(\begin{array}{l}n_{2} \\ k_{2}\end{array}\right)\{\beta[1-\exp (-\lambda)]\}^{k_{2}}\{1-\beta[1-\exp (-\lambda)]\}^{n_{2}-k_{2}}$

$m_{1} \sim \operatorname{Poisson}\left(\lambda n_{1}\right)=\frac{\exp \left(-\lambda n_{1}\right)\left(\lambda n_{1}\right)^{m_{1}}}{m_{1} !}$

$\Rightarrow$ schätzen von $\lambda$ und $\beta$ über Maximum Likelihood. 
9.3.3.1 SAS-Programm zur Berechnung der "Verunreinigung" im Bt-Maisfeld

data t;

$\mathrm{n} 2=37410 ; \mathrm{k} 2=73 ; \mathrm{n} 1=50 ; \mathrm{m} 1=40 ;$ dummy=1;

proc print data $=\mathrm{t}$;

run;

proc nlmixed data=t;

parms logit_beta $=0.02$ lambda $=0.8$;

beta $=\exp ($ logit_beta $) /(1+\exp ($ logit_beta) $)$;

II=Igamma(n2+1)-Igamma(k2+1)-Igamma(n2-k2+1)

$+\mathrm{k} 2{ }^{*} \log \left(\right.$ beta*$\left.^{*}(1-\exp (-\operatorname{lambda}))\right)+(\mathrm{n} 2-\mathrm{k} 2)^{*} \log \left(1-\right.$ beta $^{*}(1-\exp (-$ lambda $\left.))\right)$

$-\operatorname{lambda}{ }^{*} n 1+m 1^{*} \log \left(\operatorname{lambda}{ }^{*} n 1\right)-\operatorname{Igamma}(\mathrm{m} 1+1)$;

model dummy general(II);

estimate 'beta' exp(logit_beta)/(1+exp(logit_beta));

run;

Vertrauensintervall aus LR -> IML mit NLP Routine.

proc iml;

$\mathrm{n} 2=37410 ; \mathrm{k} 2=73 ; \mathrm{n} 1=50 ; \mathrm{m} 1=40$;

start II (x) global (n1, m1, n2, k2);

beta $=x[1]$;

lambda $=x[2]$;

Ioglik=Igamma(n2+1)-Igamma(k2+1)-Igamma(n2-k2+1)

$+\mathrm{k}^{*} \log \left(\right.$ beta*$\left.^{*}(1-\exp (-\operatorname{lambda}))\right)+(\mathrm{n} 2-\mathrm{k} 2)^{*} \log \left(1-\right.$ beta*$^{*}(1-\exp (-$ lambda $\left.))\right)$

$-\operatorname{lambda}{ }^{*} n 1+m 1^{*} \log \left(\operatorname{lambda}{ }^{*} 1\right)-\operatorname{Igamma}(\mathrm{m} 1+1)$;

return(loglik);

finish II;

beta $=0.02$;

lambda $=0.8$;

con $=\{00$,

$0.11\}$

parms $=$ beta//lambda;

optn $= \begin{cases}0 & 2\} \text {; }\end{cases}$

call nlpnrr(rc,xr,"Il",parms,optn,con);

print $\mathrm{xr}$;

quit;

run; 


\subsubsection{Statistik zur Effizienz der Methoden $\mathbf{F}_{2}$-Screening und Screening auf Bt- Maisfeldern}

Die statistische Auswertung erfolgte durch Professor Piepho, Universität Hohenheim Fachgebiet Bioinformatik (Piepho, pers. Mitt.).

$\mathrm{Zu}$ Grunde lag die Frage, ob das $\mathrm{F}_{2}$-Screening nach Resistenzallelen auf Nicht-BtFeldern effizienter ist als das Screening von homozygot resistenten Larven auf BtMaisflächen.

Der größte Arbeitsaufwand wird durch die Zucht und Testung der Isolinien hervorgerufen. Die effizientere Methode sollte bei gleicher Anzahl untersuchter Isolinien $(=\mathrm{x})$ eine kleinere Varianz in der Allelfrequenz $(=\mathrm{q})$ erreichen.

Zur Vereinfachung der Rechnung wird angenommen, dass der Test auf Resistenz eine $100 \%$ ige Sicherheit hat (best case).

Es gelten folgende Berechnungen:

$\mathrm{F}_{2}$-Screening im Nicht-Bt-Maisfeld:

$p=4 q$

$\operatorname{var}(\hat{p})=\frac{4 q(1-4 q)}{x}$

$\operatorname{var}(\hat{q}=\hat{p} / 4)=\frac{q(1-4 q)}{4 x}$

Screening im Bt-Maisfeld:

$\lambda=$ erwartete Zahl Larven je Pflanze

$n_{1} \quad=$ Anzahl Pflanzen im Nicht-Bt-Feld

$n_{2} \quad=$ Anzahl Pflanzen im Bt-Feld

$m_{1} \quad=$ Anzahl Larven im Nicht-Bt-Feld

$m_{2} \quad=$ Anzahl resistente Larven im Bt-Feld (von Bt-Pflanzen)

$r_{2}=$ Anzahl Larven von Nicht-Bt-Pflanzen im Bt-Feld

$\beta=$ Anteil von nicht-resistenten Nicht-Bt-Pflanzen im Bt-Feld

$p \quad=q^{2}$

$\hat{p}=\frac{m_{2} n_{1}}{m_{1} n_{2}}$

$\operatorname{var}(\hat{p}) \approx\left(\frac{n_{1}}{n_{2} E\left(m_{1}\right)}\right)^{2} \operatorname{var}\left(m_{2}\right)+\left(\frac{n_{1} E\left(m_{2}\right)}{n_{2}\left[E\left(m_{1}\right)\right]^{2}}\right)^{2} \operatorname{var}\left(m_{1}\right) \quad$ (Taylor-Reihe!)

$\operatorname{var}\left(m_{1}\right)=\mathrm{E}\left(m_{1}\right)=\lambda n_{1}$

$\operatorname{var}\left(m_{2}\right)=E\left(m_{2}\right)=q^{2} \lambda n_{2}$

$\operatorname{var}(\hat{p}) \approx\left(\frac{n_{1}}{n_{2} \lambda n_{1}}\right)^{2} q^{2} \lambda n_{2}+\left(\frac{n_{1} q^{2} \lambda n_{2}}{n_{2}\left[\lambda n_{1}\right]^{2}}\right)^{2} \lambda n_{1}$

$=\frac{1}{n_{2}^{2} \lambda^{2}} q^{2} \lambda n_{2}+\frac{q^{4}}{n_{1}^{2} \lambda^{2}} \lambda n_{1}$

$=\frac{q^{2}}{n_{2} \lambda}+\frac{q^{4}}{n_{1} \lambda} \approx \frac{q^{2}}{n_{2} \lambda}=\frac{q^{2}}{E\left(m_{2}\right) / q^{2}}=\frac{q^{4}}{E\left(m_{2}\right)}$ 
(Approximation $q^{4} /\left(n_{1} \lambda\right) \approx 0$ ist optimistisch zugunsten vom Feld!) Erwartete Zahl von zu untersuchenden Larven $=$

$2 *$ erwartete $\mathrm{Zahl} \mathrm{zu}$ untersuchender Iso-Linen $=2 x$

$=\mathrm{E}\left(m_{2}\right)+\mathrm{E}\left(r_{2}\right)=q^{2} \lambda n_{2}+\left[2 q(1-q)+(1-q)^{2}\right] \beta \lambda n_{2} \approx q^{2} \lambda n_{2}+\beta \lambda n_{2}$

$=\left[q^{2} \lambda n_{2}+\beta q^{2} \lambda n_{2} / q^{2}=\mathrm{E}\left(m_{2}\right)+\beta \mathrm{E}\left(m_{2}\right) / q^{2}=\left(1+\beta / q^{2}\right) \mathrm{E}\left(m_{2}\right)=2 x\right.$

$\Leftrightarrow \mathrm{E}\left(m_{2}\right)=2 x /\left(1+\beta / q^{2}\right)$

$\operatorname{var}(\hat{p}) \approx \frac{q^{4}}{E\left(m_{2}\right)}=\frac{q^{4}\left(1+\beta / q^{2}\right)}{2 x}$

$\operatorname{var}(\hat{q}=\sqrt{\hat{p}}) \approx\left(\frac{1}{2 \sqrt{p}}\right)^{2} \operatorname{var}(\hat{p})=\frac{1}{4 q^{2}} \frac{q^{4}\left(1+\beta / q^{2}\right)}{2 x}=\frac{q^{2}\left(1+\beta / q^{2}\right)}{8 x}$

$\mathrm{E}=\mathrm{Effizienz}=\operatorname{Varianz}($ Labor $) / \operatorname{Varianz}($ Feld $)=$

$\frac{\frac{q(1-4 q)}{4 x}}{\frac{q^{2}\left(1+\beta / q^{2}\right)}{8 x}}=\frac{2 q(1-4 q)}{q^{2}\left(1+\beta / q^{2}\right)}=\frac{2(1 / q-4)}{\left(1+\beta / q^{2}\right)}$ 
9.3.4.1 SAS-Programm zur Berechnung der Effizienz der Methoden $\mathrm{F}_{2}$-Screening im Nicht-Bt-Maisfeld und Screening im Bt-Maisfeld

data;

array b b1-b5;

$b[1]=0$;

$\mathrm{b}[2]=0.0001$;

$\mathrm{b}[3]=0.001$;

$\mathrm{b}[4]=0.01$;

$\mathrm{b}[5]=0.1$

do $i=1$ to 5 ;

beta $=\mathrm{b}[\mathrm{i}]$;

do $q=0$ to 0.1 by 0.001 ;

$E=2^{*}(1 / q-4) /(1+$ beta/q**2);

log_E= $\log (E)$;

end;

output;

end;

proc print; run;

filename fileref 'c:lelhpplbeolmeiselfig.cgm';

goptions reset=all dev=win target=cgmof97L gsfname=fileref keymap=winansi ftext=hwcgm001 gsflen=8092

gsfmode $=$ replace hsize $=10 \mathrm{~cm}$ vsize $=10 \mathrm{~cm}$ htext $=0.8$

axis 1 label=none offset $=(0 \mathrm{~cm}, 0 \mathrm{~cm}) \mathrm{w}=10$ minor=none major $=(\mathrm{w}=10)$ order $=0$ to 0.1 by 0.02 ;

axis2 label=none offset $=(0 \mathrm{~cm}, 0 \mathrm{~cm})$ minor=none $w=10$ major $=(w=10)$;

symbol $1 \mathrm{i}=$ join $\mathrm{h}=0.5 \mathrm{w}=10$ color=black line $=1$ value=none;

symbol $2 \mathrm{i}=$ join $\mathrm{h}=0.5 \mathrm{w}=10$ color=black line $=1$ value=none;

symbol $3 \mathrm{i}=$ join $\mathrm{h}=0.5 \mathrm{w}=10$ color=black line=1 value=none;

symbol $4 \mathrm{i}=$ join $\mathrm{h}=0.5 \mathrm{w}=10$ color=black line=1 value=none;

symbol5 $\mathrm{i}=$ join $\mathrm{h}=0.5 \mathrm{w}=10$ color=black line $=1$ value=none;

proc gplot;

plot $\log _{-} e^{*} q=b e t a / v r e f=0$ haxis=axis 1 vaxis=axis2 nolegend;

run 


\section{LEBENSLAUF}

Name

Geburtstag und -ort

Familienstand

Schulausbildung

Schulabschluß

Studium

\section{Studiumabschluß}

Berufspraxis

Praktika

Weiterbildung

Dissertation
8. September 1969

Thomas Meise

geboren in Rheda-Wiedenbrück

ledig

1976 - 1980 Postdammgrundschule Lintel

1980 - 1989 Ratsgymnasium Wiedenbrück

1989 Allgemeine Hochschulreife

1990 - 1997 Studium der Biologie an der Universität Bayreuth, Studienschwerpunkte: Tierökologie, Mikrobiologie und Ökologische Chemie/Geochemie

1997 Diplom-Biologe Univ.

(Diplomarbeit: Auswirkungen von Bacillus thuringiensis $\delta$-Endotoxin auf herbivore Insekten)

$1998-2002$
November $1998-$
Februar 1999

Projektleiter bei infill Kommunikation in Oberpleis

Wissenschaftlicher Mitarbeiter beim

Umweltbundesamt

Fachgebiet IV „Vollzug GenTG“ in Berlin und Projektleiter bei infill Kommunikation, Teilzeit

November 1999 - Wissenschaftlicher Mitarbeiter bei der Biologischen

Dezember 2002 Bundesanstalt, Institut für Biologischen Pflanzenschutz, Promotionsstelle im BMB+FProjekt „Monitoring der ökologischen Auswirkungen insektenresistenter Kulturpflanzen mit rekombinanten Bacillus thuringiensis Toxin-Genen: Auswirkungen auf den Maiszünsler"“

\begin{tabular}{|c|c|}
\hline Mai - August 1990 & Praktikum im Umweltlabor der Stadt Gütersloh \\
\hline März - April 1995 & $\begin{array}{l}\text { Praktikum im Amt für Umweltschutz der Stadt } \\
\text { Gütersloh }\end{array}$ \\
\hline Juni - Juli 1995 & Praktikum im Umweltbundesamt, Berlin \\
\hline $\begin{array}{r}\text { August - September } \\
1995\end{array}$ & $\begin{array}{l}\text { Praktikum im Ing.-Büro Karl-Heinz Loske für } \\
\text { Landschaftsökologie, Salzkotten-Verlar }\end{array}$ \\
\hline $\begin{array}{r}\text { September } 1997 \\
\text { - März } 1998\end{array}$ & $\begin{array}{l}\text { Praktikum beim Auswertungs- und } \\
\text { Informationsdienst für Ernährung, Landwirtschaft } \\
\text { und Forsten (aid) e. V., Bonn }\end{array}$ \\
\hline April - Juni 1998 & Englisch Auffrischungskurs Teil II (DAA) \\
\hline Mai - Oktober 1998 & $\begin{array}{l}\text { Modulare Qualifikation bei der } \\
\text { Angestellten Akademie (DAA), Bonn }\end{array}$ \\
\hline
\end{tabular}

seit Oktober 2001
Promotionsstudium im $\underset{\text { Fach }}{\text { an der Georg-August Universität Göttingen }}$ 